\title{
Modulation of Cardiac Fibroblast to Myofibroblast Transition by Rho-Associated Kinases ROCK1 and ROCK2
}

\section{Doctoral Thesis}

In partial fulfillment of the requirements for the degree

"Doctor of Philosophy (PhD)"

Division of Mathematics and Natural Sciences

in the Molecular Medicine Study Program

at the Georg-August University Göttingen

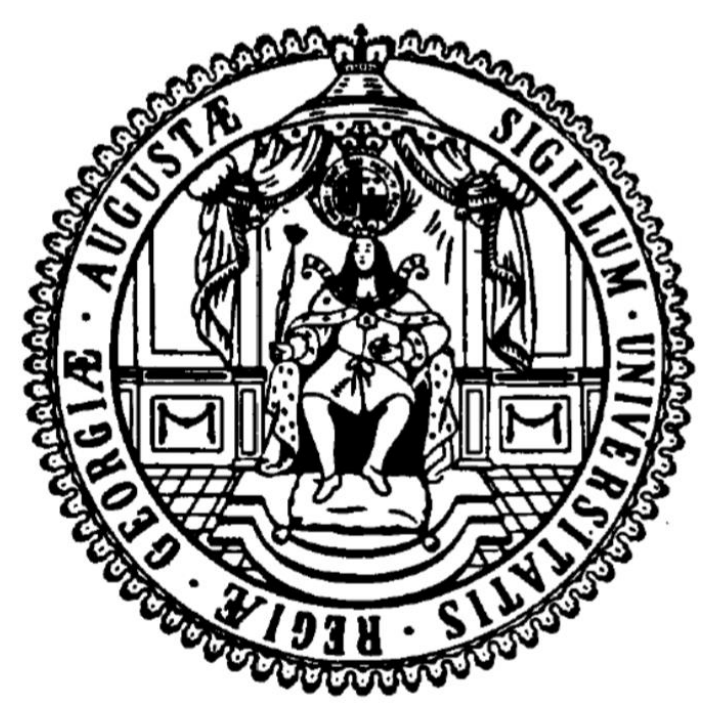

Submitted by

Svenja Hartmann

born in Hildesheim, Germany

Göttingen 2016 


\title{
Members of the Thesis Committee:
}

\author{
Prof. Dr. rer. nat. Susanne Lutz (Supervisor)
}

Email: $\quad$ susanne.lutz@med.uni-goettingen.de

Phone: $\quad$ 0551/39-10665

Postal Address: Institute of Pharmacology and Toxicology University Medical Centre Göttingen Georg-August University Göttingen Robert-Koch-Str. 40 37075 Göttingen

Prof. Dr. mult. Thomas Meyer (Second member of thesis committee)

Email: thomas.meyer@med.uni-goettingen.de

Phone: $\quad$ 0551/39-4881

Postal Address: Clinic for Psychosomatic Medicine and Psychotherapy Institute for Molecular Psychocardiology University Medical Centre Göttingen Georg-August University Göttingen Waldweg 33 37075 Göttingen

Prof. Dr. rer. nat. Ralph Kehlenbach (Third member of thesis committee)

Email:_rkehlen@gwdg.de

Phone: $\quad$ 0551/39-5950

Postal Address: Institute of Molecular Biology University Medical Centre Göttingen Georg-August University Göttingen Humboldtallee 23 37075 Göttingen

Date of Disputation: 18. October 2016 


\section{Affidavit}

Here I declare that my doctoral thesis entitled:

"Modulation of Cardiac Fibroblast to Myofibroblast Transition by Rho-Associated Kinases ROCK1 and ROCK2"

has been written independently with no other sources and aids than quoted.

Svenja Hartmann

Göttingen, August 2016 


$$
\begin{array}{r}
\text { One, remember to look up at the stars and not } \\
\text { down at your feet. }
\end{array}
$$

Two, never give up work. Work gives you meaning and purpose and life is empty without it.

Three, if you are lucky enough to find love, remember it is there and don't throw it away.

Stephen Hawking 


\section{Acknowledgement}

I would like to express my gratitude to all the people wo have contributed to the work described in my thesis. First of all, I would like to thank my supervisor Prof. Dr. Susanne Lutz for allowing me the opportunity to undertake this project in her research group, and for her support, patience, and scientific guidance throughout the duration of my studies, as well as for teaching me how to be an independent scientist. I would furthermore like to express my gratitude to my supervisor Prof. Dr. Anne Ridley for giving me the opportunity to come to London to continue my studies in her research group at the King's College London and for supporting and guiding me throughout the duration of my stay and beyond. My sincere gratitude also goes to Prof. Dr. Wolfram-Hubertus Zimmermann for giving me the chance to be part of his institute at the University of Göttingen and for insightful discussions and suggestions during our weekly institute meetings.

Special thanks go to the International Research Training Group (IRTG) 1816, funded by the German Research Council (DFG) and the King's College London British Heart Foundation Centre of Research Excellence for allowing me to be a member of this great program.

Many thanks to both my thesis committee members Prof. Dr. Thomas Meyer and Prof. Dr. Ralph Kehlenbach for their valuable support, advice, and comments throughout my project.

My sincere thanks also go to Dr. Aline Jatho, Anita Ongherth, and Susanne Schlick for the very helpful practical guidance and advice, as well as to Kerstin Schenk and Beate Ramba for their excellent technical assistance. Furthermore, I would like to express my deepest gratitude to Dr. Norman Liaw for his precious support and scientific advice, and the incredibly helpful proof reading. Many thanks go to Dr. Hanibal Bohnenberger from the department of pathology at the UMG for helping me to perform and analyse the PamGene experiments.

I would like to express a very special thank you to Lena, Norman, and Moni for the cheerful and joyful time we shared in the lab. Thank you for being not just colleagues, 
but also supporters, advisors and friends! Tim, Malte, and Brian, I will definitely miss the nice lunch breaks we shared together talking about private and scientific topics.

I thank all the members of the Institute of Pharmacology and Toxicology for being such friendly and helpful colleagues, and for creating an enjoyable atmosphere in the lab. Thanks to you it has always been a nice place to be, even during stressful times. I will miss you all!

Finally, I would like to express my deepest gratitude to my family and good friends (you know who you are!), for their support and continuous encouragement in workrelated, as well as private issues. Thank you for always believing in me. Without your support none of this would have been possible. 


\section{Table of Contents}

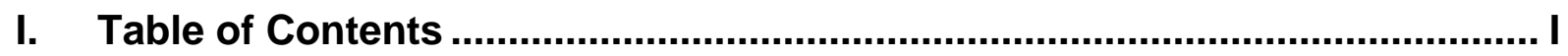

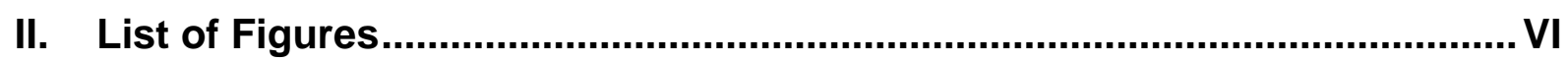

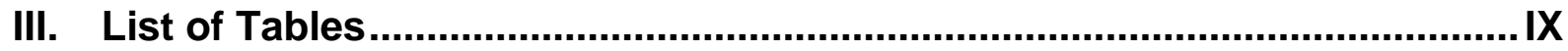

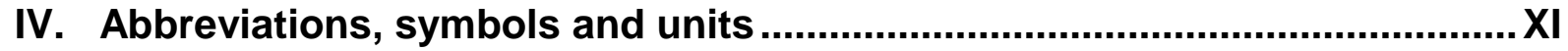

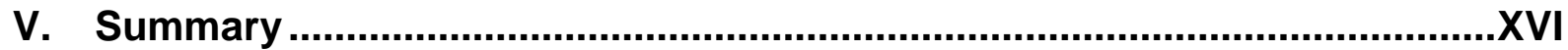

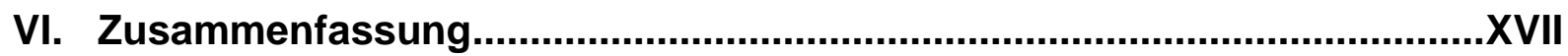

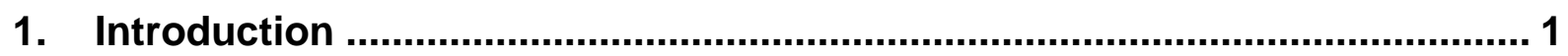

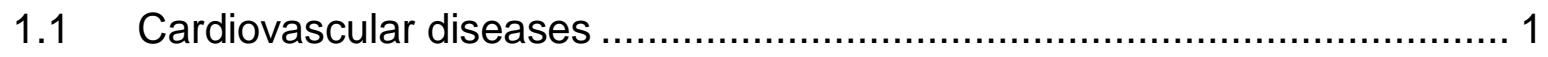

1.2 Origin and function of cardiac fibroblasts in the heart............................... 2

1.3 The cardiac myofibroblast ................................................................ 3

1.4 Rho-associated kinases ROCK1 and ROCK2: Expression and structure .... 5

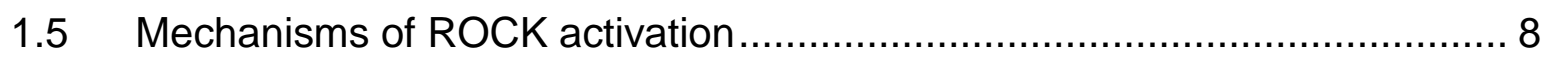

1.5.1 General mechanisms of ROCK activation ........................................... 8

1.5.2 Specific mechanisms of ROCK1 activation ........................................ 8

1.5.3 Specific mechanisms of ROCK2 activation ..................................... 9

1.6 Pharmacological ROCK inhibitors …….................................................... 10

1.7 ROCK targets in the cardiovascular system ....................................... 11

1.8 Function of ROCK1 and ROCK2 in cardiac fibroblasts .......................... 13

1.9 Function and regulation of ROCK1 and ROCK2 in human cardiovascular

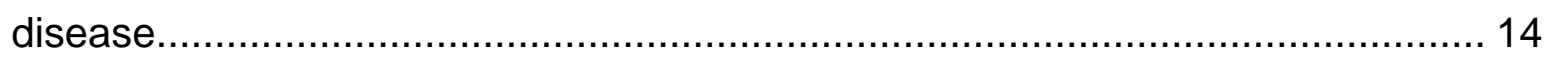

1.10 Genetic animal models of ROCK1 and ROCK2 ….............................. 17

1.10.1 Global knockout of ROCK1 and ROCK2 …................................ 17

1.10.2 Effects of ROCK1 and ROCK2 knockout on the heart ...................... 18

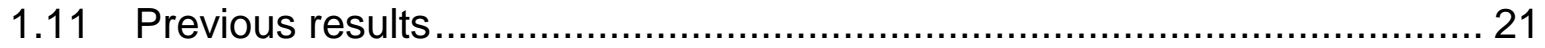

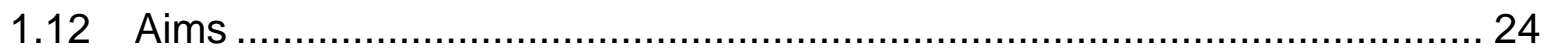

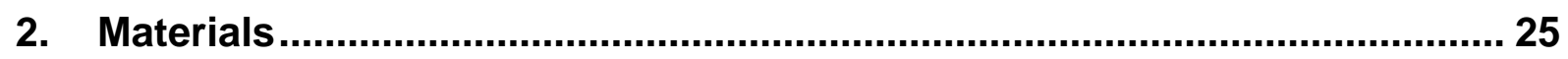

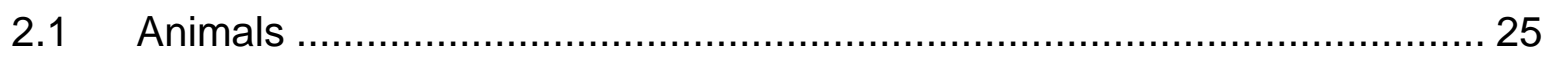

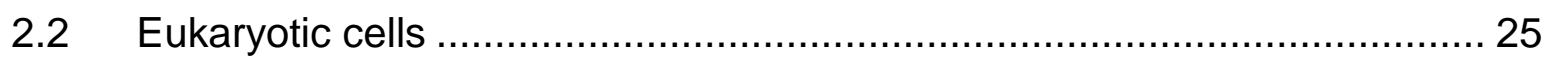

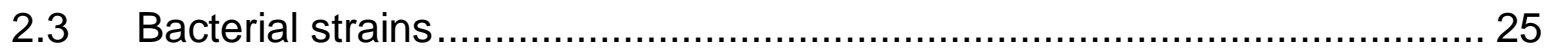


2.4 Chemicals, reagents and consumables............................................. 25

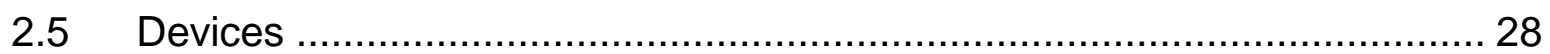

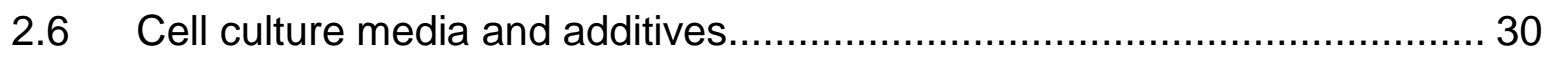

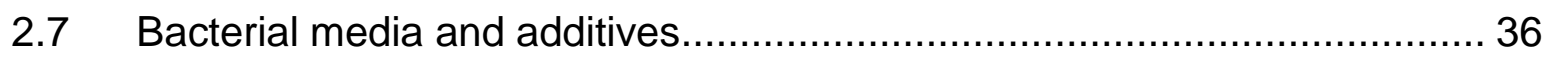

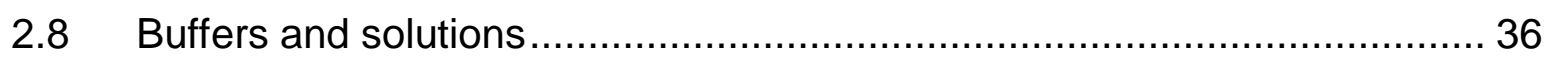

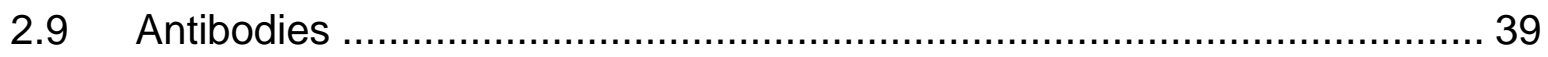

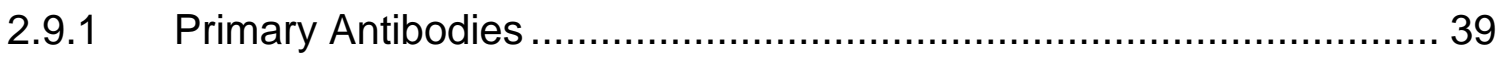

2.9.2 Secondary antibodies for immunoblot analyses ............................... 40

2.9.3 Secondary antibodies for Immunofluorescence analyses .................. 40

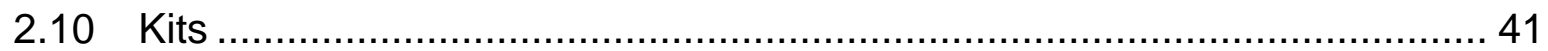

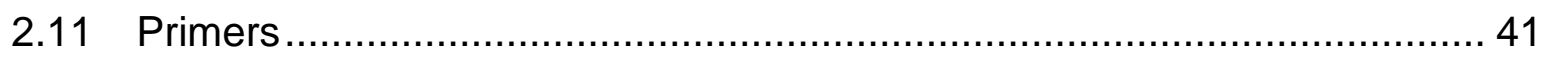

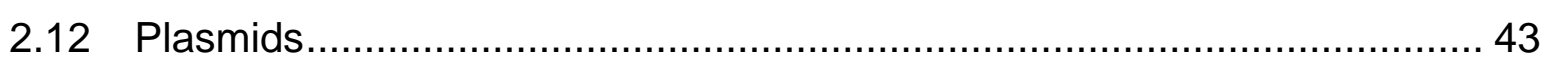

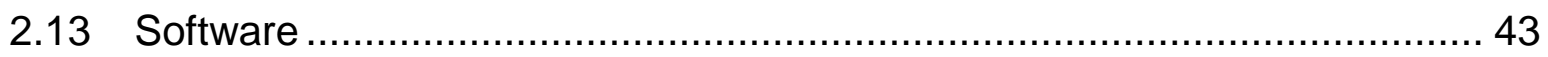

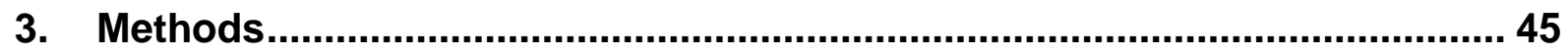

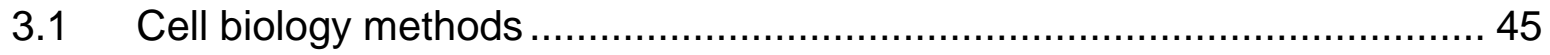

3.1.1 Preparation of cardiac cells from neonatal rats ............................... 45

3.1.2 Separation of cardiac fibroblasts and cardiomyocytes ....................... 46

3.1.3 Culturing, passaging and freezing of NRCF .................................. 46

3.1.4 Thawing, culturing and passaging of HEK293A and Tsa201 cells ..... 47

3.1.5 Thawing, culturing and passaging of normal human cardiac fibroblasts

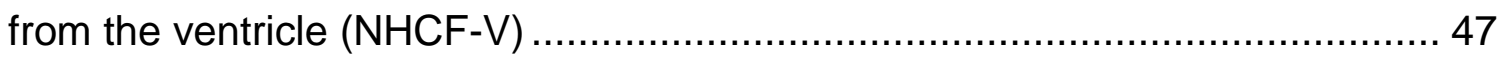

3.1.6 Culturing of human embryonic stem cell-derived cardiomyocytes....... 48

3.1.7 Generation of lentivirus particles in Tsa201 .................................... 49

3.1.8 Lentiviral transduction of NRCF to knockdown ROCK1 and ROCK2 .. 50

3.1.9 Transfection of NRCF to knockdown ROCK1 and ROCK2 ................50

3.1.10 Co-transfection of HEK293A for overexpression of ROCK1 and p21.. 51

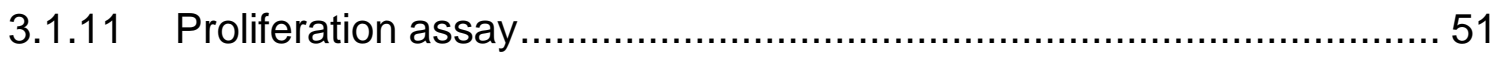

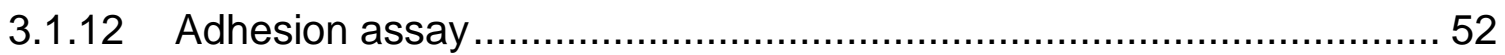

3.1.13 Live cell imaging and migration assay ............................................ 52

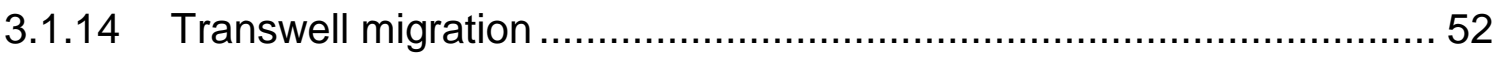

3.1.15 Generation of engineered heart muscle from isolated primary neonatal

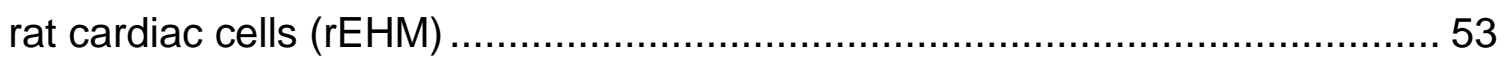


3.1.16 Generation of engineered heart muscle from hES2-wt CM and NHCF-V (hEHM) 54

3.1.17 Generation of engineered connective tissue from NRCF ( $\mathrm{rECT})$ and

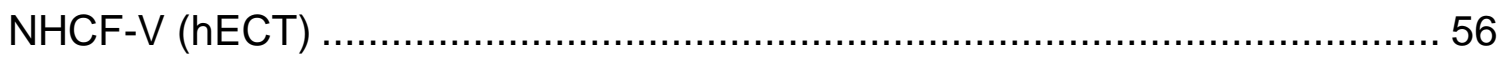

3.1.18 Isometric force measurements of rEHMs and hEHMs ...................... 57

3.1.19 Destructive tensile strength measurement ...................................... 58

3.1.20 Dissociation of cells from engineered tissues................................... 59

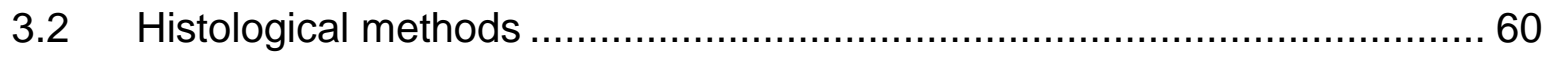

3.2.1 Immunofluorescence and staining of the actin cytoskeleton and the

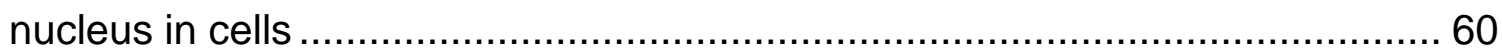

3.2.2 Quantitative evaluation of focal adhesions (FAs) in NRCF.................6 60

3.2.3 Flow cytometry cell cycle analysis.................................................. 62

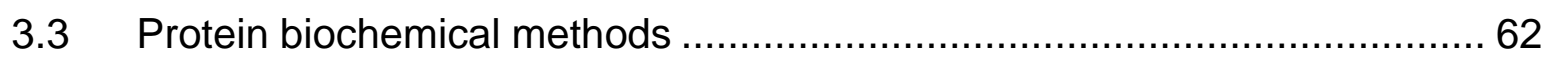

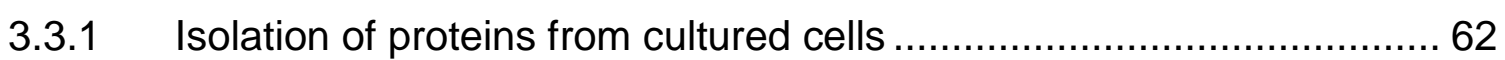

3.3.2 Determination of protein concentration (Bradford assay) ................... 62

3.3.3 Sodium dodecyl sulphate polyacrylamide gel electrophoresis (SDS-

PAGE) 63

3.3.4 Western immunoblotting 64

3.3.5 Identification of potential ROCK targets using PamGene's kinase

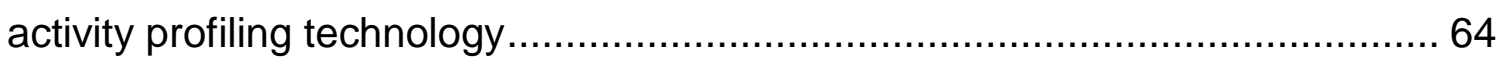

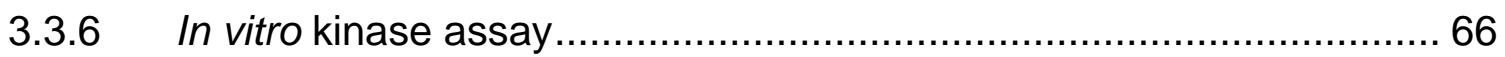

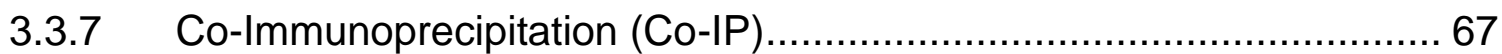

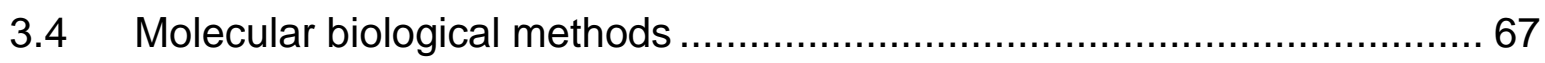

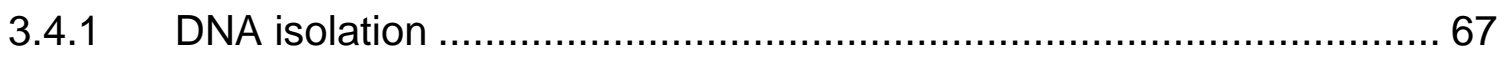

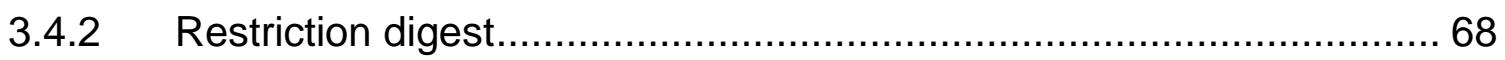

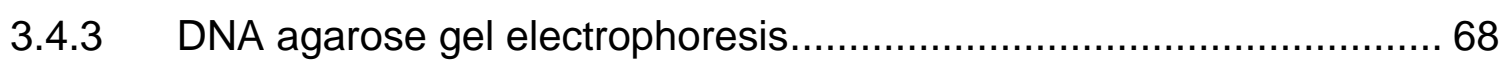

3.4.4 RNA isolation from cells and engineered tissues ..............................69

3.4.5 Formaldehyde agarose gel electrophoresis ..................................... 69

3.4.6 cDNA synthesis ........................................................................... 70

3.4.7 Quantitative real-time polymerase chain reaction (qRT-PCR) ........... 70

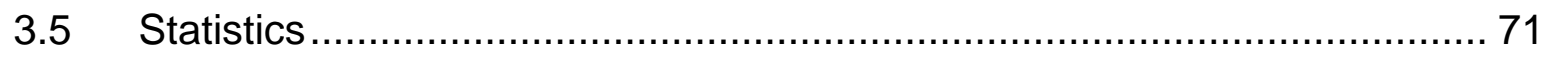

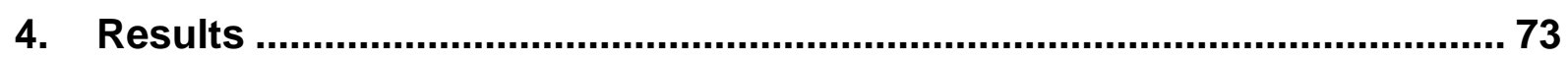

4.1 ROCK1 and ROCK2 regulate cardiac fibroblast morphology and adhesion73 
4.1.1 Selective knockdown of ROCK1 and ROCK2

4.1.2 Downregulation and inhibition of ROCK1 and ROCK2 changes NRCF morphology

4.1.3 ROCK knockdown reduces adhesion velocity and alters the size and amount of focal adhesion sites in NRCF

4.2 ROCK1 and ROCK2 regulate cardiac fibroblast migration 79

4.2.1 Knockdown and inhibition of ROCK1 and ROCK2 have contrasting effects on the migratory behaviour of NRCF on a plane surface. 79

4.2.2 Downregulation of ROCK1 and ROCK2 impairs migration of NRCF in a transwell assay

4.3 ROCK1 and ROCK2 activity is needed for cardiac fibroblast proliferation . 83

4.4 ROCK1 and ROCK2 influence the regulation and turnover of the ECM and viscoelastic properties in engineered connective tissues from rat and human cardiac fibroblasts 86

4.4.1 Inhibition of ROCK activity impairs the consolidation of hECT and decreases hECT stiffness

4.4.2 ROCK inhibition influences the cell cycle, but not proliferation of NRCF in $\mathrm{rECT} 90$

4.4.3 ROCK inhibition in ECT induces changes in genes associated with the

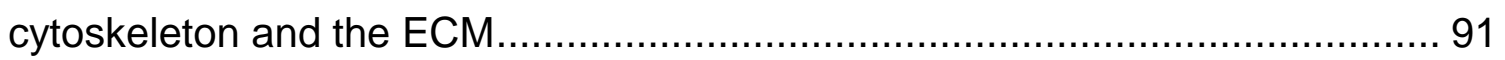

4.4.4 Inhibition of MMP12 does not alter viscoelastic properties of rECT ....92

4.4.5 Modelling tissue fibrosis using TGF $\beta 1$ as a stimulus. 96

4.5 ROCK1 and ROCK2 influence the contractility of engineered tissues and this is dependent on the maturation status of cardiomyocytes

4.5.1 Inhibition of ROCK1 and ROCK2 has no influence on contractile parameters of rEHM

4.5.2 Inhibition of ROCK1 and ROCK2 activity influences viscoelastic properties of rEHM

4.5.3 Inhibition of ROCK activity decreases contractile force of hEHM ...... 105

4.5.4 Inhibition of ROCK1 and ROCK2 activity does not change viscoelastic properties of hEHM.

4.6 Outlook: Finding new selective targets for ROCK1 and ROCK2 ............ 110

4.6.1 Identification of new potential ROCK targets.............................. 110

4.6.2 p21 and CDK7 are phosphorylated by ROCK1 and ROCK2 in vitro 112 
5. Discussion

5.1 ROCK1 and ROCK2 influence morphology and the actin cytoskeleton of cardiac fibroblasts

5.2 ROCK1 and ROCK2 are essential players in cardiac fibroblast adhesion and migration 118

5.3 ROCK1 and ROCK2 control proliferation of cardiac fibroblasts. 120

5.4 ROCK signalling influences the regulation and turnover of the ECM and thus viscoelastic properties of engineered tissues. 122

5.5 ROCK1 and ROCK2 have an influence on the contractility of EHM 124

5.6 Conclusion and perspectives 126

6. Bibliography 128 


\section{List of Figures}

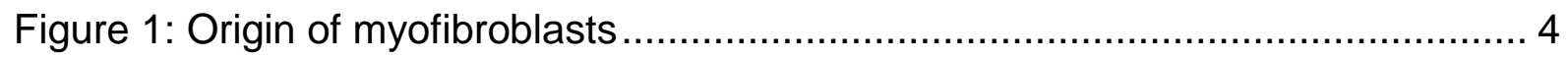

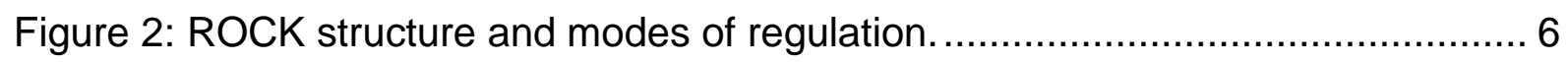

Figure 3: ROCK targets in the cardiovascular system...................................... 11

Figure 4: Involvement of ROCK1 and ROCK2 in cardiovascular disease................ 15

Figure 5: Lentivirus-mediated knockdown of ROCK1 and ROCK1/2 in neonatal rat

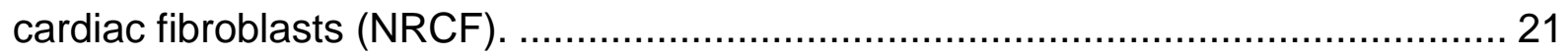

Figure 6: Characterization of lentivirus-mediated ROCK1 and ROCK1/2 knockdown

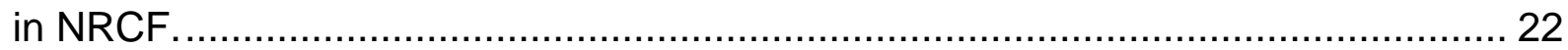

Figure 7: Analysis of contractile and viscoelastic properties of engineered tissues. . 23

Figure 8: Custom-made circular moulds for construction of rEHM. ........................ 54

Figure 9: Custom-made circular moulds for construction of hEHM......................... 55

Figure 10: Isometric force measurement set-up ……….................................. 58

Figure 11: Experimental set-up for destructive tensile strength measurement of ECT

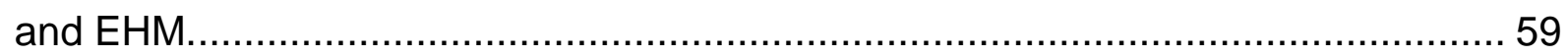

Figure 12: Graphical summary of the quantitative evaluation of focal adhesions in NRCF 61

Figure 13: Schematic drawing of the PamGene kinase activity profiling system. ..... 65

Figure 14: Validation of isoform-selective knockdown of ROCK1 and ROCK2 in NRCF. 73

Figure 15: Evaluation of cell morphological changes......................................... 75

Figure 16: Analysis of geodesic f-actin structures in NRCF................................ 76

Figure 17: Expression of cytoskeletal proteins in ROCK knockdown NRCF............. 77

Figure 18: Analysis of adhesion velocity of ROCK knockdown NRCF.................... 78

Figure 19: Evaluation of focal adhesion number and size in ROCK1 and ROCK2

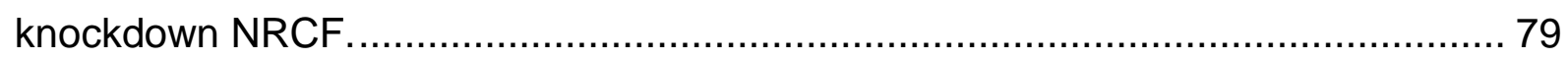


Figure 20: Analysis of migration of siRNA-mediated ROCK knockdown NRCF on a planar surface.

Figure 21: Evaluation of migration of lentivirus-mediated ROCK knockdown NRCF and NRCF treated with ROCK inhibitor.

Figure 22: Bright-field images of ROCK knockdown NRCF and NRCF treated with ROCK inhibitor H1152P during migration.

Figure 23: Analysis of transwell migration through a porous membrane.

Figure 24: Analysis of proliferation of ROCK knockdown NRCF and NRCF treated with ROCK inhibitor.

Figure 25: Analysis of single- and double-nucleated NRCF after treatment with ROCK inhibitor H1152P. 85

Figure 26: Treatment with ROCK inhibitors increased the cross-sectional area (CSA) of human engineered connective tissue (hECT).

Figure 27: Stress-strain curves of rheological destructive tensile strength measurements.

Figure 28: Analysis of the viscoelastic properties of control, Fasudil-, and H1152Ptreated hECT.

Figure 29: Flow cytometry cell cycle analysis of cells dissociated from control, Fasudil- and H1152P-treated rECT. 90

Figure 30: qPCR analysis of selected genes in control, Fasudil-, and H1152P-treated rECT. 92

Figure 31: Morphometric changes of rECT after MMP12 and ROCK inhibition. 93

Figure 32: Representative stress-strain curves of control, H1152P- and MMP408treated rECT during a rheological destructive tensile strength measurement. 94

Figure 33: Analysis of the viscoelastic properties of control, H1152P- and MMP408treated rECT.

Figure 34: Morphometric changes of rECT after ROCK inhibition and TGF $\beta 1$ treatment. 96

Figure 35: Representative stress-strain curves of control, H1152P- and TGF $\beta 1$ treated rECT during a rheological destructive tensile strength measurement. 
Figure 36: Analysis of the viscoelastic properties of control, H1152P- and TGF $\beta 1$ treated $\mathrm{rECT}$.

Figure 37: Morphometric changes of engineered heart muscle from neonatal cardiac cells of the rat ( $\mathrm{rEHM}$ ) after ROCK inhibition. 101

Figure 38: Isometric force measurement of control-, Fasudil-, and H1152P-treated rEHM. 102

Figure 39: Representative stress-strain curves of control, Fasudil-, and H1152Ptreated $\mathrm{rEHM}$ during a rheological destructive tensile strength measurement. 103

Figure 40: Analysis of the viscoelastic properties of control, Fasudil-, and H1152Ptreated $\mathrm{rEHM}$. 104

Figure 41: Morphometric changes of engineered heart muscle from hES2 wt CM and NHCF-V (hEHM). 105

Figure 42: Isometric force measurement of control- and H1152P-treated hEHM. .. 106 Figure 43: Analysis of force traces of control- and H1152P-treated hEHM. 107

Figure 44: Representative stress-strain curves of control and H1152P-treated hEHM during a rheological destructive tensile strength measurement. 108

Figure 45: Analysis of the viscoelastic properties of control and H1152P-treated hEHM. 109

Figure 46: Identification of new ROCK targets using PamGene's kinase activity profiling technology.

Figure 47: p21 is phosphorylated by ROCK2 and ROCK2 in an in vitro kinase assay.

Figure 48: CDK7 is phosphorylated by ROCK2 and ROCK2 in an in vitro kinase assay. 114

Figure 49: p21 co-immunoprecipitates with ROCK1. 115 


\section{III.List of Tables}

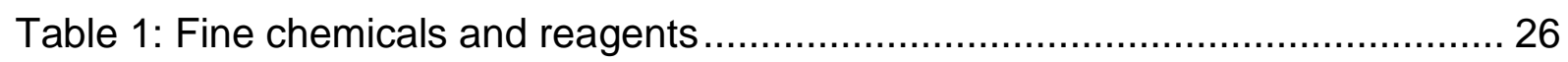

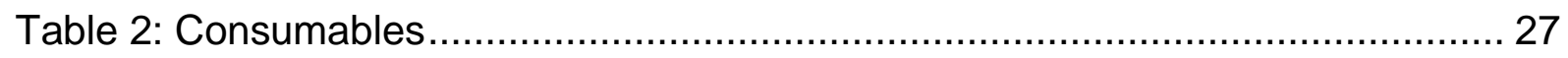

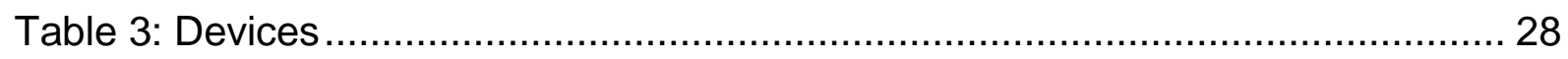

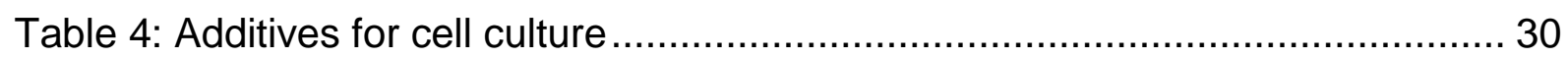

Table 5: Cell culture media and solutions …………........................................... 31

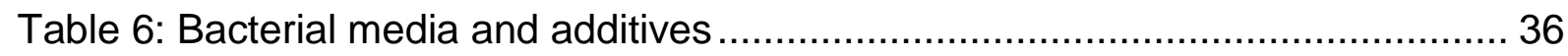

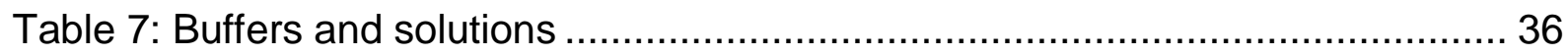

Table 8: Primary antibodies for western blot and immunofluorescence …................ 39

Table 9: Secondary antibodies for immunoblot analyses....................................... 40

Table 10: Secondary antibodies for immunofluorescence analyses ........................ 41

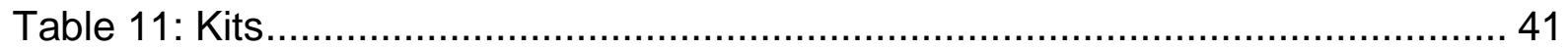

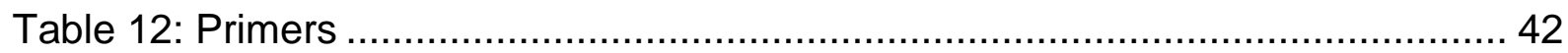

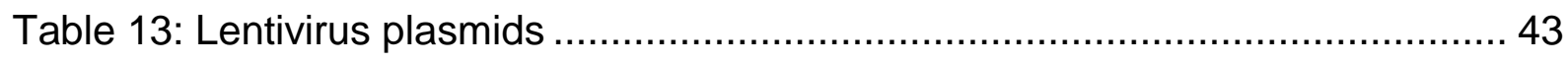

Table 14: Overexpression plasmids ................................................................ 43

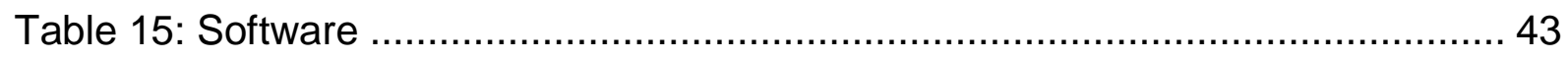

Table 16: Preparation of enzyme mix 1 and 2 for preparation of cardiac cells ........ 45

Table 17: Transfection mix for generating lentivirus particles ................................. 50

Table 18: Transfection mix for siRNA transfection into NRCF .............................. 51

Table 19: Composition of rEHM master mix .................................................... 53

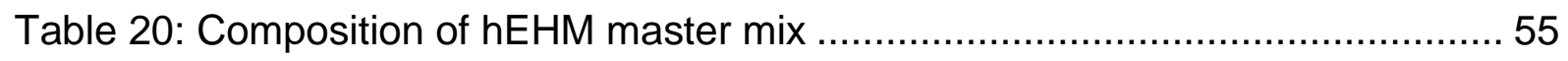

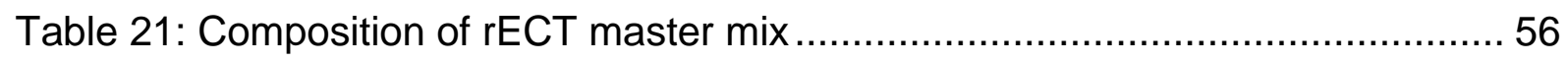

Table 22: Composition of hECT master mix …………....................................... 57

Table 23: Concentration of inhibitors and growth factors used in rECT and hECT

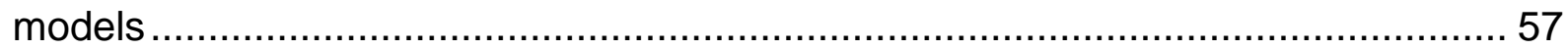

Table 24: Master mix of stacking and resolving gels used for SDS-PAGE .............. 63 
Table 25: Composition of kinase activity profiling assay master mix ....................... 66

Table 26: Composition of kinase activity profiling detection master mix ................... 66

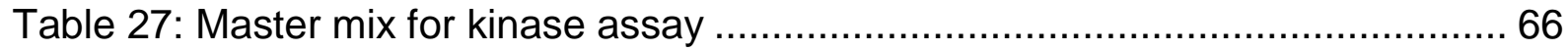

Table 28: Composition of cDNA master mix and reverse transcription protocol ....... 70

Table 29: Master mix for qRT-PCR per $1 \mu \mathrm{L}$ CDNA ……..................................... 71

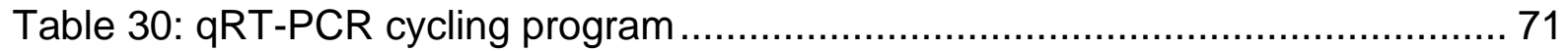




\section{Abbreviations, symbols and units}

Abbreviations

\begin{tabular}{|l|l|}
\hline $2 D$ & Two-dimensional \\
\hline 3D & Three-dimensional \\
\hline$\alpha$ SMA & $\alpha$-smooth muscle actin \\
\hline APS & Ammonium persulfate \\
\hline ATP & Adenosine triphosphate \\
\hline BSA & Bovine serum albumin \\
\hline CBFHH & Calcium and bicarbonate free hanks with HEPES \\
\hline CDK & Cyclin-dependent kinase \\
\hline cDNA & Complementary DNA \\
\hline cFB & Cardiac fibroblast \\
\hline CM & Cardiomyocyte \\
\hline CO 2 & Carbon dioxide \\
\hline CRD & Cysteine-rich domain \\
\hline CSA & Cross sectional area \\
\hline CTGF & Connective tissue growth factor \\
\hline DAPI & 4 ',6-diamidino-2-phenylindole \\
\hline ddH 2 O & Double-distilled water \\
\hline DDR2 & Discoidin domain receptor 2 \\
\hline DMEM & Dulbecco's modified eagle medium \\
\hline DMSO & Dimethyl sulfoxide \\
\hline DNA & Deoxyribonucleic acid \\
\hline dNTP & Deoxyribonucleic triphosphate \\
\hline DPBS & Dulbecco's phosphate- buffered saline \\
\hline EDTA & Ethylenediaminetetraacetic acid \\
\hline EtOH & Ethanol \\
\hline ECM & Extracellular matrix \\
\hline EMT & Epithelial-mesenchymal transition \\
\hline EndMT & Endothelial-mesenchymal transition \\
\hline ERK & Extracellular signal-regulated mitogen-activated protein \\
\hline
\end{tabular}




\begin{tabular}{|l|l|}
\hline & kinase \\
\hline F-Actin & Filamentous actin \\
\hline FA & Formaldehyde \\
\hline FBS & Foetal bovine serum \\
\hline FGF & Fibroblast growth factor \\
\hline FGM-3 & Fibroblast growth medium-3 \\
\hline FHL2 & Four-and-a-half LIM-only protein-2 \\
\hline Fig. & Figure \\
\hline FITC & Fluorescein isothiocyanate \\
\hline FL2-A & Pulse area \\
\hline FL2-W & Pulse width \\
\hline FoC & Force of contraction \\
\hline for & Forward \\
\hline FS & Forward scatter \\
\hline FSP-1 & Fibroblast specific protein 1 \\
\hline H2O & Water \\
\hline HAS2 & Hyaluronan synthase 2 \\
\hline hECT & Engineered connective tissue from NHCF-V \\
\hline hEHM & Engineered heart muscle from NHCF-V and hES2 wt CM \\
\hline HEPES & 4-(2-hydroxyethyl)-1-piperazineethanesulfonic acid \\
\hline $\begin{array}{l}\text { hES2 } \\
\text { CM }\end{array}$ & Cardiomyocytes differentiated from wild \\
\hline embryonic stem cells \\
\hline HRP & Human embryonic stem cell \\
\hline IGF-1 & Horse-radish peroxidase \\
\hline IgG & Insulin-like growth factor 1 \\
\hline IP & Immunoglobulin G \\
\hline IF & Immunoprecipitation \\
\hline IL & Immunofluorescence \\
\hline LB & Interleukin \\
\hline LGALS3 & Lysogeny broth \\
\hline LIMK & Galectin-3 \\
\hline Lmax & Length of maximum force generation \\
\hline
\end{tabular}




\begin{tabular}{|l|l|}
\hline L_NAME & NG-nitro-arginine methyl ester \\
\hline LOX & Lysyl oxidase \\
\hline LV & Left ventricle \\
\hline MAPK & Mitogen-activated protein kinase \\
\hline MBS & Myosin binding subunit \\
\hline MI & Myocardial infarction \\
\hline MMP & Matrix metalloproteinase \\
\hline MOPS & 3-[N]-morpholino]propanesulfonic acid \\
\hline mRNA & Messenger RNA \\
\hline MRTF & Myocardin-related transcription factor \\
\hline NaCl & Sodium chloride \\
\hline NaOH & Sodium hydroxide \\
\hline NEAA & Non-essential amino acids \\
\hline NHCF-V & Normal human cardiac fibroblasts from the ventricle \\
\hline NRCF & Neonatal rat cardiac fibroblasts \\
\hline NRCM & Neonatal rat cardiomyocytes \\
\hline ori & Origin of replication \\
\hline P/S & Penicillin/Streptomycin \\
\hline PBGD & Porphobilinogen deaminase \\
\hline PCNA & Proliferating cell nuclear antigen \\
\hline PCR & Polymerase chain reaction \\
\hline PDK1 & Phosphoinositide-dependent kinase 1 \\
\hline PFA & Paraformaldehyde \\
\hline PI & Propidium iodide \\
\hline qRT-PCR & Quantitative real-time PCR \\
\hline RAAS & Renin-angiotensin-aldosterone system \\
\hline RBD & Rho-binding domain \\
\hline rECT & Engineered connective tissue from NRCF \\
\hline rEHM & Engineered heart muscle from neonatal cardiac cells \\
\hline rev & Reverse \\
\hline RhoA & Ras homolog gene family, member A \\
\hline RNA & Ribonucleic acid \\
\hline RNAi & RNA Interference \\
\hline
\end{tabular}




\begin{tabular}{|l|l|}
\hline ROCK & Rho associated kinase \\
\hline ROCKi & ROCK inhibitor \\
\hline RT & Room temperature \\
\hline RV & Right ventricle \\
\hline scr & Scrambled \\
\hline SDS & Sodium dodecyl sulphate \\
\hline SDS-PAGE & SDS polyacrylamide gel electrophoresis \\
\hline SEM & Standard error of mean \\
\hline Ser & Serine \\
\hline SERCA & Sarco/endoplasmic reticulum Ca ${ }^{2+-A T P a s e}$ \\
\hline SFMM & Serum-free maturation medium \\
\hline shRNA & Short hairpin RNA \\
\hline shROCK1 & shRNA targeting ROCK1 \\
\hline shROCK1/2 & shRNA targeting ROCK1/2 \\
\hline siRNA & Small interfering RNA \\
\hline siROCK1 & siRNA targeting ROCK1 \\
\hline siROCK2 & siRNA targeting ROCK2 \\
\hline sm & Smooth-muscle \\
\hline SRF & Serum response factor \\
\hline SS & Side scatter \\
\hline ssRNA & Single stranded RNA \\
\hline TAE & Tris-acetate-EDTA \\
\hline TEMED & Tetramethylethylenediamine \\
\hline TFIIH & Transcription factor 2 H \\
\hline TGF $\beta$ & Transforming growth factor \\
\hline Thr & Threonine \\
\hline TNF- $\alpha$ & Tumour necrosis factor- $\alpha$ \\
\hline TRIS & Trishydroxymethylaminomethane \\
\hline TRITC & Tetramethylrhodamine isothiocyanate \\
\hline UV & Ultraviolet \\
\hline V/v & Volume percent \\
\hline VEGF & Vascular endothelial growth factor \\
\hline w/o & Without \\
\hline
\end{tabular}




\begin{tabular}{|l|l|}
\hline w/v & Mass fraction \\
\hline wt & Wild type \\
\hline
\end{tabular}

\section{Symbols and units}

\begin{tabular}{|l|l|}
\hline$\alpha$ & Alpha \\
\hline$\beta$ & Beta \\
\hline$\kappa$ & Kappa \\
\hline$\%$ & Percent \\
\hline${ }^{\circ} \mathrm{C}$ & Degree Celsius \\
\hline $\mathrm{Da}$ & Dalton \\
\hline $\mathrm{g}$ & Gram \\
\hline $\mathrm{g}$ & Gravity \\
\hline $\mathrm{h}$ & Hour \\
\hline $\mathrm{Hz}$ & Hertz \\
\hline $\mathrm{K}$ & Kilo \\
\hline $\mathrm{kb}$ & Kilo base \\
\hline $\mathrm{kDa}$ & Kilo Dalton \\
\hline $\mathrm{L}$ & Litre \\
\hline $\mathrm{m}$ & Milli $\left(10^{-3}\right)$ \\
\hline$\mu$ & Micro $\left(10^{-6}\right)$ \\
\hline $\mathrm{M}$ & Molar $\left(\mathrm{mol}^{-}\right)$ \\
\hline $\mathrm{min}$ & Minute \\
\hline $\mathrm{n}$ & Nano $\left(10^{-9}\right)$ \\
\hline $\mathrm{rpm}$ & Rounds per minute \\
\hline $\mathrm{U}$ & Units \\
\hline $\mathrm{V}$ & Volt \\
\hline
\end{tabular}




\section{V.Summary}

Rho-associated kinases ROCK1 and ROCK2 are serine/threonine kinases that are downstream targets of the small GTPases RhoA, RhoB, and RhoC. They play a critical role in the pathogenesis of myocardial fibrosis; however, their specific function in cardiac fibroblasts (CFB) remains unclear. Remodelling processes in the diseased heart propels the transition of cFBs to a myofibroblast phenotype exemplified by increased proliferation, migration and synthesis of extracellular matrix (ECM) proteins. Therefore, we sought to investigate whether ROCK1 and ROCK2 protein signalling intermediates have an impact on cFB characteristics in isolated cells and engineered cardiac tissue.

Knockdown of ROCK1 and ROCK2 and inhibition of ROCK1/2 activity altered cFB morphology, disrupted cytoskeletal structures, and increased adhesion velocity. In line, absolute number and area of focal adhesions was increased in ROCK1 and ROCK2 knockdown cells. Moreover, the double knockdown and inhibition of ROCK1/2 attenuated proliferation of cFBs. Interestingly, downregulation of either ROCK1 or ROCK2 decreased migration velocity and absolute distance, whereas the double knockdown and inhibition of ROCK activity increased both. Destructive tensile strength measurement of a three-dimensional engineered tissue model composed of cFBs (engineered connective tissue, ECT) treated with ROCK inhibitors showed that rigidity was significantly reduced compared to control tissues. This suggests that ROCK1 and ROCK2 influence the regulation and turnover of the ECM and thus viscoelastic properties of engineered tissues. Indeed, GPCR analysis of ROCK inhibitor-treated ECT showed that both ROCKs are involved in the regulation of several ECM proteins, including elastin and its degrading enzyme MMP12. In contraction measurements, human engineered heart muscle (hEHM) treated with ROCK inhibitors developed a significantly lower force of contraction per cross sectional area than control hEHM, whereas in the rat model (rEHM) no change in force of contraction could be detected. This demonstrates that ROCKs influence contractile parameters of engineered tissues. 


\section{Zusammenfassung}

Die Rho-abhängigen Kinasen ROCK1 und ROCK2 gehören zu den Serin/ThreoninKinasen und sind Effektoren der kleinen GTPasen RhoA, RhoB und RhoC. Beide Kinasen spielen eine wichtige Rolle in der Pathogenese der kardialen Fibrose. Allerdings ist über ihre spezifische Funktion in kardialen Fibroblasten, den vorrangigen Zelltypen in fibrotischen Prozessen, bisher wenig bekannt. Strukturelle Umbauprozesse im Herzen sind charakterisiert durch die Differenzierung von kardialen Fibroblasten in sogenannte Myofibroblasten. Myofibroblasten zeichnet eine gesteigerte Proliferation und Migration aus; außerdem sezernieren diese Zellen vermehrt extrazelluläre Matrix. Aus diesem Grund sollte in dieser Arbeit untersucht werden, inwiefern ROCK1 und ROCK2 einen Einfluss auf spezifische FibroblastenCharakteristika in isolierten Zellen und künstlichen Gewebemodellen haben.

Der spezifische Knockdown von ROCK1 und ROCK2, bzw. ROCK Inhibition führte auf zellulärer Ebene zu einer Veränderung der zellulären Morphologie und des Aktinzytoskeletts in kardialen Fibroblasten. Außerdem konnte beobachtet werden, dass die kardialen Fibroblasten schneller adhärierten. Dies ging mit einer Zunahme der absoluten Anzahl und Größe der Fokaladhäsionen einher. Der doppelte Knockdown sowie die Inhibition beider Kinasen führte zu einer verringerten Proliferation der Zellen. Die planare Migration der kardialen Fibroblasten wurde durch einen spezifischen ROCK1 und ROCK2 Knockdown verringert, interessanterweise jedoch durch einen doppelten Knockdown bzw. die Inhibition der Kinasen gesteigert. Analysen der Zugfestigkeit künstlicher Gewebemodelle bestehend aus kardialen Fibroblasten (engineered connective tissue, ECT), die mit ROCK Inhibitoren behandelt wurden, zeigten eine reduzierte Steifigkeit im Vergleich zu Kontrollgeweben. Dies zeigte, dass ROCK1 und ROCK2 einen Einfluss auf die biomechanischen Eigenschaften künstlicher Gewebemodelle haben, mutmaßlich durch die Beeinflussung von Produktion und Abbau der extrazellulären Matrix. Dies konnte durch qPCR Analysen teilweise bestätigt werden. Mit ROCK Inhibitor behandelte ECT zeigten beispielsweise eine verringerte Elastin-Expression, wohingegen die Expression der Elastin-abbauenden Matrix-Metalloprotease MMP12 erhöht war. In Kontraktionsexperimenten künstlicher Herzgewebe (engineered heart muscle, EHM), die mit ROCK Inhibitoren behandelt wurden, zeigte sich außerdem 
eine verringerte Kontraktionskraft im Vergleich zu Kontrollgeweben im humanen Modell, wohingegen im Ratten Modell (rEHM) eine ähnliche Kraft beobachtet werden konnte. Dies zeigte, dass auch die Kontraktionsfähigkeit künstlicher Herzgewebe von beiden ROCKs beeinflusst wird. 


\section{Introduction}

\subsection{Cardiovascular diseases}

Cardiovascular diseases (CVD) are the leading cause of morbidity and mortality worldwide, accounting for an estimated $31 \%$ of all deaths [1].

CVDs involving an imbalance between cardiac output and metabolic demands of the body may result as a consequence of cardiomyocyte (CM) death or dysfunction. This is typical after a myocardial infarction (MI) whereby reduced contractility (systolic dysfunction) and/or insufficient filling of the heart with blood (diastolic dysfunction) can be detected. During disease progression, pathological cardiac remodelling occurs involving morphological and functional changes. These include CM hypertrophy, along with apoptotic/necrotic CM death, cardiac fibrosis, chronic inflammation, and dilation of the heart [2].

Cardiac fibrosis is a complex mechanism involving the transdifferentiation of cardiac fibroblasts (cFB), endothelial cells, and other cell types into myofibroblasts, concomitant with excess deposition of extracellular matrix (ECM) proteins [3]. In addition to physiological alterations following a Ml, fibrosis and the formation of a fibrotic scar causes collagens to substitute apoptotic/necrotic CM in an attempt to preserve the structural integrity of the heart. Fibrosis then leads to increased mechanical stiffness, which contributed to and deteriorates systolic and diastolic function and results in a vicious cycle towards decompensated heart failure [2, 4].

Despite our enhanced mechanistic understanding of heart diseases, it is still not possible to reverse the effects of pathological cardiac remodelling. Current therapy for heart failure, including $\beta$-adrenergic receptor blockers, angiotensin-converting enzyme (ACE) inhibitors, diuretics and aldosterone antagonists, only target heart failure symptoms and do not address the underlying aetiology. Optimally, such therapies would stimulate CM proliferation and regeneration of scar tissue [5, 6]. The majority of our understanding stems from work focussed on CM, but recent studies have increasingly implicated non-myocyte cell populations, including cFBs, as major determinants in these pathological processes. 


\subsection{Origin and function of cardiac fibroblasts in the heart}

Fibroblasts are cells of mesenchymal origin and can be found in all vertebrate organs [7]. In the heart, cFBs make up to $70 \%$ of the cell content depending on species [8]. They are morphologically flat and spindle-shaped in culture with a prominent Golgi apparatus, but usually lack a basement membrane [7, 9].

A significant issue is the absence of a specific marker for cFBs. Three proteins that are commonly used for this purpose are the collagen receptor discoidin domain receptor 2 (DDR2), the intermediate filament vimentin, and the filament-associated calcium-binding protein fibroblast specific protein 1 (FSP-1) [10, 11]. However, all these markers lack fibroblasts specificity [9, 10, 12]. The lack of a specific marker might stem from cFBs being highly heterogeneous as they originate from several sources [9, 10]. During cardiac development, epicardium-derived cells undergo epithelial-mesenchymal transition (EMT) and differentiate into fibroblasts; a process driven by transforming growth factor $\beta$ (TGF $\beta$ ) and periostin [13-15]. Moreover, endothelial cells of the endocardium have been shown to transdifferentiate into fibroblasts in a process called endothelial-mesenchymal transition (EndMT) [16]. An additional source of fibroblasts are fibrocytes that derive from the bone marrow, and can be recruited to the site of injury following a $\mathrm{MI}$ [11].

cFBs play critical roles in maintaining the homeostasis of the ECM and normal cardiac function by participating in cardiac development, secretion of stimulatory/inhibitory molecules and remodelling processes. As such, cFBs secrete ECM proteins (predominantly collagen I, collagen III, and fibronectin) to provide a scaffold for other cell types [17]. They also secrete matrix metalloproteases (MMPs) that degrade ECM proteins ensuring proper ECM turnover [18]. cFBs also produce and secrete a number of growth factor and cytokines that can act in an autocrine or paracrine manner [7].

Moreover, cFBs are coupled to CM via connexin gap junctions (Cx40, Cx43, Cx45) that are vital for proper electrical conduction [19, 20]. cFBs are also connected to the ECM via integrins and can integrate their contractile properties on the intracellular collagen network, thereby subsequently exerting mechanical forces on CM. Their high membrane resistance permit cFBs to conduct electrical signals and form an 
insulating layer between the atria and ventricles; this ensures proper and sequential contraction in the different areas of the heart [21].

Cumulatively, it is becoming more appreciated that cFBs partake a pivotal role in maintaining proper function of the myocardium by providing structural, biomechanical, and electrical support.

\subsection{The cardiac myofibroblast}

cFBs in the healthy heart are usually considered quiescent, although they play an important background role in maintaining overall homeostasis. Nevertheless, cFBs may be activated to myofibroblasts by various stimuli such as an overly active reninangiotensin-aldosterone system (RAAS) and TGF $\beta$ agonism. TGF- $\beta$ is thought to be the major factor in the transdifferentiation of cells into myofibroblasts, promoting proliferation, migration, and ECM production [22]. In the first phase after an acute injury, TGF- $\beta$ is considered to have a beneficial, protective role. However, continuously high TGF- $\beta$ secretion leads to excess deposition of ECM resulting in cardiac muscle stiffening accompanied by impaired contractile performance [23, 24]. The RhoA/myocardin-related transcription factors (MRTF)/serum response factor (SRF) pathway which itself can be activated via TGF $\beta$ signalling through $G$ protein coupled receptors or mechanical tension is another important mechanism [25-28]. RhoA signalling then leads to activation of its effectors ROCK and mDia, both influencing actin dynamics and cytoskeletal organisation [29, 30]. Also, transcriptional activity can be regulated through MRTF operating as co-activators for the SRF. Promoter regions of genes important in myofibroblast transdifferentiation and functionality are highly enriched for SRF binding sites [31, 32].

Myofibroblasts can also originate from epithelial-like and endothelial cells undergoing EMT and EndMT, respectively. They can also stem from fibrocytes from the bone marrow and pericytes (Figure 1) [32]. 


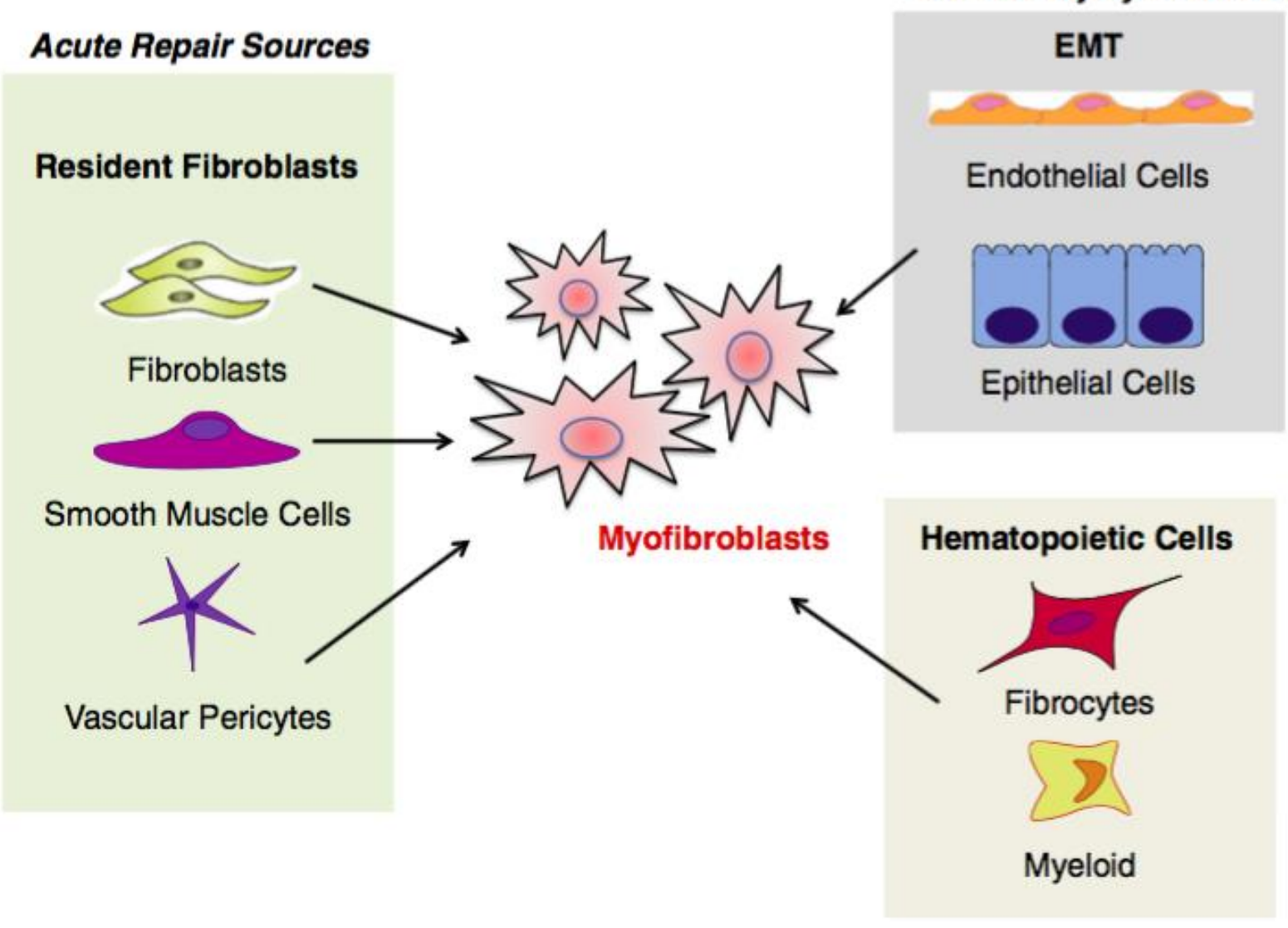

Figure 1: Origin of myofibroblasts

Cellular sources of myofibroblasts in acute (left) and chronic injury scenarios (right) [32].

After an acute $\mathrm{Ml}$, cFBs have been demonstrated to pass through a two-stage differentiation process into myofibroblasts. In the first, "proto-myofibroblast" stage, actin stress fibres are forming and they increasingly secrete collagens and fibronectin [33]. Additionally, these proto-myofibroblasts show relatively fast adhesion site formation and turnover enabling them to migrate into the wounded area [33, 34]. Approximately $20-30 \mathrm{~h}$ later, the second stage is initiated defined by a prominent stress fibre network due to the expression of $\alpha$-smooth muscle actin ( $\alpha S M A)$ and the development of a strong contractile phenotype [33].

Mature myofibroblasts are characterised by certain features such as the de novo expression of $\alpha S M A$ and a spindle-shaped morphology with protruding dendritic-like processes [26, 34]. Defining markers for myofibroblasts are the hyper-secretion of ECM proteins like periostin, collagen I, collagen III, and fibronectin [33, 35]. This is important for fibrotic scar formation in wound healing and, in case of a $\mathrm{Ml}$, prevents 
rupture of the ventricular wall [36-38]. Simultaneously myofibroblasts secrete ECM degrading MMPs that assist in migration within the scar to the repair site.

Myofibroblasts are also an important source of bioactive auto- and paracrine acting molecules. Upon injury, myofibroblasts start to build an inflammatory environment by secreting cytokines, interleukins (IL), and recruiting neutrophils and macrophages to clear the injured area of apoptotic/necrotic cells [39]. Where acute cardiac remodelling is activated, myofibroblasts secrete tumour necrosis factor- $\alpha$ (TNF- $\alpha$ ), IL$1 \beta$, IL- 6 , and TGF- $\beta$. TNF- $\alpha$ was also demonstrated to participate in myofibroblast invasion, MMP secretion, and proliferation, whereas IL-6 acts as a stimulus for CM hypertrophy $[40,41]$.

After stabilisation of the injury, a number of myofibroblasts become senescent or undergo apoptosis [42-44]. However, the fate of the remaining myofibroblasts is not well understood. They may continue producing and secreting ECM through selfreinforcing molecular signalling pathways leading to a vicious cycle of myofibroblast activation. In this scenario, TGF- $\beta$ acts as a pro-survival stimulus of myofibroblasts. An enhanced understanding of the molecular mechanisms that drive these processes may aid in finding therapeutics that stop or prevent myofibroblast activation in chronic disease states [32].

\subsection{Rho-associated kinases ROCK1 and ROCK2: Expression and structure}

The Rho-associated kinases ROCK1 (Rok- $\beta$ ) and ROCK2 (Rok- $\alpha$ ) belong to the family of serine/threonine AGC kinases that are named after the protein kinase $A, G$, and $C$ family members. They were first described as downstream mediators of the monomeric GTPase RhoA [45, 46]. ROCK1 and ROCK2 are encoded by two different genes and consist of 1354 and 1388 amino acids, respectively [47]. A schematic overview of ROCK1 and ROCK2 structure, including important phosphorylation and cleavage sites for activity regulation are summarised in Figure 2. In general, ROCK1 and ROCK2 share $65 \%$ identity in their amino acid sequence [48]. They are most divergent within their coiled-coil region (55\% identity), but are $90 \%$ homologous within their kinase domain; this explains their similar function and kinase activity [49]. 

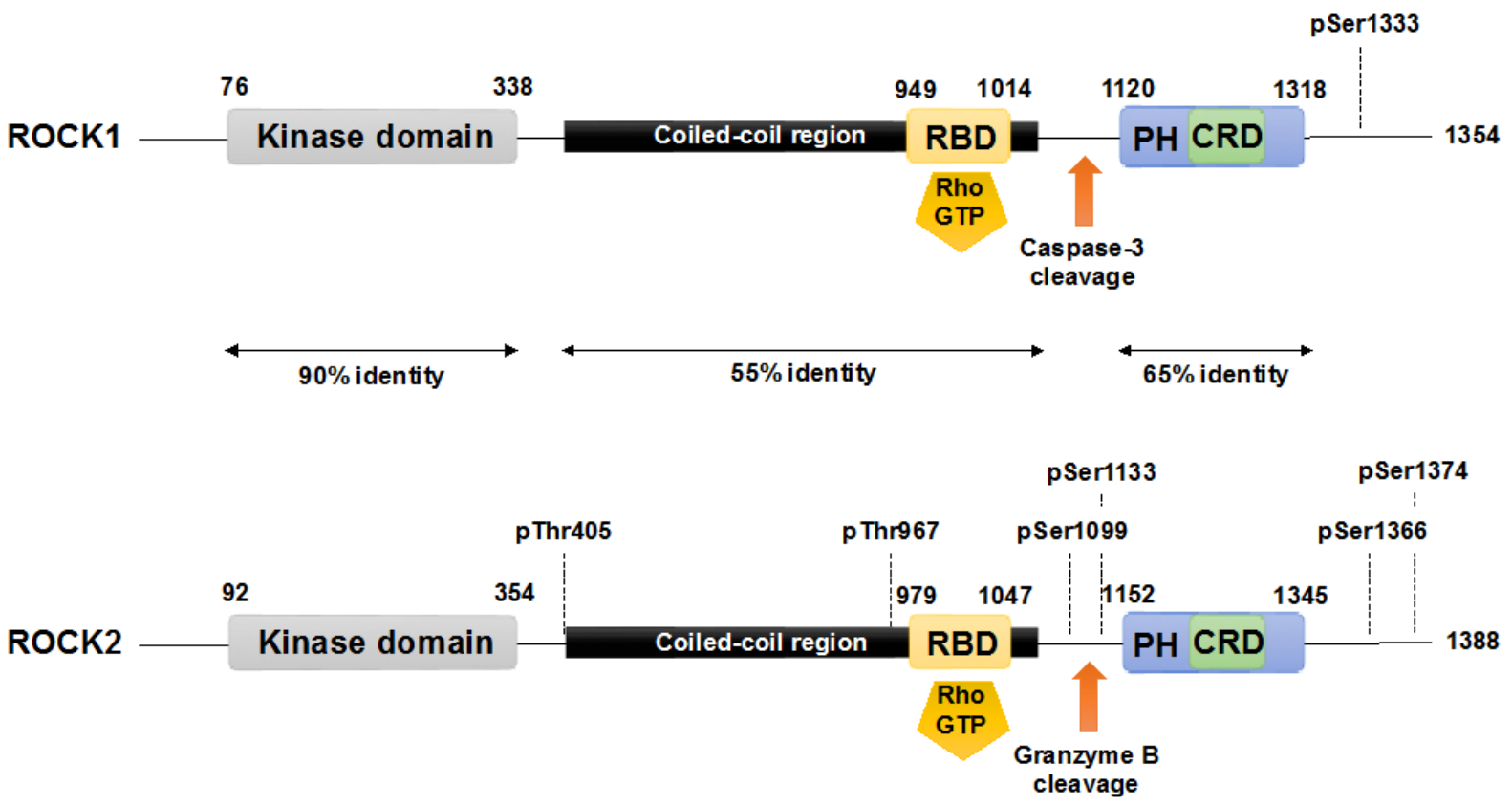

Figure 2: ROCK structure and modes of regulation.

ROCK1 and ROCK2 consist of an N-terminally located kinase domain and a C-terminally located pleckstrin homology $(\mathrm{PH})$ domain containing a cysteine-rich $\mathrm{C} 1$ domain (CRD). The region between the ROCK kinase domain and the $\mathrm{PH}$ domain forms a coiled-coil structure where the Rho binding domain (RBD) is located. Both are highly homologous and share overall $64 \%$ amino acid sequence identity. A splice variant of ROCK2 contains an insertion of 57 amino acids following the RBD and is called ROCK2m. ROCK1 and ROCK2 can be activated by binding of RhoGTP to the RBD and through cleavage of ROCK1 by caspase- 3 and ROCK2 by granzyme B and caspase-2. Autophosphorylation of ROCK1 at Ser1333 and ROCK2 at Ser1366 reflects the activation status of the kinases. Phosphorylation of ROCK2 at Thr967, Ser1099, Ser1133, or Ser1374 increased its activation status, whereas phosphorylation of Tyr722 decreases the ability of ROCK2 to bind to RhoA. Interaction of Thr405 of ROCK2 with the N-terminal extension of the ROCK2's kinase domain is essential for substrate phosphorylation and kinase domain dimerisation [3].

ROCK1 and ROCK2 both contain an N-terminally located kinase domain, followed by a coiled-coil region and a Rho-binding domain (RBD; [47]). The RBD of ROCK1 and ROCK2 binds exclusively to the switch I and switch II regions of activated RhoA, $B$, and $\mathrm{C}[50,51]$. No difference in binding affinity of ROCK1 or ROCK2 for the RBD has been described. RhoA, B, and C are monomeric GTPases that act as a molecular binary switches by cycling between an inactive GDP-bound, and an active GTPbound state. The mechanism of RhoGTPase activation is, on the one hand, mediated by guanine nucleotide exchange factors (GEFs) that are responsible for the 
exchange of GDP and GTP and, on the other hand, by GTPase activating proteins (GAPs) that stimulate the intrinsic hydrolytic GTPase activity of RhoGTPases [52].

A split $\mathrm{PH}$-domain is located at the $\mathrm{C}$-terminus including a cysteine-rich $\mathrm{C} 1$ domain. The PH-domain has been shown to play an autoinhibitory role on ROCK function as it sequesters the $\mathrm{N}$-terminal kinase domain, thereby reducing its kinase activity. Binding of the $\mathrm{PH}-\mathrm{C} 1$ tandem motif to membrane bilayers via positively charged surfaces on each domain regulates the cellular localisation of ROCK1 and ROCK2 and leads to the activation of kinases by releasing the kinase domain from its close conformation (see 1.5) [53]. ROCK1 and ROCK2 bind to different lipids using their $\mathrm{PH}$ domain. ROCK2 preferentially binds to phosphatidylinositol $(3,4,5)$-trisphosphate and phosphatidylinositol $(4,5)$-bisphosphate, whereas ROCK1 does not [54].

There are also differences in ROCK1 and ROCK2 protein expression. In the mouse, ROCK1 and ROCK2 are ubiquitously expressed with highest expression of ROCK2 in brain, muscle, heart, lung, and placenta [48]. In a recent review, Julian and Olson (2014) analysed the expression of both kinases based on expressed sequence tags, confirming the higher abundance of ROCK2 in heart and brain and suggesting a more prominent expression of ROCK1 in blood cells and the thymus [3, 55]. Moreover, a novel spliced variant of ROCK2 called ROCK2m was detected in skeletal muscle, heart, and skin from humans and mice. It contains a 57 amino acid insertion following the RBD. During myogenic differentiation, ROCK2m is expressed together with ROCK2. However, its regulation and function are unknown [56].

ROCK1 and ROCK2 were differentially located within the cell that may vary for dependent on cell type. For ROCK2, a cytosolic and nuclear distribution has been reported, as well as association with the centrosome, and actin and vimentin filaments [57-63]. In striated muscle, ROCK2 can be found at intercalated disks and the Z-disc [64]. ROCK2 was additionally found near the cleavage furrow in late mitosis, arguing for a role in the formation of the contractile ring during cytokinesis [65]. In contrast, ROCK1 was reported to be located in the cytosol, and to associate with centrosomes, the plasma membrane, cell-cell contacts and adhesions sites, and vesicles [64, 66-68]. 


\subsection{Mechanisms of ROCK activation}

\subsubsection{General mechanisms of ROCK activation}

The common mode of activation for both ROCK1 and ROCK2 is the so-called "derepression". The C-terminus, including the PH domain of ROCKs directly binds to the kinase interface, thereby acting in an autoinhibitory manner. Upon binding of the GTP-loaded active RhoA to the RBD, this autoinhibitory stimulus is removed, leading to an active "open" conformation of the kinase domain, thereby increasing the kinase activity.

Several studies have shown that deletion of C-terminal portions lead to a constitutively active kinase [47, 69-72]. So far, it is not clear whether further phosphorylation or other posttranslational modifications play a role in the regulation or fine-tuning of ROCK kinase activity. However, ROCK1 and ROCK2 crystal structures revealed that unlike other kinases, phosphorylation of the activation loop is not required for full activity [71, 72]. Instead, autophosphorylation of ROCK1 at Ser1333 and ROCK2 at Ser1366 reflect the activation status of each kinase. Intriguingly, antibodies targeting these phosphorylation sites may assist in studying the activation of these kinases that is usually achieved via analysis of the phosphorylation of ROCK targets like myosin light chain (MLC) phosphatase [73, 74].

Additionally, ROCK1 and ROCK2 can form homodimers that are dependent on the $\mathrm{N}$-terminal extension of the kinase domains, the kinase domains themselves, and the coiled-coil region. Through this homodimerisation, the kinase's active sites face the same direction, possibly enabling interaction with substrate dimers [71, 72].

\subsubsection{Specific mechanisms of ROCK1 activation}

ROCK1 and ROCK2 share common modes of activation but can also be regulated differently. ROCK1 can be cleaved by caspase 3 at a conserved C-terminal DETD1113/G sequence upon activation during early apoptosis. This cleavage leads to the removal of the autoinhibitory C-terminus and thus, a constitutively active ROCK1 is formed, which results in actomyosin-dependent membrane blebbing [75]. 
Furthermore, ROCK1 can be inhibited indirectly via Rnd3/p190RhoGAP-dependent inhibition of Rho/ROCK signalling. Rnd3 itself is an atypical RhoGTPase as it can bind GTP, however, does not possess hydrolytic activity and is therefore not regulated by the classical GTP/GDP switch mechanism of typical GTPases [76]. Rnd3 can be inhibited by ROCK1-dependent phosphorylation at different phosphorylation sites, thereby inducing Rnd3 translocation from the membrane to the cytosol and reducing the ability to induce the formation of stress fibres [77-79]. Phosphoinositide-dependent kinase 1 (PDK1) competes with Rnd3 in binding to ROCK1 independent of protein phosphorylation. In the absence of PDK1, inhibition of Rho/ROCK signalling via Rnd3 dominates, resulting in decreased actomyosin contractility and motility in cancer cells [80].

\subsubsection{Specific mechanisms of ROCK2 activation}

Similar to ROCK1, ROCK2 can be cleaved and activated by proteases. Granzyme B, which is released together with perforin from cytotoxic granules during induction of apoptosis in natural killer cells and cytotoxic T-cells, was reported to cleave ROCK2 at the IGLD1131 sequence at the C-terminus, which is absent in ROCK1 [81, 82]. This cleavage was independent from caspases and resulted in a constitutively active ROCK2. Intriguingly, ROCK2 cleavage led to the activation of caspases and ROCK1 cleavage [82]. Moreover, caspase-2 can cleave ROCK2 into a $140 \mathrm{kDa}$ fragment leading to kinase activation [83].

Both ROCK1 and ROCK2 have similar hydrophobic motifs located near the Cterminus of the kinase domain. Phosphorylation of these motifs promotes the active conformation of other members of the AGC protein kinase family leading to further activation. In contrast to ROCK1, Thr-405 in the hydrophobic motif of ROCK2 interacts with the $\mathrm{N}$-terminal extension of the kinase domain, and is essential for promoting substrate phosphorylation and kinase domain dimerisation [71, 72].

In addition, the peripheral clock gene BMAL1 was reported to modulate the expression and activity of ROCK2 by binding directly to the promoter of ROCK2 in a time-of-day-dependent manner, leading to time-of-day variances in ROCK2 activity. In accordance, BMAL1 deletion from smooth muscle in mice decreased myosin 
phosphorylation in the mesenteric arteries and suppressed the time-of-day variations in response to agonist-induced vasoconstriction [84].

\subsection{Pharmacological ROCK inhibitors}

Many compounds have been developed to interfere with ROCK activity, the most prominent are Fasudil (formerly HA-1077) and Y-27632. Both act as competitive antagonists for ATP at the kinase domain and are non-selective for ROCK1 or ROCK2 with IC 50 values of $330 \mathrm{nM}$ for Fasudil and $140 \mathrm{nM}$ for Y-27632 in cell-free assays [85-87]. When used at higher concentrations, they also inhibit other kinases involved in the same cellular processes as ROCKs, as PKA ( $\mathrm{IC}_{50}$ of $1.6 \mu \mathrm{M}$ for Fasudil) or PKC (IC50 of $3.3 \mu \mathrm{M}$ for Fasudil) $[85,88,89]$. Fasudil is activated in the liver to its metabolite hydroxyfasudil, which exerts a more specific action on ROCKs than Fasudil itself [90]. Fasudil is the only ROCK inhibitor approved for human use; first in 1995 in Japan and China for the prevention and treatment of cerebral vasospasm following subarachnoid haemorrhage. Since then, Fasudil has been used widely in various clinical studies and showed beneficial effects in patients with PAH, systemic hypertension, vasospastic angina, stroke, and heart failure [91-95].

As most studies show promising and beneficial effects of the use of Fasudil and $\mathrm{Y}$ 27632 in various in vitro and in vivo studies, significant efforts were made to develop more potent and isoform-selective inhibitors for ROCK1 and ROCK2.

A derivative of Fasudil is $\mathrm{H} 1152 \mathrm{P}$ ([(S)-(+)-2-methyl-1-[(4-methyl-5-isoquinolinyl) sulfonyl]-hexahydro-1H-1,4-diazepine]), which shows a higher potency and specificity for ROCKs than Fasudil itself with an $\mathrm{IC}_{50}$ of $1.6 \mathrm{nM}$, while the $\mathrm{IC}_{50}$ for other kinases remained relatively constant. So far, $\mathrm{H} 1152 \mathrm{P}$ has only been used in preclinical in vitro and in vivo studies [96].

In 2008, Boerma et al. described the first and only ATP-competitive ROCK2-selective inhibitor named KD-025 ([2-(3-(4-((1H-indazol-5-yl)amino)quinazolin-2-yl) phenoxy)$\mathrm{N}$-isopropylacetamide; formerly SLx-2119), which effectively decreased CTGF expression in human dermal fibroblasts. KD-025 is approximately 200-fold more selective toward ROCK2 than ROCK1, with $\mathrm{IC}_{50}$ values of $105 \mathrm{nM}$ for ROCK2 and 
$24 \mathrm{mM}$ for ROCK1 [97]. In two studies, KD-025 already showed therapeutic potential for the treatment of ischemic stroke and autoimmune diseases [98, 99].

\subsection{ROCK targets in the cardiovascular system}

The best characterised phosphorylation motifs for ROCK1 and ROCK2 are Arg/Lys$\mathrm{X}-\mathrm{Ser} / \mathrm{Thr}$ or Arg/Lys-X-X-Ser/Thr. They share this motif with many other AGC kinases, including PKA, PKG, and PKC [79, 100]. Due to their high homology, the function of both ROCKs has long been considered to be similar, and their specificity has not been completely analysed. The only substrate specific for one of the kinases is Rnd3, which is exclusively phosphorylated by ROCK1 [3, 78]. An overview of ROCK substrates in the cardiovascular system described in this thesis can be seen in Figure 3.

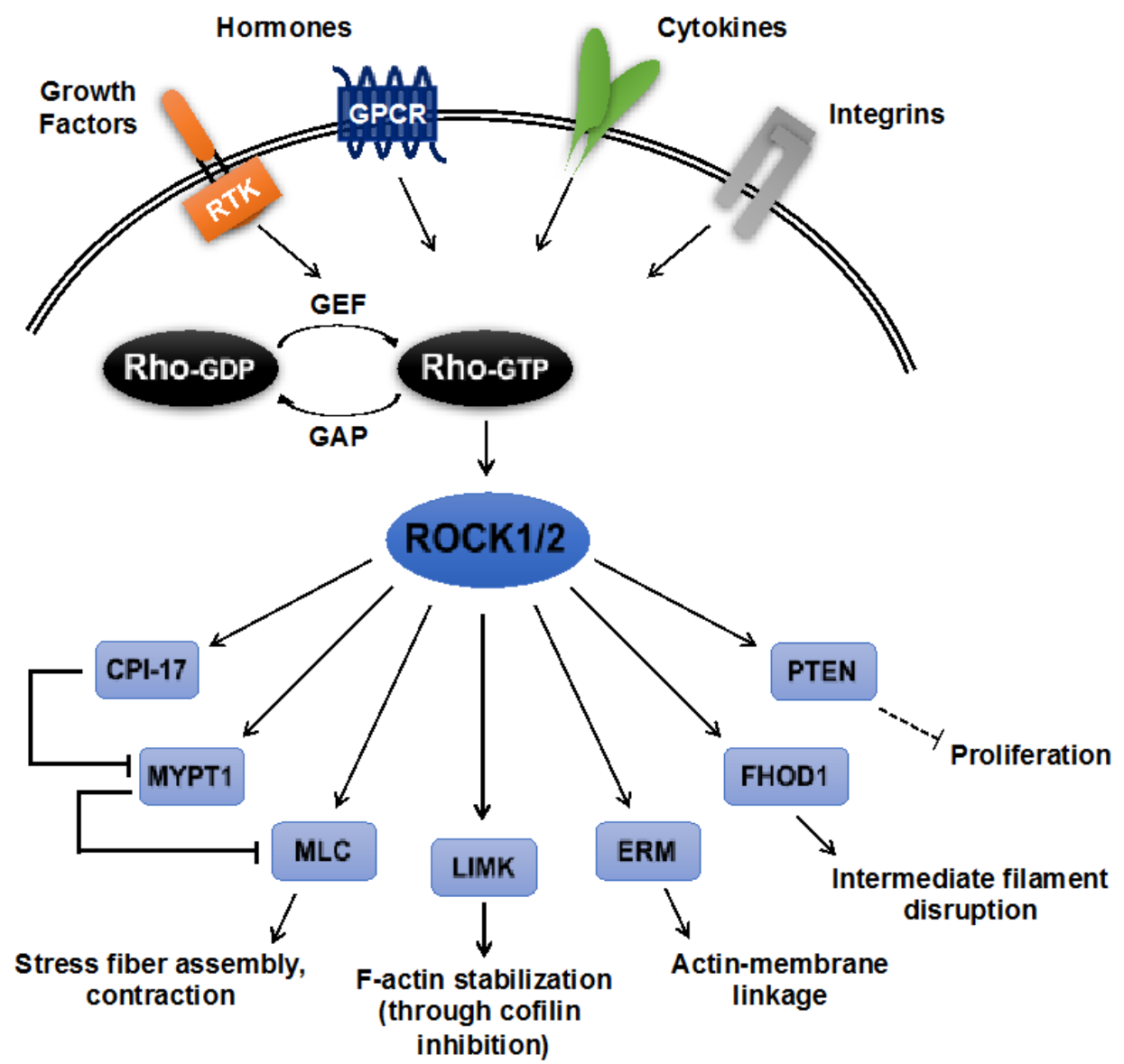

Figure 3: ROCK targets in the cardiovascular system.

Rho proteins can be activated by guanine nucleotide exchange factors (GEFs) that are themselves activated by receptor tyrosine kinases (RTKs), G protein-coupled receptors (GPCRs), cytokines and integrins. Rho-GTP subsequently activates ROCK1 and ROCK2, 
both having a broad range of substrates and is responsible for diverse cellular responses. CIP-17, kinase C-potentiated phosphatase inhibitor of $17 \mathrm{kDa}$; ERM, ezrin-radixin-moesin; FHOD1, formin homology 2 domain-containing 1; GAP, GTPase activating protein; LIMK, LIM-kinase; MLC, myosin II regulatory light chain; MYPT1, myosin phosphatase target subunit 1; PTEN, phosphatase and tensin homolog deleted on chromosome 10 [3].

The best characterised ROCK substrate is the myosin phosphatase target subunit 1 (MYPT1), a regulatory subunit of myosin light chain phosphatase (MLCP). MLCP and MYPT1 modulate the $\mathrm{Ca}^{2+}$-dependent phosphorylation of myosin light chain (MLC) by dephosphorylating MLC. This counteracts the activity of MLC kinase and leads to decreased contraction of smooth muscle cells (SMC) [3]. Species-dependent phosphorylation of MYPT1 at Thr697, Ser854, or Thr855 by ROCK indirectly increases net MLC phosphorylation and actomyosin contraction by reducing MLCP activity [101, 102]. Furthermore, myosin II is dissociated from MLCP [103]. ROCKs have also been demonstrated to directly phosphorylate MLC at Ser19, the same residue phosphorylated by MLCK, thus increasing actomyosin contractility [45, 104]. In adult rat ventricular CMs, increased phosphorylation of MYPT and MLC2 was a consequence of $\alpha$-adrenergic receptor stimulation. Additionally, $\mathrm{Ca}^{2+}$ sensitivity of tension was enhanced and PP1-myofilament association was decreased in a ROCKdependent manner [105].

ROCKs, together with other kinases like PKC, directly phosphorylate protein kinase C-potentiated phosphatase inhibitor of $17 \mathrm{kDa}(\mathrm{CPI}-17)$ at Thr-38, believed to be important in the regulation of SMC contraction [106]. Phosphorylation of CPI-17 by ROCK or PKC enhanced phosphatase inhibition by more than 1000-fold [107].

LIM kinases (LIMK) 1 and 2 are also well-characterised ROCK targets and are ubiquitously expressed [108]. Upon phosphorylation of LIMK by ROCKs, LIMK phosphorylates cofilin, thereby inhibiting its actin-depolymerising and actin-severing functions. This leads to an increase in actin filament formation [109, 110]. Cofilin itself is an important mediator during pathological remodelling of the heart. Mice that are haploinsufficient for cofilin-2 in CMs had a dilated heart with increased left ventricular volume, decreased wall thickness, and reduced contractile function. Additionally, myofibrils showed a disorganisation of actin structures, as well as a poorly organised 
sarcomere [111]. RhoA/ROCK-dependent cofilin phosphorylation was reported to be present in adult CMs that were treated with adiponectin, an important regulator of peripheral energy metabolism. The resulting increase in vesicular trafficking of lipoprotein lipase to the surface of CMs suggests a role of ROCK in metabolic processes [112].

FHOD3, a diaphanous related formin involved in actin filament polymerisation, is a further known target of ROCKs. Specifically, ROCK1 has been shown to interact with and phosphorylate FHOD3, thereby activating it [113].

Ezrin, radixin, and moesin (ERM) proteins that crosslink the plasma membrane with actin filaments, are phosphorylated by ROCKs in vitro. This is thought to occur at a threonine residue located in the last $34 \mathrm{C}$-terminal amino acid region, also important in actin binding [114]. Phosphorylation in this region impedes intramolecular and/or intermolecular head-to-tail association, thereby interfering with regulatory mechanisms important for their proper function [115]. Similar to CPI-17, ERM proteins can also be phosphorylated by PKC and in endothelial cells, PKC was shown to be the major kinase $[116,117]$. However, phosphorylation by ROCKs has been shown to play a role in the ERM-dependent localisation of leukocyte adhesion molecules in a docking structure, and coordination of barrier function [118-120]. The adapter molecule $\mathrm{Na}^{+} / \mathrm{H}^{+}$exchanger regulatory factor 2 (NHERF2) was reported to be important for the interaction with and phosphorylation of ERM proteins by ROCK [121]. In smooth muscle cells, ERM proteins were shown to be phosphorylated by ROCKs and PKC in response to vasoconstrictors, leading to binding of moesin to adaptor molecule EBP50 and regulating smooth muscle cell contractility [122].

\subsection{Function of ROCK1 and ROCK2 in cardiac fibroblasts}

Only a limited amount of studies focusses on the function of ROCK1 and ROCK2 in cardiac fibroblasts. Recently, RhoA/ROCK signalling was linked to expression of collagen I and III, the main ECM components secreted by cardiac fibroblasts. Treatment of cultured cardiac fibroblasts with alendronate, a farnesylpyrophosphate synthase inhibitor, was shown to inhibit RhoA geranylgeranylation, thereby preventing collagen I gene and protein expression. This effect could be mimicked by 
treatment with inhibitors of the RhoA/ROCK pathway [123]. In addition, the ROCK inhibitors Y-27632 and Fasudil were shown to inhibit prostaglandin F2 $\alpha$ - and hyperglycaemia-induced collagen I and III expression in rat cardiac fibroblasts [124, 125]. RhoA/ROCK signalling has also been shown to regulate cardiac fibroblast migration as treatment with Fasudil impaired migration of neonatal rat cardiac fibroblasts on a planar surface [126]. In a different study, simvastatin reduced the TNF $\alpha$-induced migration of cardiac fibroblasts via ROCK inhibition and subsequent disruption of the actin cytoskeleton [127]. Moreover, RhoA/ROCK was associated with proliferation of human atrial myofibroblasts, as simvastatin reduced proliferation of these cells via inhibition of RhoA geranylgeranylation [128].

\subsection{Function and regulation of ROCK1 and ROCK2 in human cardiovascular disease}

Increased ROCK activity has been demonstrated in various cardiovascular diseases, including hypertension, pulmonary hypertension, stable angina pectoris, vasospastic angina, heart failure, and stroke [91, 92, 94, 95, 129-131]. An overview of the involvement of ROCK in human cardiovascular disease can be seen in Figure 4 [3].

Hypertension is one of the leading health problems in the world and is characterised by elevated vascular contractility and arterial wall remodelling leading to atherosclerosis. As a consequence, arterial pressure is elevated due to an increased vascular resistance in the peripheral vascular system [3]. ROCK activity as a result of an upregulated RAAS and an increase in reactive oxygen species was detected in hypertensive patients and models [91, 132-138]. For example, treatment of hypertensive patients with Fasudil markedly decreased peripheral vascular resistance [91]. In line with that, ROCK inhibitor treatment of spontaneously hypertensive rats decreased the mean arterial blood pressure, whereas the systolic blood pressure remained the same [139]. Specifically, ROCKs were found to be involved in structural and functional alterations of blood vessels in these rats [140]. Moreover, certain polymorphisms in the ROCK2 gene were associated with a lower risk of developing hypertension in patients [141]. Thus, although ROCK inhibitors do not always lower blood pressure in hypertension and studies in ROCK KO models 
regarding blood pressure regulation have been inconclusive, strong evidence for involvement of ROCK signalling in hypertension remains [3].

Endothelial cell

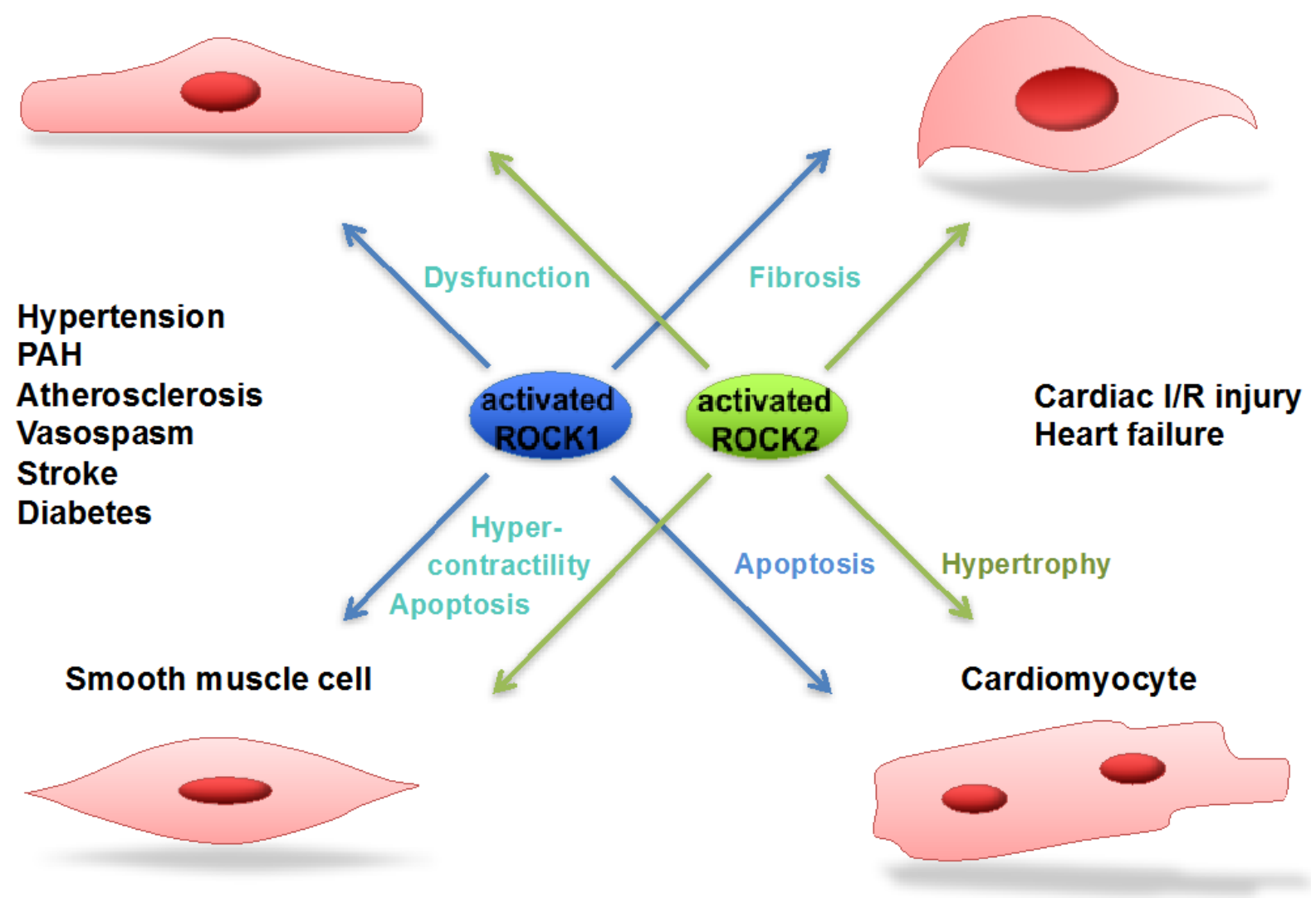

Figure 4: Involvement of ROCK1 and ROCK2 in cardiovascular disease.

Activated ROCK1 and ROCK2 play a pivotal role in processes leading to cardiovascular diseases such as hypertension, pulmonary arterial hypertension (PAH), atherosclerosis, vasospastic angina, stroke, diabetes, cardiac ischemia/reperfusion $(\mathrm{l} / \mathrm{R})$ injury and heart failure. Where possible, a distinction between the function of ROCK1 and ROCK2 in the different processes is made [3].

Similarly, ROCKs have been implicated in PAH. Patients that received Fasudil showed acute pulmonary vasodilation [131]. Also, ROCK2 expression was increased in the media of pulmonary arteries and pulmonary arterial smooth muscle cells from patients with idiopathic PAH [142]. In addition, Fasudil reduced pulmonary hypertension, RV hypertrophy, pulmonary vascular remodelling and mortality in hypertensive rats. On the cellular level, VSMC proliferation was reduced, along with improved VSMC hypercontractility and endothelial dysfunction [143]. 
In addition, Fasudil showed beneficial effects in reducing angina, as the treatment increased maximum exercise time and reduced the number of angina attacks in patients suffering from stable angina [129]. Likewise, in patients with vasospastic angina, Fasudil alleviated coronary artery spasms and myocardial ischaemia induced by acetylcholine [92]. This is supported by findings in porcine models in which interleukin $1 \beta$ was chronically applied to coronary arteries from the adventitia to induce inflammatory lesions. Treatment with Fasudil decreased the serotonininduced coronary hyperconstriction as a result of an increased activation of MYPT1 [144-146]. Moreover, exogenous NO, which is widely given as an anti-anginal agent to dilate the vasculature, decreased ROCK activity in peripheral leukocytes whereas expression of ROCK protein was unaltered [147, 148]. ROCK activity in circulating peripheral leucocytes is usually measured by calculating the levels of phosphorylated MYPT1 to total MYPT1 [149].

Patients with acute heart failure show an enhanced ROCK activity, which decreases during the time course of the disease [150]. However, elevated ROCK activity in circulating leukocytes can still be detected in patients with chronic heart failure, along with systolic dysfunction [151]. In addition, congestive heart failure patients show an increased ROCK activity which might be associated with increased mortality risk [152]. In line with these findings, treatment of chronic heart failure patients with Fasudil decreased forearm vascular resistance and increased simultaneously increased forearm vasodilation [94]. However, no correlation between established heart failure markers like cardiac troponin I and brain natriuretic peptide and enhanced ROCK activity could be found [150]. On the other hand, increased ROCK activity was demonstrated to correlate with high $\mathrm{N}$-terminal pro-B-type natriuretic peptide in myocardial infarction. Therefore, enhanced ROCK activity could be used as a biomarker to identify high risk patients with acute coronary syndrome [153]. The findings in patients suffering from heart failure are supported by several animal models. For example, hypertensive rats that develop congestive heart failure and were treated with Y-27632 exhibited reduced vascular remodelling and cardiac dysfunction compared to control rats [154]. Similarly, mice that underwent myocardial infarction operation and were treated with Fasudil showed increased LV function, accompanied by reduced CM hypertrophy, interstitial fibrosis, and inflammatory cytokine expression [155]. 
Taken together these studies show that inhibition of ROCK activity might be cardioprotective. Indeed, findings in cultured CM from mouse and rat and mouse models also point in this direction. Upon inhibition of ROCK, there was improved cardiac contractility due to a reduced phosphorylation of cardiac troponin I/T254, which led to preserved expression of sarco/endoplasmic reticulum $\mathrm{Ca}^{2+}$-ATPase $2 \mathrm{a}$ (SERCA2a) [156]. CM hypertrophy was shown to be reduced as a result of a decreased angiotensin II and endothelin-I signalling [157-160]. Additionally, CM apoptosis was decreased by activation of PI3K/Akt and extracellular signal-regulated mitogen-activated protein kinase (ERK)/mitogen-activated protein kinase (MAPK) pathways, as well as suppression of the pro-apoptotic Bcl-2 family protein Bax [161, 162]. Finally, cardiac fibrosis was found to be decreased by ROCK inhibition, likely due to decreased expression of fibrotic and inflammatory cytokines [163].

\subsection{Genetic animal models of ROCK1 and ROCK2}

\subsubsection{Global knockout of ROCK1 and ROCK2}

The global knockout (KO) of ROCK1 in C57BL/6 mice, first described by Shimizu et al. in 2005, reported a failure of eyelid and ventral body wall closure. Most mice died however soon after birth due to maternal cannibalisation. At the cellular level, actin cytoskeleton organisation was disturbed and MLC phosphorylation levels decreased [164].

In contrast, global KO of ROCK2 was more severe in mice with $90 \%$ dying in utero as a result of constrained embryo-placenta interaction. The few surviving mice were smaller directly after birth when compared to wild type (wt), however caught up soon after and did not exhibit histological changes [165].

Interestingly, the phenotype of both $\mathrm{KO}$ models seems to be partly dependent on the genetic background. The ROCK1 KO was more severe with a FVB background compared to the firstly described $\mathrm{KO}$ in C57BL/6, as $60 \%$ of mice died in utero [163]. Likewise, the disturbed embryo-placenta interaction was only present in C57BL/6 $\times$ 129/SvJ mice, but not in CD-1 (C57BL/6 $\times$ Dba) background mice [166]. Similar to 
the ROCK1 KO, ROCK2 KO mice with a C57BL/6 background also showed failure of eyelid and ventral body wall closure [167].

\subsubsection{Effects of ROCK1 and ROCK2 knockout on the heart}

ROCK1 plays an important functional role in cFBs and CMs. Mice with a global KO of ROCK1 were subjected to transverse aortic constriction (TAC). TAC is the ligation of the transverse aorta and a model for aortic stenosis and pressure overload of the heart, resulting in cardiac hypertrophy and heart failure. Initially, TAC results in compensated hypertrophy of the heart, often associated with a temporary improvement of cardiac contractility. Nevertheless, due to the chronic hemodynamic overload the response becomes maladaptive over time, leading to cardiac dilatation, fibrosis, and heart failure $[168,169]$. ROCK1 global KO mice subjected to transverse aortic constriction (TAC) were reported to have reduced perivascular and interstitial cardiac fibrosis after three weeks, but not one week post-ligation. Accordingly, expression and secretion of the pro-fibrotic cytokines TGF $\beta 2$, CTGF and ECM proteins decreased. However, KO of ROCK1 did not have an effect on cardiac hypertrophy [163].

The role of ROCK1 in cardiac fibrosis in mice with a CM-specific overexpression of

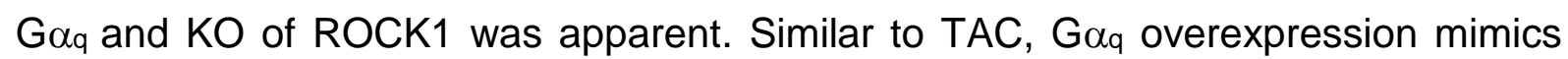
pressure-overload induced cardiac hypertrophy. Also, decreased gene expression of TGF $\beta 2$ and CTGF were detected in these mice [163]. This was further supported by another transgenic model of $\mathrm{G} \alpha_{q}$ overexpression that attenuated left ventricular dilation, contractile dysfunction and CM apoptosis after ROCK1 KO, but did not reduce cardiac hypertrophy. However, the expression of hypertrophic markers was reduced by ROCK1 KO, suggesting ROCK1 might be able to modify cardiac hypertrophy [170].

In accordance, further studies showed that loss of ROCK1 aided in preventing the transition from cardiac hypertrophy towards heart failure. Usually, mice with an overexpression of $G_{\alpha q}$ develop lethal cardiomyopathy after pregnancy or at senescence. However, after deletion of ROCK1 in Gaq overexpressing mice, survival 
improved and left ventricular dilation, wall thinning, and CM apoptosis were reduced. Moreover, contractile function was preserved after pregnancy and in 12-month-old mice. The authors also reported, that overexpression of ROCK1 in transgenic Gaq mice resulted in an increase in CM apoptosis and development of decompensated cardiomyopathy, independent of pregnancy stress [162].

The role of ROCK1 in fibrotic processes was further apparent in haploinsufficient ROCK1 KO mice. Following TAC or myocardial infarction evoked by the ligation of the left anterior descending coronary artery, haploinsufficient ROCK1 KO mice exhibited less perivascular fibrosis. Treatment with angiotensin II or NG-nitro-arginine methyl ester (L-NAME) in wt mice led to a similar increase in systemic blood pressure elevation, increase in left ventricular wall thickness and mass, and hypertrophy relative to haploinsufficient ROCK1 KO mice. Regardless of surgical or pharmacological evoked stress, reduced perivascular fibrosis and a decrease in TGF $\beta 2$, CTGF, and collagen III was reported [171].

Expression of a C-terminally truncated active form of ROCK1 (ROCK1 $1 \Delta 1$ ) in CMs increased cardiac fibrosis in these mice. Additional treatment with angiotensin II led to the development of fibrotic cardiomyopathy with diastolic dysfunction, elevated NF$\kappa B$ and SRF-dependent TGF $\beta 1$ signalling. Cumulatively, this led to the activation of adjacent cFBs that could explain the observed fibrosis. However, replacement fibrosis due to enhanced CM death is another plausible reason [161, 172].

The interlinked mechanism between Rnd3 and ROCK1 has already been described in section 1.5.2. Global haploinsufficient Rnd3 mice are susceptible to left ventricular pressure overload at basal state. When subjected to TAC, they develop severe heart failure, accompanied with increased CM apoptosis, enhanced levels of cleaved caspase 3 , and increased ROCK activity. By crossbreeding these haploinsufficient Rnd3 with global ROCK1 KO mice, all of the effects were diminished after TAC, suggesting that the Rnd3-ROCK1 signalling axis participates in CM apoptosis [173].

The role of ROCK1 in pathological remodelling processes during heart disease was further analysed using the ischemia/reperfusion cardiomyopathy $(\mathrm{I} / \mathrm{RC})$ model, in which the left anterior descending coronary artery was occluded and subsequently 
unoccluded. Mice with ROCK1 KO did not develop I/RC-mediated myocardial dysfunction and showed reduced cardiac fibrosis. In addition, a lower number of CD34/CD45 positive cells was detected which are believed to be blood-borne monocytic fibroblast precursors that get attracted to the myocardium upon I/RC [174]. Also, their differentiation into fibroblasts was reduced in ROCK1 KO mice [175].

However, no CM or cFB-specific genetic KO model is available for ROCK1. Therefore, to date it is not possible to determine whether ROCK1 primarily functions in CMs, cFBs, or both [3].

In contrast to ROCK1, ROCK2 has an influence on cardiac hypertrophy in mice. CMspecific ROCK2 KO mice showed no impairment under basal conditions, however, after TAC or angiotensin II infusion developed less cardiac hypertrophy, intraventricular fibrosis, cardiac apoptosis and showed decreased oxidative stress compared to wt mice. This might be due to the upregulation of four-and-a-half LIMonly protein-2 (FHL2), which controls the inhibition of SRF and ERK signalling that are both involved in $\mathrm{CM}$ growth. After crossbreeding of haploinsufficient ROCK2 KO with global FHL2 KO mice and angiotensin II infusion, the mice showed the same extent of cardiac fibrosis as their wt counterparts [176].

ROCK1 and ROCK2 signalling in the heart partake in complex interlinked mechanisms. This was nicely shown in a study by lkeda et al. in which two models of pressure overload were utilised: TAC to induce pressure overload in the left ventricle (LV) and pulmonary artery constriction (PAC), which simulates pressure overload in the right ventricle $(\mathrm{RV})$. In the TAC model, ROCK1 and ROCK2 expression in the vascular wall and perivascular area was increased three and seven days after TAC, respectively. In contrast, after PAC only ROCK2 expression was increased during the first days in the RV, but not in the LV. Transgenic overexpression of a dominant negative Rho-kinase (DN-RhoK), which inhibits ROCK1 and ROCK2 function, led to fewer pathological changes upon TAC and PAC in the ventricles and improved survival of the mice. The beneficial effects might be due to the downregulation of ERK1/2-GATA4 signalling [177]. 


\subsection{Previous results}

In preliminary experiments, a knockdown of ROCK1 and of both kinases was established to study the role of ROCK1 and ROCK2 in cardiac fibroblasts. This was achieved using lentiviral-mediated gene transfer of ROCK-specific shRNAs.
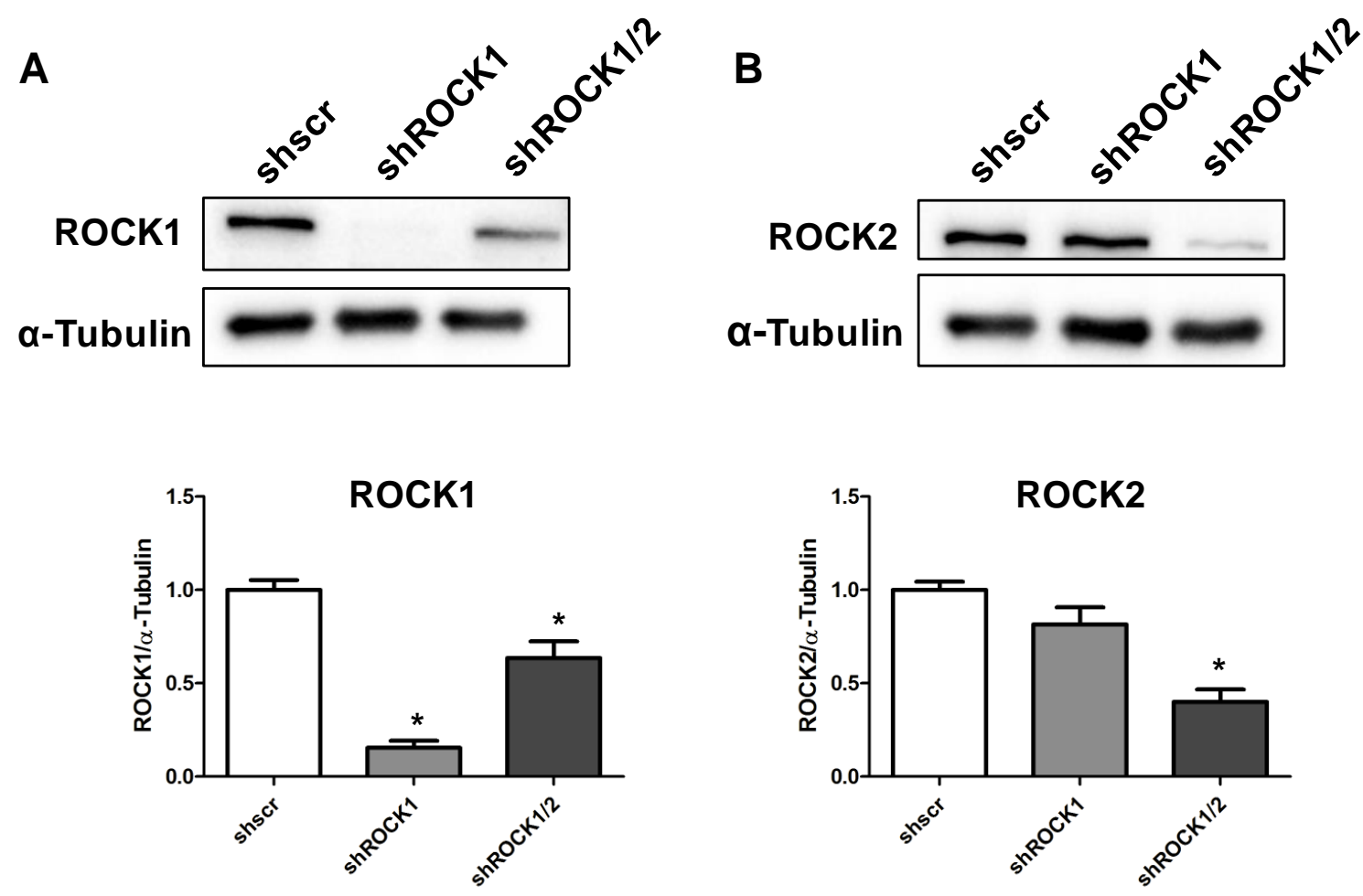

Figure 5: Lentivirus-mediated knockdown of ROCK1 and ROCK1/2 in neonatal rat cardiac fibroblasts (NRCF).

(A) Immunoblots of ROCK1 and $\alpha$-tubulin in shROCK1 and shROCK1/2 compared to shscr$\mathrm{NRCF}$, and quantification of the relative change in ROCK1 protein expression in shROCK1 and shROCK1/2 compared to shscr NRCF. (B) Representative immunoblots of ROCK2 and a-tubulin and quantification of the relative change in ROCK2 protein expression in shROCK1 and shROCK1/2 compared to shscr NRCF are shown (means \pm SEM, $n=6-8,{ }^{*} p<0.05$ vs. shscr).

Primary, neonatal cardiac fibroblasts from the rat (NRCF) transduced with a lentivirus targeting ROCK1 or ROCK1 and ROCK2 are referred to as shROCK1 and shROCK $1 / 2$ cells, respectively. A scrambled, non-targeting shRNA (shscr) was used as a control. After selection with puromycin, the ROCK1 protein level was reduced by 
$85 \%$ in shROCK1 NRCF. In the double knockdown, ROCK1 and ROCK2 protein expression was reduced by about $40 \%$ and $70 \%$, respectively (Figure 5 ).

The ROCK knockdown NRFC were then further characterised and it was found that upon knockdown of ROCK1, as well as upon knockdown of both kinases, NRCF morphology was altered, as there was an increase in cell area of $45 \%$ when compared to shscr NRCF (Figure 6A). Additionally, the FBS-driven proliferation of NRCF stopped after downregulation of ROCK1 and ROCK2. Downregulation of ROCK1 alone did not change the proliferative behaviour (Figure 6B).

A

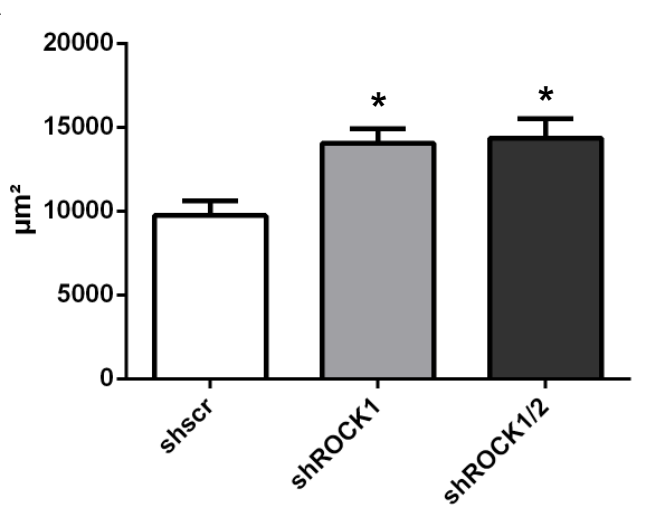

B

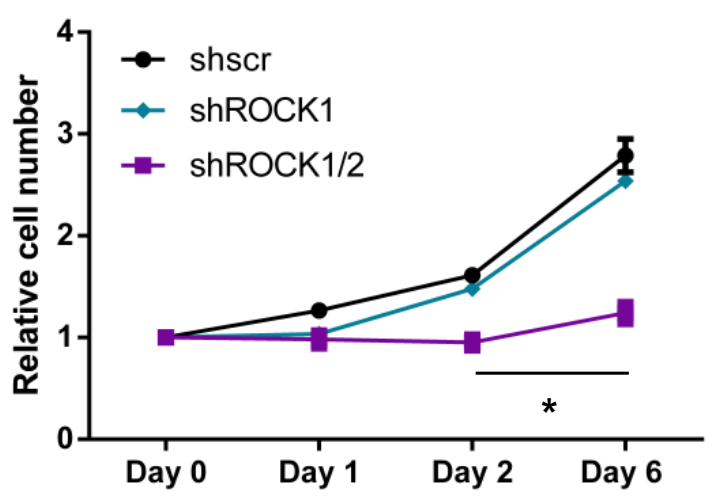

Figure 6: Characterization of lentivirus-mediated ROCK1 and ROCK1/2 knockdown in NRCF.

(A) Evaluation of cell morphology. Relative cell area of siROCK1 and shROCK1/2 compared to shscr NRCF is shown (means \pm SEM, $n=3,30-50$ cells each, ${ }^{*} p<0.05$ ). (B) Proliferation assay of shscr, shROCK1 and shROCK1/2 NRCF over a time course of 6 days (means $\pm S E M, n=8$, measured in 4 technical replicates/experiment, ${ }^{*} p<0.05$ ).

To assess the influence of ROCK signalling on properties of cFBs and CMs in a more physiological model than a 2D culture, two different models of engineered tissues were used. Firstly, engineered heart muscle composed of neonatal cardiac cells from the rat ( $\mathrm{rEHM}$ ) and collagen type I as a matrix was generated. The rEHM were allowed to consolidate for seven days in custom-made moulds and then transferred onto phasic stretchers for mechanical load, which is essential for functional rEHM formation and maturation. During this phase, $\mathrm{rEHM}$ were treated with the nonselective ROCK inhibitors Fasudil $(10 \mu \mathrm{M})$ and $\mathrm{H} 1152 \mathrm{P}(3 \mu \mathrm{M})$. Isometric force measurement at increasing concentrations of $\mathrm{Ca}^{2+}$ revealed that Fasudil-treated 
rEHM had a significantly decreased resting tension when compared to control rEHM. This trend could also be observed in H1152P-treated rEHM (Figure 7A).

A

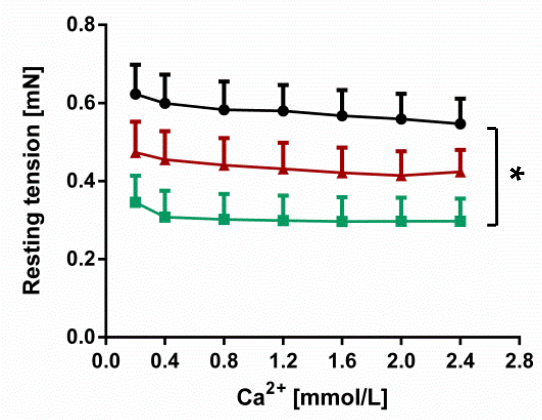

C

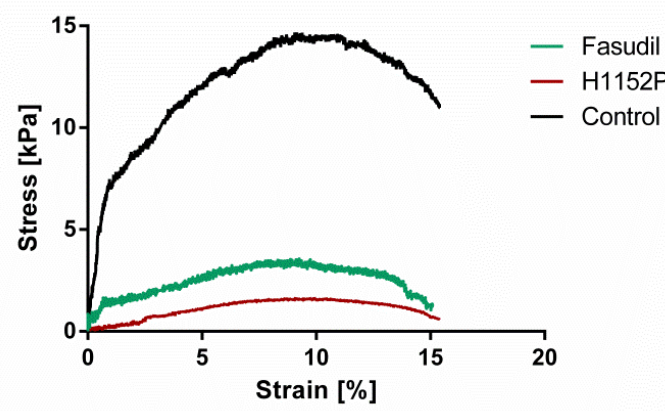

B

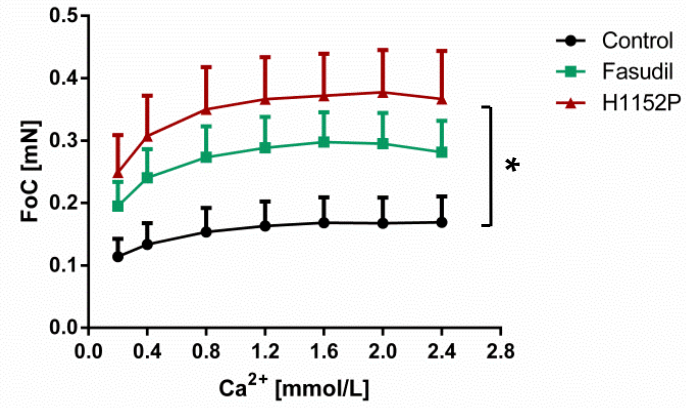

D Young's modulus

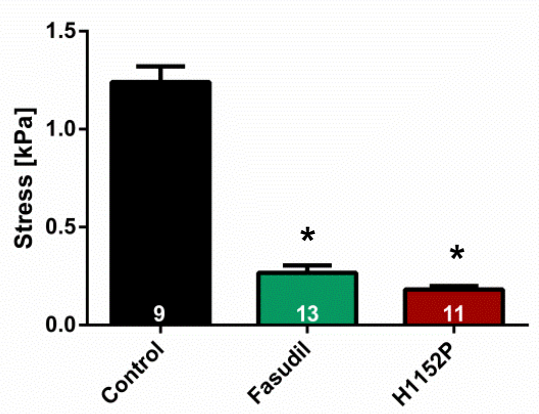

Figure 7: Analysis of contractile and viscoelastic properties of engineered tissues.

(A, B) Isometric force measurement of engineered heart muscle from cardiac cells of the rat ( $\mathrm{rEHM}$ ) that were treated with ROCK inhibitors Fasudil $(10 \mu \mathrm{M})$ and H1152P $(3 \mu \mathrm{M})$. Analysis of (A) the resting force and (B) the force of contraction (FoC) of rEHM at different calcium concentrations (means $\pm S E M, n=4$, in total 8-14 rEHM per condition, * $p<0.05$ vs. control). (C, D) Rheological destructive tensile strength measurement of engineered connective tissue from NRCF ( $r E C T)$ that were treated with ROCK inhibitors Fasudil $(10 \mu \mathrm{M})$ and H1152P $(3 \mu \mathrm{M})$. (C) Representative stress-strain curves and (D) changes in the Young's modulus of control, Fasudil- and H1152P-treated rECT are shown (means $\pm S E M, n=4,{ }^{*} p<0.05$, values illustrate numbers of $\mathrm{rECT}$ measured).

In contrast, force of contraction (FoC) was significantly enhanced in H1152P-treated rEHM compared to control. A trend towards an improved contractility was also observed in Fasudil-treated rEHM (Figure 7B). However, a limitation of this experiment is, that the generated forces were not based on the cross-sectional area (CSA) of the tissues, which is important when comparing forces of muscles with 
different CSA. Treatment with both ROCK inhibitors increased the CSA of $\mathrm{rEHM}$ when compared to control, however, was not quantified.

Secondly, engineered connective tissue was generated from NRCF and collagen I ( $r E C T)$ and $r E C T$ treated with Fasudil $(10 \mu \mathrm{M})$ and H1152P $(3 \mu \mathrm{M})$. Rheological destructive tensile strength measurement revealed that stress-strain curved of rECT treated with ROCK inhibitors had an extremely flat shape compared to control (Figure 7C). Additionally, the Young's modulus, which is a measure for the rigidity of materials, was significantly reduced by $80 \%$ for Fasudil- and $85 \%$ for $\mathrm{H} 1152 \mathrm{P}$-treated rECT (Figure 7D).

\subsection{Aims}

It is increasingly appreciated that cFBs are essential for maintaining homeostasis and functionality of the myocardium, but after transdifferentiation into myofibroblasts also play as critical role in cardiac fibrosis. We hypothesised that ROCK1 and ROCK2 have an impact on cFB characteristics and are important mediators of myofibroblast differentiation.

In my preliminary studies, it was demonstrated that the knockdown of ROCKs has an influence on the morphology and proliferative behaviour of neonatal cardiac fibroblasts. Moreover, it was determined that ROCK1 and ROCK2 might have an influence on the viscoelastic and contractile parameters of engineered tissue models. Therefore, the aims of this thesis were:

I. To investigate the effects of specific ROCK1 and ROCK2 knockdown on cFB morphology, protein expression, proliferation, migration, production and secretion of extracellular matrix components;

II. Elucidate the importance of ROCK1 and ROCK2 signalling on viscoelastic and contractile properties of murine engineered tissues further, and to transfer these findings into a human model;

III. To determine new downstream targets for either ROCK1 or ROCK2. 


\section{Materials}

\subsection{Animals}

Wistar-Kyoto Rats, Charles River, Sulzfeld

\subsection{Eukaryotic cells}

Primary cells:

hES2 wild type-derived cardiomyocytes (hES2 CM), kindly provided by the Stem Cell Unit - Göttingen (SCU-G)

Neonatal rat cardiac fibroblasts (NRCF), see 3.1.1 for detailed isolation procedure Normal human cardiac fibroblasts (ventricle, NHCF-V), Cat. No. CC-2904, Lonza

Cell lines:

HEK293A: Human embryonic kidney, immortalized by adenovirus serotype 5 TSA201: Human embryonic kidney, immortalized by SV-40 large T antigen

\subsection{Bacterial strains}

E.Coli DH10B (Life Technologies; Genotype: F- mcrA $\Delta$ (mrr-hsdRMS-mcrBC) Ф80dlacZ $\Delta$ M15 $\Delta$ lacX74 endA1 recA1 deoR $\Delta$ (ara,leu)7697 araD139 galU galK nupG rpsL $\lambda-$ )

\subsection{Chemicals, reagents and consumables}

All chemicals were purchased in highest quality available from AppliChem, Carl Roth, Fluka, Merck and Sigma Aldrich. 
Table 1: Fine chemicals and reagents

\begin{tabular}{|l|l|}
\hline Reagent & Company \\
\hline a-Myc agarose beads & Sigma Aldrich \\
\hline Acrylamide solution rotiphorese gel 30 & Carl Roth \\
\hline Ammonium persulfate (APS) & AppliChem \\
\hline ATP & Thermo Scientific \\
\hline [Y-32P]ATP & $\begin{array}{l}\text { PerkinElmer Health Sciences } \\
\text { B.V. }\end{array}$ \\
\hline BamHI & NEB \\
\hline Bradford reagent (Roti-Quant) & Carl Roth \\
\hline Bromphenol blue & Sigma Aldrich \\
\hline CDK7, unactive (C36-14G) & SignalChem \\
\hline cOmplete Protease Inhibitor Cocktail Tablets & Roche \\
\hline DAPI (4',6-diamidino-2-phenylindole) & Sigma Aldrich \\
\hline $\begin{array}{l}\text { DNA molecular weight standard (1 kb DNA } \\
\text { ladder) }\end{array}$ & Thermo Scientific \\
\hline $\begin{array}{l}\text { DNA molecular weight standard (1 kb plus DNA } \\
\text { ladder) }\end{array}$ & Thermo Scientific \\
\hline DTT & Sigma Aldrich \\
\hline Ethidiumbromide 10 mg/mL & Sigma Aldrich \\
\hline EvaGreen ${ }^{\circledR}$ dye for qPCR & Solis Biodyne \\
\hline Fasudil hydrochloride & Biomol \\
\hline H1152P dihydrochloride & Biomol \\
\hline Igepal CA-630 & Sigma Aldrich \\
\hline Loading dye 6x (Agarose gel electrophoresis) & Thermo Scientific \\
\hline Lumi- LightPLUs Western Blotting Substrate & Roche \\
\hline Ndel & NEB \\
\hline p21CIP1 protein (C27-30G), GST tag & SignalChem \\
\hline Paraformaldehyde (PFA) & Sigma Aldrich \\
\hline peqGOLD Universal Agarose & peqLab \\
\hline PhosSTOP Phosphatase Inhibitor Cocktail & Roche \\
\hline Pablets & \\
\hline
\end{tabular}




\begin{tabular}{|l|l|}
\hline Protein Marker „Roti- Mark Standard“ & Carl Roth \\
\hline ROCK1, active (R10-11G), GST tag & SignalChem \\
\hline ROCK2, active (R11-11G), GST tag & SignalChem \\
\hline Roti- Block (Blocking reagent) & Carl Roth \\
\hline Roti- Nanoquant (Bradford reagent) & Carl Roth \\
\hline SLx-2119 & MedChem Express \\
\hline Sodium dodecyl sulfate (SDS) & AppliChem \\
\hline SR-3677 dihydrochloride & Tocris \\
\hline Sucrose & AppliChem \\
\hline SuperSignal West Femto & Thermo Fisher Scientific \\
\hline Tetramethylethylenediamine (TEMED) & Merck \\
\hline TRITC- Phalloidin & Sigma Aldrich \\
\hline Triton-X 100 & Carl Roth \\
\hline Trizol & Life Technologies \\
\hline Tween-20 & Carl Roth \\
\hline
\end{tabular}

Table 2: Consumables

\begin{tabular}{|l|l|l|}
\hline Consumables & Type & Company \\
\hline Cell culture flasks & T75; T175 & Sarstedt \\
\hline Cell culture plates & $10 \mathrm{~cm} ; 15 \mathrm{~cm}$ & Sarstedt \\
\hline Cell culture multi wells & 6 well; 12 well; 24 well & Sarstedt \\
\hline Cell scraper & $25 \mathrm{~cm} ; 2$-position blade & Sarstedt \\
\hline Collecting tubes & $15 \mathrm{~mL} ; 50 \mathrm{~mL}$ & Cellstar \\
\hline Cryotubes & $1.8 \mathrm{~mL}$ & NUNC \\
\hline Filter Tips & $10 \mu \mathrm{L} ; 100 \mu \mathrm{L} ; 1000 \mu \mathrm{L}$ & Greiner Bio One \\
\hline Microscope cover glasses & $22 \mathrm{~mm}$ & Thermo Scientific \\
\hline Microscope slides & SuperFrost Plus & Thermo Scientific \\
\hline $\begin{array}{l}\text { Multi Tips } \\
\text { Nitrocellulose protran transfer } \\
\text { membrane }\end{array}$ & $2 \mathrm{~mL} ; 5 \mathrm{~mL} ; 10 \mathrm{~mL}$ & Eppendorf \\
\hline Optical adhesive film & $\begin{array}{l}\text { MicroAmp optical adhesive } \\
\text { film }\end{array}$ & Applied Biosystems \\
\hline
\end{tabular}




\begin{tabular}{|l|l|l|}
\hline Pipette tips & $10 \mu \mathrm{L} ; 100 \mu \mathrm{L} ; 1000 \mu \mathrm{L}$ & Sarstedt \\
\hline qPCR plates & $\begin{array}{l}\text { MicroAmp optical 384-well } \\
\text { reaction plate }\end{array}$ & Applied Biosystems \\
\hline Reaction vessels & $0.5 \mathrm{~mL} ; 1.5 \mathrm{~mL} ; 2 \mathrm{~mL}$ & Eppendorf \\
\hline Sterile pipettes & $2 \mathrm{~mL} ; 5 \mathrm{~mL} ; 10 \mathrm{~mL} ; 25 \mathrm{~mL}$ & Sarstedt \\
\hline Ultracentrifuge tubes & $\begin{array}{l}\text { Polyallomer centrifugation } \\
\text { tubes, } 14 \mathrm{~mL}\end{array}$ & Beckman \\
\hline X-ray film & $\begin{array}{l}\text { Fuji Medical X-Ray Film; } \\
\text { Super RX-N }\end{array}$ & Fujifilm \\
\hline
\end{tabular}

\subsection{Devices}

Table 3: Devices

\begin{tabular}{|c|c|c|}
\hline Device & Type & Company \\
\hline Blotting chamber & Mini Trans-Blot Cell & Bio-Rad Laboratories \\
\hline $\begin{array}{l}\text { Automated multiparameter } \\
\text { cell analysis machine }\end{array}$ & Cellavista & SynenTec \\
\hline Cell counter and analyzer & CASY Model TTC & Roche \\
\hline \multirow[t]{2}{*}{ Centrifuges } & Centrifuge 5804R & Eppendorf \\
\hline & Megafuge 3.OR & Heraeus Sepatech \\
\hline Chemiluminescence Imager & ChemiDoc MP & Biorad \\
\hline Freezing container & Mr. Frosty & Nalgene \\
\hline Gel electrophoresis chamber & Mini-PROTEAN Tetra & Bio-Rad Laboratories \\
\hline Imaging system & GelDoc XR Imaging System & Bio-Rad Laboratories \\
\hline $\begin{array}{l}\text { Inverted fluorescence } \\
\text { microscope }\end{array}$ & IX81 & Olympus \\
\hline Microscope camera & XM10 & Olympus \\
\hline Microscope filter blue & 350 DAPI & Olympus \\
\hline Microscope filter red & 575 TxRed & Olympus \\
\hline Microscope filter green & 485 FITC & Olympus \\
\hline Microscope objective $4 x$ & UPlanFLN4xPh & Olympus \\
\hline Microscope objective 10x & UPlanFLN10xPh & Olympus \\
\hline Microscope objective 20x & & \\
\hline
\end{tabular}




\begin{tabular}{|c|c|c|}
\hline Microscope objective 40x & $\begin{array}{l}\text { LUCPlanFLN20xPh } \\
\text { LUCPlanFLN20xPh }\end{array}$ & $\begin{array}{l}\text { Olympus } \\
\text { Olympus }\end{array}$ \\
\hline Heating block & Thermomixer comfort & Eppendorf \\
\hline \multirow[t]{2}{*}{ Incubators } & Bacteria; $37^{\circ} \mathrm{C}$ & SANYO \\
\hline & Cell culture; $37^{\circ} \mathrm{C} ; 5 \% \mathrm{CO}_{2}$ & Labotec \\
\hline Large scale shaker & Innova 4300 & Eppendorf \\
\hline Microplate reader & Flex Station 3 & $\begin{array}{l}\text { MDS Analytical } \\
\text { Technologies }\end{array}$ \\
\hline Micro scales & AX224 & Sartorius \\
\hline $\begin{array}{ll}\text { Micro } & \text { volume } \\
\text { spectrophotometer } & \end{array}$ & NanoDrop1000 & peqLab \\
\hline PCR machine & Mastercycler gradient & Eppendorf \\
\hline $\mathrm{pH}$ meter & Inolab pH & Wtw \\
\hline Power supply & Power PAC HD & Bio-Rad Laboratories \\
\hline qPCR machine & $\begin{array}{llll}\text { ViiA }^{\text {TM }} 7 & \text { Real-Time } & \text { PCR } \\
\text { System } & & \end{array}$ & Life Technologies \\
\hline Rheometer & RSA-G2 & TA Instruments \\
\hline Rocker & Diomax 1030 & Heidolph \\
\hline Rotor ultracentrifuge & SW32.1 Swinging Bucket & Beckmann \\
\hline Rotation shaker & Reax 3 & Heidolph \\
\hline Scales & Portable & Sartorius \\
\hline $\begin{array}{l}\text { Shaker } \\
\text { Shaker } 4^{\circ} \mathrm{C}\end{array}$ & $\begin{array}{l}3016 \\
\text { Vibramax } 100\end{array}$ & $\begin{array}{l}\text { GFL } \\
\text { Heidolph }\end{array}$ \\
\hline $\begin{array}{l}\text { Stereo microscope } \\
\text { Microscope camera }\end{array}$ & $\begin{array}{l}\text { SteREO Lumar.V12 } \\
\text { AxioCam MRc }\end{array}$ & $\begin{array}{l}\text { Zeiss } \\
\text { Zeiss }\end{array}$ \\
\hline Sterile hood & Telstar Bio II A & Prettl \\
\hline Table centrifuge & Centrifuge 5415D & Eppendorf \\
\hline Thermomixer & Thermomixer compact & Eppendorf \\
\hline $\begin{array}{l}\text { Ultracentrifuge } \\
\text { Ultracentrifuge rotor }\end{array}$ & $\begin{array}{l}\text { L8-70M } \\
\text { SW } 28.1\end{array}$ & $\begin{array}{l}\text { Beckman } \\
\text { Beckman }\end{array}$ \\
\hline Vortexer & VF2 & W. Krannich \\
\hline Water bath & 2764 & Eppendorf \\
\hline Medical Film Processor & SRX-101A & Konica Minolta \\
\hline
\end{tabular}




\subsection{Cell culture media and additives}

Table 4: Additives for cell culture

\begin{tabular}{|c|c|}
\hline Reagent & Company \\
\hline 2-mercaptoethanol & Sigma Aldrich \\
\hline Accutase solution & Merck-Millipore \\
\hline $\begin{array}{l}\text { Activin A (stock solution } 10 \mu \mathrm{g} / \mathrm{mL} \text { in } 1 \times \text { PBS with } \\
0.1 \% \mathrm{HSA} \text { ) }\end{array}$ & R\&D systems \\
\hline Albumin, recombinant & Sigma Aldrich \\
\hline B27 supplement (50x) & Invitrogen \\
\hline B27 supplement minus insulin (50x) & Invitrogen \\
\hline $\begin{array}{l}\text { BMP4 (stock solution } 10 \mu \mathrm{g} / \mathrm{mL} \text { in } 1 \times \text { PBS with } \\
0.1 \% \mathrm{HSA} \text { ) }\end{array}$ & R\&D systems \\
\hline CHIR (stock solution $10 \mathrm{mmol} / \mathrm{L}$ in DMSO) & Stemgent \\
\hline Collagen I (bovine) & Collagen solutions LLC \\
\hline Collagen I (rat tail) & own production \\
\hline $\begin{array}{l}\text { DMEM (Dulbeccos modified eagle medium) } \\
\text { powder }\end{array}$ & BD Biosciences \\
\hline DMEM GlutaMAX $1 \mathrm{~g} / \mathrm{L}$ glucose, pyruvate & Life Technologies \\
\hline DMEM GlutaMAX, $1 \mathrm{~g} / \mathrm{L}$ Glucose & Biochrom \\
\hline DMEM GlutaMAX 4.5 g/L glucose & Life Technologies \\
\hline DNasel stock solution (1 mg/mL) & Calbiochem \\
\hline $\begin{array}{l}\text { DPBS (Dulbeccos phosphate buffered saline), } \\
\text { w/o calcium and magnesium chloride }\end{array}$ & Life Technologies \\
\hline 0.5 M EDTA solution & Appli-Chem \\
\hline Fetal bovine serum (FBS) & Life Technologies \\
\hline FGF & Preprotech \\
\hline $\begin{array}{l}\text { Fibroblast growth medium-3 (FGM-3) BulletKit } \\
\text { (CC-3131 \& CC-4525) }\end{array}$ & Lonza \\
\hline Hexadimethrine bromide (Polybrene) & Sigma Aldrich \\
\hline Horse serum (HS) & Life Technologies \\
\hline HSA & Sigma-Aldrich \\
\hline IGF-1 & Preprotech \\
\hline IMDM & Life Technologies \\
\hline
\end{tabular}




\begin{tabular}{|l|l|}
\hline IWP4 (stock solution $5 \mathrm{mmol} / \mathrm{L}$ in DMSO) & Stemgent \\
\hline Knockout (KO) DMEM & Invitrogen \\
\hline Knockout serum replacement (KSR) & Invitrogen \\
\hline $\begin{array}{l}\text { L-Ascorbic acid 2-phosphate sesquimagnesium } \\
\text { salt hydrate }\end{array}$ & Sigma Aldrich \\
\hline Lipofectamine RNAiMAX Transfection Reagent & Life Technologies \\
\hline Non-essential amino acids (NEAA), 100x & Life Technologies \\
\hline $\begin{array}{l}\text { Penicillin-streptomycin (P/S), 100x } \\
\text { (10000 U/mL Penicillin, 10000 } \quad \mu g / m L \\
\text { Streptomycin) }\end{array}$ & Life Technologies \\
\hline PolyFect transfection reagent & \\
\hline Puromycin (10 mg/mL) & Qiagen \\
\hline RPMI 1640 GlutaMAX & Life Technologies \\
\hline RPMI 1640 wlo D-Glucose \& L-Glutamine & Invitrogen \\
\hline RPMl powder & Biological Industries \\
\hline Sodium DL-Lactate solution $50 \%$ in $\mathrm{H}_{2} \mathrm{O}$ & Life Technologies \\
\hline Sodium pyruvate & Sigma Aldrich \\
\hline TGF- 31 & Life Technologies \\
\hline Trypan blue (0.4\%) & Preprotech \\
\hline TrypLE Express & Fluka \\
\hline Trypsin EDTA, 0.05\% & Life Technologies \\
\hline TurboFect & Life Technologies \\
\hline VEGF & Thermo Fisher \\
\hline
\end{tabular}

Table 5: Cell culture media and solutions

\section{Isolation of neonatal cardiac cells}

Calcium and bicarbonate free Hanks with HEPES (CBFHH)
$40 \mathrm{~mL} \mathrm{NaCl}$ stock (200 g/L)
$10 \mathrm{~mL} \mathrm{MgSO} 4$ stock (20 g/L)

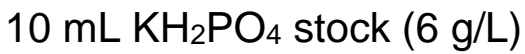
$10 \mathrm{~mL} \mathrm{Na} \mathrm{HPO}_{4} \cdot 2 \mathrm{H}_{2} \mathrm{O}(5.95 \mathrm{~g} / \mathrm{L})$
$10 \mathrm{~mL}$ Glucose dehydrate stock (100 g/L)
$\mathrm{ddH}_{2} \mathrm{O}$ up to $1 \mathrm{~L}$, sterile filtered, $\mathrm{pH} 7.4$ with
$\mathrm{NaOH}$




\begin{tabular}{|c|c|}
\hline Heat-inactivated FBS & $\begin{array}{l}50 \mathrm{~mL} \text { FBS were incubated in a water bath at } \\
56^{\circ} \mathrm{C} \text { for } 30 \mathrm{~min}\end{array}$ \\
\hline NCM (Non cardiomyocyte) medium & $\begin{array}{l}\text { DMEM GlutaMAX } 1 \mathrm{~g} / \mathrm{L} \text { glucose } \\
10 \% \mathrm{FBS}(\mathrm{v} / \mathrm{v} \text {, heat inactivated) } \\
1 \% \mathrm{P} / \mathrm{S}(\mathrm{v} / \mathrm{v})\end{array}$ \\
\hline $\begin{array}{l}\text { Neonatal Heart Dissociation Kit, } \\
\text { mouse and rat (Miltenyi Biotec) }\end{array}$ & $\begin{array}{l}\text { Buffer X } \\
\text { Buffer Y } \\
\text { Enzyme A (reconstituted with } 1 \mathrm{~mL} \text { buffer A) } \\
\text { Enzyme D (reconstituted with } 3 \mathrm{~mL} \text { DMEM) } \\
\text { Enzyme P (ready to use) }\end{array}$ \\
\hline \multicolumn{2}{|l|}{ NRCF culturing } \\
\hline NRCF growth medium & $\begin{array}{l}\text { DMEM GlutaMAX } 4.5 \mathrm{~g} / \mathrm{L} \text { glucose } \\
10 \% \text { FBS active }(\mathrm{v} / \mathrm{v}) \\
1 \% \mathrm{P} / \mathrm{S}(\mathrm{v} / \mathrm{v}) \\
1 \% \mathrm{NEAA}(\mathrm{v} / \mathrm{v})\end{array}$ \\
\hline NRCF selection medium & $\begin{array}{l}\text { DMEM GlutaMAX } 4.5 \mathrm{~g} / \mathrm{L} \text { glucose } \\
10 \% \text { FBS }(\mathrm{v} / \mathrm{v}) \\
1 \% \mathrm{P} / \mathrm{S}(\mathrm{v} / \mathrm{v}) \\
1 \% \mathrm{NEAA}(\mathrm{v} / \mathrm{v}) \\
1 \mu \mathrm{g} / \mathrm{mL} \text { puromycin }\end{array}$ \\
\hline Serum-reduced NRCF medium & $\begin{array}{l}\text { DMEM GlutaMAX } 1 \mathrm{~g} / \mathrm{L} \text { glucose } \\
1 \% \text { FBS active }(\mathrm{v} / \mathrm{v}) \\
1 \% \mathrm{P} / \mathrm{S}(\mathrm{v} / \mathrm{v}) \\
1 \% \mathrm{NEAA}(\mathrm{v} / \mathrm{v})\end{array}$ \\
\hline Serum-depleted NRCF medium & $\begin{array}{l}\text { DMEM GlutaMAX } 1 \mathrm{~g} / \mathrm{L} \text { glucose } \\
1 \% \mathrm{P} / \mathrm{S}(\mathrm{v} / \mathrm{v})\end{array}$ \\
\hline \multicolumn{2}{|l|}{ HEK293A, Tsa201 culturing } \\
\hline HEK293/TSA201 growth medium & $\begin{array}{l}\text { DMEM GlutaMAX } 4.5 \mathrm{~g} / \mathrm{L} \text { glucose } \\
10 \% \text { FBS heat-inactivated }(\mathrm{v} / \mathrm{v}) \\
1 \% \mathrm{P} / \mathrm{S}(\mathrm{v} / \mathrm{v})\end{array}$ \\
\hline $\begin{array}{l}\text { Serum-reduced HEK293/TSA201 } \\
\text { medium }\end{array}$ & $\begin{array}{l}\text { DMEM GlutaMAX } 4.5 \mathrm{~g} / \mathrm{L} \text { glucose } \\
0.5 \% \text { FBS heat-inacitvated }(\mathrm{v} / \mathrm{v}) \\
1 \% \mathrm{P} / \mathrm{S}(\mathrm{v} / \mathrm{v})\end{array}$ \\
\hline
\end{tabular}




\section{NHCF-V culturing}

\begin{tabular}{|c|c|}
\hline FGM-3 & $\begin{array}{l}\text { FGM-3 Basal Medium } \\
10 \% \text { FBS (v/v) } \\
\text { Insulin } \\
\text { Rh-FGF-B (r-human FGF-B) } \\
\text { GA-1000 (Gentamycin, Amphotericin) }\end{array}$ \\
\hline \multicolumn{2}{|c|}{ hES2 wild type cardiomyocyte (hES2-wt CM) differentiation and culturing } \\
\hline Cardiac specification medium & $\begin{array}{l}\text { CM basal medium } \\
5 \mu \mathrm{mol} / \mathrm{mL} \text { IWP4 }\end{array}$ \\
\hline CM basal medium & $\begin{array}{l}\text { RPMI } 1640 \text { GlutaMAX } \\
1 \% \text { Sodium pyruvate } \\
1 \% \text { P/S } \\
2 \% \text { B27 supplement (added on day of use) } \\
200 \mu \mathrm{M} \text { L-Ascorbic acid 2-phosphate } \\
\text { sesquimagnesium salt hydrate }\end{array}$ \\
\hline EDTA digestion solution & $\begin{array}{l}500 \mathrm{ml} 1 \times \text { PBS containing } 0.45 \mathrm{~g} \mathrm{NaCl} \\
500 \mu \mathrm{l} \text { of } 0.5 \mathrm{M} \text { EDTA solution } \\
\text { sterile filter, keep aliquots at } 4{ }^{\circ} \mathrm{C}\end{array}$ \\
\hline hCM selection medium & $\begin{array}{l}\text { RPMI medium 1640, wlo D-Glucose, wlo L- } \\
\text { Glutamine } \\
1 \% \mathrm{P} / \mathrm{S}(\mathrm{v} / \mathrm{v}) \\
0.5 \% \text { Sodium DL-Lactate solution } 50 \% \text { in } \mathrm{H}_{2} \mathrm{O} \\
(\mathrm{v} / \mathrm{v}) \\
50 \mathrm{mmol} / \mathrm{L} \text { 2-mercaptoethanol }\end{array}$ \\
\hline hESC conditioned medium & $\begin{array}{l}50 \% \mathrm{hESC} \text { culture medium }(\mathrm{v} / \mathrm{v}) \\
50 \% \mathrm{hFF} \text { conditioned medium }(\mathrm{v} / \mathrm{v}) \\
10 \mathrm{ng} / \mathrm{mL} \text { FGF }\end{array}$ \\
\hline hESC culture medium & $\begin{array}{l}\text { KO DMEM medium } \\
20 \% \text { KSR (v/v) } \\
1 \% \text { NEAA (v/v) } \\
1 \% \text { L-Glutamine (v/v) } \\
1 \% \mathrm{P} / \mathrm{S}(\mathrm{v} / \mathrm{v}) \\
10 \mathrm{ng} / \mathrm{mL} \text { FGF }\end{array}$ \\
\hline hFF conditioned medium & hESC culture medium \\
\hline
\end{tabular}




\begin{tabular}{|c|c|}
\hline & $\begin{array}{l}10 \mathrm{ng} / \mathrm{mL} \text { FGF } \\
\text { add onto hFFs for } 48 \text { hours }\end{array}$ \\
\hline Medsoderm-induced medium & $\begin{array}{l}\text { CM basal medium } \\
1 \mu \mathrm{mol} / \mathrm{mL} \text { CHIR } \\
5 \mathrm{ng} / \mathrm{mL} \text { BMP4 } \\
9 \mathrm{ng} / \mathrm{mL} \text { Activin-A } \\
5 \mathrm{ng} / \mathrm{mL} \mathrm{FGF}\end{array}$ \\
\hline \multicolumn{2}{|c|}{$\begin{array}{l}\text { Generation and culturing of engineered heart muscle from primary neonatal } \\
\text { rat cardiac cells (rEHM) }\end{array}$} \\
\hline 10x DMEM & 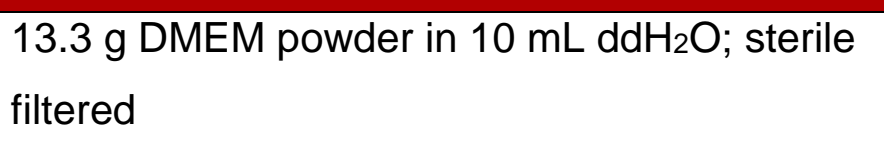 \\
\hline 2x DMEM & $\begin{array}{l}20 \% 10 \times \text { DMEM }(\mathrm{v} / \mathrm{v}) \\
20 \% \mathrm{HS}(\mathrm{v} / \mathrm{v}) \\
2 \% \mathrm{P} / \mathrm{S}(\mathrm{v} / \mathrm{v}) \\
\text { in } \mathrm{ddH}_{2} \mathrm{O}, \text { sterile filtered }\end{array}$ \\
\hline rEHM medium & $\begin{array}{l}\text { DMEM GlutaMAX, } 1 \mathrm{~g} / \mathrm{L} \text { Glucose (Biochrom) } \\
10 \% \mathrm{HS}(\mathrm{v} / \mathrm{v}) \\
1 \% \mathrm{P} / \mathrm{S}(\mathrm{v} / \mathrm{v})\end{array}$ \\
\hline \multicolumn{2}{|c|}{$\begin{array}{l}\text { Generation and culturing of engineered heart muscle from NHCF-V and hES2 } \\
\text { wt CM (hEHM) }\end{array}$} \\
\hline 10x RPMI & 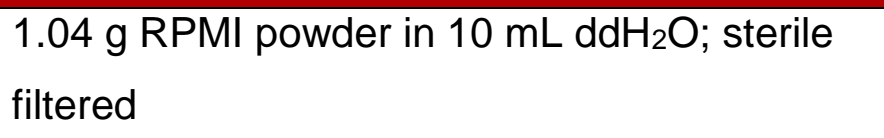 \\
\hline 2x RPMI (serum-free) & $\begin{array}{l}\text { 20\% 10x RPMI (v/v) } \\
8 \% \mathrm{~B} 27 \text { minus insulin }(\mathrm{v} / \mathrm{v}) \\
2 \% \mathrm{P} / \mathrm{S}(\mathrm{v} / \mathrm{v}) \\
\text { in } \mathrm{ddH}_{2} \mathrm{O} \text {, sterile filtered }\end{array}$ \\
\hline Digestion medium & $\begin{array}{l}98 \mathrm{~mL} \text { Accutase solution } \\
2 \mathrm{~mL} \text { DNasel stock solution }\end{array}$ \\
\hline Growth factors & $\begin{array}{l}\text { FGF (10 } \mu \mathrm{g} / \mathrm{mL} \text { in DPBS, } 0.1 \% \text { recombinant } \\
\text { albumin) } \\
\text { IGF-1 }(100 \mu \mathrm{g} / \mathrm{mL} \text { in DPBS, } 0.1 \% \text { recombinant } \\
\text { albumin) } \\
\text { TGF- } \beta 1(5 \mu \mathrm{g} / \mathrm{mL} \text { in DPBS, } 0.1 \% \text { recombinant }\end{array}$ \\
\hline
\end{tabular}




\begin{tabular}{|c|c|}
\hline & $\begin{array}{l}\text { albumin) } \\
\text { VEGF ( } 5 \mu \mathrm{g} / \mathrm{mL} \text { in DPBS, } 0.1 \% \text { recombinant } \\
\text { albumin) }\end{array}$ \\
\hline Serum-free base medium (SFBM) & $\begin{array}{l}\text { IMDM } \\
1 \% \text { sodium pyruvate }(\mathrm{v} / \mathrm{v}) \\
1 \% \mathrm{P} / \mathrm{S}(\mathrm{v} / \mathrm{v}) \\
300 \mu \mathrm{M} \text { L-Ascorbic acid 2-phosphate } \\
\text { sesquimagnesium salt hydrate }\end{array}$ \\
\hline $\begin{array}{l}\text { Serum-free maturation medium } \\
\text { (SFMM) with TGF- } \beta 1\end{array}$ & $\begin{array}{l}\text { SFBM } \\
4 \% \text { B27 minus insulin } \\
10 \text { ng/mL FGF } \\
100 \text { ng/mL IGF-1 } \\
5 \text { ng/mL TGF- } \beta 1 \\
5 \text { ng/mL VEGF }\end{array}$ \\
\hline $\begin{array}{l}\text { Serum-free maturation medium } \\
\text { (SFMM) without TGF- } \beta 1\end{array}$ & $\begin{array}{l}\text { SFBM } \\
4 \% \text { B27 minus insulin } \\
10 \mathrm{ng} / \mathrm{mL} \text { FGF } \\
100 \mathrm{ng} / \mathrm{mL} \text { IGF-1 } \\
5 \mathrm{ng} / \mathrm{mL} \text { VEGF }\end{array}$ \\
\hline \multicolumn{2}{|c|}{ Generation of engineered heart muscle from NRCF (rECT) and NHCF-V (hECT) } \\
\hline 2x DMEM & $\begin{array}{l}20 \% 10 x \text { DMEM (v/v) } \\
20 \% \mathrm{FBS}(\mathrm{v} / \mathrm{v}) \\
2 \% \mathrm{P} / \mathrm{S}(\mathrm{v} / \mathrm{v}) \\
\text { in } \mathrm{ddH}_{2} \mathrm{O}, \text { sterile filtered }\end{array}$ \\
\hline Isometric force measurement & \\
\hline Tyrode's solution & $\begin{array}{l}120 \mathrm{mM} \mathrm{NaCl} \mathrm{mM} \mathrm{CaCl}_{2} \\
0.2 \mathrm{mM} \mathrm{KCl} \\
1.05 \mathrm{mM} \mathrm{MgCl}_{2} \\
22.6 \mathrm{mM} \mathrm{NaHCO}_{3} \\
0.42 \mathrm{mM} \mathrm{NaH}_{2} \mathrm{PO}_{4} \\
0.1 \% \text { Glucose (w/v) } \\
0.01 \text { ascorbic acid (w/v) }\end{array}$ \\
\hline
\end{tabular}




\subsection{Bacterial media and additives}

Table 6: Bacterial media and additives

\begin{tabular}{|l|l|}
\hline Reagent & Company \\
\hline Agar-agar & AppliChem \\
\hline Agar plates & $2.8 \mathrm{~g} \mathrm{Agar-Agar}$ \\
& $200 \mathrm{ml}$ autoclaved LB medium \\
& $50 \mathrm{\mu g} / \mathrm{ml}$ Carbenicillin \\
\hline Carbenicillin & AppliChem \\
\hline LB medium & $10 \mathrm{~g}$ Trypton \\
& $5 \mathrm{~g}$ Yeast extract \\
& $5 \mathrm{~g} \mathrm{NaCl}$ \\
& $\rightarrow$ ad $1 \mathrm{~L}$ with ddH $\mathrm{H}_{2}$; autoclaved \\
\hline SOB medium & $20 \mathrm{~g}$ Tryptone \\
& $5 \mathrm{~g}$ Yeast extract \\
& $0.5 \mathrm{~g} \mathrm{NaCl}$ \\
& ad $1 \mathrm{~L}$ with distilled $\mathrm{H} 2 \mathrm{O}$ \\
& $\rightarrow$ autoclaved \\
& $10 \mathrm{~mL}$ MgCl2 stock (10 mM) \\
& $10 \mathrm{~mL}$ MgSO 4 stock (1 mM) \\
\hline Yeast extract & AppliChem \\
\hline
\end{tabular}

\subsection{Buffers and solutions}

Table 7: Buffers and solutions

\section{Immunofluorescence}

\begin{tabular}{|l|l|}
\hline $4 \%$ paraformaldehyde (PFA) & $40 \mathrm{~g}$ paraformaldehyde \\
& $200 \mu \mathrm{L} 10 \mathrm{~N} \mathrm{NaOH}$ \\
$100 \mathrm{~mL} 10 \times \mathrm{DPBS}^{-/-}$ \\
& $\mathrm{ddH}_{2} \mathrm{O}$ to $250 \mathrm{~mL}, \mathrm{pH} 7.0$ with $\mathrm{HCl}$ \\
\hline $0.2 \%$ Triton X-100 & $\begin{array}{l}1 \mathrm{~mL} 10 \times \text { Triton X-100 } \\
\mathrm{ddH}_{2} \mathrm{O} \text { to } 50 \mathrm{~mL}\end{array}$ \\
\hline 1x Roti block & $\begin{array}{l}5 \mathrm{~mL} \text { Roti block } \\
\mathrm{ddH}_{2} \mathrm{O} \text { to } 50 \mathrm{~mL}\end{array}$ \\
\hline
\end{tabular}




\begin{tabular}{|c|c|}
\hline Blocking buffer & $\begin{array}{l}5 \mathrm{~mL} \text { Roti block } \\
1 \mathrm{~mL} 10 x \text { Triton } \mathrm{X}-100 \\
\mathrm{ddH}_{2} \mathrm{O} \text { to } 50 \mathrm{~mL}\end{array}$ \\
\hline \multicolumn{2}{|l|}{ Flow cytometry cell cycle analysis } \\
\hline Phosphate-citrate buffer & $\begin{array}{l}192 \mathrm{~mL} 0.2 \mathrm{M} \mathrm{Na}_{2} \mathrm{HPO}_{4} \\
8 \mathrm{~mL} 0.1 \mathrm{M} \text { citric acid (pH 7.8) }\end{array}$ \\
\hline \multicolumn{2}{|l|}{ SDS-Page and immunoblot } \\
\hline Lysis buffer (GST-Fish) & $\begin{array}{l}6 \mathrm{~g} \text { Tris } \\
8.8 \mathrm{~g} \mathrm{NaCl} \\
0.4 \mathrm{~g} \mathrm{MgCl} 2 \\
100 \mathrm{~mL} \text { Glycerol }(\mathrm{v} / \mathrm{v}) \\
10 \mathrm{~mL} \text { Igepal } \mathrm{CA}-630(\mathrm{v} / \mathrm{v}) \\
\mathrm{ddH}_{2} \mathrm{O} \text { to } 1 \mathrm{~L}, \mathrm{pH} 7.4 \text { with } \mathrm{HCl} \\
\text { Phosphatase inhibitor cocktail added prior } \\
\text { to use }\end{array}$ \\
\hline $\begin{array}{l}\text { 4x SDS-PAGE sample buffer w/o } \\
\text { glycerol }\end{array}$ & $\begin{array}{l}10 \mathrm{~mL} \beta \text {-Mercaptoethanol } \\
\text { 3.6 } \mathrm{g} \text { Tris } \\
\text { 5.7 } \mathrm{g} \text { SDS } \\
0.2 \mathrm{~g} \text { Bromophenol blue } \\
\mathrm{ddH}_{2} \mathrm{O} \text { to } 100 \mathrm{~mL}, \mathrm{pH} 7.4 \text { with } \mathrm{HCl}\end{array}$ \\
\hline $\begin{array}{l}\text { 4x SDS-PAGE sample buffer w/ } \\
\text { glycerol (Laemmli buffer) }\end{array}$ & $\begin{array}{l}50 \mathrm{~mL} \text { Glycerol } \\
10 \mathrm{~mL} \text {-Mercaptoethanol } \\
3.6 \mathrm{~g} \text { Tris } \\
5.7 \mathrm{~g} \text { SDS } \\
0.2 \mathrm{~g} \text { Bromophenol blue } \\
\mathrm{ddH}_{2} \mathrm{O} \text { to } 100 \mathrm{~mL}, \mathrm{pH} 7.4 \text { with } \mathrm{HCl}\end{array}$ \\
\hline 10x APS & $\begin{array}{l}1 \mathrm{~g} \mathrm{APS} \\
\mathrm{ddH}_{2} \mathrm{O} \text { to } 10 \mathrm{~mL}\end{array}$ \\
\hline $10 \%$ SDS & $\begin{array}{l}10 \mathrm{~g} \text { SDS } \\
\mathrm{ddH}_{2} \mathrm{O} \text { to } 100 \mathrm{~mL}\end{array}$ \\
\hline 5x SDS-PAGE buffer & $\begin{array}{l}30.2 \mathrm{~g} \text { Tris } \\
188 \mathrm{~g} \text { Glycine } \\
10 \mathrm{~g} \mathrm{SDS}(\mathrm{w} / \mathrm{v}) \\
\mathrm{ddH}_{2} \mathrm{O} \text { to } 2 \mathrm{~L}, \mathrm{pH} 8.3 \text { with } \mathrm{HCl}\end{array}$ \\
\hline
\end{tabular}




\begin{tabular}{|c|c|}
\hline 1x SDS-PAGE buffer & $\begin{array}{l}400 \mathrm{~mL} 5 \times \text { SDS-PAGE buffer } \\
\mathrm{ddH}_{2} \mathrm{O} \text { to } 2 \mathrm{~L}\end{array}$ \\
\hline 1x Immunoblot buffer & $\begin{array}{l}6 \mathrm{~g} \text { Tris } \\
28.8 \mathrm{~g} \text { Glycine } \\
400 \mathrm{~mL} \text { Methanol }(\mathrm{v} / \mathrm{v}) \\
\mathrm{H}_{2} \mathrm{O} \text { to } 2 \mathrm{~L}, \mathrm{pH} 8.4\end{array}$ \\
\hline 10x Tris-buffered saline (TBS) & $\begin{array}{l}24.2 \mathrm{~g} \text { Tris } \\
175.3 \mathrm{~g} \mathrm{NaCl} \\
\mathrm{ddH}_{2} \mathrm{O} \text { to } 2 \mathrm{~L}, \mathrm{pH} 7.4 \text { with } \mathrm{HCl}\end{array}$ \\
\hline $1 \times$ TBS with tween-20 (TBST) & $\begin{array}{l}200 \mathrm{~mL} \text { TBS } \\
2 \mathrm{~mL} \text { Tween-20 } \\
\mathrm{dd}_{2} \mathrm{O} \text { to } 2 \mathrm{~L}\end{array}$ \\
\hline Ponceau-S solution & $\begin{array}{l}0.2 \mathrm{~g} \text { Ponceau-S } \\
3 \mathrm{~mL} \text { Acetic acid } \\
\mathrm{ddH}_{2} \mathrm{O} \text { to } 100 \mathrm{~mL}\end{array}$ \\
\hline \multicolumn{2}{|l|}{ In vitro kinase assay } \\
\hline Gel fixing solution & $\begin{array}{l}35 \mathrm{~mL} \text { Acetic acid } \\
100 \mathrm{~mL} \text { Ethanol } \\
\mathrm{dd}_{2} \mathrm{O} \text { to } 400 \mathrm{~mL}\end{array}$ \\
\hline 2x Kinase buffer & $\begin{array}{l}40 \mathrm{mM} \mathrm{MgCl}_{2} \\
4 \mathrm{mM} \mathrm{MnCl}_{2} \\
60 \mathrm{mM} \text { Tris pH } 7.4\end{array}$ \\
\hline \multicolumn{2}{|l|}{ Co-Immunoprecipitation } \\
\hline Immunoprecipitation lysis buffer & $\begin{array}{l}1 \% \text { Triton } \mathrm{X}-100 \\
20 \mathrm{mM} \text { Tris, } \mathrm{pH} 8 \\
130 \mathrm{mM} \mathrm{NaCl} \\
1 \mathrm{mM} \text { DTT } \\
\text { Protease inhibitor cocktail } \\
\text { Phosphatase inhibitor cocktail } \\
10 \mathrm{mM} \mathrm{NaF}\end{array}$ \\
\hline DNA agarose gel electrophore & \\
\hline 50x TAE buffer & $\begin{array}{l}2 \mathrm{M} \text { Tris- } \mathrm{HCl}, \mathrm{pH} 8 \\
5.7 \% \text { Acetic acid }(\mathrm{v} / \mathrm{v}) \\
0.05 \text { M EDTA }\end{array}$ \\
\hline
\end{tabular}




\begin{tabular}{|c|c|}
\hline 1x TAE buffer & $\begin{array}{l}20 \mathrm{~mL} 50 \times \text { TAE buffer } \\
\mathrm{H}_{2} \mathrm{O} \text { to } 1 \mathrm{~L}\end{array}$ \\
\hline \multicolumn{2}{|c|}{ Formaldehyde agarose gel electrophoresis } \\
\hline 10x RNA gel buffer & $\begin{array}{l}200 \mathrm{mM} \text { 3-N-morpholino propanesulfonic } \\
\text { acid (MOPS) } \\
50 \text { mM Sodium acetate } \\
10 \text { mM EDTA } \\
\text { RNase free } \mathrm{H} 2 \mathrm{O} \text { to } 1 \mathrm{~L}, \mathrm{pH} 7.0 \text { with } \mathrm{NaOH}\end{array}$ \\
\hline 1x RNA gel buffer & $\begin{array}{l}100 \mathrm{~mL} 10 \times \mathrm{FA} \text { gel buffer } \\
20 \mathrm{~mL} 37 \% \text { Formaldehyde } \\
\text { RNase-free } \mathrm{H}_{2} \mathrm{O} \text { to } 1 \mathrm{~L}\end{array}$ \\
\hline 5x RNA loading buffer & $\begin{array}{l}16 \mu \mathrm{L} \text { saturated aqueous bromophenol blue } \\
\text { solution } \\
80 \mu \mathrm{L} 500 \mathrm{mM} \text { EDTA, pH } 8.0 \\
720 \mu \mathrm{L} 37 \% \text { Formaldehyde } \\
2 \mathrm{~mL} 100 \% \text { Glycerol } \\
2.084 \mathrm{~mL} \text { Formamide } \\
4 \mathrm{~mL} 10 x \mathrm{FA} \text { gel buffer } \\
\text { RNase-free } \mathrm{H}_{2} \mathrm{O} \text { to } 10 \mathrm{~mL}\end{array}$ \\
\hline
\end{tabular}

\subsection{Antibodies}

\subsubsection{Primary Antibodies}

Primary antibodies were incubated over night at $4^{\circ} \mathrm{C}$ whilst shaking.

Table 8: Primary antibodies for western blot and immunofluorescence

\begin{tabular}{|l|c|l|l|l|}
\hline \multirow{2}{*}{$\begin{array}{l}\text { Primary Antibody } \\
\text { against }\end{array}$} & \multicolumn{2}{|c|}{ Dilution } & Clone/Company & Species \\
\cline { 3 - 6 } & WB & \multicolumn{1}{|c|}{ IF } & & \\
\hline $\begin{array}{l}\text { a-smooth muscle (sm)- } \\
\text { actin }\end{array}$ & $1: 3000$ & - & $\begin{array}{l}\text { monoclonal 1A4 } \\
\text { A 5228, Sigma Aldrich }\end{array}$ & Mouse \\
\hline$\beta$-actin & $1: 5000$ & - & AC-47, Sigma Aldrich & Mouse \\
\hline c-myc & $1: 2000$ & - & $\begin{array}{l}\text { monoclonal, } \\
\text { M4439, Sigma Aldrich }\end{array}$ & Mouse \\
\hline
\end{tabular}




\begin{tabular}{|l|l|l|l|l|}
\hline p21 & $1: 200$ & - & $\begin{array}{l}\text { polyclonal C19, } \\
\text { sc-397, Santa Cruz } \\
\text { monoclonal, } \\
611136, \text { BD }\end{array}$ & Rabbit \\
\hline ROCK1 & $1: 500$ & - & Mouse \\
\hline ROCK2 & $1: 200$ & - & $\begin{array}{l}\text { polyclonal, } \\
\text { sc-5561, Santa Cruz }\end{array}$ & Rabbit \\
\hline Tubulin & $1: 5000$ & - & $\begin{array}{l}\text { monoclonal B-5-1-2 } \\
\text { T 5168, Sigma Aldrich }\end{array}$ & Mouse \\
\hline Vimentin & $1: 2000$ & - & $\begin{array}{l}\text { monoclonal V9 } \\
\text { V 6630, Sigma Aldrich }\end{array}$ & Mouse \\
\hline Vinculin & $1: 2000$ & $1: 500$ & $\begin{array}{l}\text { monoclonal hVIN-1 } \\
\text { V 9264, Sigma Aldrich }\end{array}$ & Mouse \\
\hline
\end{tabular}

\subsubsection{Secondary antibodies for immunoblot analyses}

Secondary antibodies were incubated for $1 \mathrm{~h}$ at room temperature (RT) whilst shaking.

Table 9: Secondary antibodies for immunoblot analyses

\begin{tabular}{|l|l|l|l|}
\hline Secondary Antibody against & Dilution & Lot No./Company & Species \\
\hline $\begin{array}{l}\text { anti-mouse-IgG-horse-radish } \\
\text { peroxidase conjugate }\end{array}$ & $1: 10000$ & $\begin{array}{l}031 \mathrm{M} 4752 \\
\text { Sigma Aldrich }\end{array}$ & Goat \\
\hline $\begin{array}{l}\text { anti-rabbit-IgG-horse-radish } \\
\text { peroxidase conjugate }\end{array}$ & $1: 40000$ & $\begin{array}{l}119 \mathrm{~K} 4815 \\
\text { Sigma Aldrich }\end{array}$ & Goat \\
\hline $\begin{array}{l}\text { anti-goat-IgG-horse-radish } \\
\text { peroxidase conjugate }\end{array}$ & $1: 10000$ & $\begin{array}{l}\text { Sc-2020 } \\
\text { Santa Cruz }\end{array}$ & Donkey \\
\hline
\end{tabular}

\subsubsection{Secondary antibodies for Immunofluorescence analyses}

Secondary antibodies were incubated for $1 \mathrm{~h}$ at room temperature whilst shaking. 
Table 10: Secondary antibodies for immunofluorescence analyses

\begin{tabular}{|l|l|l|l|l|}
\hline Secondary Antibody against & Dilution & Clone/Company & Species \\
\hline $\begin{array}{l}\text { AlexaFluor } 488 \text { anti-Rabbit } \\
\text { conjugate }\end{array}$ & $1: 500$ & $\begin{array}{l}111-545-003, \text { Jackson } \\
\text { Immuno Research }\end{array}$ & Goat \\
\hline $\begin{array}{l}\text { AlexaFluor 488 anti-Mouse } \\
\text { conjugate }\end{array}$ & $1: 500$ & $\begin{array}{l}115-545-003, \text { Jackson } \\
\text { Immuno Research }\end{array}$ & Goat \\
\hline
\end{tabular}

\subsection{Kits}

Table 11: Kits

\begin{tabular}{|c|c|c|}
\hline Application & Name & Company \\
\hline cDNA synthesis & $\begin{array}{l}\text { RevertAid First Strand cDNA Synthesis } \\
\text { Kit }\end{array}$ & Life Technologies \\
\hline Endpoint PCR & PrimeStar HS polymerase & TaKaRa \\
\hline Heart cell preparation & $\begin{array}{l}\text { Neonatal Heart Dissociation Kit (mouse } \\
\text { and rat) }\end{array}$ & Miltenyi Biotec \\
\hline $\begin{array}{ll}\text { Kinase } & \text { activity } \\
\text { profiling } & \end{array}$ & $\begin{array}{l}\text { Ser/Thr Kinase Pam Chip \& STK } \\
\text { reagent kit }\end{array}$ & PamGene \\
\hline $\begin{array}{ll}\text { PCR } & \text { product } \\
\text { purification } & \end{array}$ & High Pure PCR Product Purification Kit & Roche \\
\hline $\begin{array}{l}\text { Plasmid } \quad \text { DNA } \\
\text { preparation }\end{array}$ & Exprep mini kit & GeneAll \\
\hline $\begin{array}{l}\text { Plasmid } \quad \text { DNA } \\
\text { preparation }\end{array}$ & Plasmid midi kit & Qiagen \\
\hline $\begin{array}{l}\text { Plasmid } \\
\text { preparation }\end{array}$ & PeqGold XChange Plasmid Maxi Kit & peqLab \\
\hline $\begin{array}{ll}\text { Total } & \text { RNA } \\
\text { preparation } & \end{array}$ & RNeasy Maxi Kit & Qiagen \\
\hline
\end{tabular}

\subsection{Primers}

Primers were synthesized by Eurofins/MWG and are indicated in $5^{\text {‘ }} \rightarrow 3^{\text {‘ direction. }}$ 
Table 12: Primers

\begin{tabular}{|c|c|}
\hline Name & Sequence \\
\hline $\begin{array}{l}\text { Biglycan for } \\
\text { Biglycan rev }\end{array}$ & $\begin{array}{l}\text { gct cc gga aca tga act gca } \\
\text { ggt agt tga gct tca ggc cat }\end{array}$ \\
\hline $\begin{array}{l}\text { Col1a1 for } \\
\text { Col1a1 rev }\end{array}$ & $\begin{array}{l}\text { acg cca tca agg tct act gc } \\
\text { act cga acg gga atc cat cg }\end{array}$ \\
\hline $\begin{array}{l}\text { Col3a1 for } \\
\text { Col3a1 rev }\end{array}$ & $\begin{array}{l}\text { cca tga ctg tcc cac gta agc ac } \\
\text { gga ggg cca tag ctg aac tga aaa c }\end{array}$ \\
\hline $\begin{array}{l}\text { CTGF for } \\
\text { CTGF rev }\end{array}$ & $\begin{array}{l}\text { ccg ggt tac caa tga caa ta } \\
\text { cac acc cca cag aac tta gc }\end{array}$ \\
\hline $\begin{array}{l}\text { Decorin for } \\
\text { Decorin rev }\end{array}$ & $\begin{array}{l}\text { get att cct caa ggt ctg cc } \\
\text { ctg cca ttt tcc aca acg gt }\end{array}$ \\
\hline $\begin{array}{l}\text { Elastin for } \\
\text { Elastin rev }\end{array}$ & $\begin{array}{l}\text { cag gag tca agg cca agg tt } \\
\text { gcc act cca tag ggc agt tt }\end{array}$ \\
\hline $\begin{array}{l}\text { GUSB for } \\
\text { GUSB rev }\end{array}$ & $\begin{array}{l}\text { tac ttc aag acg ctg atc gcc } \\
\text { atc acct cc aga tgc ccg ta }\end{array}$ \\
\hline $\begin{array}{l}\text { HAS2 for } \\
\text { HAS2 rev }\end{array}$ & $\begin{array}{l}\text { ctg ggc aga agc gtg gat ta } \\
\text { aac atc tcc ccc aac acc tc }\end{array}$ \\
\hline $\begin{array}{l}\text { LGALS3 for } \\
\text { LGALS3 rev }\end{array}$ & $\begin{array}{l}\text { agc cca acg caa aca gta tca } \\
\text { tga atg gtt tgc cgc tct ca }\end{array}$ \\
\hline $\begin{array}{l}\text { LOX for } \\
\text { LOX rev }\end{array}$ & $\begin{array}{l}\text { gct gca cca ttt cac cg tatt ag } \\
\text { gtc caa aca cca ggt act gct t }\end{array}$ \\
\hline $\begin{array}{l}\text { MMP2 for } \\
\text { MMP2 rev }\end{array}$ & $\begin{array}{l}\text { tcc ccc gat get gat act ga } \\
\text { ccg cca aat aaa ccg gtc ctt }\end{array}$ \\
\hline $\begin{array}{l}\text { MMP9 for } \\
\text { MMP9 rev }\end{array}$ & $\begin{array}{l}\text { gga taa cga gtt ctc tgg cgt } \\
\text { cac ggc agg agg tca tag gtc }\end{array}$ \\
\hline $\begin{array}{l}\text { MMP12 for } \\
\text { MMP12 rev }\end{array}$ & $\begin{array}{l}\text { ggt acc aga gcc aca cta tc } \\
\text { tcc tgc ctc aca tcg tac ct }\end{array}$ \\
\hline $\begin{array}{l}\text { PBGD for } \\
\text { PBGD rev }\end{array}$ & $\begin{array}{l}\text { cct gaa act ctg ctt cgc tg } \\
\text { ctg gac cat ctt ctt gct gaa }\end{array}$ \\
\hline $\begin{array}{l}\text { ROCK1 for } \\
\text { ROCK1 rev }\end{array}$ & $\begin{array}{l}\text { ggt gaa aca cca gaa gga gct gaa } \\
\text { ttt gca cgc acc tgc tca ata tca c }\end{array}$ \\
\hline $\begin{array}{l}\text { ROCK2 for } \\
\text { ROCK2 rev }\end{array}$ & $\begin{array}{l}\text { ttc cca acc aac tgt gag gc } \\
\text { aca aca gat tct ttg ccg atg ata }\end{array}$ \\
\hline
\end{tabular}




\begin{tabular}{|l|l|}
\hline TGF- $\beta$ for & aga gcc ctg gat acc aac ta \\
TGF- $\beta$ rev & tgt tgg ttg tag agg gca ag \\
\hline Vimentin for & gag agc acc ctg cag tca tt \\
Vimentin rev & tgg atc tct tca tcg tgc agc \\
\hline
\end{tabular}

\subsection{Plasmids}

Table 13: Lentivirus plasmids

\begin{tabular}{|l|l|l|l|}
\hline Name & Plasmid & Coding for & Company \\
\hline psPAX.2 & psPAX.2 & $\begin{array}{l}\text { Lentiviral proteins (Gag, Rev, } \\
\text { Tat) }\end{array}$ & D. Trono Lab \\
\hline pMD2.G & pMD2.G & $\begin{array}{l}\text { Glycoprotein of the human } \\
\text { vesicular stomatitis virus }\end{array}$ & D. Trono Lab \\
\hline shROCK1 & pLKO.1 & gca cca gtt gtg cct gat tta & Open Biosystems \\
\hline shROCK1/2 & pLKO.1 & att tgt ttc ttc aag aga tgc & Open Biosystems \\
\hline shscr & pLKO.1 & $\begin{array}{l}\text { shRNA, no fit to any mammal } \\
\text { gene, cct aag gtt aag tcg ccc tcg }\end{array}$ & Sigma-Adrich \\
\hline
\end{tabular}

Table 14: Overexpression plasmids

\begin{tabular}{|l|l|}
\hline Plasmid & Provided by \\
\hline pCAG-myc-ROCK1 & Prof. Shuh Narumiya \\
\hline pCAG-myc-ROCK1 1-1080 (ROCK1 $\Delta 1)$ & Prof. Shuh Narumiya \\
\hline
\end{tabular}

\subsection{Software}

Table 15: Software

\begin{tabular}{|l|l|}
\hline Analyses & Software \\
\hline Confocal images & Zen 2012 (Zeiss) \\
\hline Flow cytometry cell cycle analyses & FACSDiva (BD) \\
\hline Image processing \& analyses & ImageJ \\
\hline Immunoblot & ImageLab 5.1 (Biorad Laboratories) \\
\hline Immunofluorescence/Life cell imaging & Xcellence pro (Olympus) \\
\hline
\end{tabular}




\begin{tabular}{|c|c|}
\hline Migration assay (Life cell imaging) & $\begin{array}{l}\text { ImageJ } \\
\text { Plug-in: manual tracking, } \\
\text { chemotaxis assay }\end{array}$ \\
\hline Multi-mode microplate reader measurements & SoftMax Pro 5.4 \\
\hline Proliferation assay & Cellavista \\
\hline qRT-PCR & 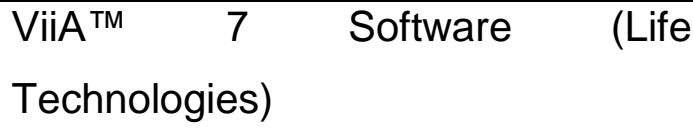 \\
\hline Rheological measurements & TRIOS (TA Instruments) \\
\hline Statistical evaluations & $\begin{array}{l}\text { GraphPad Prism 6, Microsoft Excel } \\
\text { (Office } 365 \text { University) }\end{array}$ \\
\hline
\end{tabular}




\section{Methods}

\subsection{Cell biology methods}

\subsubsection{Preparation of cardiac cells from neonatal rats}

Neonatal rat cardiac fibroblasts (NRCF) and cardiomyocytes (NRCM) were isolated using the Neonatal Heart Dissociation Kit, mouse and rat (Miltenyi Biotec) according to the manufacturer's instructions. All steps were performed on ice. 40-60 neonatal Wistar rats (P0-P3) were decapitated, a thoracotomy performed, and the heart, including the vascular pedicle, was excised and transferred into a $10 \mathrm{~cm}$ cell culture dish containing CBFHH buffer. For a preparation containing ventricular cells only, the atria, vascular pedicle and remaining connective tissue was dissected.

To remove adverse blood, the ventricles were washed twice with $\mathrm{CBFHH}$. Subsequently, the ventricles were cut into small $1 \mathrm{~mm}^{3}$ pieces and again washed twice with CBFHH. Enzyme mix 1 and 2 were prepared as shown in Table 16.

Table 16: Preparation of enzyme mix 1 and 2 for preparation of cardiac cells

\begin{tabular}{|l|l|l|l|l|l|}
\hline & \multicolumn{2}{|l|}{ Enzyme mix 1 } & \multicolumn{2}{l|}{ Enzyme mix 2 } \\
\hline $\begin{array}{l}\text { Number of neonatal } \\
\text { rats }\end{array}$ & Enzyme P & Buffer X & Buffer Y & $\begin{array}{l}\text { Enzyme } \\
\text { A }\end{array}$ & $\begin{array}{l}\text { Enzyme } \\
\text { D }\end{array}$ \\
\hline 40 & $125 \mu \mathrm{L}$ & $4600 \mu \mathrm{L}$ & $50 \mu \mathrm{L}$ & $25 \mu \mathrm{L}$ & $200 \mu \mathrm{L}$ \\
\hline 60 & $187.5 \mu \mathrm{L}$ & $6900 \mu \mathrm{L}$ & $75 \mu \mathrm{L}$ & $37.5 \mu \mathrm{L}$ & $300 \mu \mathrm{L}$ \\
\hline
\end{tabular}

Enzyme mix 1 was heated for 5 min at $37^{\circ} \mathrm{C}$, then added to enzyme mix 2 (hereafter referred to as enzyme mix). The diced ventricular tissue was transferred to two gentleMACS C tubes; $2.5 \mathrm{~mL}$ or $3.75 \mathrm{~mL}$ of enzyme mix for 40 or 60 neonatal rat hearts respectively, was added to each tube. The tubes were inverted and the samples incubated for $15 \mathrm{~min}$ at $37^{\circ} \mathrm{C}$. Subsequently, the tubes were attached onto the sleeve of the gentleMACS dissociator and the dissociation was started using the gentleMACS program htumor3.01. The incubation and dissociation steps were repeated three times. 
The cells were resuspended in $7.5 \mathrm{~mL}$ of NCM medium and strained through $250 \mu \mathrm{m}$ pore stainless steel mesh. The resultant cell suspension was centrifuged at $60 \mathrm{~g}$ for $20 \mathrm{~min}$, supernatant discarded and the pellet resuspended in $20 \mathrm{~mL} \mathrm{NCM} \mathrm{medium.}$ To determine cell number, $10 \mu \mathrm{L}$ of the cell suspension were diluted $1: 1$ with $0.4 \%$ trypan blue solution, and counted using a Neubauer counting chamber.

\subsubsection{Separation of cardiac fibroblasts and cardiomyocytes}

To separate NRCF from NRCM, $8 \cdot 10^{6}$ cardiac cells were seeded on a $15 \mathrm{~cm}$ cell culture dish in ice-cold NCM medium and incubated for $45 \mathrm{~min}$ in a humidified incubator $\left(37^{\circ} \mathrm{C}, 5 \% \mathrm{CO}_{2}\right)$. During this time the fibroblasts adhered to the cell culture dish, whereas cardiomyocytes remained mostly in the medium. The NCM medium containing non-cardiac fibroblasts was removed and changed to NRCF growth medium (see 2.6). NRCF were cultured according to 3.1.3 until they were confluent.

\subsubsection{Culturing, passaging and freezing of NRCF}

NRCF were cultured in NRCF growth medium in a humidified cell culture incubator at $37^{\circ} \mathrm{C}, 5 \% \mathrm{CO}_{2}$. Medium was replenished every second day. To passage NRCF's, medium was aspirated, cells washed once with DPBS, and incubated with $0.05 \%$ trypsin-EDTA $\left(2.5 \mathrm{~mL} / 10 \mathrm{~cm}\right.$ culture dish or $5 \mathrm{~mL} / 15 \mathrm{~cm}$ culture dish and $175 \mathrm{~cm}^{2}$ culture flask). After $3-5 \mathrm{~min}$ incubation at $37^{\circ} \mathrm{C}$, detachment of the fibroblasts was monitored with a light microscope. The enzymatic activity of trypsin was halted by the addition of double the volume of NRCF growth medium. The cells were collected and centrifuged at $300 \mathrm{~g}$ for $5 \mathrm{~min}$, supernatant discarded and the remaining cell pellet resuspended in NRCF growth medium. Cell number and viability were measured by electrical current exclusion using the CASY TT system (Roche). NRCF were seeded at the required density on new culture dishes, or used to construct rat engineered connective tissue (rECT).

To freeze NRCF, cells were mixed with NRCF growth medium containing $10 \%$ DMSO, the suspension transferred into cryovials and placed into a "Mr. Frosty" 
freezing container. The cells were permitted to gradually freeze for $4-5 \mathrm{~h}$ at $-80^{\circ} \mathrm{C}$. NRCF were then transferred to $-152^{\circ} \mathrm{C}$ for long-term storage.

\subsubsection{Thawing, culturing and passaging of HEK293A and Tsa201 cells}

HEK293A and Tsa201 cells were thawed in a $37^{\circ} \mathrm{C}$ water bath, diluted with HEK293A/Tsa201 growth medium (see 2.6), and seeded in an appropriate culture vessel. Medium was replenished the following day to remove residual DMSO and every second day thereafter.

For passaging of HEK293A and Tsa201, medium was aspirated, cells washed once with DPBS, and incubated with $0.05 \%$ trypsin-EDTA $(2.5 \mathrm{~mL} / 10 \mathrm{~cm}$ culture dish or $5 \mathrm{~mL} / 15 \mathrm{~cm}$ culture dish and $175 \mathrm{~cm}^{2}$ culture flask) for $2 \mathrm{~min}$ at room temperature (RT). The enzymatic reaction was stopped by adding two volumes of HEK293A/Tsa201 growth medium. Cells were harvested, centrifuged (see 3.1.3), resuspended in HEK293A/Tsa201 growth medium, and cell number and viability were measured using the Casy TTS (see 3.1.3). HEK293A and Tsa201 were frozen for long-term storage as described in 3.1.3.

\subsubsection{Thawing, culturing and passaging of normal human cardiac fibroblasts from the ventricle (NHCF-V)}

NHCF-V were thawed in a $37^{\circ} \mathrm{C}$ water bath. The contents of the cryovial was transferred to a tube, the cryovial washed with $1 \mathrm{~mL}$ of Fibroblast growth medium-3 (FGM-3) containing growth factors, cytokines, and supplements supplied by Lonza (see 2.6) and slowly added to the cells to avoid osmotic shock. Under constant shaking, another $8 \mathrm{~mL}$ of FGM-3 were added to the tube and the NHCF-V seeded in an appropriate cell culture vessel. Medium was exchanged the next day to remove residual DMSO and then every second day thereafter. NHCF-V were cultured in FGM-3 in a humidified cell culture incubator at $37^{\circ} \mathrm{C}, 5 \% \mathrm{CO}_{2}$.

To passage NHCF-V, medium was discarded, cells washed once with DPBS, and incubated with TrypLE Express reagent $\left(6 \mathrm{~mL} / 175 \mathrm{~cm}^{2}\right.$ culture flask) for $3-5 \mathrm{~min}$ at 
$37^{\circ} \mathrm{C}$. The enzymatic reaction was stopped by adding two volumes of FGM-3. Cells were harvested, centrifuged, resuspended in FGM3, and cell number and viability were measured using the Casy TTS (see 3.1.3). NHCF-V were seeded in the required density on new culture dishes, used for the construction of human engineered connective tissue ( $\mathrm{hECT}$ ), or human engineered heart muscle (hEHM).

To freeze NHCF-V, cells were mixed with FBS containing 10\% DMSO, cryovials were placed into a freezing container and transferred to $-80^{\circ} \mathrm{C}$ to gradually freeze for 4-5 h. NHCF-V were then transferred to $-152^{\circ} \mathrm{C}$ for long-term storage.

\subsubsection{Culturing of human embryonic stem cell-derived cardiomyocytes}

The human embryonic stem cell line "hES2" was purchased from Embryonic Stem Cell International (Singapore). Differentiation of hES2-wt cells into cardiomyocytes (CM) was kindly performed by the stem cell unit Göttingen (SCU-G). In brief, human embryonic stem cells (hESCs) were initially cultured on irradiated human foreskin fibroblasts (hFFs) in hESC culture medium (see 2.7). For expansion and single cell adaptation, hESCs were passaged using EDTA digestion solution (see 2.7) and plated on feeder free Matrigel ${ }^{\mathrm{TM}}$-coated plates (diluted 1:30 in DPBS) in a seeding density of $5 \cdot 10^{4}$ to $1 \cdot 10^{5}$ in hESC-conditioned medium (see 2.7). During differentiation into $\mathrm{CM}$, medium was changed every other day. One day after plating, hESCs were rinsed once with CM basal medium and then cultured in mesoderminduction medium (see 2.7) for three days. Cells were again washed with CM basal medium and cultured in cardiac specification medium (see 2.7) for the following ten days. To obtain a pure population of $\mathrm{CM}$, they were metabolically selected in $\mathrm{CM}$ selection medium (see 2.7) for further five days. Thereafter, hES2-wt CM were cultured in $\mathrm{CM}$ basal medium in a humidified cell culture incubator at $37^{\circ} \mathrm{C}, 5 \% \mathrm{CO}_{2}$. Medium was exchanged every second day.

For dissociation of hES2-wt CM, medium was removed, cells were washed twice with DPBS and incubated with accutase containing digestion medium (see 2.7) for 5 to $15 \mathrm{~min}$ at RT. Detachment of hES2-wt CM was controlled using a light microscope and enzymatic reaction was stopped by adding three volumes of $\mathrm{CM}$ 
basal medium. Cells were harvested, centrifuged, resuspended in CM basal medium, and cell number and viability were measured using the Casy TTS (see 3.1.3).

\subsubsection{Generation of lentivirus particles in Tsa201}

Stable knockdown of ROCK1 and ROCK2 was induced by lentiviral delivery of short hairpin RNAs (shRNAs) and RNA interference (RNAi). pLKO.1 HIV-based lentiviral vectors encoding for the respective shRNA constructs were purchased from Thermo Scientific. The pLKO.1 vectors also contained integration and packaging elements of lentivirus particles, a puromycin resistance cassette for selection of transduced cells, and a SV40 origin of replication (ori), enabling replication in cell lines expressing the large $T$ antigen and allows high-level expression.

Tsa201, a cell line derived from human embryonic kidney cells, are highly transfectable and express the SV40 large $T$ antigen necessary for activation of plasmid expression via SV40 ori. To generate non-replicating transducing lentivirus particles, three separate plasmids for expression of lentiviral proteins and the transgene were co-transfected: pMD2.G encodes for a glycoprotein of the vesicular stomatitis virus, PPAX2 is a packaging plasmid containing the viral structural genes, and pLKO.1 contains the shRNA targeting either ROCK1, ROCK2, or the shRNA shscr (no target in the corresponding genome and thus used as a control).

Tsa201 cells were cultured on $10 \mathrm{~cm}$ culture dishes in HEK293A/Tsa201 growth medium until $70 \%$ confluent. Medium was changed to HEK293A/Tsa201 serumreduced medium and transfection was performed according to the polyfect transfection reagent handbook (Qiagen). The transfection mix was prepared as shown in Table 17. After 10 min incubation at RT, $620 \mu \mathrm{L}$ HEK293A/Tsa201 serumreduced medium was added to the reaction mix, which was then carefully added to the Tsa201 cells. 
Table 17: Transfection mix for generating lentivirus particles

\begin{tabular}{|l|c|}
\hline Reagent & Amount \\
\hline Plasmid with GOI & $3 \mu \mathrm{g}$ \\
\hline psPAX.2 & $3 \mu \mathrm{g}$ \\
\hline pMD2.G & $2 \mu \mathrm{g}$ \\
\hline Medium without antibiotics or serum & $300 \mu \mathrm{L}$ \\
\hline Polyfect & $80 \mu \mathrm{L}$ \\
\hline
\end{tabular}

After $48 \mathrm{~h}$ and $72 \mathrm{~h}$, the lentivirus particle-containing supernatants were harvested and replenished with fresh HEK293A/Tsa201 serum-reduced medium. The collected supernatants were pooled and filtered through a $45 \mu \mathrm{m}$ syringe filter to remove cell debris.

For concentration and purification of the lentivirus, harvested supernatants were transferred to a $14 \mathrm{~mL}$ ultracentrifuge tube containing $1 \mathrm{~mL}$ of $20 \%$ sucrose in TNE buffer and centrifuged for $4 \mathrm{~h}, 22,000 \mathrm{~g}$, and $4^{\circ} \mathrm{C}$. The virus containing sucrose solution was frozen in liquid nitrogen and stored at $-80^{\circ} \mathrm{C}$.

\subsubsection{Lentiviral transduction of NRCF to knockdown ROCK1 and ROCK2}

When required, the lentivirus particles were thawed on ice. NRCF were passaged according to 3.1.3 and seeded with NRCF growth medium containing the suitable virus and $8 \mu \mathrm{g} / \mu \mathrm{L}$ polybrene to improve the infection rate. After $48 \mathrm{~h}$ and $96 \mathrm{~h}$, the medium was changed to NRCF selection medium containing $1 \mu \mathrm{g} / \mathrm{mL}$ puromycin. Seven days after infection, cells were transferred into multiwell dishes according to the experiments to be performed.

\subsubsection{Transfection of NRCF to knockdown ROCK1 and ROCK2}

Another application of RNAi is mediated by small interfering RNAs (siRNAs), which can be transfected into cells using various transfection reagents.

NRCF were passaged according to 3.1.3 and cultured in NRCF growth medium on 12-well plates until $70 \%$ confluent. Transfection of siRNAs was performed using 
Lipofectamine RNAiMAX in Opti-MEM (Life Technologies). The transfection mix was prepared as shown in Table 18, combined, mixed thoroughly and incubated for 20 min at RT.

Table 18: Transfection mix for siRNA transfection into NRCF

\begin{tabular}{|l|l|l|l|l|}
\hline & \multicolumn{3}{|l|}{ Mix 1 } & Mix 2 \\
\hline Cell culture plate & $\begin{array}{l}\text { siRNA } \\
(100 ~ p M)\end{array}$ & $\begin{array}{l}\text { Opti- } \\
\text { MEM }\end{array}$ & $\begin{array}{l}\text { Lipofectamine } \\
\text { RNAiMAX }\end{array}$ & $\begin{array}{l}\text { Opti- } \\
\text { MEM }\end{array}$ \\
\hline 1 well (12-well plate) & $1.1 \mu \mathrm{L}$ & $110 \mu \mathrm{L}$ & $3.3 \mu \mathrm{L}$ & $120 \mu \mathrm{L}$ \\
\hline 1 well (6-well plate) & $2.75 \mu \mathrm{L}$ & $275 \mu \mathrm{L}$ & $8.25 \mu \mathrm{L}$ & $300 \mu \mathrm{L}$ \\
\hline
\end{tabular}

NRCF were washed twice with DPBS and medium was replaced with $300 \mu \mathrm{L}$ or $750 \mu \mathrm{L}$ Opti-MEM per well of a 12-well or 6-well plate, respectively. After $20 \mathrm{~min}$ incubation, $200 \mu \mathrm{L}$ (12-well) or $500 \mu \mathrm{L}$ (6-well) of the transfection mix was added to the cells. After $6 \mathrm{~h}$, the transfection medium was changed to NRCF growth medium and incubated for $48 \mathrm{~h}$.

\subsubsection{Co-transfection of HEK293A for overexpression of ROCK1 and p21}

One day before transfection, $2 \cdot 10^{6}$ HEK293A cells were seeded on a $10 \mathrm{~cm}$ culture dish to achieve $70-90 \%$ confluent cells the following day. For transfection, $10 \mu \mathrm{g}$ of plasmid DNA was mixed with $1 \mathrm{~mL}$ Opti-MEM and $20 \mu \mathrm{L}$ TurboFect (Thermo Fisher). The transfection mix was briefly vortexed, incubated for $20 \mathrm{~min}$ at $\mathrm{RT}$, added to the $10 \mathrm{~cm}$ culture dish containing HEK293A cells and HEK293A/Tsa201 growth medium. The medium was exchanged after $4 \mathrm{~h}$ and the cells harvested after $48 \mathrm{~h}$ for subsequent immunoprecipitation (see 3.3.7).

\subsubsection{Proliferation assay}

The proliferation of NRCF was analysed over six days. 10,000 knockdown NRCF or wild type NRCF were seeded on 24-well plates with NRCF growth medium changed daily. Wild type NRCF were treated with $3 \mu \mathrm{M} \mathrm{H1152P}$ every day. Cells were then fixed with $4 \%$ paraformaldehyde (PFA) in DPBS for $15 \mathrm{~min}$ after $24 \mathrm{~h}$ (=Day 0 ) and 
on days 1,2, and 6. After two washing steps with DPBS, cells were incubated with Hoechst $33342(10 \mu \mathrm{g} / \mathrm{mL})$ in DPBS for $30 \mathrm{~min}$. Automated evaluation of cell numbers was performed using the Cellavista system (Roche).

\subsubsection{Adhesion assay}

Knockdown NRCF were seeded in NRCF growth medium on uncoated 12-well plates or coated with $1 \%$ collagen I in DPBS. After 20, 40 and $60 \mathrm{~min}$, ten bright-field images per condition were taken using the time-lapse function of an inverted fluorescence microscope (Olympus) with a CM $10 \mathrm{~T}$ camera (Olympus) and 10x objective equipped with a humidified climate chamber at $37^{\circ} \mathrm{C}, 5 \% \mathrm{CO}_{2}$. The number of adhered and non-adhered cells was counted and values expressed relative to the total cell number.

\subsubsection{Live cell imaging and migration assay}

Knockdown or wild type NRCF were seeded on 24-well plates. Wild type NRCF were treated with $3 \mu \mathrm{M} \mathrm{H1152P}$ for $24 \mathrm{~h}$. Live cell imaging was performed in NRCF growth medium using the time-lapse function of an inverted fluorescence microscope (Olympus) with a CM $10 \mathrm{~T}$ camera (Olympus) and 10x objective equipped with a humidified climate chamber at $37^{\circ} \mathrm{C}, 5 \% \mathrm{CO}_{2}$. Bright-field images were taken every $20 \mathrm{~min}$ for $24 \mathrm{~h}$. Cell tracking was performed using the manual tracking macro in ImageJ. Migration parameters were calculated using the chemotaxis plug-in for ImageJ provided by Ibidi.

\subsubsection{Transwell migration}

To analyse the ability for cells to migrate through pores, cell culture inserts with $8 \mu \mathrm{m}$ porous membranes from Greiner Bio One (thincerts) were used. The thincerts were inserted into a 24-well plate and the wells filled with NRCF growth medium or NRCF serum-reduced medium. 5,000 knockdown NRCF in NRCF serum-reduced medium were seeded into one thincert and incubated for $24 \mathrm{~h}$ at $37^{\circ} \mathrm{C}, 5 \% \mathrm{CO}_{2}$. After $24 \mathrm{~h}$, the thincerts were washed once with DPBS and cells were fixed with 4\% PFA in 
DPBS for $15 \mathrm{~min}$. After two additional washing steps with DPBS, the remaining cells were carefully removed from the top of the membrane using a cotton swab. The membrane was cut out, placed on a microscope slide and incubated with Hoechst $33342(10 \mu \mathrm{g} / \mathrm{mL})$ in DPBS for $30 \mathrm{~min}$. Subsequently, the membranes were imaged using an inverted fluorescence microscope (Olympus) with a CM $10 \mathrm{~T}$ camera (Olympus) and 10x objective equipped with a humidified climate chamber at $37^{\circ} \mathrm{C}, 5 \% \mathrm{CO}_{2}$. Cells found in the pores or at the bottom of the membrane were counted.

\subsubsection{Generation of engineered heart muscle from isolated primary neonatal rat cardiac cells (rEHM)}

Neonatal rat cardiac cells were isolated from 0 to 3-day old neonatal rat hearts as described in 3.1.1. To generate rat engineered heart muscle (rEHM), all materials required were pre-chilled to $4^{\circ} \mathrm{C}$ and all steps were performed on ice. $\mathrm{rEHMs}$ were prepared from mixtures of collagen type I (rat tail, self-made), a basement membrane protein mixture (Matrigel ${ }^{\mathrm{TM}}, \mathrm{BD}$ ), concentrated serum-containing culture medium (2x DMEM, pH adjusted to 7.4) and neonatal rat heart cells in EHM culture medium (see 2.6) as shown in Table 19. The master mix volumes are adjusted to account for volume loss $(\approx 15 \%)$ due to a viscous EHM mixture. EHMs were cast into custommade circular moulds (Figure 8) and allowed to solidify for $1 \mathrm{~h}$ in a humidified incubator at $37^{\circ} \mathrm{C}$ and $5 \% \mathrm{CO}_{2}$.

Table 19: Composition of rEHM master mix

\begin{tabular}{|l|l|}
\hline Master mix components & Volume $[\mu \mathrm{L}]$ \\
\hline Collagen $(3.81 \mathrm{mg} / \mathrm{mL}), 0.8 \mathrm{mg} / \mathrm{rEHM}$ & 283 \\
\hline $2 \mathrm{x}$ DMEM & 283 \\
\hline $0.1 \mathrm{~N} \mathrm{NaOH}$ & 46 \\
\hline Matrigel $^{\mathrm{TM}}$ & 207 \\
\hline Total cell number $\left(11.5 \cdot 10^{6}\right), 2.5 \cdot 10^{6} / \mathrm{rEHM}$ & 1251 \\
\hline Total volume of master mix & 2070 \\
\hline Number of $\mathrm{rEHM}(900 \mu \mathrm{L} / \mathrm{rEHM})$ & 2 \\
\hline
\end{tabular}


A

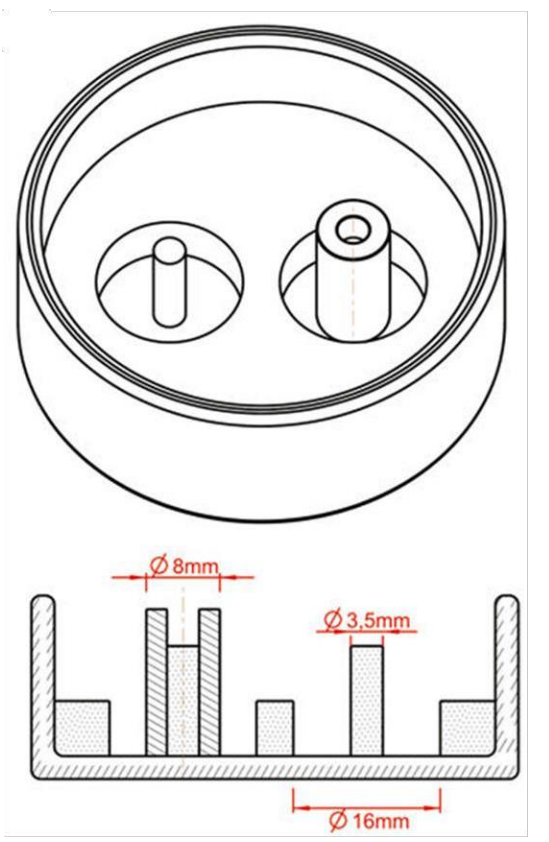

B

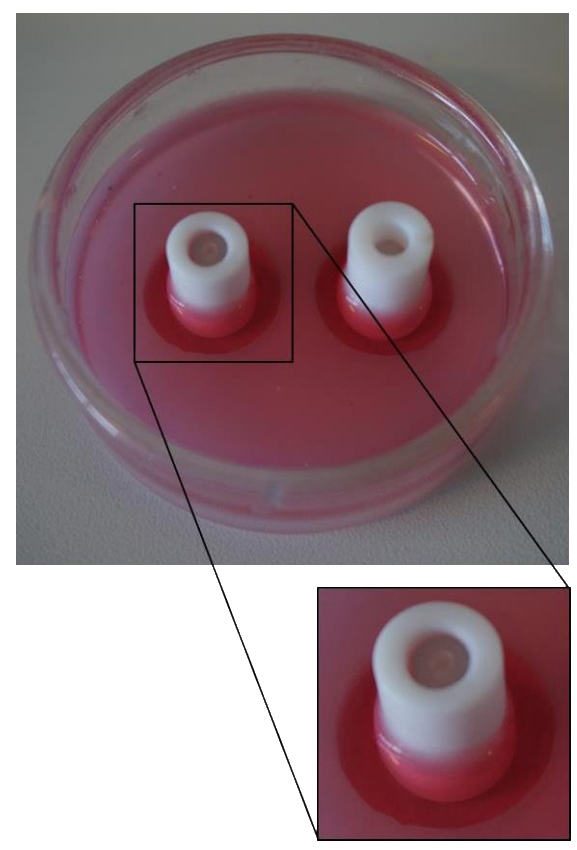

Figure 8: Custom-made circular moulds for construction of rEHM.

(A) Technical drawing of custom-made circular moulds for construction of two rEHMs with $900 \mu \mathrm{L}$ volume [178], (B) Mould with two consolidated rEHMs on culture day eight and magnified view of single mould.

After gelation, $7 \mathrm{~mL}$ EHM culture medium were added to the casting mould. Medium was changed the next day and then every second day thereafter. On culture day eight, rEHMs were subjected to dynamic mechanical stretch at $1 \mathrm{~Hz}$ for $24 \mathrm{~h}$, then at $2 \mathrm{~Hz}$ for another six days. During this phase, rEHMs were treated with ROCK inhibitors Fasudil $(10 \mu \mathrm{M})$ and $\mathrm{H} 1152 \mathrm{P}(3 \mu \mathrm{M})$. Medium was changed every other day.

\subsubsection{Generation of engineered heart muscle from hES2-wt CM and NHCF-V (hEHM)}

NHCF-V and hES2-wt CM were cultured and dissociated as described in 3.1 .5 and 3.1.6, respectively. However, for NHCF-V the enzymatic reaction was also stopped by adding three volumes of CM basal medium. The required number of hES2 wt CM and NHCF-V were combined, centrifuged at $300 \mathrm{~g}$ for $5 \mathrm{~min}$ at RT and the cells resuspended in CM basal medium to achieve appropriate dilution (see Table 20). 
For construction of engineered heart muscle from human cells ( $h E H M$ ), all materials required were pre-chilled and all steps performed on ice. Bovine collagen type I (Collagen Solutions, UK) and concentrated culture medium (2x RPMI, pH adjusted to 7.4) were mixed with hES2 wt CM and NHCF-V in CM basal medium as shown in Table 20 . The master mix volumes are adjusted to account for volume loss $(\approx 17 \%)$ due to a viscous EHM mixture.

Table 20: Composition of hEHM master mix

\begin{tabular}{|l|l|}
\hline Master mix components & Volume $[\mu \mathrm{L}]$ \\
\hline Collagen $(6.9 \mathrm{mg} / \mathrm{mL}), 0.4 \mathrm{mg} / \mathrm{hEHM}$ & 271 \\
\hline $2 \mathrm{RPMI}$ & 271 \\
\hline $0.1 \mathrm{~N} \mathrm{NaOH}$ & 53 \\
\hline $\begin{array}{l}\text { Total cell number }\left(4 \cdot 10^{6} \mathrm{hES} 2 \mathrm{wt} \mathrm{CM}+2 \cdot 10^{6} \mathrm{NHCF}-\mathrm{V}\right) \text {, in total } \\
1.25 \cdot 10^{6} / \mathrm{hEHM}\end{array}$ & 1506 \\
\hline Total volume of master mix & 2101 \\
\hline Number of hEHM $(450 \mu \mathrm{L} / \mathrm{hEHM})$ & 4 \\
\hline
\end{tabular}

The hEHM master mix was cast into custom-made circular moulds (Figure 9) and permitted to gel for $1 \mathrm{~h}$ in a humidified incubator at $37^{\circ} \mathrm{C}$ and $5 \% \mathrm{CO}_{2}$.

A

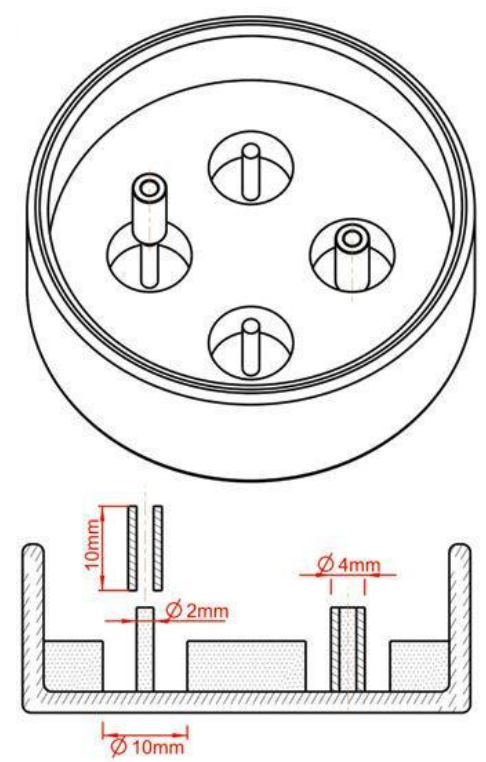

B

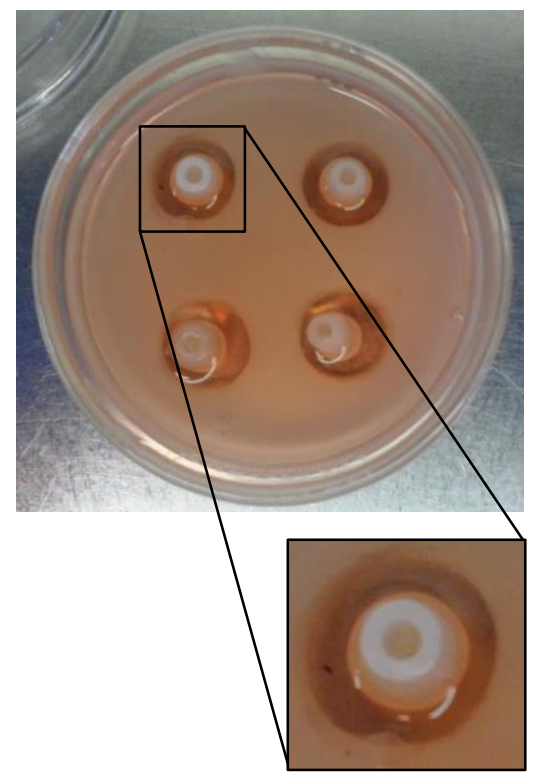

Figure 9: Custom-made circular moulds for construction of hEHM.

(A) Technical drawing of custom-made circular moulds for construction of $4 \mathrm{hEHMs}$ with $450 \mu \mathrm{L}$ volume [178], (B) Mould with four consolidated hEHMs on culture day three and magnified view of single mould. 
After gelation, $6 \mathrm{~mL}$ SFMM containing TGF $\beta 1$ was added to each mould. Medium was replenished with fresh SFMM containing TGF $\beta 1$ the next day. On culture day three, hEHMs were transferred to custom-made silicone dynamic stretchers (Sylgard 184, Dow Corning) and SFMM medium without TGF $\beta 1$. During this phase, hEHMs were treated with ROCK inhibitor H1152P $(3 \mu \mathrm{M})$. Medium was changed every second day and hEHMs were cultured until day 28.

\subsubsection{Generation of engineered connective tissue from NRCF (rECT) and NHCF-V (hECT)}

NRCF and NHCF-V were cultured as described in 3.1.3 and 3.1.5, respectively. To generate engineered connective tissue from NRCF ( $\mathrm{rECT}$ ) and engineered connective tissue from NHCF-V (hECT), all materials required were pre-chilled and all steps performed on ice. rECTs were prepared by mixing collagen type I (rat tail, self-made) and 2x DMEM with NRCF in NRCF growth medium according to Table 21.

Table 21: Composition of rECT master mix

\begin{tabular}{|l|l|}
\hline Master mix components & Volume $[\mu \mathrm{L}]$ \\
\hline Collagen $($ rat tail, $3.81 \mathrm{mg} / \mathrm{mL}), 1.2 \mathrm{mg} / \mathrm{rECT}$ & 725 \\
\hline $2 x$ DMEM & 725 \\
\hline $0.1 \mathrm{~N} \mathrm{NaOH}$ & 118 \\
\hline Total cell number $\left(3.91 \cdot 10^{6}\right), 1.7 \cdot 10^{6} / \mathrm{rECT}$ & 502 \\
\hline Total volume of master mix & 2070 \\
\hline Number of $\mathrm{rECT}(900 \mu \mathrm{L} / \mathrm{rECT})$ & $\mathbf{2}$ \\
\hline
\end{tabular}

rECTs were cast into custom-made circular moulds (rat scale, see Figure 8) and allowed to gel for $1 \mathrm{~h}$ in a humidified incubator at $37^{\circ} \mathrm{C}$ and $5 \% \mathrm{CO}_{2}$.

hECTs were prepared by mixing collagen type I (bovine) and 2x DMEM with NHCF-V in FGM3 according to Table 22. The $\mathrm{pH}$ of both mixtures was titrated to 7.4. Typically, rECTs and hECTs were prepared with an individual volume of $900 \mu \mathrm{L} / \mathrm{rECT}$ and $450 \mu \mathrm{L} / \mathrm{hECT}$. 
Table 22: Composition of hECT master mix

\begin{tabular}{|l|l|}
\hline Master mix components & Volume $[\mu \mathrm{L}]$ \\
\hline Collagen $($ bovine, $6.9 \mathrm{mg} / \mathrm{mL}), 0.6 \mathrm{mg} / \mathrm{hECT}$ & 400 \\
\hline $2 \mathrm{x}$ DMEM & 400 \\
\hline $0.1 \mathrm{~N} \mathrm{NaOH}$ & 71 \\
\hline Total cell number $\left(3.45 \cdot 10^{6}\right), 0.75 \cdot 10^{6} / \mathrm{rECT}$ & 1200 \\
\hline Total volume of master mix & 2071 \\
\hline Number of $\mathrm{hECT}(450 \mu \mathrm{L} / \mathrm{hECT})$ & $\mathbf{4}$ \\
\hline
\end{tabular}

Similar to rECTs, hECTs were cast into custom-made circular moulds (human scale, see Figure 9) and allowed to gel for $1 \mathrm{~h}$ in a humidified incubator at $37^{\circ} \mathrm{C}$ and $5 \%$ $\mathrm{CO}_{2}$. Inhibitors and growth factors were directly added to the rECT or hECT master mix and also into the NRCF growth medium or FGM3. Concentrations of the inhibitors and growth factors used in the different experiments are outlined in Table 23.

Table 23: Concentration of inhibitors and growth factors used in rECT and hECT models

\begin{tabular}{|l|l|}
\hline Reagent & Concentration \\
\hline Fasudil & $10 \mu \mathrm{M}$ \\
\hline $\mathrm{H} 1152 \mathrm{P}$ & $3 \mu \mathrm{M}$ \\
\hline MMP408 & $10 \mu \mathrm{M}$ \\
\hline TGF $\beta 1$ & $5 \mathrm{ng} / \mathrm{mL}$ \\
\hline
\end{tabular}

After condensation, $7 \mathrm{~mL}$ NRCF growth medium or FGM3 were added to the casting mould. Medium was changed every other day. rECTs and hECTs were cultured five days.

\subsubsection{Isometric force measurements of rEHMs and hEHMs}

EHM functionality was assessed by isometric force measurements in organ baths containing oxygenated Tyrode's solution at $37^{\circ} \mathrm{C}$ (Figure 10) as described previously [179]. rEHMs were measured on culture day 14, and hEHMs on culture day 28. 

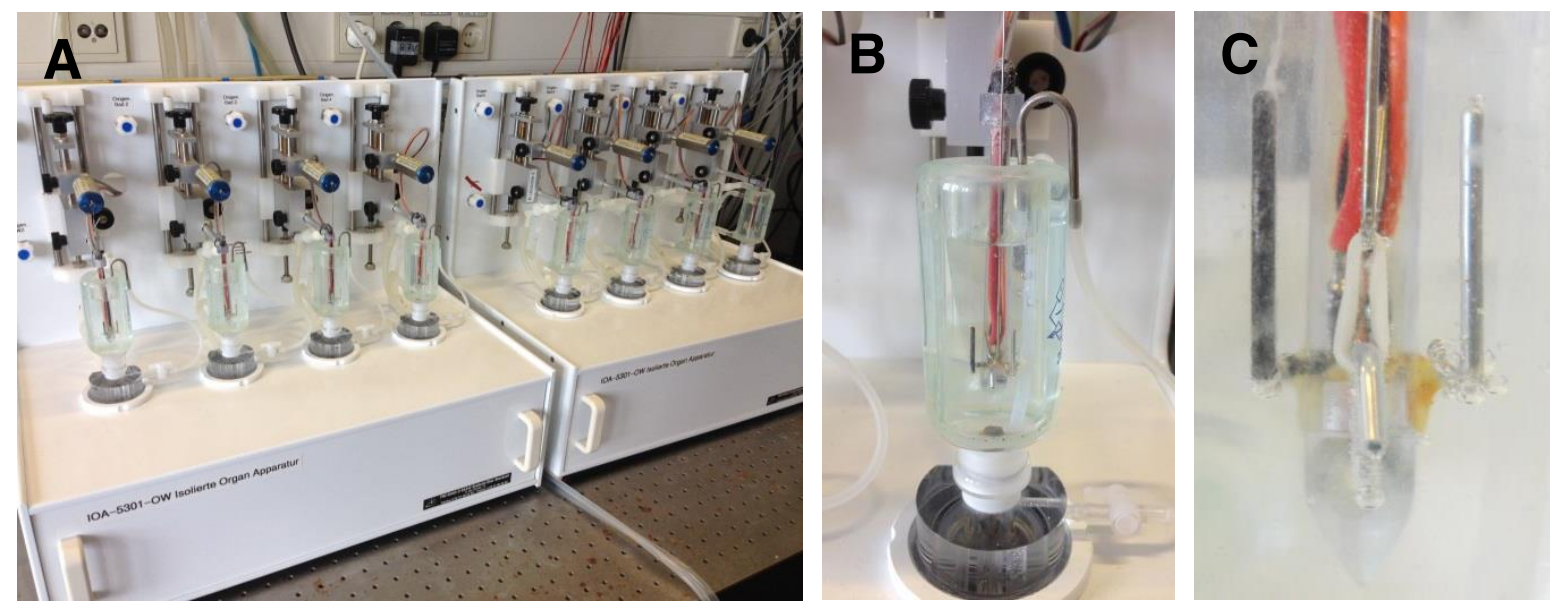

Figure 10: Isometric force measurement set-up

(A) Set-up for isometric force measurements showing eight organ baths, (B) Magnified view of an organ bath, (C) hEHM during isometric force measurement in an organ bath.

Prior to force measurements, the force transducers were calibrated with a $50 \mathrm{mg}$ weight. rEHMs were stretched by stepwise length adjustment $(125 \mu \mathrm{m})$ at $2 \mathrm{~Hz}$ electrical field stimulation in the presence of $1 \mathrm{mmol} / \mathrm{L}$ extracellular calcium until the length at which maximum force was generated (Lmax) was reached.

hEHMs were stretched by stepwise length adjustment $(62.5 \mu \mathrm{m})$ at $1.5 \mathrm{~Hz}$ electrical field stimulation in the presence of $1.8 \mathrm{mmol} / \mathrm{L}$ extracellular calcium. Contractile force of EHMs was measured under increasing extracellular calcium $(0.2-2.4 \mathrm{mmol} / \mathrm{L}$ for rEHMs and 0.2 - $4 \mathrm{mmol} / \mathrm{L}$ for hEHMs).

\subsubsection{Destructive tensile strength measurement}

Destructive tensile strength of engineered tissues was performed using an RSA-G2 rheometer (TA Instruments, see Figure 11A) to assess the viscoelastic properties of the extracellular matrix. 

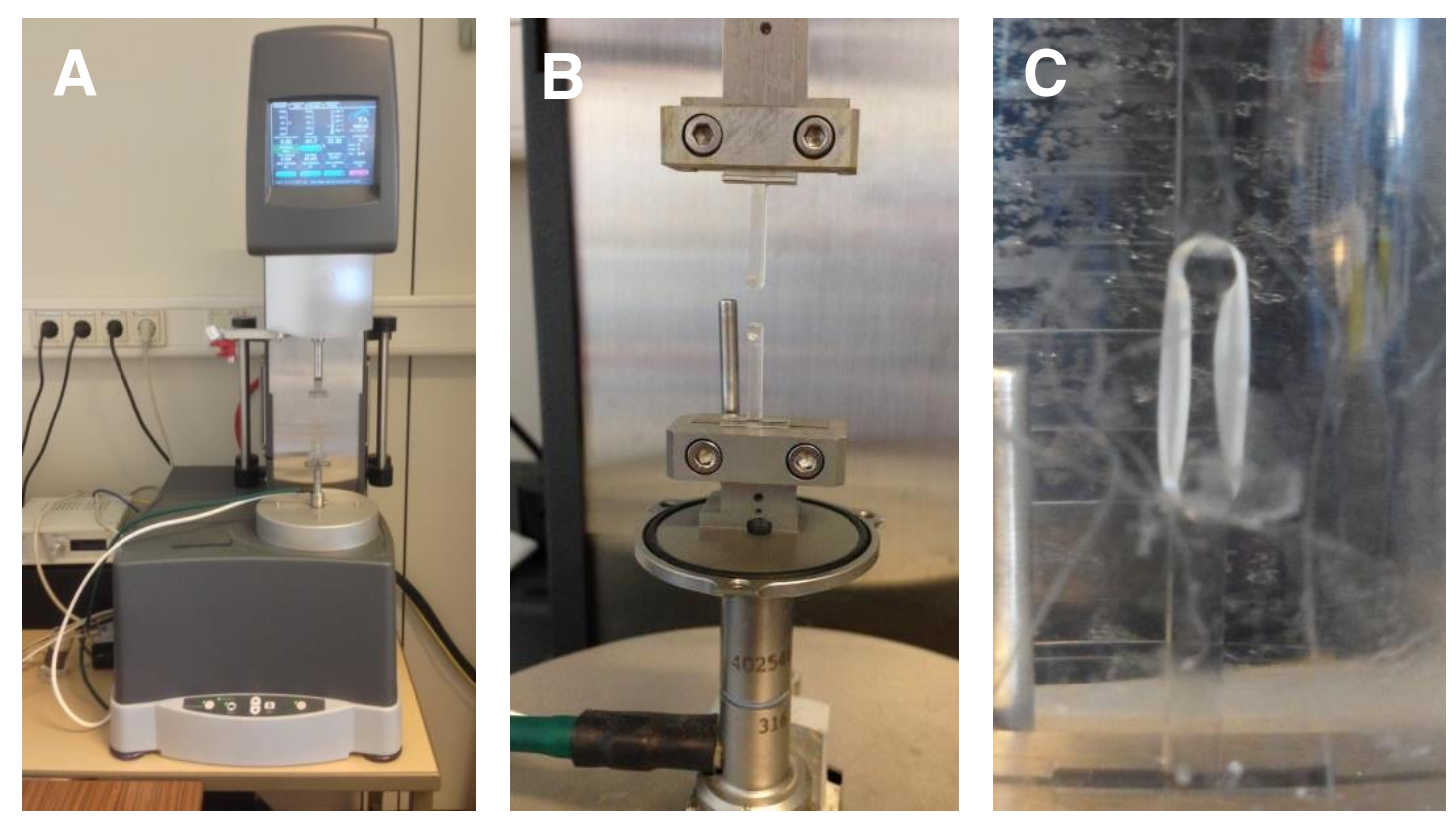

Figure 11: Experimental set-up for destructive tensile strength measurement of ECT and EHM.

(A) Rheometer RSA-G2. (B) Tissues were fixed between two hooks and (C) measured in a controlled environment of $37^{\circ} \mathrm{C}$ in DPBS.

Before the measurement was started, the transducer element of the rheometer was reset to zero. Engineered tissues were transferred to a bath containing DPBS at $37^{\circ} \mathrm{C}$ and suspended between two custom-made hooks (see Figure 11B and $\mathrm{C}$ ). Tissues were then stretched with a constant linear rate of $0.05 \mathrm{~mm} / \mathrm{s}$ for rat tissues and $0.03 \mathrm{~mm} / \mathrm{s}$ for human tissues till the point of rupture.

\subsubsection{Dissociation of cells from engineered tissues}

Engineered tissues were dissociated by incubation in $500 \mu \mathrm{L}$ (rat tissues) or $250 \mu \mathrm{L}$ (human tissues) collagenase I solution (see 2.6) for $2 \mathrm{~h}$ at $37^{\circ} \mathrm{C}$. The supernatant was transferred to a tube, tissues were washed once with PBS containing 5\% FBS and incubated in the same volume of digestion medium (see 2.6) for $45 \mathrm{~min}$ at RT to achieve complete dissociation. The remaining tissue was mechanically dissociated by gentle pipetting and the supernatant transferred to the tube. Cells were centrifuged for $5 \mathrm{~min}$ at $300 \mathrm{~g}$ and $4^{\circ} \mathrm{C}$, resuspended in PBS containing $5 \% \mathrm{FBS}$, counted as described before using the CASY TT system and subsequently fixed with 
ice-cold $70 \%$ ethanol for FACS analyses or RNA isolated for gene expression analyses.

\subsection{Histological methods}

\subsubsection{Immunofluorescence and staining of the actin cytoskeleton and the nucleus in cells}

Cells were washed with DPBS and fixed with 4\% Paraformaldehyde (PFA) in DPBS for $15 \mathrm{~min}$. They were then washed three times with DPBS, permeabilized with $0.02 \%$ Triton $X-100$ in DPBS for 3 min and again washed three times prior to blocking in $1 \mathrm{x}$ Roti-Block (in DBPS) for $1 \mathrm{~h}$ at RT. After three more washes with DBPS, cells were incubated with the appropriate primary protein-specific antibody in DBPS overnight at $4^{\circ} \mathrm{C}$ (see 2.9.1).

The next day, cells were washed three times with DBPS, followed by incubation with fluorochrome-conjugated secondary antibodies in DBPS for $1 \mathrm{~h}$ at RT in the dark (see 2.9.3). Additionally, staining of the actin cytoskeleton with TRITC-labelled phalloidin and of the cell nucleus with DAPI $(1 \mu \mathrm{g} / \mathrm{mL})$ in DBPS was performed for $1 \mathrm{~h}$ at RT in the dark. Finally, cells were washed twice with DBPS and the samples were imaged using an inverted fluorescence microscope (Olympus) with a CM $10 \mathrm{~T}$ camera (Olympus) and 10x-60x objectives. CellM Software (Olympus) was used for image processing, including adjustments for brightness and contrast.

\subsubsection{Quantitative evaluation of focal adhesions (FAs) in NRCF}

FAs were immunostained for vinculin, a membrane-cytoskeletal protein found in FAs. In order to analyse the quantity and size of FAs in NRCF, image processing was carried out using ImageJ and an optimized analysis protocol published by Horzum et al. [180]. A graphical depiction of the single steps can be seen in Figure 12. 
In brief, the raw images were processed as follows:

I. Subtract background: Sliding paraboloid option with rolling ball radius set to 2 pixels

II. CLAHE (Contrast Limited Adaptive Histogram Equalization): block size $=19$, histogram bins $=256$, slope $=6$, no mask and fast [181]

III. Mathematical exponential (Exp)

IV. Brightness \& Contrast: Automatically adjusted

V. Threshold: default method; pixel values: 255 (white) and 3 (black)

VI. Analyse particles: size $=0.001-50{\mu m^{2}}^{2}$ and circularity $=0.00-1.00$

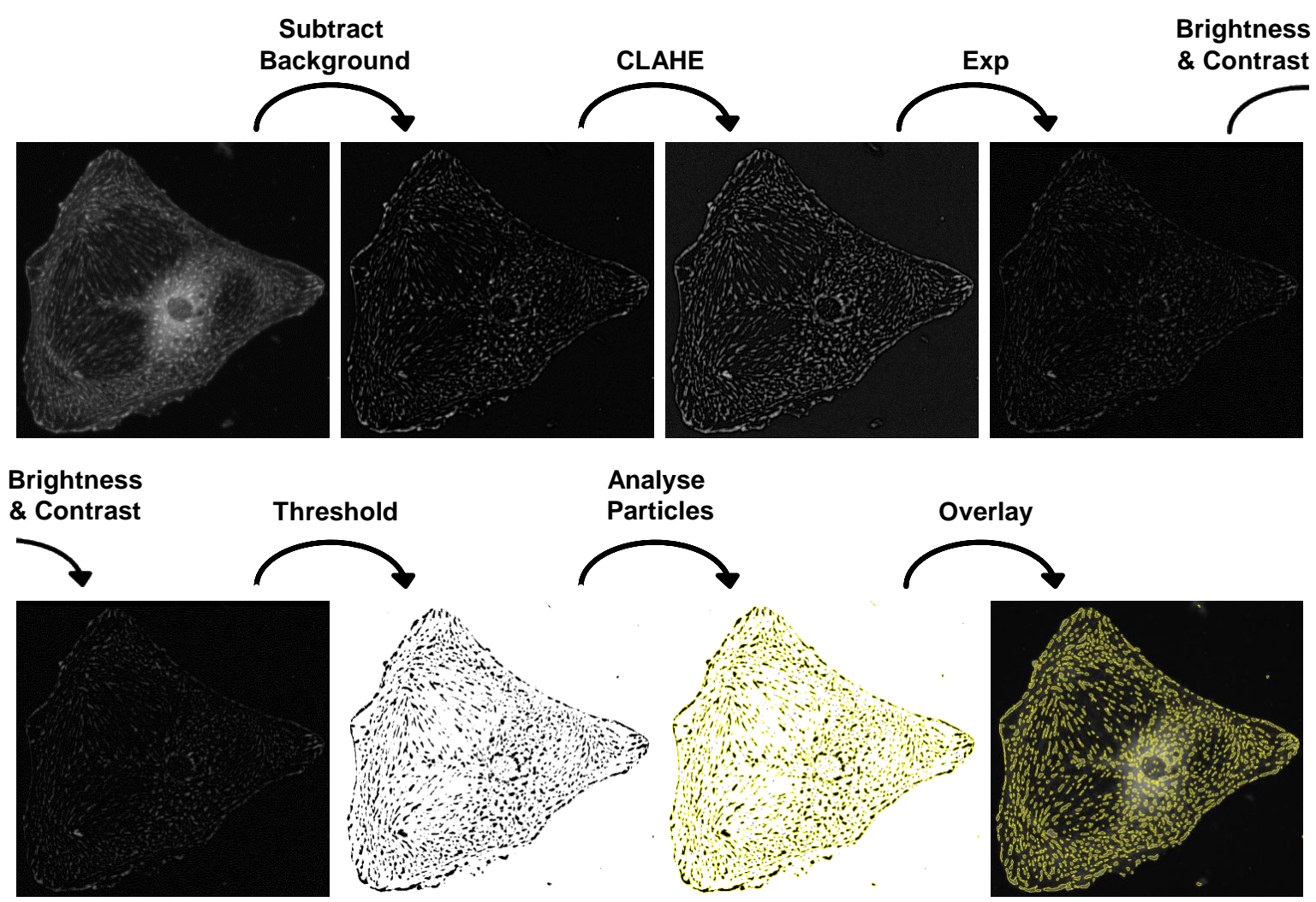

Figure 12: Graphical summary of the quantitative evaluation of focal adhesions in NRCF.

From the raw image, background was subtracted. Afterwards, local contrast of the image was enhanced using CLAHE and mathematical exponential was applied to further minimize the background. Brightness and contrast were adjusted and the image converted to a binary image using the threshold command. Finally, analyse particles command was used to count and measure FAs. 


\subsubsection{Flow cytometry cell cycle analysis}

Analysis of the replication state of a cell population can be achieved by fluorescently labelling and quantifying DNA content. Cells that are in S phase will have more DNA than quiescent and G1 cells. Accordingly, they proportionally uptake more dye and thus fluoresce brighter. Cells in G2 or M phase have two copies of DNA and will be approximately twice as bright as cells in G0/G1 phase.

Engineered tissues were dissociated according to 3.1.20 and resultant cells were fixed in ice-cold $70 \%$ ethanol for $30 \mathrm{~min}$ at $4^{\circ} \mathrm{C}$. Samples can be left at this step for several weeks. Cells were then washed twice in phosphate-citrate buffer. To ensure that only DNA is stained, cells were subsequently treated with $50 \mu \mathrm{L}$ of $100 \mu \mathrm{g} / \mathrm{mL}$ RNase. To stain the DNA, cells were incubated in $300 \mu \mathrm{L}$ of $50 \mu \mathrm{g} / \mathrm{mL}$ propidium iodide (PI) for $30 \mathrm{~min}$ at $37^{\circ} \mathrm{C}$, centrifuged $\left(300 \mathrm{~g}, 5 \mathrm{~min}, 4^{\circ} \mathrm{C}\right)$, resuspended in $500 \mu \mathrm{L}$ DPBS and then analysed by flow cytometry.

Cell debris was excluded by measuring for forward scatter (FS) and side scatter (SS). Pulse processing was used to exclude aggregates by plotting pulse area (FL2A) vs. pulse width (FL2-W). Subsequently, cells in G0/G1, S, and G2/M phase were identified using a histogram of the pulse area (FL2-A).

\subsection{Protein biochemical methods}

\subsubsection{Isolation of proteins from cultured cells}

To obtain protein from NRCF, cells were washed with cold DBPS and scraped off using an adequate volume of cold GST-Fish lysis buffer. Samples were centrifuged at $13,000 \mathrm{~g}, 4^{\circ} \mathrm{C}$ for $10 \mathrm{~min}$, snap frozen in liquid nitrogen and stored at $-80^{\circ} \mathrm{C}$.

\subsubsection{Determination of protein concentration (Bradford assay)}

A modified Bradford colorimetric protein assay was performed to determine the concentration of protein lysates [182]. A series of bovine serum albumin (BSA) standards $(0-2.0 \mu \mathrm{g} \mathrm{BSA})$ and protein samples were prepared in $50 \mu \mathrm{L} \mathrm{ddH}_{2} \mathrm{O}$ and 
pipetted into 96-well microtiter plates in triplicate. $200 \mu \mathrm{L} 1 \times$ Roti Nanoquant solution was added to each well. The formation of the protein-dye complex was detected at $595 \mathrm{~nm}$ using a spectrophotometric microplate reader (FlexStation3). Protein concentration was calculated according to the obtained BSA standard curve.

\subsubsection{Sodium dodecyl sulphate polyacrylamide gel electrophoresis (SDS- PAGE)}

SDS-PAGE was used for separation of protein mixtures according to their size. For efficient separation of proteins, a $5 \%$ stacking gel and, according to the size of proteins to be detected, a resolving gel with an acrylamide/bisacrylamide concentration of $6-15 \%$ was used (see Table 24).

Table 24: Master mix of stacking and resolving gels used for SDS-PAGE

\begin{tabular}{|l|l|l|l|l|l|}
\hline Reagent & $\begin{array}{l}\mathbf{5 \%} \\
\text { stacking } \\
\text { gel }\end{array}$ & $\begin{array}{l}\mathbf{8} \% \\
\text { resolving } \\
\text { gel }\end{array}$ & $\begin{array}{l}\mathbf{1 0 \%} \\
\text { resolving } \\
\text { gel }\end{array}$ & $\begin{array}{l}\mathbf{1 2 \%} \\
\text { resolving } \\
\text { gel }\end{array}$ & $\begin{array}{l}\mathbf{1 5 \%} \\
\text { resolving } \\
\text { gel }\end{array}$ \\
\hline $\begin{array}{l}\text { ddH } \mathrm{O}_{2} \mathrm{O} \\
6.8\end{array}$ & $2.8 \mathrm{~mL}$ & $2.3 \mathrm{~mL}$ & $1.9 \mathrm{~mL}$ & $1.6 \mathrm{~mL}$ & $1.1 \mathrm{~mL}$ \\
\hline $\begin{array}{l}1.5 \mathrm{M} \mathrm{Tris} / \mathrm{HCl}, \mathrm{pH} / \mathrm{HCl}, \mathrm{pH} \\
8.8\end{array}$ & $0.38 \mathrm{~mL}$ & - & - & - & - \\
\hline $\begin{array}{l}\text { Acrylamide/bisacryla } \\
\text { mide mix }\end{array}$ & $1.3 \mathrm{~mL}$ & $1.3 \mathrm{~mL}$ & $1.7 \mathrm{~mL}$ & $2.0 \mathrm{~mL}$ & $2.5 \mathrm{~mL}$ \\
\hline $\begin{array}{l}10 \% \mathrm{SDS} \\
10 \% \text { APS }\end{array}$ & $0.03 \mathrm{~mL}$ & $0.05 \mathrm{~mL}$ & $0.05 \mathrm{~mL}$ & $0.05 \mathrm{~mL}$ & $0.05 \mathrm{~mL}$ \\
\hline TEMED & $0.03 \mathrm{~mL}$ & $0.05 \mathrm{~mL}$ & $0.05 \mathrm{~mL}$ & $0.05 \mathrm{~mL}$ & $0.05 \mathrm{~mL}$ \\
\hline Volume & $0.003 \mathrm{~mL}$ & $0.003 \mathrm{~mL}$ & $0.002 \mathrm{~mL}$ & $0.002 \mathrm{~mL}$ & $0.002 \mathrm{~mL}$ \\
\hline
\end{tabular}

Whole cell lysates were mixed with 4x SDS loading buffer without glycerol on the basis of the calculated protein concentrations and incubated at $95^{\circ} \mathrm{C}$ for $5 \mathrm{~min}$. Protein samples were loaded and separated at $200 \mathrm{~V}$ in $1 \mathrm{x}$ SDS running buffer until the dye front ran from the gel. 


\subsubsection{Western immunoblotting}

Following SDS-PAGE, proteins were electrotransferred to nitrocellulose membranes. For this, the gel and membrane were sandwiched between filter paper and immersed in ice-cold immunoblotting buffer for $1 \mathrm{~h}$ at $100 \mathrm{~V}$. The immunoblot setup was additionally cooled with ice. To visualise successful protein transfer, membranes were stained with PonceauS solution for $3 \mathrm{~min}$. They were then washed with TBST buffer until the PonceauS stain was no longer visible. Membranes were blocked with $1 \times$ Roti-Block in $\mathrm{ddH}_{2} \mathrm{O}$ for $1 \mathrm{~h}$ at $\mathrm{RT}$.

Membranes were incubated with primary antibodies against the desired protein of interest diluted in TBST buffer and incubated overnight at $4^{\circ} \mathrm{C}$ (see 2.9.1). Membranes were washed thrice for $10 \mathrm{~min}$ in TBST buffer and probed with appropriate horseradish peroxidase-conjugated secondary antibodies for $1 \mathrm{~h}$ at RT (see 2.9.2). After a final round of washing with TBST buffer, protein signals were visualised by enhanced chemiluminescence (Lumi-LightPLUS or Super Signal West Femto) in a VersaDoc imaging system (Bio-Rad Laboratories). Quantification of the signals was performed using ImageLab 5.1 analysis software (Bio-Rad Laboratories).

\subsubsection{Identification of potential ROCK targets using PamGene's kinase activity profiling technology}

The PamGene kinase activity profiling system can be used to identify new targets for kinases, in this case ROCK1 and ROCK2. In this study, PamChip arrays were utilised, which consist of $140 \mathrm{Ser} / \mathrm{Thr}$ containing peptides and 4 positive phosphorylated control peptides immobilized on the microarray. Each peptide represents a 15 amino acid sequence, of which 13 residues were derived from phosphorylation sites in various human proteins.

Measurements of peptide phosphorylation by kinases is accomplished by incubating the purified kinase on the microarray and detection using a mixture of primary and fluorescently labelled secondary antibodies. Images of the fluorescence intensity were taken with a CCD camera in-built to the PamStation (Figure 13). 


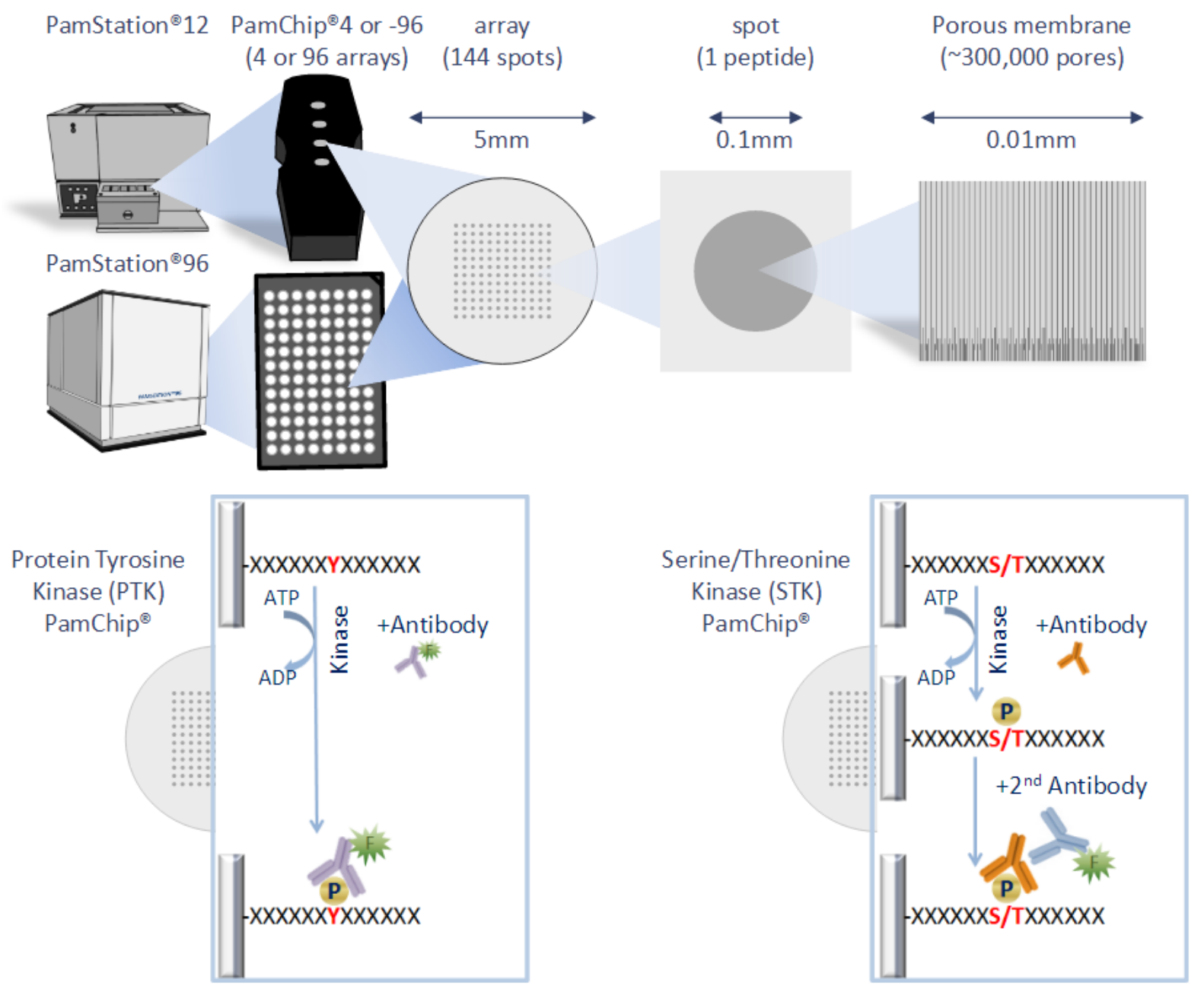

Figure 13: Schematic drawing of the PamGene kinase activity profiling system.

The PamChip arrays consist of 144 peptides which are spotted on a porous membrane. Peptide phosphorylation by kinases is detected using a mixture of primary and fluorescently labelled secondary antibodies [183].

Phosphorylation of peptides was measured according to the kinase activity profiling protocol supplied by the manufacturer. Briefly, the PamChip arrays were blocked with $2 \%$ BSA, the assay master mix was prepared on ice as shown in Table 25, and applied to the array. After termination of the run, the detection master mix was prepared on ice as shown in Table 26 and loaded onto the array.

Data analysis consisting of image quantification, quality control and statistical analyses was kindly performed by Dr. Hanibal Bohnenberger (Institute of Pathology, UMG) by using the Evolve and BioNavigator software supplied by the manufacturer. 
Table 25: Composition of kinase activity profiling assay master mix

\begin{tabular}{|l|l|}
\hline Master mix components & Amount \\
\hline 10x PK buffer & $4 \mu \mathrm{L}$ \\
\hline 100x BSA solution & $0.4 \mu \mathrm{L}$ \\
\hline Sample (purified kinase) & $0.1-20 \mathrm{ng}$ \\
\hline 4 mM ATP solution & $4 \mu \mathrm{L}$ \\
\hline Water & To a final volume of $40 \mu \mathrm{L}$ \\
\hline
\end{tabular}

Table 26: Composition of kinase activity profiling detection master mix

\begin{tabular}{|l|l|}
\hline Master mix components & Amount \\
\hline $10 x$ Ab buffer & $3 \mu \mathrm{L}$ \\
\hline STK antibody mix & $0.23 \mu \mathrm{L}$ \\
\hline STK antibody FITC-labelled & $0.08 \mu \mathrm{L}$ \\
\hline Water & $26.69 \mu \mathrm{L}$ \\
\hline
\end{tabular}

\subsubsection{In vitro kinase assay}

To verify whether ROCK1 and ROCK2 can phosphorylate p21 and CDK7 in an in vitro kinase assay, recombinant human ROCK1 or ROCK2 (SignalChem) was incubated with the target substrate (recombinant p21 or recombinant inactive CDK7, SignalChem) in kinase buffer in the presence of adenosine 5'-triphosphate (ATP) and [Y-32P]ATP (see Table 27) at $30^{\circ} \mathrm{C}$ for $30 \mathrm{~min}$.

Subsequently, $10 \mu \mathrm{L} 4 \mathrm{x}$ SDS loading buffer with glycerol were added and the samples incubated at $95^{\circ} \mathrm{C}$ for $5 \mathrm{~min}$. Samples were loaded on a $4-15 \%$ gradient gel and separated at $100 \mathrm{~V}$ in $1 \times$ SDS running buffer until the dye front ran from the gel. The gel was then fixed in fixing buffer for $30 \mathrm{~min}$ at $\mathrm{RT}$, dried for $2 \mathrm{~h}$ at $70^{\circ} \mathrm{C}$ and protein phosphorylation was analysed by autoradiography of the dried gel.

Table 27: Master mix for kinase assay

\begin{tabular}{|l|l|}
\hline Master mix components & Amount \\
\hline 2x Kinase buffer & $15 \mu \mathrm{L}$ \\
\hline ATP & $0.3 \mu \mathrm{L}$ \\
\hline
\end{tabular}




\begin{tabular}{|l|l|}
\hline [ $\mathrm{Y}$-32P]ATP & $0.1 \mu \mathrm{Ci} / \mu \mathrm{L}$ \\
\hline Substrate $(\mathrm{p} 21, \mathrm{CDK} 7)$ & $2 \mu \mathrm{g}$ \\
\hline Kinase (ROCK1, ROCK2) & $100 \mathrm{ng}$ \\
\hline $\mathrm{dd}_{2} \mathrm{O}$ & ad $30 \mu \mathrm{L}$ \\
\hline
\end{tabular}

\subsubsection{Co-Immunoprecipitation (Co-IP)}

HEK293A cells were co-transfected as described in 3.1.10. After 24 hours, cells were washed with DPBS and $1 \mathrm{~mL}$ of IP lysis buffer was added to each dish. After $10 \mathrm{~min}$ of incubation on ice, cells were scraped and lysates centrifuged at $13,000 \mathrm{rpm}$ at $4^{\circ} \mathrm{C}$ for $10 \mathrm{~min}$. The supernatant was transferred to a fresh microtube, and $150 \mu \mathrm{L}$ of the supernatant was separated to check total protein levels by immunoblotting.

a-myc agarose beads were washed three times with IP lysis buffer. Cell lysates were incubated with $10 \mu \mathrm{L}$ of $\alpha$-myc agarose beads per sample for $2 \mathrm{~h}$ at $4^{\circ} \mathrm{C}$ with rotation. Subsequently, beads were washed three times with IP lysis buffer and immunocomplexes were dissociated from the beads by boiling with 2x SDS loading buffer containing glycerol. The samples were analysed by SDS-PAGE followed by immunoblotting.

\subsection{Molecular biological methods}

\subsubsection{DNA isolation}

Small scale preparation of DNA was performed for quality control of the lentiviral plasmids containing the respective shRNAs to knockdown ROCK1 and both kinases. This was performed using the Exprep Plasmid SV mini kit (GeneAll) following recommended manufacturer instructions.

Large scale preparation of DNA was performed to isolate the lentiviral plasmids containing the respective shRNAs to knockdown ROCK1 and ROCK2 for transfection into Tsa201 cells. For this, XChange Plasmid Maxi Kit (Peqlab) was used and protocol followed according to the manufacturer's instructions. 
The concentration and purity of isolated nucleic acids were measured using spectrophotometric quantification with the NanodropTM ND-1000 system. DNA concentration was calculated as follows:

\section{DNA concentration $(\mu \mathrm{g} / \mathrm{mL})=A_{2 w e} \times$ dilution factor $\times 50 \mu \mathrm{g} / \mathrm{mL}$}

A260: Absorbance at $260 \mathrm{~nm}$

$\mathrm{A}_{260}$ of $1.0=50 \mu \mathrm{g} / \mathrm{ml}$ pure dsDNA

To evaluate DNA purity, the ratio of the absorbance at $260 \mathrm{~nm}$ divided by the reading at $280 \mathrm{~nm}$ was calculated. Good quality DNA will have an $\mathrm{A}_{260} / \mathrm{A}_{280}$ ratio of 1.7-2.0. Samples were stored at $-20^{\circ} \mathrm{C}$ until required.

\subsubsection{Restriction digest}

For quality control of lentiviral plasmids, plasmid DNA was digested using BamHI and Ndel (NEB). $10 \mathrm{U}$ of the respective restriction enzyme was added to $1 \mathrm{x}$ reaction buffer and $1 \mu \mathrm{g}$ of vector DNA. Water was added to a final volume of $30 \mu \mathrm{L}$ and the reaction mix was incubated for $4 \mathrm{~h}$, or overnight at $37^{\circ} \mathrm{C}$. Restriction enzymes were inactivated at $65^{\circ} \mathrm{C}$ for $20 \mathrm{~min}$.

\subsubsection{DNA agarose gel electrophoresis}

DNA agarose gel electrophoresis was used to separate and analyse DNA fragments based on their size and charge. To prepare a 1\% agarose gel, $1 \mathrm{~g}$ agarose was mixed with $100 \mathrm{~mL}$ of $1 \times$ TAE buffer. After heating the mixture to melt the agarose and cooling it down to $65^{\circ} \mathrm{C}, 0.5 \mu \mathrm{g} / \mu \mathrm{L}$ of ethidium bromide was added and the solution was poured onto the gel support. DNA samples were separated in 1X TAE buffer at $120 \mathrm{~V}$. DNA bands were visualized at $312 \mathrm{~nm}$ in the GelDoc XR imaging system (Biorad). Fragment size was estimated using DNA standard markers (see 2.4). 


\subsubsection{RNA isolation from cells and engineered tissues}

Isolation of total RNA from cultured cells was performed using the RNeasy Mini Kit (Qiagen) according to the manufacturer's instructions.

For isolation of RNA from engineered tissues, the phenol-chloroform method was used. For this, $1 \mathrm{~mL}$ TriFast $^{\mathrm{TM}}$ (peqGOLD) was added per tissue and incubated at $4^{\circ} \mathrm{C}$ overnight to dissolve the collagen hydrogel. The following day, remaining pieces of tissue were mechanically dissociated by vigorous pipetting and subsequent RNA isolation as per the manufacturer's protocol. To further clean up the RNA, the cleanup protocol of the RNeasy Mini Kit was used.

Isolated RNA was eluted in the appropriate amount of RNase-free $\mathrm{H}_{2} \mathrm{O}$. Concentration and purity of isolated RNA was measured using spectrophotometric quantification by the NanodropTM ND-1000 system. RNA concentration was calculated as follows:

\section{RNA concentration $(\mu \mathrm{g} / \mathrm{mL})=A_{200} \times$ dilution factor $\times 40 \mu \mathrm{g} / \mathrm{mL}$}

$A_{260}$ : Absorbance at $260 \mathrm{~nm}$

$\mathrm{A}_{260}$ of $1.0=40 \mu \mathrm{g} / \mathrm{ml}$ pure ssRNA

RNA had an $A_{260} / A_{280}$ ratio between of $1.9-2.1$. Samples were stored at $-80^{\circ} \mathrm{C}$ until required.

\subsubsection{Formaldehyde agarose gel electrophoresis}

Formaldehyde agarose gel electrophoresis was performed to verify the integrity of RNA samples. To prepare a $1.2 \%$ formaldehyde gel, $1.2 \mathrm{~g}$ agarose were mixed with $10 \mathrm{~mL}$ of $10 x \mathrm{FA}$ buffer and $100 \mathrm{~mL}$ of RNase-free $\mathrm{H}_{2} \mathrm{O}$. After heating the mixture to melt the agarose and cooling down to $65^{\circ} \mathrm{C}, 1.8 \mathrm{~mL}$ of $37 \%$ formaldehyde and $0.5 \mu \mathrm{g} / \mu \mathrm{L}$ Ethidium bromide were added. The solution was then poured onto the gel support. 
Prior to performing the electrophoresis, the gel was equilibrated in 1x FA gel running buffer for at least $30 \mathrm{~min}$. For RNA sample preparation, 1 volume of $5 x$ RNA loading buffer was mixed to 4 volumes of RNA sample. Before sample loading into the equilibrated gel, samples were incubated for $3-5 \mathrm{~min}$ at $65^{\circ} \mathrm{C}$ and then chilled on ice. RNA samples were separated in $1 \times$ FA gel running buffer at $120 \mathrm{~V}$ for at least $45 \mathrm{~min}$. RNA bands were visualized at $312 \mathrm{~nm}$ with the GelDoc XR imaging system (Biorad).

\subsection{6 cDNA synthesis}

Isolated RNA (see 3.4.4) was used to transcribe RNA into copyDNA (cDNA) using the RevertAid ${ }^{\mathrm{TM}}$ First Strand cDNA Synthesis kit (Fermentas) according to the manufacturer's instructions. All steps were performed on ice. The composition of the cDNA master mix and the reverse transcription protocol are outlined in Table 28. The cDNA samples were stored at $-80^{\circ} \mathrm{C}$.

Table 28: Composition of cDNA master mix and reverse transcription protocol

\begin{tabular}{|l|l|}
\hline Master mix components & Amount \\
\hline Template RNA & $150 \mathrm{ng}$ \\
\hline Oligo (dT) 18 primer & $1 \mu \mathrm{L}$ \\
\hline$\rightarrow$ Incubate at $65^{\circ} \mathrm{C}$ for $5 \mathrm{~min}$ & $4 \mu \mathrm{L}$ \\
\hline $5 x$ reaction buffer & $1 \mu \mathrm{L}$ \\
\hline RiboLock RNase inhibitor $(20 \mathrm{U} / \mu \mathrm{L})$ & $2 \mu \mathrm{L}$ \\
\hline $10 \mathrm{mM}$ dNTP mix & $1 \mu \mathrm{L}$ \\
\hline RevertAid M-MuLV RT $(200 \mathrm{U} / \mu \mathrm{L})$ & \\
\hline $\begin{array}{l}\rightarrow \text { incubate at } 42^{\circ} \mathrm{C} \text { for } 60 \mathrm{~min}, \text { terminate } \\
70^{\circ} \mathrm{C} \text { for } 5 \text { min }\end{array}$ \\
\hline
\end{tabular}

\subsubsection{Quantitative real-time polymerase chain reaction (qRT-PCR)}

Quantitative real-time PCR was used to simultaneously amplify and semi-quantify cDNA. Non-specific fluorescent dyes, such as the EvaGreen ${ }^{\circledR}$ dye (Solis Biodyne) The fluorescence measured after each elongation cycle is thus proportional to the 
amount of CDNA in the reaction. The normalized target gene expression level was calculated as follows using the comparative Ct method ( $\Delta \Delta$ ct method):

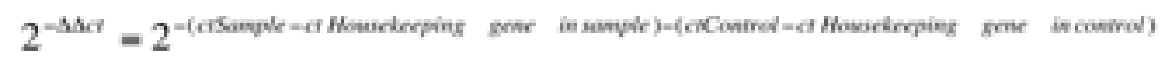

All measurements were performed in quadruplicates. The final reaction was mixed as shown in Table 29. The qRT-PCR program is shown in Table 30. The list of the qRTPCR primer sets can be found in 2.11 .

Table 29: Master mix for qRT-PCR per $1 \mu \mathrm{L}$ cDNA

\begin{tabular}{|l|l|}
\hline Reagent & Volume \\
\hline cDNA $(1: 40)$ & $1 \mu \mathrm{L}$ \\
\hline Primer for $(10 \mathrm{pmol} / \mu \mathrm{L})$ & $1 \mu \mathrm{L}$ \\
\hline Primer rev $(10 \mathrm{pmol} / \mu \mathrm{L})$ & $1 \mu \mathrm{L}$ \\
\hline Template DNA /Standard DNA (1:20) & $1 \mu \mathrm{L}$ \\
\hline RNase-free water & $13 \mu \mathrm{L}$ \\
\hline $5 x$ EvaGreen ${ }^{\circledast}$ dye & $4 \mu \mathrm{L}$ \\
\hline
\end{tabular}

Table 30: qRT-PCR cycling program

\begin{tabular}{|c|c|c|c|}
\hline Cycle & Temperature & Time & Number of Cycles \\
\hline Initial denaturation & $95^{\circ} \mathrm{C}$ & $15 \min$ & 1 \\
\hline Denaturation & $95^{\circ} \mathrm{C}$ & $15 \mathrm{~s}$ & \multirow{3}{*}{40} \\
\hline Annealing & $60^{\circ} \mathrm{C}$ & $20 \mathrm{~s}$ & \\
\hline Elongation & $72^{\circ} \mathrm{C}$ & $40 \mathrm{~s}$ & \\
\hline \multirow[t]{3}{*}{ Dissociation curve } & $95^{\circ} \mathrm{C}$ & $15 \mathrm{~s}$ & \multirow{3}{*}{1} \\
\hline & $60^{\circ} \mathrm{C}$ & $15 \mathrm{~s}$ & \\
\hline & $95^{\circ} \mathrm{C}$ & $15 \mathrm{~s}$ & \\
\hline
\end{tabular}

\subsection{Statistics}

Experimental data are presented as means \pm SEM. Data was analysed by 1-way or 2way ANOVA, with Bonferroni's post hoc multiple comparison test, or by unpaired t- 
test assuming normal distribution. Statistical calculations were performed utilising GraphPad Prism software (version 6). If $p<0.05$, significance was assumed. 


\section{Results}

\subsection{ROCK1 and ROCK2 regulate cardiac fibroblast morphology and adhesion}

\subsubsection{Selective knockdown of ROCK1 and ROCK2}

In order to study the role of ROCK1 and ROCK2 in cardiac fibroblasts further, primary neonatal cardiac fibroblasts from the rat (NRCF) were transfected with siRNAs.

A
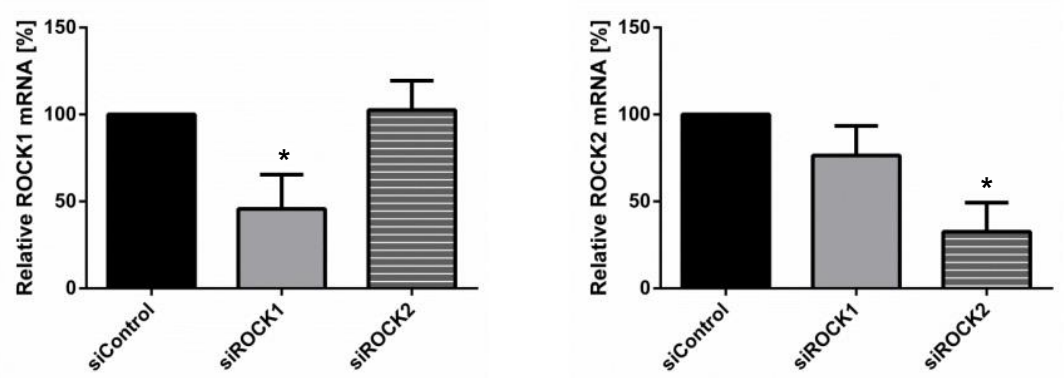

B
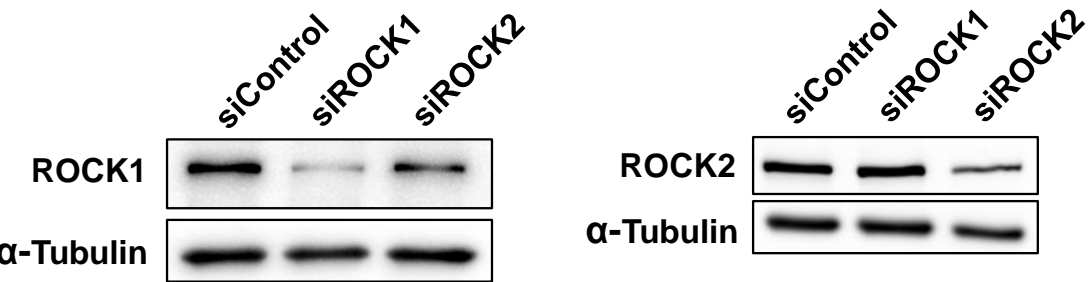

C
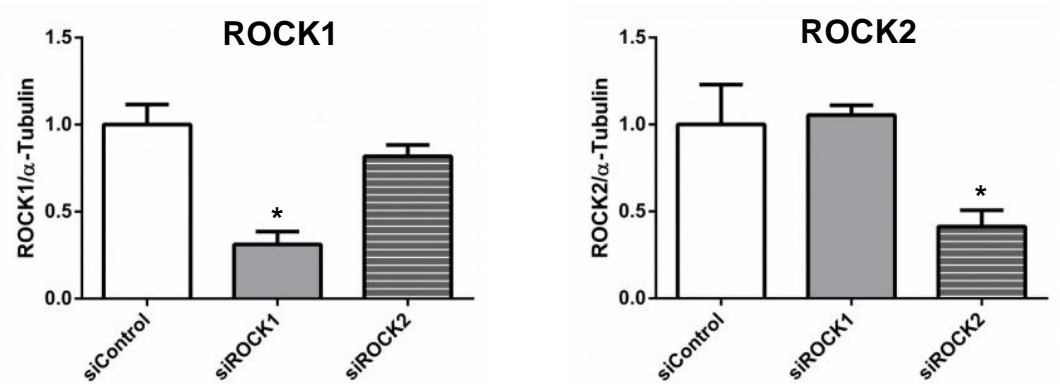

Figure 14: Validation of isoform-selective knockdown of ROCK1 and ROCK2 in NRCF.

(A) qPCR analysis of ROCK1 and ROCK2 mRNA in siROCK1 and siROCK2 compared to siControl NRCF are shown (means \pm SEM, $n=4,{ }^{*} p<0.05$, values were normalized to the mean of glucuronidase $\beta$, PBGD, and vimentin). (B) Representative immunoblots of ROCK1, ROCK2, and a-tubulin in siControl, siROCK1, and siROCK2 NRCF. (C) Quantification of the relative change in ROCK1 and ROCK2 protein expression in siROCK1 and SiROCK2 compared to siControl NRCF are shown (means $\pm S E M, n=6-8,{ }^{*} p<0.05$ ). 
As can be seen in Figure 14A, a selective downregulation of ROCK1 mRNA by about $50 \%$ and ROCK 2 mRNA by about $60 \%$ was achieved. Additionally, ROCK1 protein was reduced by $70 \%$ and ROCK2 protein by $60 \%$ (Figure 14B, C). NRCF transfected with siRNAs targeting ROCK1 and ROCK2 are referred to as siROCK1 and siROCK2, respectively.

\subsubsection{Downregulation and inhibition of ROCK1 and ROCK2 changes NRCF morphology}

As ROCK1 and ROCK2 are major regulators of the cytoskeleton in various cell types, the effect of ROCKs on NRCF morphology was evaluated. In Figure 15A representative fluorescent images of siControl, siROCK1, and siROCK2 NRCF are depicted. The downregulation of ROCK1 and ROCK2 was associated with changes in cardiac fibroblast morphology, as the area of NRCF was significantly increased 1.6-fold in siROCK1 and 2-fold in siROCK2 NRCF when the cells were attached (Figure 15B). Additionally, NRCF were treated with the non-selective ROCK inhibitors Fasudil and H1152P to inhibit ROCK activity. Also here, cell area was significantly increased 1.6-fold in Fasudil- and 1.7-fold in H1152P treated NRCF (Figure 15C). 
A
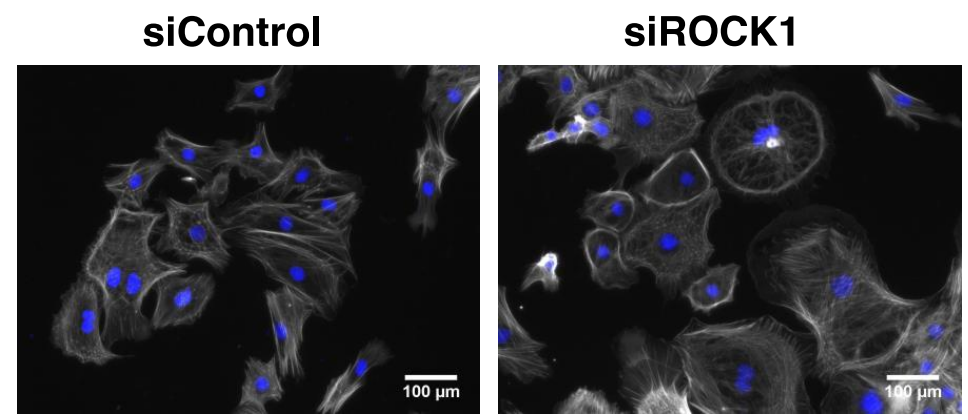

siROCK2

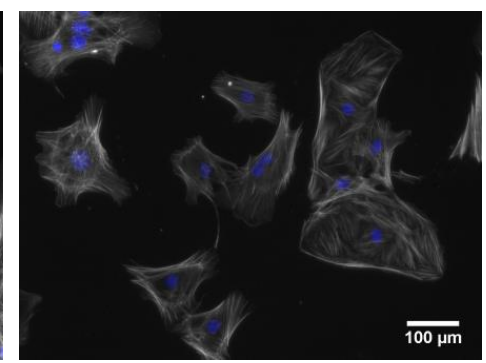

B

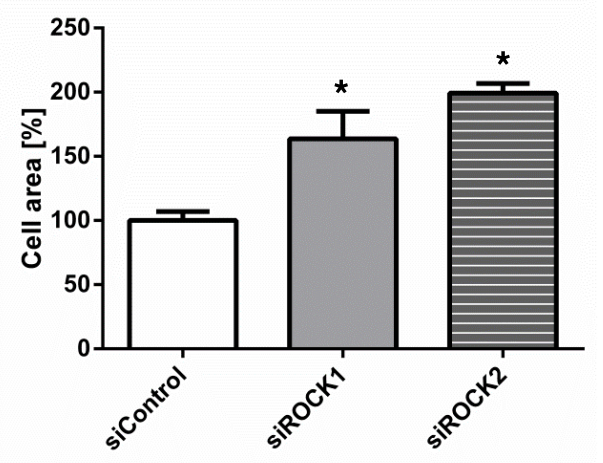

C

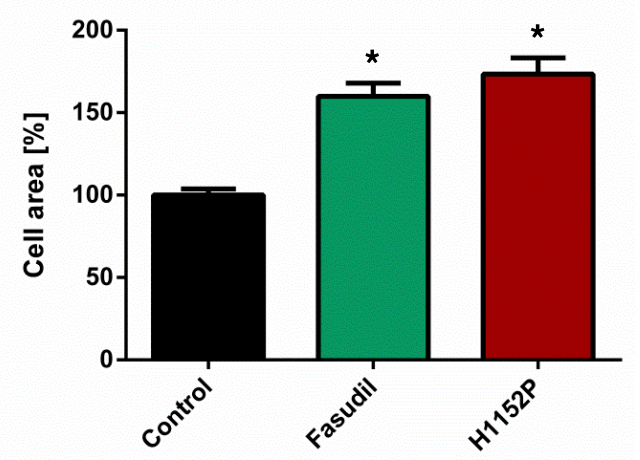

Figure 15: Evaluation of cell morphological changes.

(A) Fluorescence staining of f-actin with phalloidin (grey) and cell nuclei with DAPI (blue) in siControl, siROCK1, and siROCK2 NRCF. Relative cell area of (B) siROCK1 and siROCK2 compared to siControl NRCF (means \pm SEM, $n=3-5,{ }^{*} p<0.05,>50$ cells each) and (C) Fasudil- $(10 \mu \mathrm{M})$ and H1152P-treated $(3 \mu \mathrm{M})$ compared to control NRCF is shown (means $\pm \mathrm{SEM}, \mathrm{n}=3,{ }^{*} \mathrm{p}<0.05,>50$ cells each).

In addition, the organisation and formation of the actin cytoskeleton was found to be disturbed in NRCF with a downregulation of ROCK1 and of both kinases. Higher order actin structures, including geodesic domes and partially geodesic structures were reduced in shROCK1 and shROCK1/2 cells, whereas star-shaped actin bundles and cortical actin structures were increasingly present (Figure 16A, B). The observed change in NRCF morphology was most prominent in NRCF with a downregulation of ROCKs which was achieved by lentiviral delivery of shRNAs. Geodesic dome actin structures were highly present in shscr cells (20\% of all cells), whereas in siRNA transfected or control NRCF only $2.5 \%$ or $5 \%$ of all cells showed geodesic structures (Figure 16C). This suggests that the high number of geodesic NRCF might be a result of the lentiviral transduction. 
A

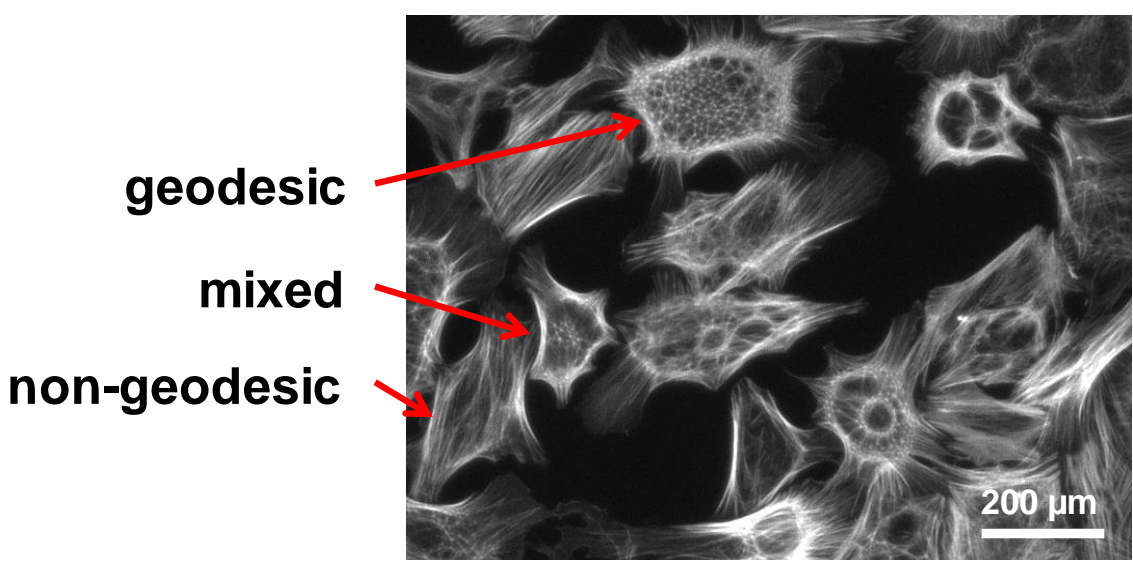

B

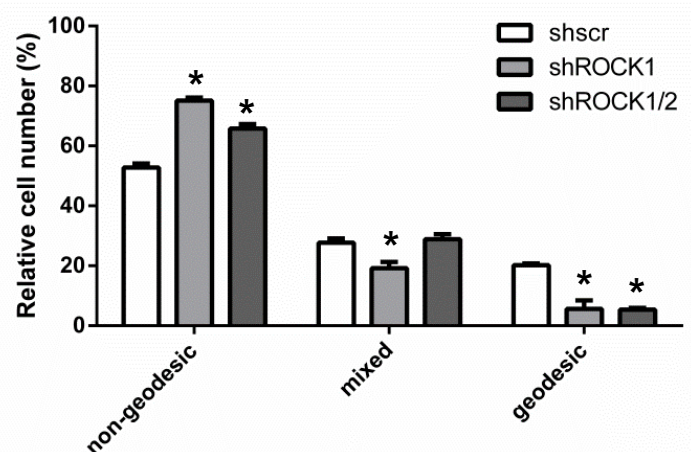

C

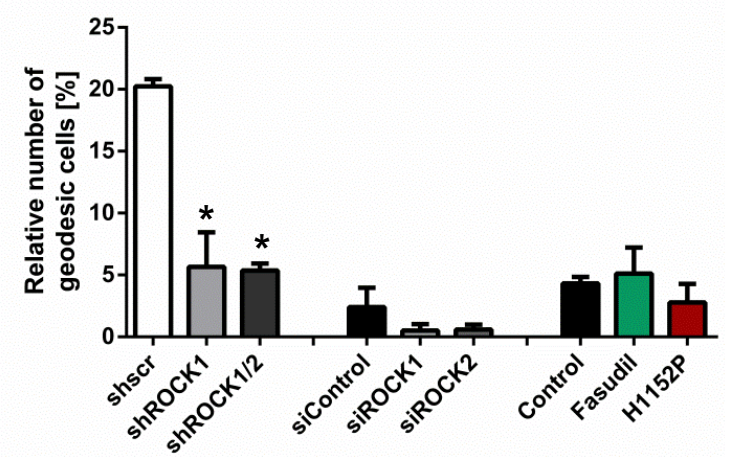

Figure 16: Analysis of geodesic f-actin structures in NRCF.

(A) Fluorescence staining of f-actin structures in NRCF showing geodesic, mixed, and nongeodesic cells. (B) The percentage of geodesic, mixed, and non-geodesic NRCF in shscr, shROCK1, and shROCK1/2 NRCF is shown. (C) Comparison of number of geodesic NRCF in lentivirus-mediated ROCK knockdown, siRNA-mediated ROCK knockdown, and NRCF treated with ROCK inhibitors Fasudil $(10 \mu \mathrm{M})$ and H1152P $(3 \mu \mathrm{M}$; means \pm SEM, $n=3$, ${ }^{*} \mathrm{p}<0.05,>50$ cells each).

Although a strong effect on NRCF morphology after downregulation of ROCKs could be seen, no change in the expression of cytoskeletal proteins, as for example $\beta$-actin, a-tubulin or aSMA, an important myofibroblast marker, could be detected by immunoblot analyses (Figure 17). 


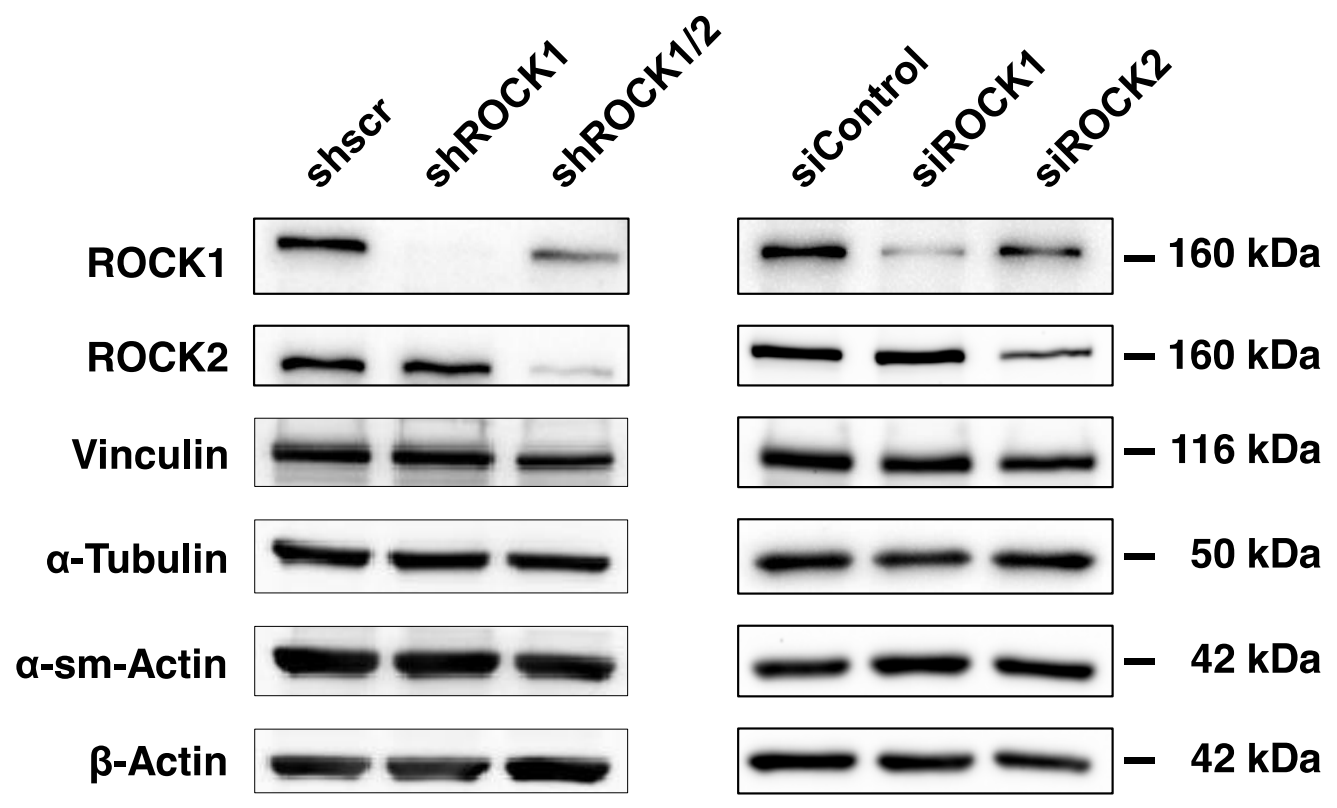

Figure 17: Expression of cytoskeletal proteins in ROCK knockdown NRCF.

Representative immunoblots of ROCK1, ROCK2, vinculin, $\alpha$-tubulin, $\alpha$-sm-actin, and $\beta$-actin in shROCK1 and shROCK1/2 compared to shscr, and in siROCK1 and siROCK2 compared to siControl NRCF are shown.

\subsubsection{ROCK knockdown reduces adhesion velocity and alters the size and amount of focal adhesion sites in NRCF}

To evaluate whether the morphological changes had an impact on adhesion of NRCF, a static adhesion assay was performed. The knockdown ROCK1 or ROCK2 significantly increased adhesion velocity to a normal cell culture surface (Figure 18A, left); however, no difference could be seen for adhesion to a collagen-coated surface (Figure 18A, right). Double knockdown of ROCK1 and ROCK2 did not have a cumulative effect on fibroblast adhesion (Figure 18B). 

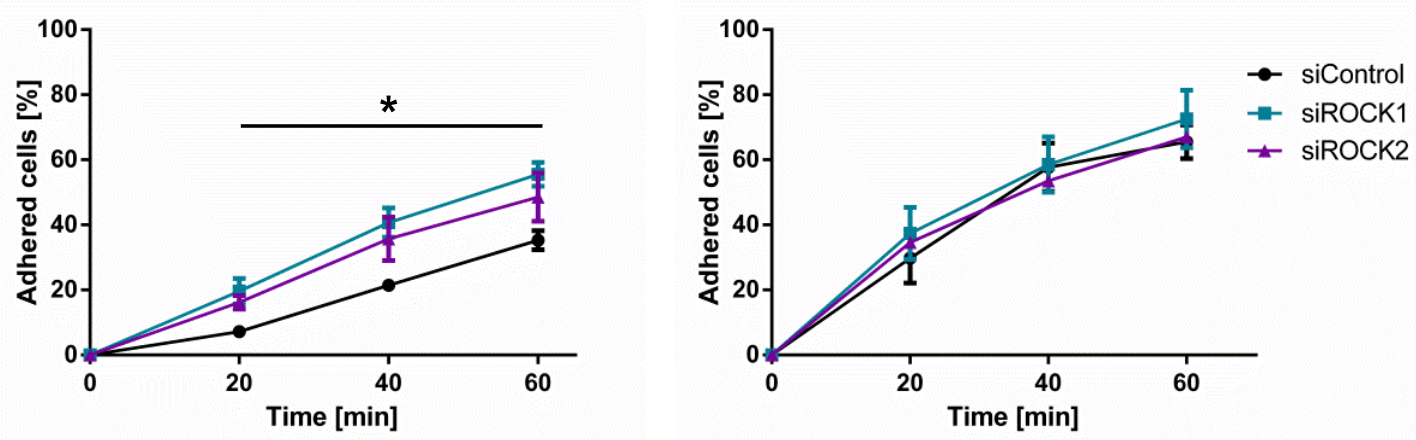

B

Cell culture surface

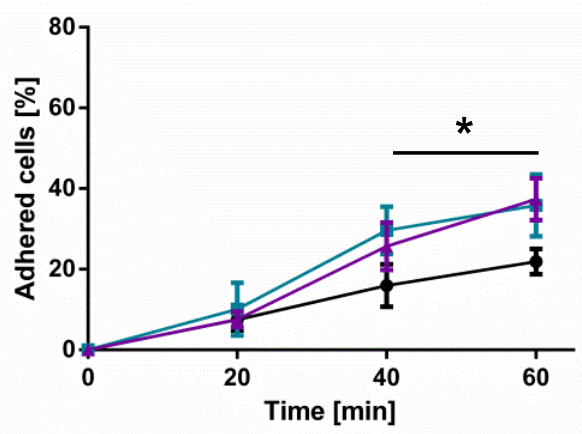

Collagen-coated suface

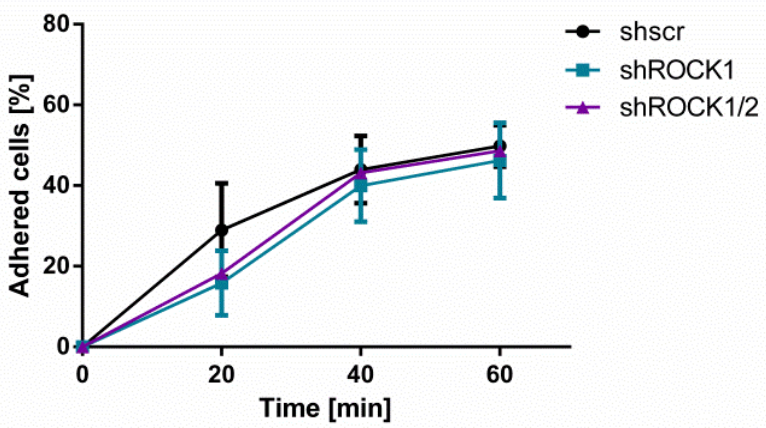

Figure 18: Analysis of adhesion velocity of ROCK knockdown NRCF.

Adhesion assay on a plastic tissue culture surface (left graphs) and on collagen (right graphs) over the time course of $1 \mathrm{~h}$. (A) Adherent siROCK1 and siROCK2 compared to siControl NRCF and (B) adherent shROCK1 and shROCK1/2 compared to shscr NRCF are shown (means \pm SEM, $n=3-5,{ }^{*} p<0.05, \%$ of total cells).

To evaluate this further, the number and size of focal adhesions (FAs) in siROCK1 and siROCK2 was compared to siControl NRCF using quantitative analysis of images with vinculin immunostaining. A representative processed image can be seen in Figure 19A. In accordance to the results of the static adhesion assay, the number of focal adhesion sites per cell was significantly increased by $163 \%$ in siROCK 1 and by $156 \%$ in siROCK2 NRCF compared to siControl (Figure 19B). Interestingly, the average size of a single FA in siROCK1 and siControl NRCF was the same, whereas siROCK2 NRCF formed 38\% smaller FAs (Figure 19C). In addition, the area of all FAs in one cell was significantly increased by $230 \%$ in siROCK1, and by $60 \%$ in siROCK2 NRCF compared to siControl (Figure 19D). 
A
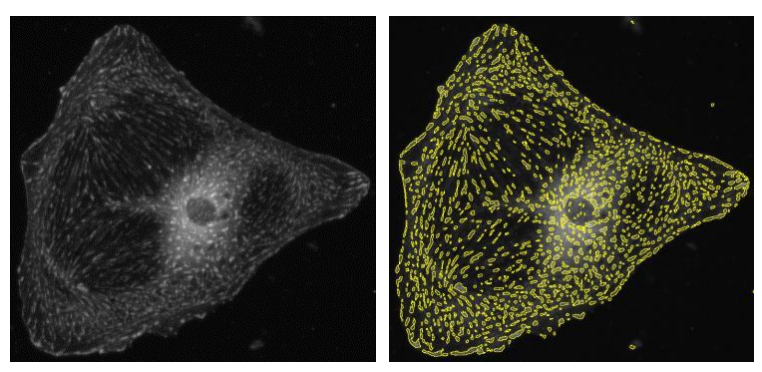

C

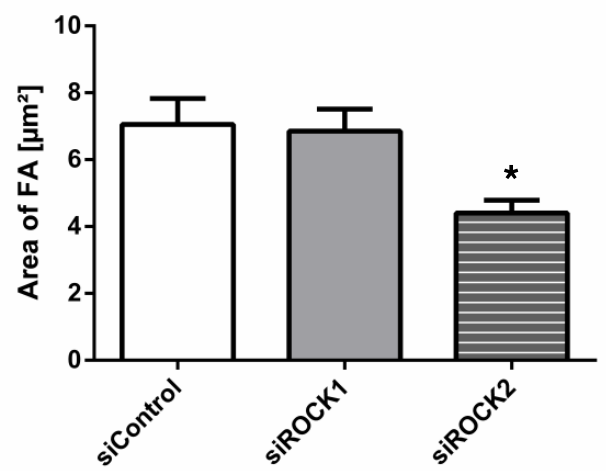

B

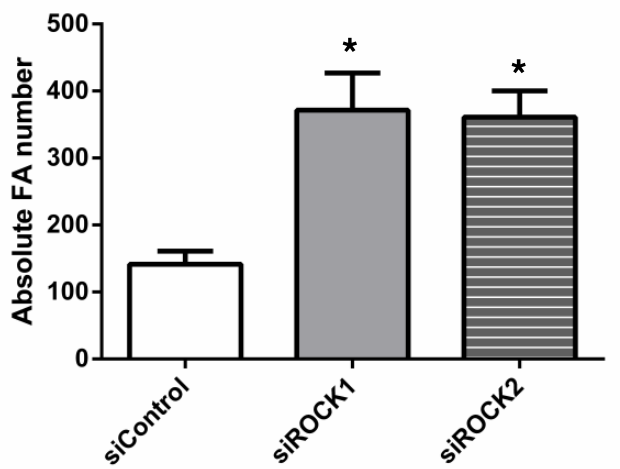

D

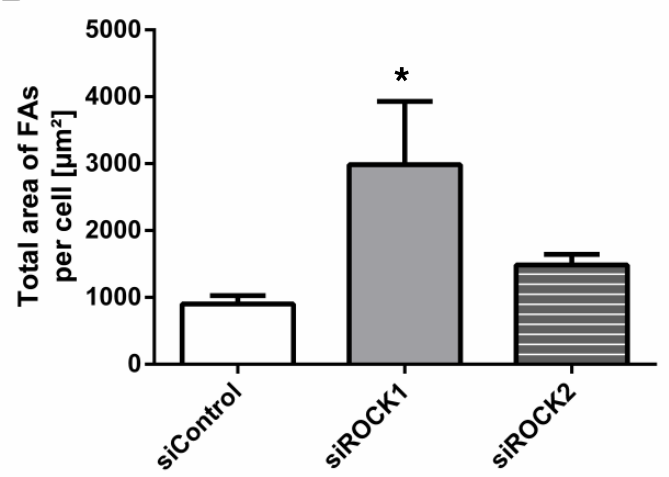

Figure 19: Evaluation of focal adhesion number and size in ROCK1 and ROCK2 knockdown NRCF.

(A) Representative image of a cell following image processing by ImageJ with detected FAs shown in yellow. Analysis of (B) total number of FAs identified per cell, (C) average size of a single FA, and (D) area of all FAs in one cell (means $\pm S E M, n=3,{ }^{*} p<0.05,10$ cells each).

\subsection{ROCK1 and ROCK2 regulate cardiac fibroblast migration}

\subsubsection{Knockdown and inhibition of ROCK1 and ROCK2 have contrasting effects on the migratory behaviour of NRCF on a plane surface}

In order to evaluate whether the changes in cardiac fibroblast morphology and adhesion also impact the migration behaviour of NRCF with a downregulation of ROCK1 and ROCK2, live cell experiments over a time course of $24 \mathrm{~h}$ were performed. The data shows that the knockdown of ROCK1 and ROCK2 decreased velocity of migration by $60 \%$ and $70 \%$, respectively (Figure $20 \mathrm{~A}$ ). Absolute migrated distance of NRCF was reduced by $55 \%$ in siROCK 1 NRCF and by $70 \%$ in siROCK2 NRCF compared to siControl (Figure 20B). Directionality of migration was unchanged (Figure 20C). Analysis of the migrated distance of siROCK1 and siROCK2 NRCF per 
hour showed, that cells migrated approximately the same distance each hour proving that the assay did not have a detrimental effect on the migration capacity (Figure 20D).

A

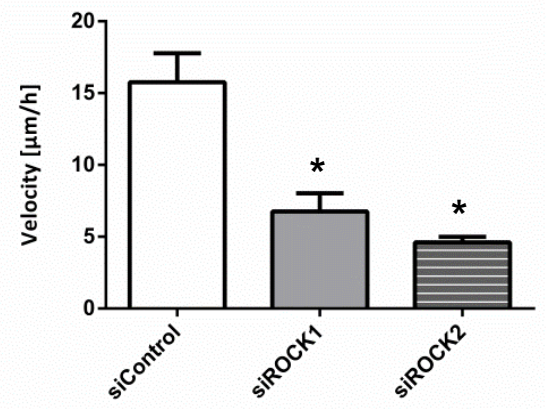

C

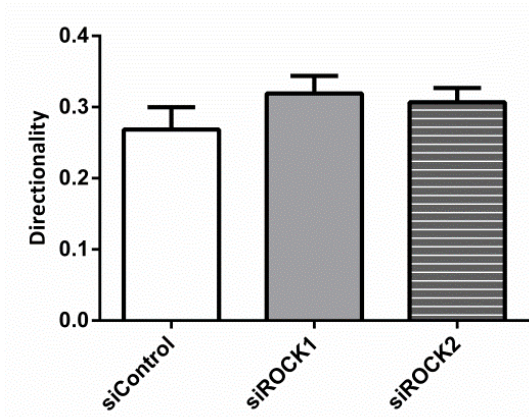

B

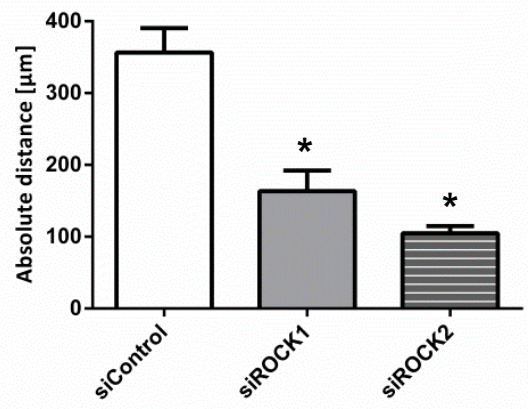

D

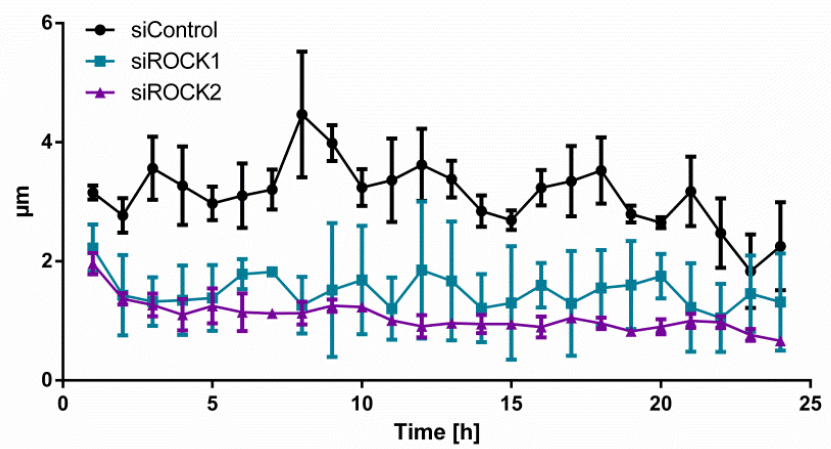

Figure 20: Analysis of migration of siRNA-mediated ROCK knockdown NRCF on a planar surface.

Migration of ROCK knockdown NRCF on a planar surface over the course of $24 \mathrm{~h}$. Bar graph summary of (A) average migration velocity, (B) directionality of migration, and (C) absolute migrated distance of siROCK1 and siROCK2 compared to siControl NRCF shown (means \pm SEM, $n=6,{ }^{*} p<0.05,>15$ cells each). (D) Migrated distance of siROCK1 and siROCK2 NRCF per hour compared to siControl NRCF (means \pm SEM, $n=3,{ }^{*} p<0.05$, $>15$ cells each).

Interestingly, knockdown of both kinases, as well as inhibition of ROCK activity using $\mathrm{H} 1152 \mathrm{P}$ had a contrasting effect on the migratory behaviour of NRCF. Velocity of migration and absolute migrated distance of NRCF were both significantly increased by about $80 \%$ in shROCK $1 / 2$ NRCF compared to shscr. An effect of the lentivirus on NRCF can be excluded, as a trend towards a decreased migration velocity and distance could also be observed in shROCK1 NRCF (Figure 21A, B). Likewise, treatment with $3 \mu \mathrm{M} \mathrm{H} 1152 \mathrm{P}$ resulted in an increase in migration velocity and distance by about $160 \%$. Treatment with 10 -fold less inhibitor did not change NRCF 
migratory behaviour (Figure 21D, E). Moreover, both downregulation of ROCK1 and ROCK2, as well as inhibition of ROCK activity did not change directionality of migration (Figure 21C, F).

A

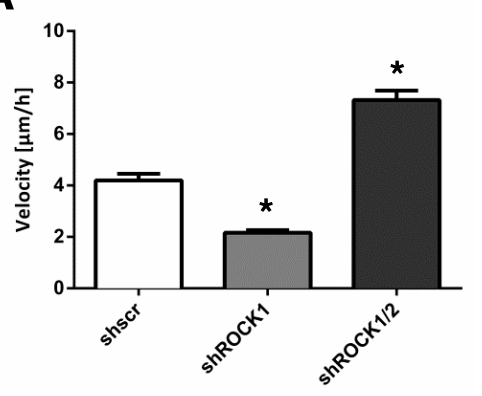

D

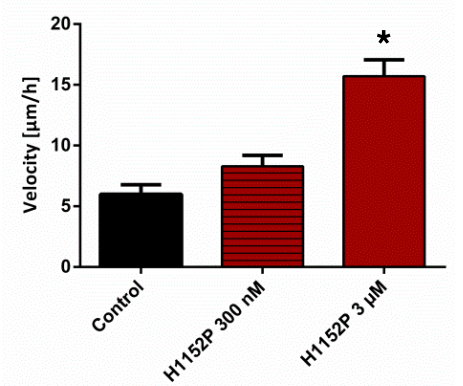

B

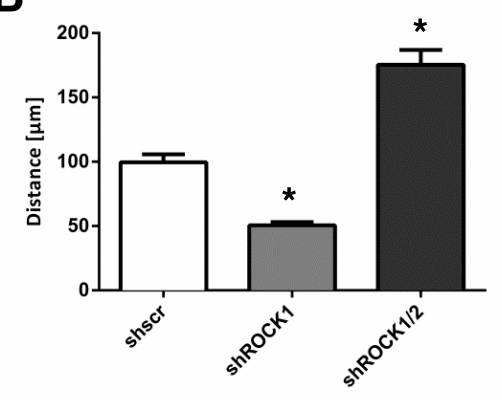

$\mathbf{E}$

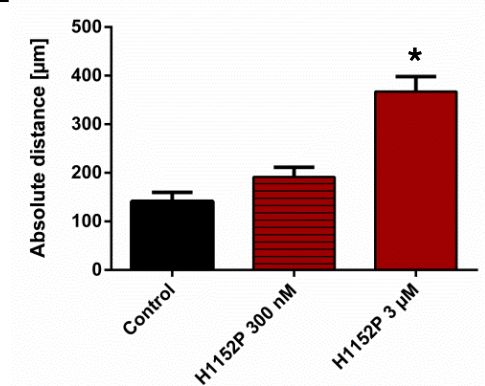

C

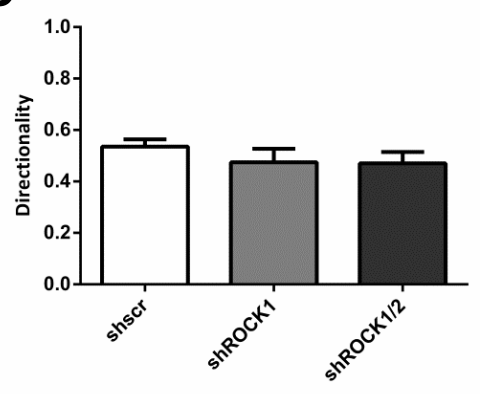

$\mathbf{F}$

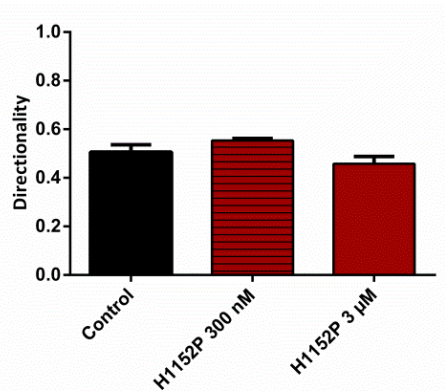

Figure 21: Evaluation of migration of lentivirus-mediated ROCK knockdown NRCF and NRCF treated with ROCK inhibitor.

Migration of NRCF on a planar surface over the course of $24 \mathrm{~h}$. Bar graph summary of (A) average migration velocity, (B) absolute migrated distance, and (C) directionality of migration of shROCK1 and shROCK $1 / 2$ compared to shscr NRCF is shown (means \pm SEM, $n=3$, ${ }^{*} p<0.05,>15$ cells each). Bar graph summary of (D) average migration velocity, (E) absolute migrated distance, and (F) directionality of migration of NRCF treated with ROCK inhibitor $\mathrm{H} 1152 \mathrm{P}$ ( $300 \mathrm{nM}$ and $3 \mu \mathrm{M}$ ) compared to control NRCF is shown (means $\pm S E M, n=3-4$, ${ }^{*} \mathrm{p}<0.05,>15$ cells each).

In Figure 22, representative bright field images of the differently treated NRCF during the live cell experiment are shown. As can be seen in Figure 22B and C, shROCK1/2 NRCF, as well as NRCF treated with $3 \mu \mathrm{M} \mathrm{H1152P} \mathrm{showed} \mathrm{a} \mathrm{highly} \mathrm{collapsed} \mathrm{cell}$ shape, which stayed constant over time. This could not be observed in NRCF with a siRNA-induced knockdown (Figure 22A) or in the corresponding control cells. 
A

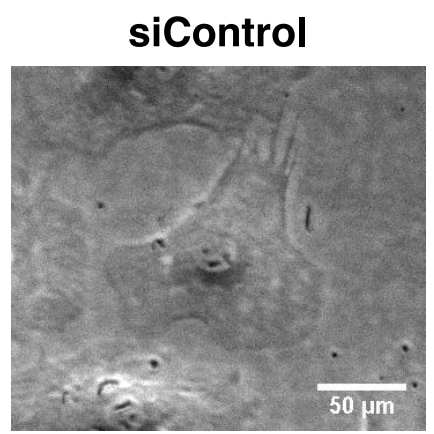

B

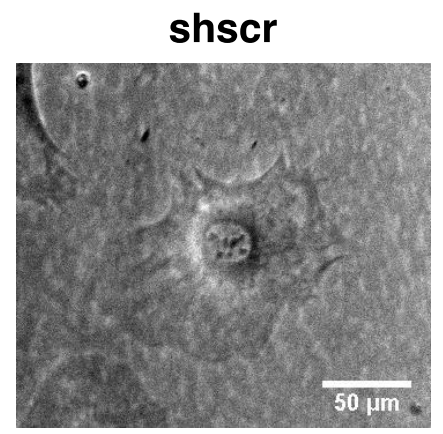

C

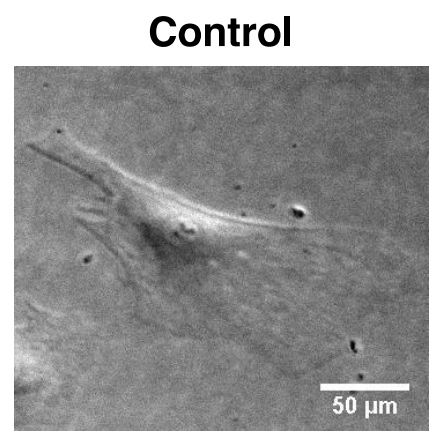

siROCK1

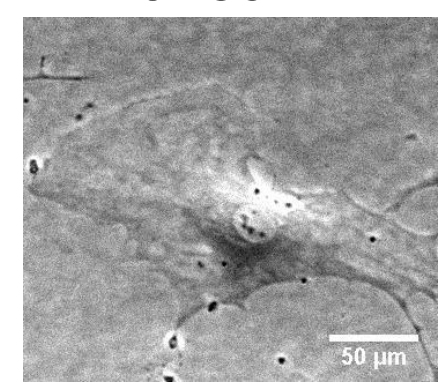

shROCK1

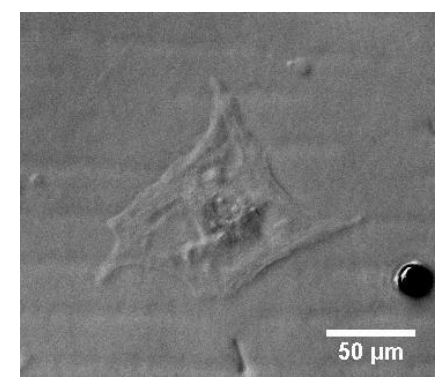

H1152P $300 \mathrm{nM}$

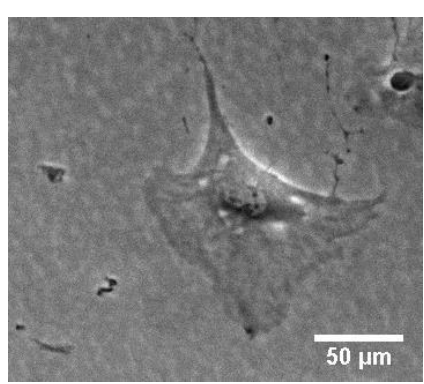

$8 \quad 10$
siROCK2

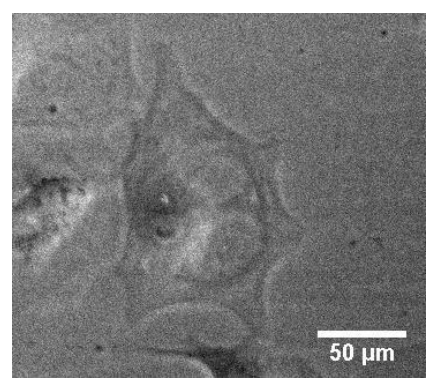

ShROCK $1 / 2$

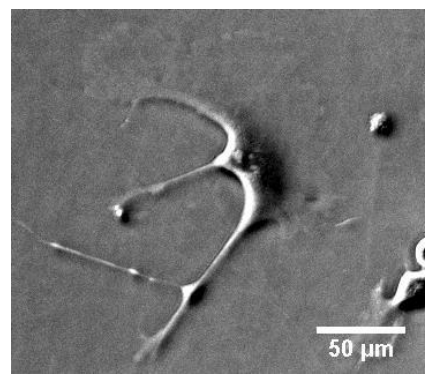

$\mathrm{H} 1152 \mathrm{P} 3 \mu \mathrm{M}$

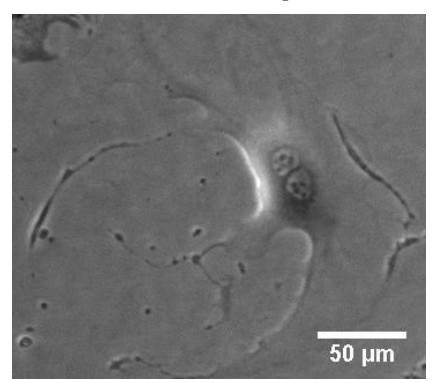

14

$1820 \mathrm{~h}$
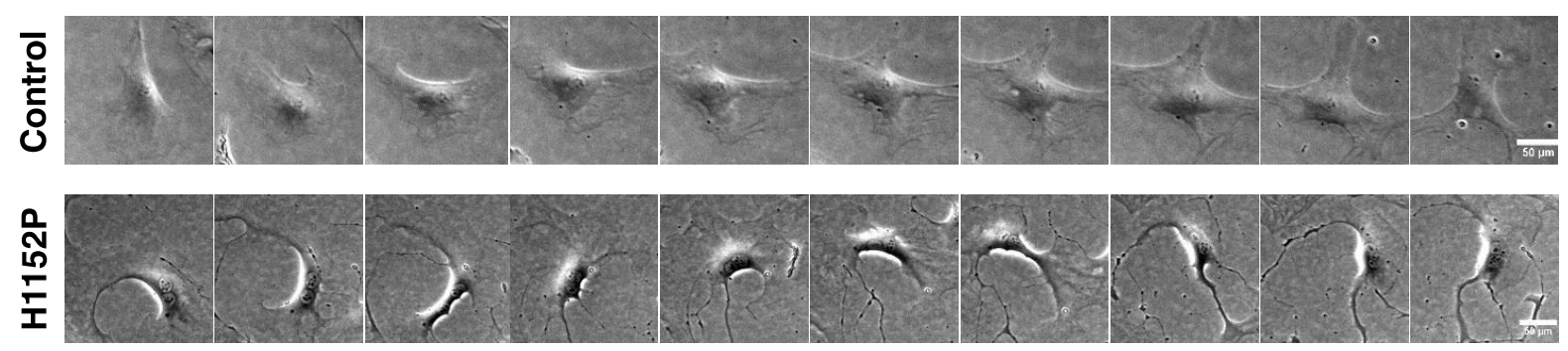

Figure 22: Bright-field images of ROCK knockdown NRCF and NRCF treated with ROCK inhibitor H1152P during migration.

Representative bright-field images of differently treated NRCF during migration on a planar surface. (A) siControl, siROCK1, and siROCK2 NRCF, (B) shscr, shROCK1, and shROCK1/2 NRCF, and (C) control NRCF and those treated with either $300 \mathrm{nM}$ or $3 \mu \mathrm{M}$ H1152P. (D) Representative bright field images of H1152P-treated and control NRCF during the live cell experiment are shown. 


\subsubsection{Downregulation of ROCK1 and ROCK2 impairs migration of NRCF in a transwell assay}

In the next step, the migration of NRCF through pores, as assessed by a transwell migration assay, was analysed. For this, NRCF were seeded on a porous membrane and the number of cells located inside the pores after $24 \mathrm{~h}$ was evaluated (Figure $23 \mathrm{~A})$. The experiments were performed with low serum (1\%) or with $10 \%$ serum as a migration stimulus. NRCF with a knockdown of both ROCK1 and ROCK2 showed a significantly reduced migratory performance of about $50 \%$ under low and high serum conditions when compared to shscr NRCF. Interestingly, shROCK1 cells showed only a trend towards a reduced migration under no serum conditions, but not under high serum conditions (Figure 23B).

A

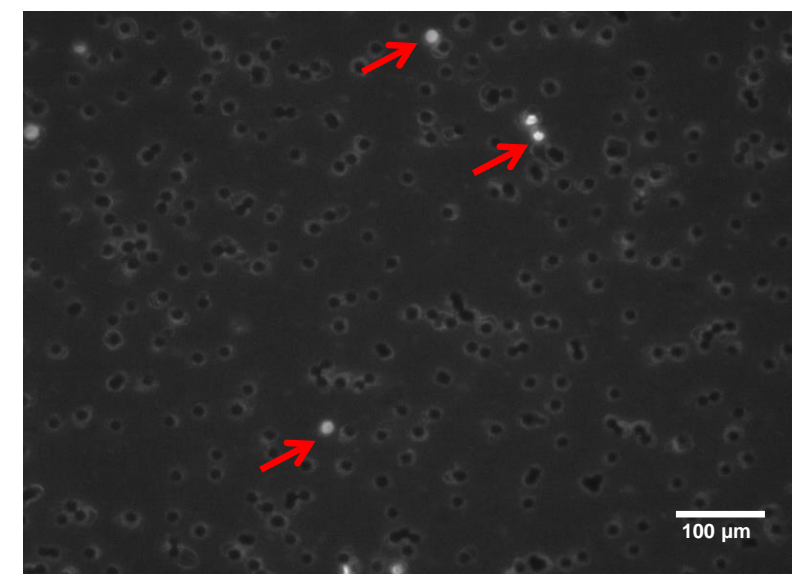

B

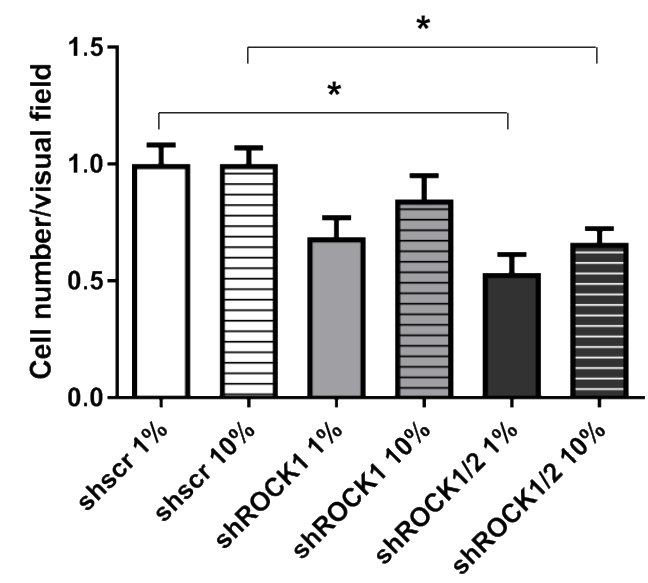

Figure 23: Analysis of transwell migration through a porous membrane.

Representative fluorescent image of a membrane with NRCF inside a porous membrane (pore size $8 \mu \mathrm{m}$ ) assessed by Hoechst staining (NRCF marked by red arrows). (B) Quantitative analysis of shROCK1 and shROCK $1 / 2$ compared to shscr NRCF migrating through a porous membrane in the presence of low serum (1\%) and high serum $(10 \%)$ is shown. The relative number of cells is given (means $\pm S E M, n=7,{ }^{*} p<0.05$ ).

\subsection{ROCK1 and ROCK2 activity is needed for cardiac fibroblast proliferation}

To further establish the important role of ROCK1 and ROCK2 in the fibroblastmyofibroblast transition, the proliferative capacity of cardiac fibroblasts after ROCK knockdown or inhibition of ROCK activity over the time course of six days was 
analysed. Interestingly, only the knockdown of both kinases (see Figure 6), as well as the general inhibition of ROCK activity by H1152P (Figure 24B) stopped proliferation of NRCF, whereas downregulation of either ROCK1 or ROCK2 did not have an effect on proliferation capacity (Figure 24A). This suggests that proliferation of cardiac fibroblasts is dependent both ROCK1 and ROCK2, or that they can compensate for each other.

A

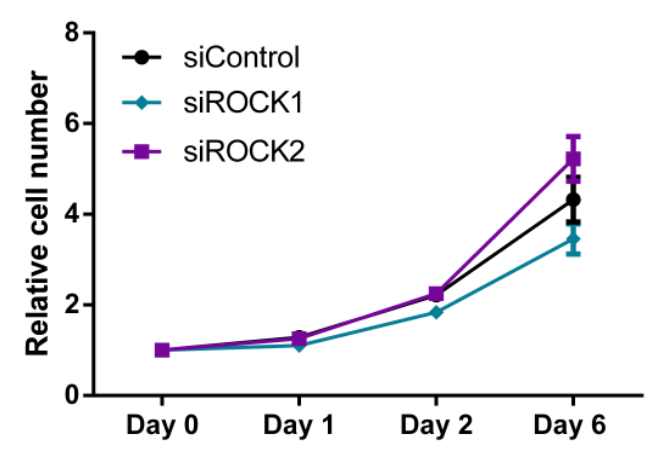

B

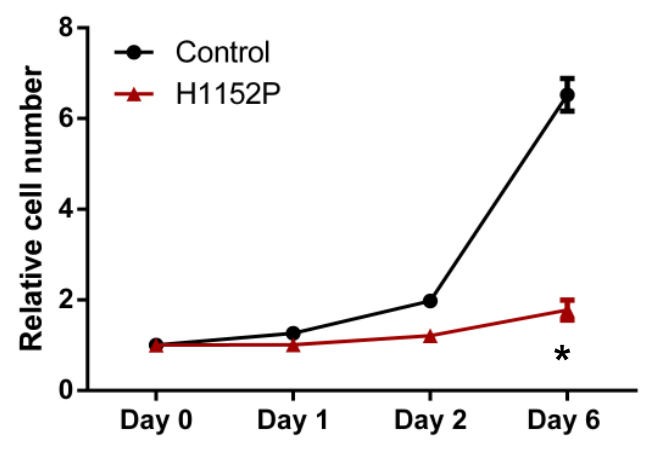

Figure 24: Analysis of proliferation of ROCK knockdown NRCF and NRCF treated with ROCK inhibitor.

(A) Proliferation assay of siROCK1 and siROCK2 compared to siControl NRCF over the time course of six days (means $\pm S E M, n=5$, measured in 4 technical replicates/experiment). (B) Proliferation assay of control NRCF treated with H1152P $(3 \mu \mathrm{M})$ over a time course of 6 days (means $\pm S E M, n=4$, measured in 4 technical replicates/experiment, ${ }^{*} p<0.05$ ).

The cause for the diminished proliferation was investigated further and fluorescent analysis of NRCF revealed that H1152P-treated fibroblasts were mostly doublenucleated ( $66 \%$ double-nucleated vs. $34 \%$ single-nucleated), whereas control cells displayed predominantly one nucleus (14\% double-nucleated vs. $86 \%$ singlenucleated; Figure 25B). Moreover, in live cell experiments it was shown that $\mathrm{H} 1152 \mathrm{P}$ treatment led to a cytokinesis defect in NRCF. Rather than dividing into two daughter cells, H1152P-treated NRCF failed to divide, which resulted in a higher percentage of double-nucleated cells as compared to control (59\% vs. $18 \%$ double-nucleated in H1152P-treated NRCF vs. control; Figure 25C, D). 
A

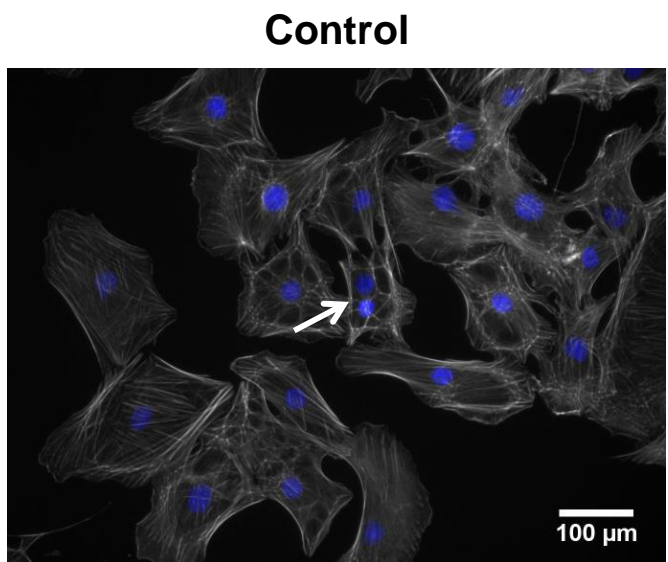

B

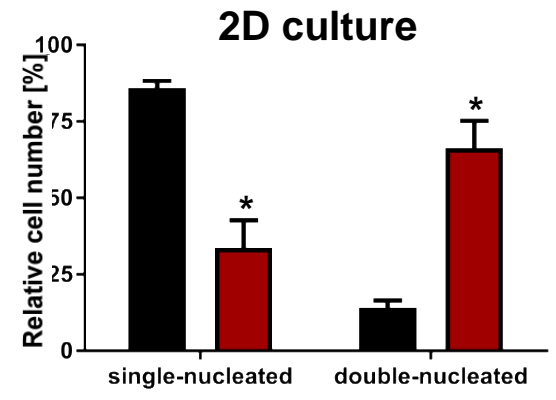

C
H1152P
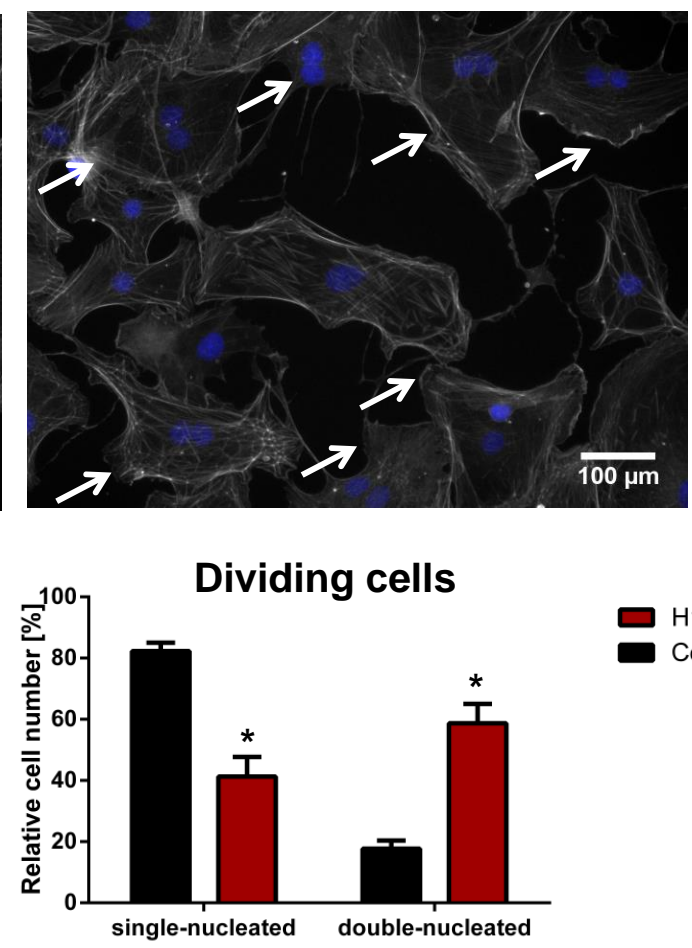

D
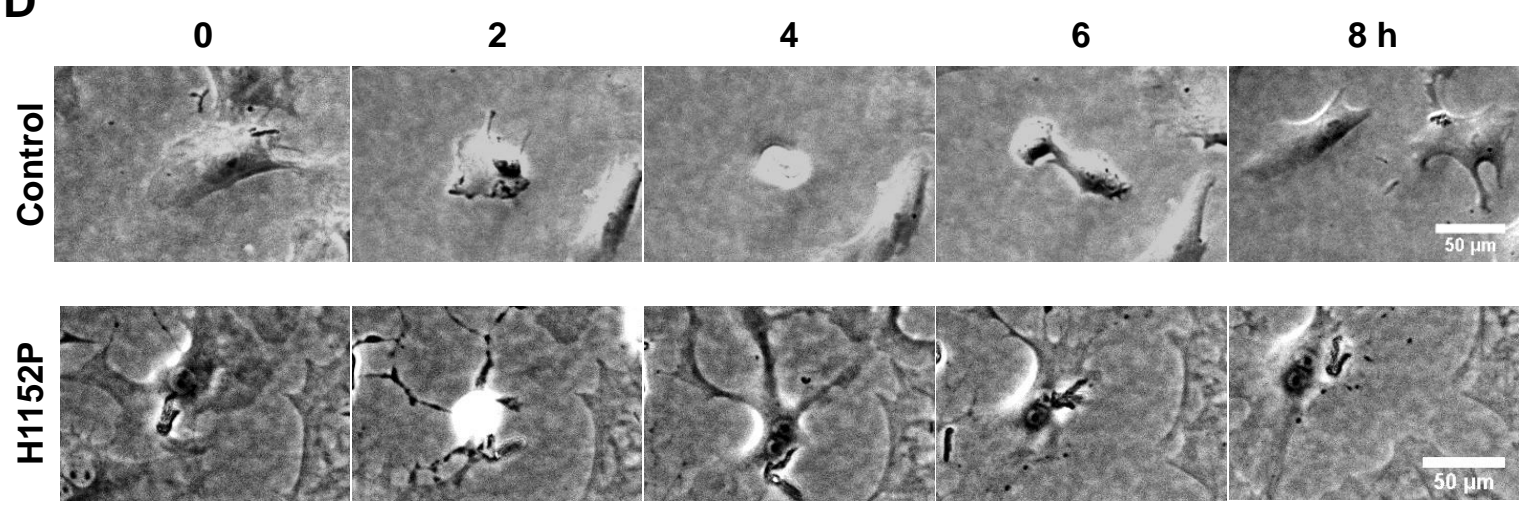

E

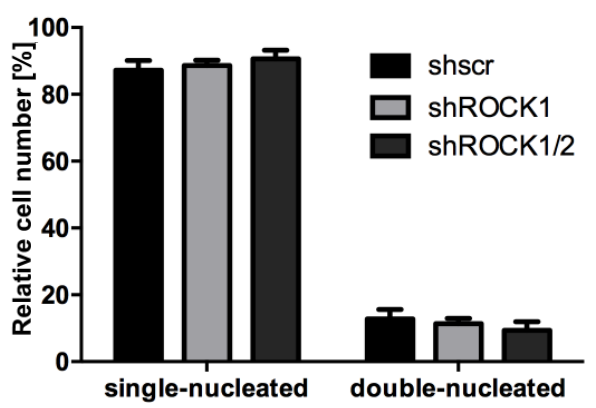

Figure 25: Analysis of single- and double-nucleated NRCF after treatment with ROCK inhibitor H1152P.

(A) Representative fluorescent stainings of f-actin by phalloidon (red) and cell nuclei by DAPI (blue) of control and NRCF treated with H1152P $(3 \mu \mathrm{M})$. Double-nucleated cells are marked by a white arrow. (B) Bar graph summary showing the relative number of single- or doublenucleated cells in a two-dimensional culture of NRCF treated with H1152P (means \pm SEM, 
$\mathrm{n}=3,>150$ cells each, * $\mathrm{p}<0.05$ vs. control). (C) NRCF were treated with $\mathrm{H} 1152 \mathrm{P}(3 \mu \mathrm{M})$ and live cell imaging over the time course of $24 \mathrm{~h}$ was performed. Shown is the relative number of cells that divided into two single-nucleated daughter cells or that failed to divide resulting in a double-nucleated cell (means $\pm S E M, n=3,{ }^{*} p<0.05$ vs. control). (D) Representative images of control and H1152P-treated NRCF undergoing cell division during live cell imaging are shown. (E) Bar graph summary showing the relative number of single- or double-nucleated shROCK1, shROCK1/2, and shscr NRCF (means \pm SEM, $n=3,>150$ cells each, * $p<0.05$ vs. shscr).

\subsection{ROCK1 and ROCK2 influence the regulation and turnover of the ECM and viscoelastic properties in engineered connective tissues from rat and human cardiac fibroblasts}

\subsubsection{Inhibition of ROCK activity impairs the consolidation of hECT and decreases hECT stiffness}

Another characteristic of myofibroblasts is their altered gene expression profile and increased secretory behaviour when compared to quiescent cardiac fibroblasts. In order to study the functional role of cardiac fibroblasts in a more physiological model than a 2D culture, engineered connective tissue (ECT) consisting of cardiac fibroblasts and collagen I as a hydrogel were used. In preliminary experiments, the influence of ROCK1 and ROCK2 signalling on ECT consisting of NRCF (rECT) was analysed (see 2.10). In the following experiment, this should also be demonstrated in the human model using human cardiac fibroblasts (NHCF-V). Therefore, we generated $\mathrm{hECT}$ from an initially liquid mixture composed of NHCF-V and collagen type I and treated them with the non-selective ROCK inhibitors Fasudil and H1152P. In Figure 26A, representative images of the hECT are depicted. Both Fasudil- and H1152P-treated hECT were less consolidated after five days in culture with an increase in cross-sectional area (CSA) of $45 \%$ in Fasudil- and of $120 \%$ in H1152Ptreated hECT compared to control (Figure 26B). 


\section{A}

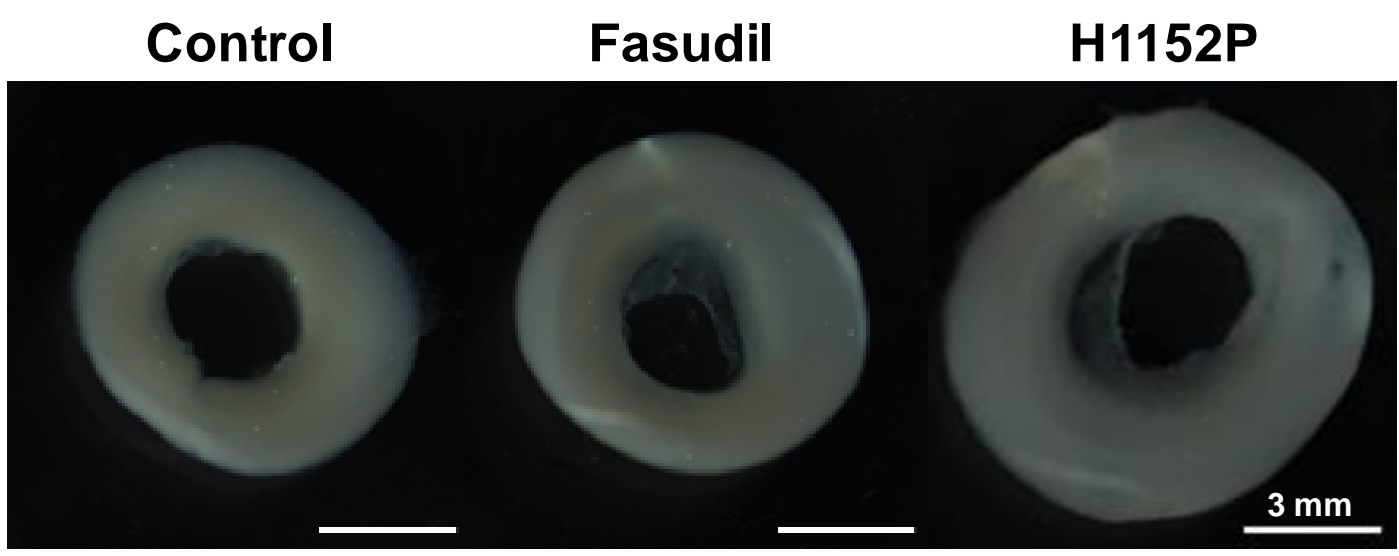

B

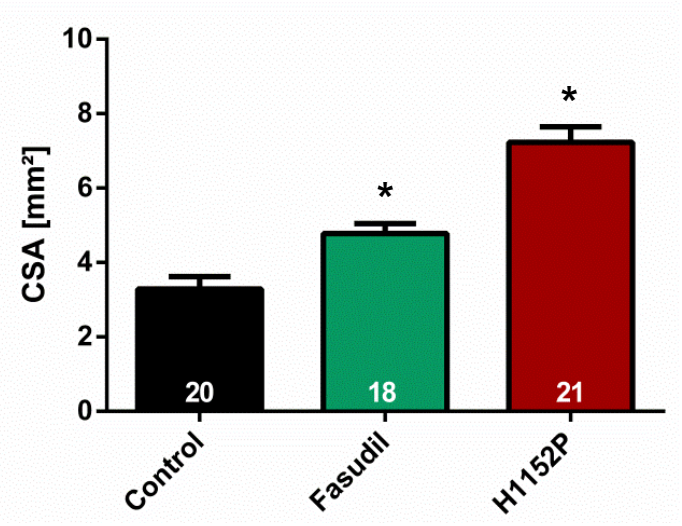

Figure 26: Treatment with ROCK inhibitors increased the cross-sectional area (CSA) of human engineered connective tissue (hECT).

(A) Representative images of control, Fasudil- $(10 \mu \mathrm{M})$ and H1152P-treated $(3 \mu \mathrm{M}) \mathrm{hECT}$ composed of normal human cardiac fibroblasts from the ventricle (NHCF-V). (B) Differences in calculated CSA of the different $h E C T$ are shown (means $\pm S E M, n=5,{ }^{*} p<0.05$ vs. control, values illustrate numbers of $\mathrm{hECT}$ measured).

To define viscoelastic properties of the hECT, rheological destructive tensile strength measurement was performed. In Figure 27A, a typical stress-strain curve as a result of these measurements including important parameters is depicted. Representative stress-strain curves of control, Fasudil-, and H1152P-treated hECT can be seen in Figure 27B. Similar to rECT, hECT showed a flatter curve shape than control tissues. 
A

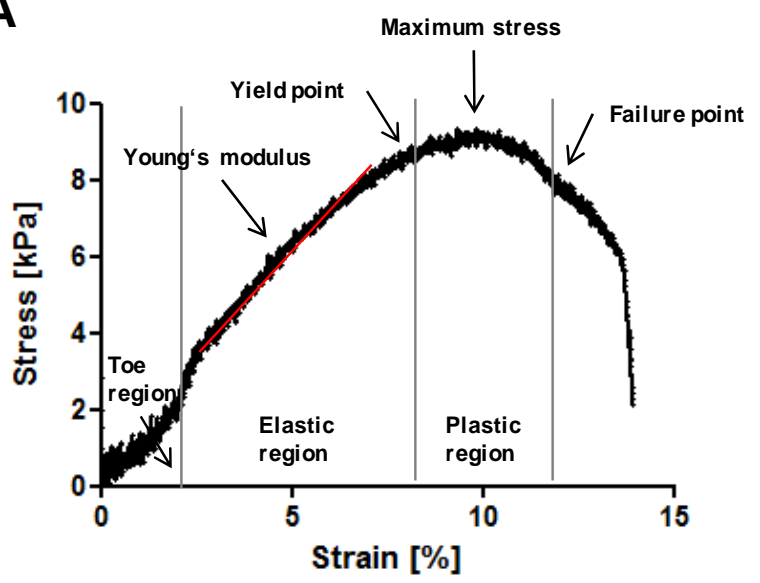

B

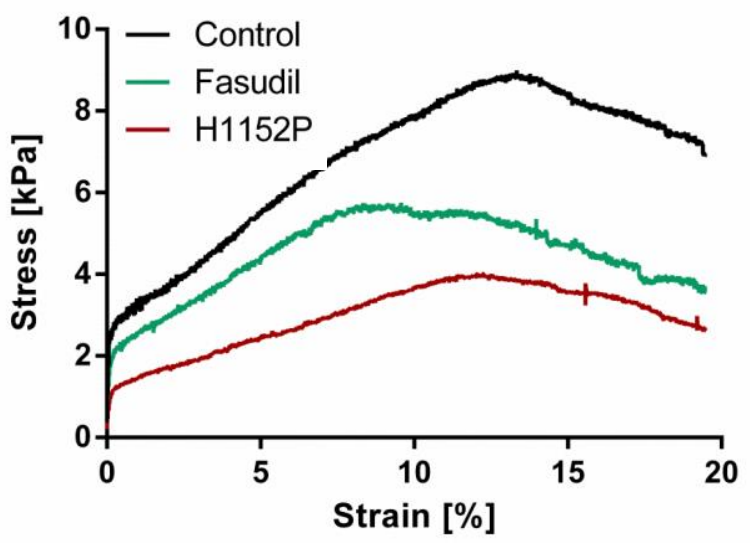

Figure 27: Stress-strain curves of rheological destructive tensile strength measurements.

(A) Representative stress-strain curve of a cellular collagen hydrogel as a result of rheological destructive tensile strength measurement highlighting important parameters. (B) Representative stress-strain curves of control, Fasudil- $(10 \mu \mathrm{M})$ and $\mathrm{H} 1152 \mathrm{P}$-treated $(3 \mu \mathrm{M})$ hECT during a rheological destructive tensile strength measurement.

Measurements revealed that stiffness of the hECT as defined by the Young's modulus was significantly reduced by $30 \%$ in Fasudil- and by about $50 \%$ in $\mathrm{H} 1152 \mathrm{P}$ treated tissues compared to control (Figure 28A). Moreover, ROCK inhibitor-treated tissues tolerated less maximal stress than control tissues (Figure 28B) with a decrease of $35 \%$ in Fasudil- and 55\% in H1152P-treated hECT. In addition, more ultimate stress was needed until microfractures in the tissues occurred (Yield point), as the stress value at the yield point was decreased by $40 \%$ in Fasudil- and by $55 \%$ in H1152P-treated hECT (Figure 28C, left). Likewise, rupture of the tissue (Failure point) after ROCK inhibition occurred at a lower stress value compared to control, which was decreased by $30 \%$ in Fasudil- and by $50 \%$ in H1152P-treated hECT (Figure 28D, left). However, there was no significant difference found regarding strain values at the yield and failure point, meaning the ROCK inhibitor-treated hECT were torn apart the same length as control tissues when they experienced microfractures or ruptured (Figure 28C, D right). 
A

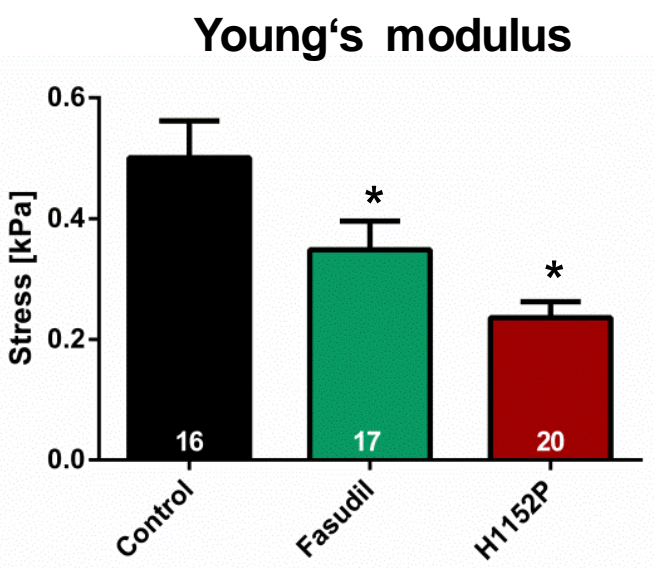

B

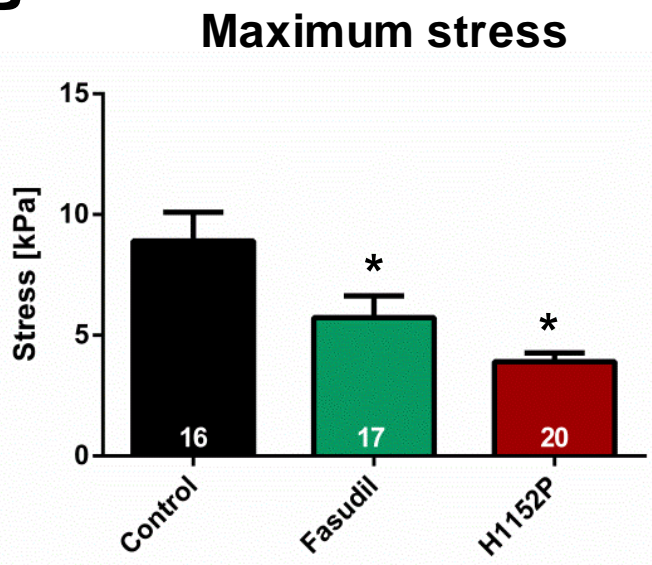

C

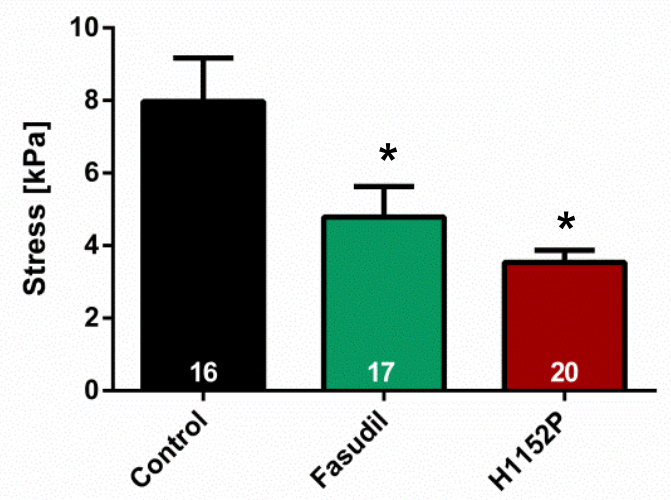

Yield point

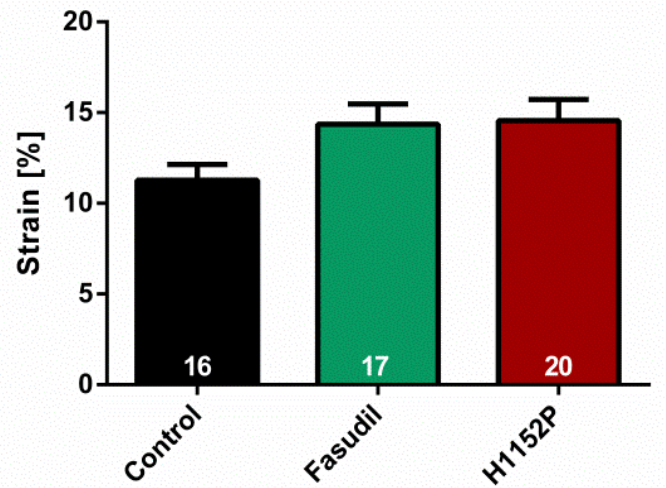

D

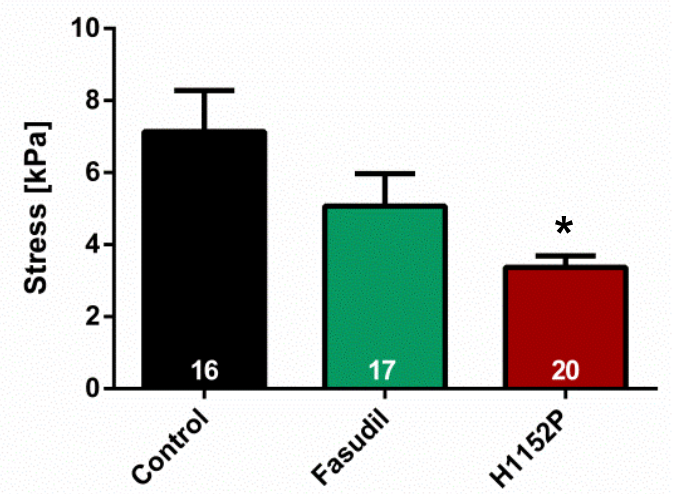

Failure point

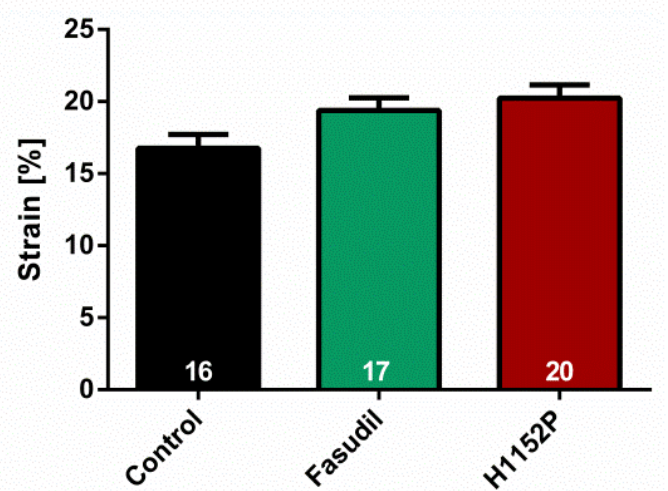

Figure 28: Analysis of the viscoelastic properties of control, Fasudil-, and H1152Ptreated hECT.

Changes in (A) the Young's modulus, (B) maximum stress value, (C) stress (left) and strain value (right) at the yield point, and (D) stress (left) and strain value (right) at the failure point are depicted (means \pm SEM, $n=5,{ }^{*} p<0.05$ vs. control, values illustrate numbers of $h E C T$ measured). 


\subsubsection{ROCK inhibition influences the cell cycle, but not proliferation of NRCF in $\mathrm{rECT}$}

To evaluate changes that occur in response to ROCK inhibition in ECT further, the experiments were continued using ECT from NRCF ( $\mathrm{rECT}$ ) due to feasibility reasons. Re-isolation of NRCF by collagenase/accutase digestion of rECT revealed that the cell number in the ROCK inhibitor-treated rECT were the same as in control tissues, excluding that the observed changes were due to excessive cell proliferation or cell death as a reason for the observed decrease in tissue stiffness (Figure 29A).

A

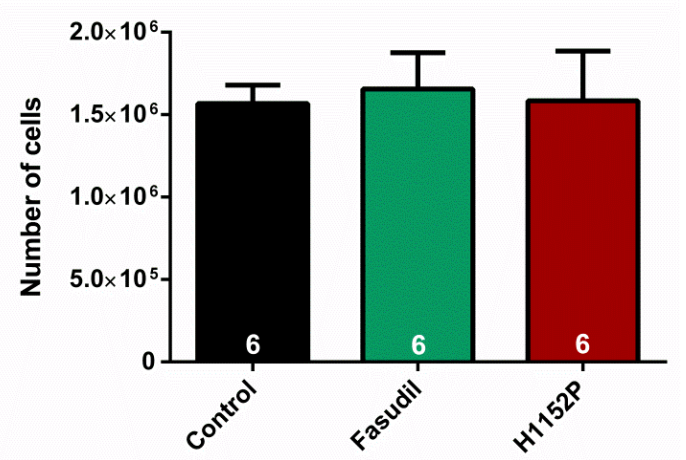

C

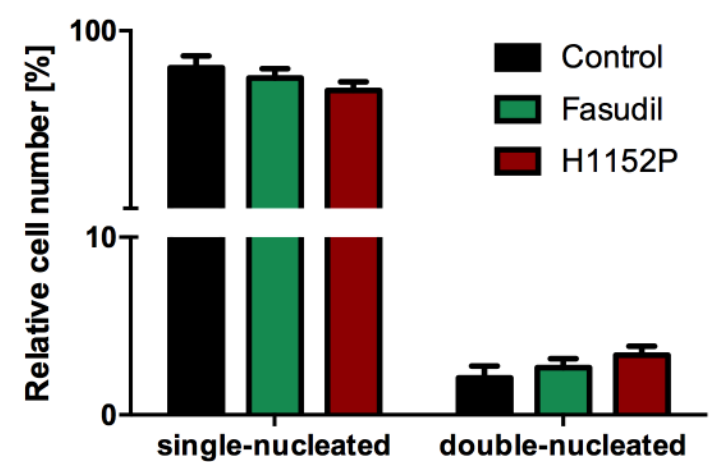

B

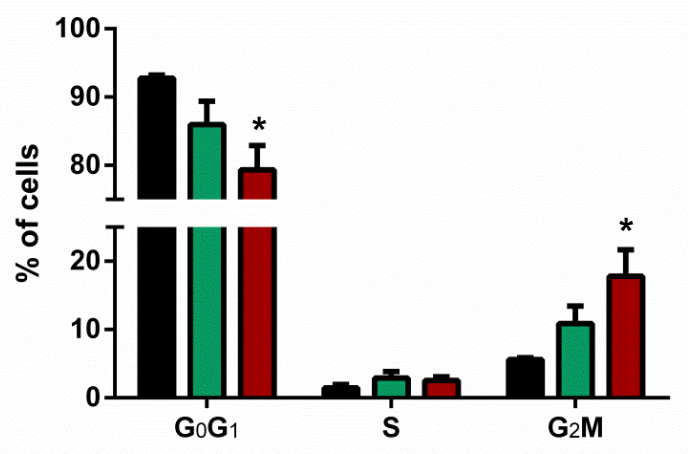

Figure 29: Flow cytometry cell cycle analysis of cells dissociated from control, Fasudil- and H1152P-treated rECT.

NRCF were dissociated from $\mathrm{rECT}$ and DNA was stained with propidium iodide to analyse the replication state of the cell populations. (A) Bar graph summary of number of NRCF after dissociation from control, Fasudil-, and H1152P-treated rECT (means \pm SEM, $n=6$ ). (B) Bar graph summary of cell populations in $\mathrm{G}_{0} \mathrm{G}_{1^{-}}$, S-, and $\mathrm{G}_{2} \mathrm{M}$-phase of NRCF dissociated from control, Fasudil-, and H1152P-treated rECT. (C) Number of single- and double-nucleated NRCF measured after dissociation from control, Fasudil-, and H1152P-treated rECT (means \pm SEM, $n=4-6,{ }^{*} p<0.05$ vs. control). 
Interestingly, cell cycle analysis of re-isolated NRCF using propidium iodide and flow cytometry measurements showed that in H1152P-treated rECTs number of cells in $G_{0} / G_{1}$ phase decreased by $15 \%$, whereas the number of cells in $G_{2} / M$ phase increased by $220 \%$ (Figure 29B). Using the same flow cytometry analysis, the number of NRCF that were double-nucleated was determined. In accordance with the results from the $2 \mathrm{D}$ culture of NRCF treated with $\mathrm{H} 1152 \mathrm{P}$, also in these cells a trend towards an increased number of NRCF displaying two nuclei could be detected (Figure 29C).

\subsubsection{ROCK inhibition in ECT induces changes in genes associated with the cytoskeleton and the ECM}

Gene expression analysis by QPCR of rECT treated with Fasudil and H1152P showed that both kinases are involved in the expression of genes associated with cytoskeletal and ECM proteins, as well as the regulation and turnover of the ECM. For example, inhibition of ROCK using Fasudil and H1152P led to a 15.5-fold and 2.6-fold increase in expression of elastin. Expression of its respective degrading enzyme elastase/matrix metalloproteinase 12 (MMP12) was significantly downregulated by $52 \%$ upon $\mathrm{H} 1152 \mathrm{P}$-treatment, whereas ROCK inhibition by Fasudil did not have an influence on MMP12 expression. Moreover, expression of hyaluronan synthase 2 (HAS2) was decreased by about $67 \%$ after treatment with both ROCK inhibitors. Expression of lysyl oxidase (LOX), an important mediator of the cross-linking of collagen and elastin, was reduced by $43 \%$ in Fasudil- and by $34 \%$ in H1152P-treated rECT [184]. Interestingly, the expression of collagens 1a1 and 3a1, the collagen organisers biglycan and decorin, MMP2 and 9, and the pro-fibrotic factors CTGF and TGF $\beta$ was not affected by inhibition of ROCK activity in rECT. In addition, the expression of galectin-3 (LGALS3), which is upregulated in various types of tissue fibrosis and is considered to be a new biomarker for cardiovascular risk assessment [185], was unchanged (Figure 30). 


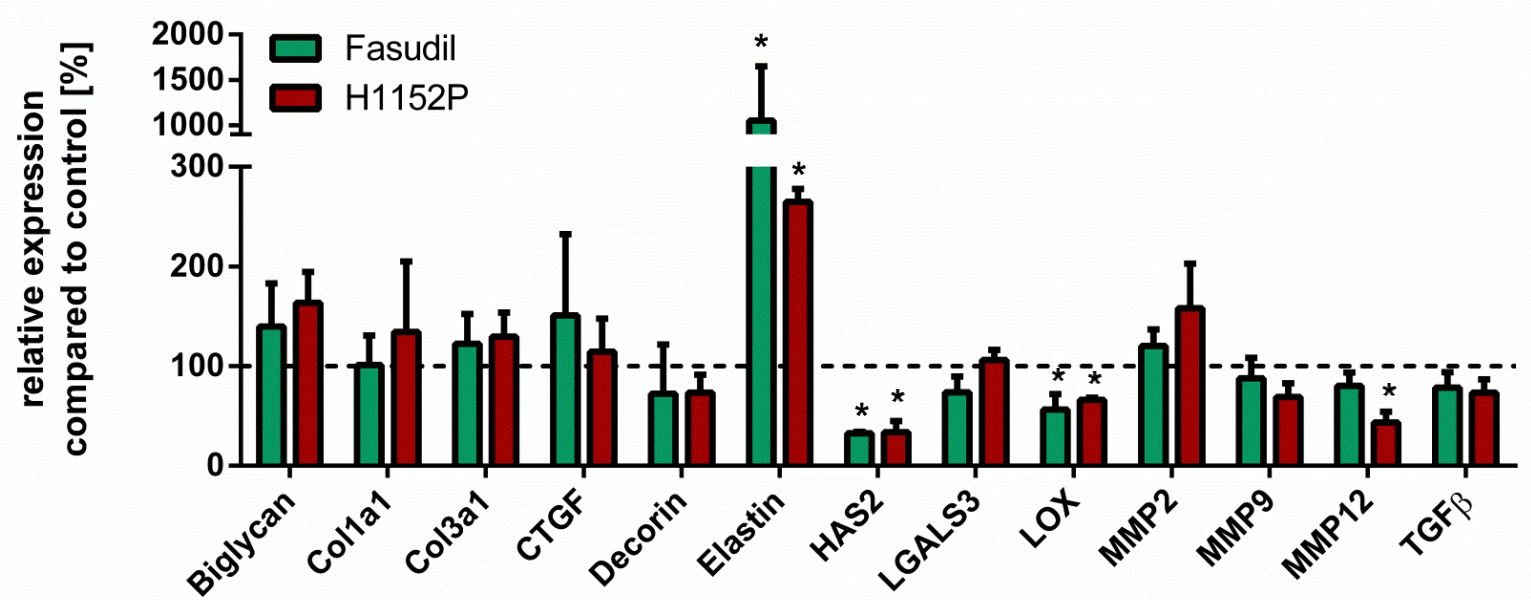

Figure 30: qPCR analysis of selected genes in control, Fasudil-, and H1152P-treated rECT.

The change in mRNA in Fasudil- $(10 \mu \mathrm{M})$ and $\mathrm{H} 1152 \mathrm{P}$-treated $(3 \mu \mathrm{M})$ rECT relative to control rECT is given (means $\pm S E M, n=4-6$, ${ }^{*} p<0.05$ vs. control, values were normalized to the mean of glucuronidase $\beta, P B G D$, and vimentin).

\subsubsection{Inhibition of MMP12 does not alter viscoelastic properties of rECT}

As described above, elastin gene expression was found to be upregulated upon treatment of ECTs with the ROCK inhibitor H1152P, and expression of its respective elastase, MMP12, was downregulated. Therefore, it was tested whether inhibition of MMP12 alone shows a similar effect and whether inhibition of MMP12 and ROCKs at the same time has a cumulative effect. To investigate this, rECTs were generated from NRCF and collagen I and treated with H1152P $(3 \mu \mathrm{M})$, MMP408 $(3 \mu \mathrm{M})$, a specific MMP12 inhibitor, or both inhibitors. In Figure 31A, representative images of the rECT are depicted. The treatment of rECT with MMP408 did not increase the CSA of rECT, whereas H1152P-treated rECT showed an increase in CSA of about $200 \%$ compared to control. However, combined treatment with MMP408 and H1152P did not have an additional effect on CSA (Figure 31B). 

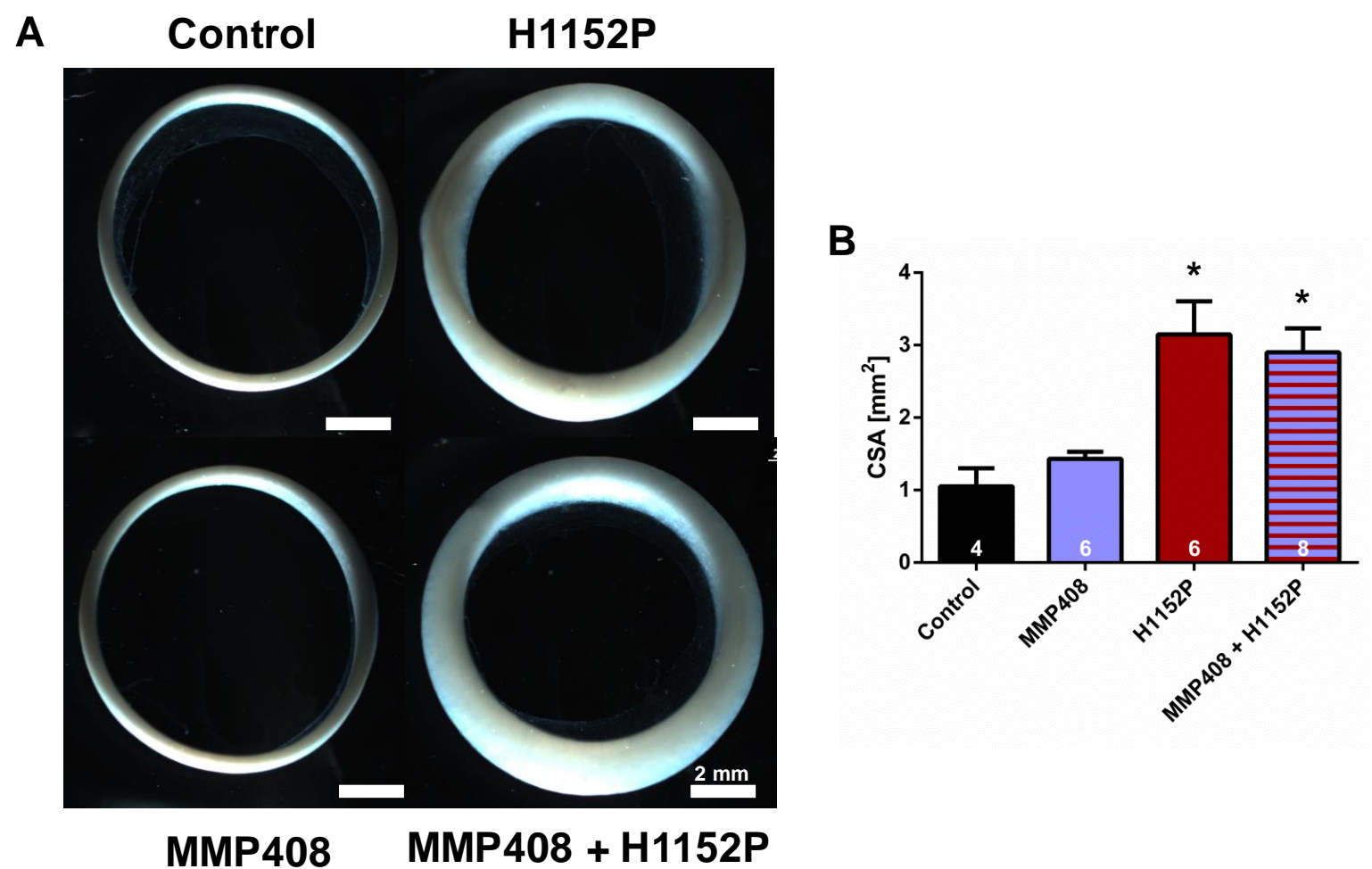

Figure 31: Morphometric changes of rECT after MMP12 and ROCK inhibition.

rECT were treated with H1152P $(3 \mu \mathrm{M})$, MMP408 $(3 \mu \mathrm{M})$ or both inhibitors. (A) Shown are representative images of the rECT. (B) Differences in calculated CSA of the different rECT are shown (means $\pm S E M, n=3,{ }^{*} p<0.05$ vs. control, values illustrate numbers of $r E C T$ measured).

To evaluate possible differences in viscoelastic properties, rECT were subjected to rheological destructive tensile strength measurement. In Figure 32, representative stress-strain curves of control, MMP408-, H1152P-treated rECT and those treated with both inhibitors are depicted. rECT treated with H1152P and with both inhibitors showed a flatter curve shape than control rECT, whereas those treated with MMP408 alone slightly tolerated less stress than control. 


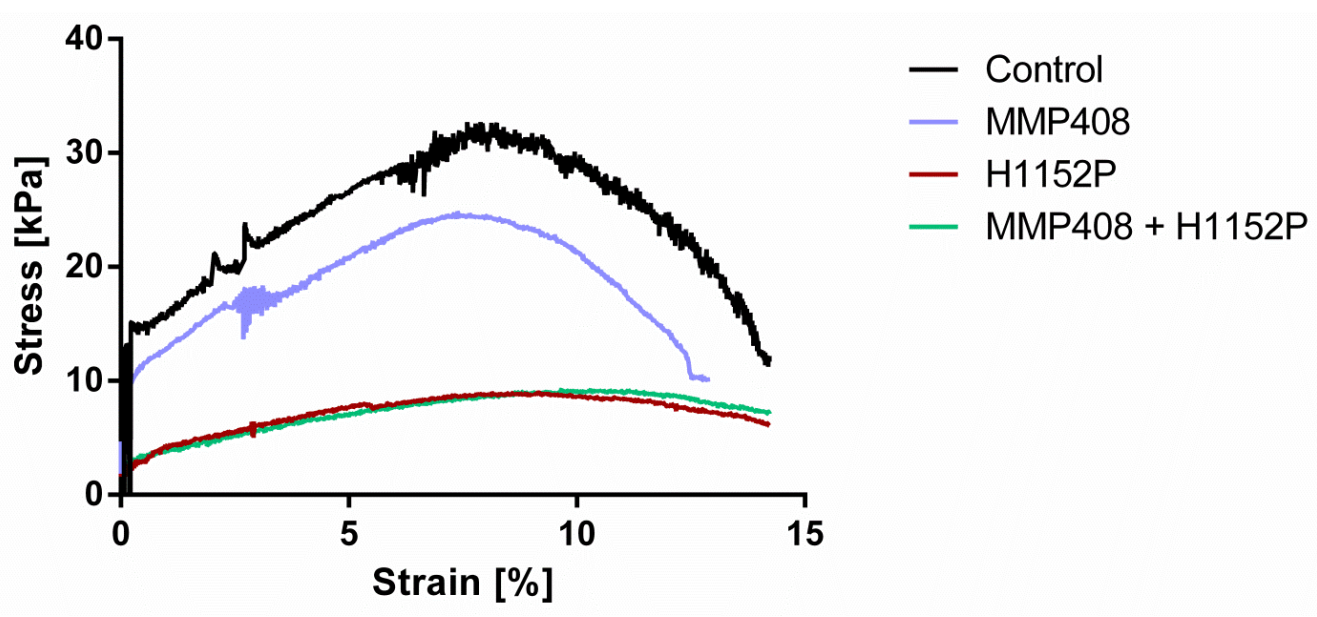

Figure 32: Representative stress-strain curves of control, H1152P- and MMP408treated rECT during a rheological destructive tensile strength measurement.

rECT were treated with H1152P $(3 \mu \mathrm{M})$, MMP408 $(3 \mu \mathrm{M})$ or both inhibitors. Shown are representative stress-strain curves for each condition.

Stiffness as defined by the Young's modulus was significantly reduced by $64 \%$ in $\mathrm{H} 1152 \mathrm{P}$ - and by $61 \%$ in H1152P and MMP408-treated rECT. No change of stiffness was found in MMP408-treated tissues (Figure 33A). The maximum stress value was significantly decreased in H1152P-treated $\mathrm{rECT}(69 \%)$ and $\mathrm{rECT}$ treated with H1152P and MMP408 (66\%, Figure 33B). Stress at the yield point was significantly decreased by $70 \%$ in $\mathrm{H} 1152 \mathrm{P}$-treated $\mathrm{rECT}$ and by $66 \%$ in $\mathrm{rECT}$ treated with both inhibitors (Figure 33C, left). No change was found regarding strain at the yield point (Figure 33C, right). Similarly, stress at the failure point was significantly decreased by $70 \%$ in H1152P-treated rECT and by $67 \%$ in those treated with both inhibitors (Figure 33D, left), whereas no change was observed for strain at the failure point (Figure 33D, right). In summary, the inhibition of MMP408 alone was not sufficient to achieve the same decrease in stiffness as seen with ROCK inhibition by H1152P. Moreover, combined inhibition of ROCK and MMP12 did not have a cumulative effect. 
A

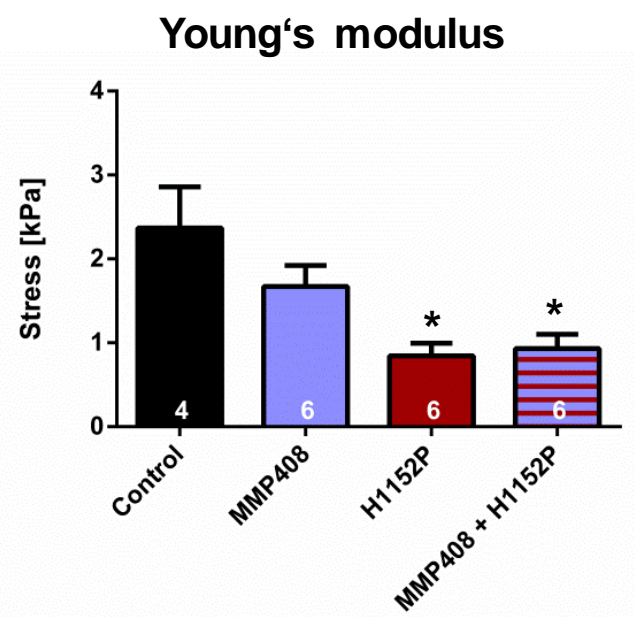

B

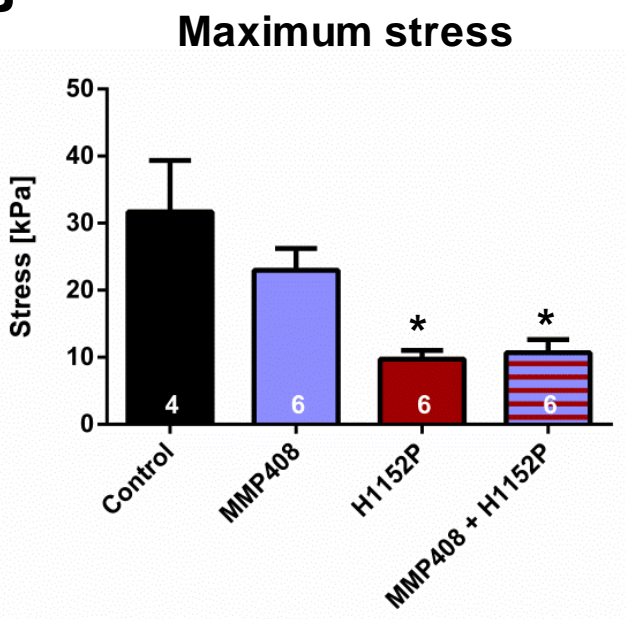

C

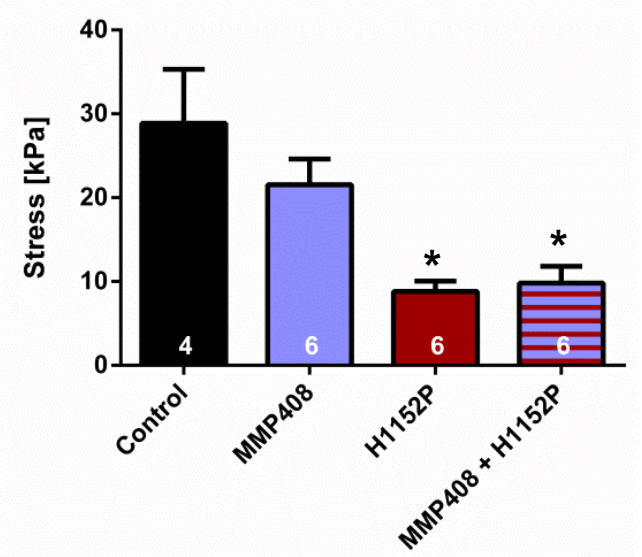

Yield point

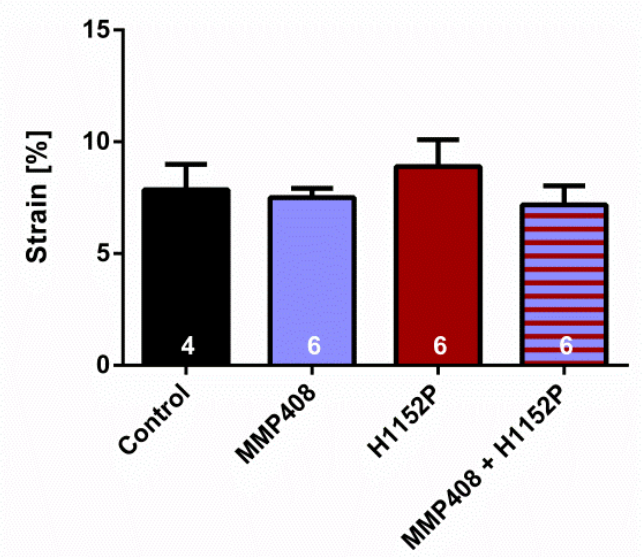

Failure point

D

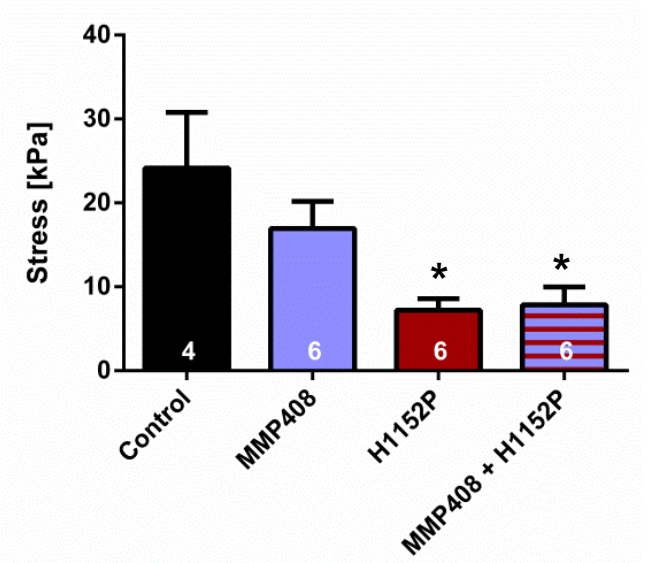

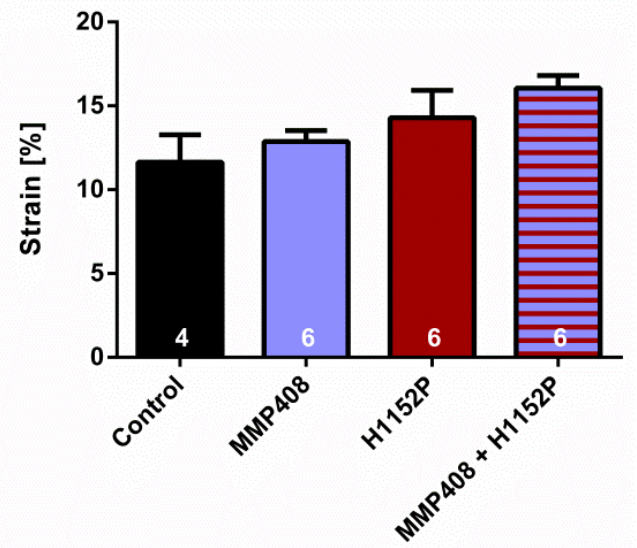

Figure 33: Analysis of the viscoelastic properties of control, H1152P- and MMP408treated rECT.

Changes in (A) the Young's modulus, (B) maximum stress value, (C) stress (left) and strain value (right) at the yield point, and (D) stress (left) and strain value (right) at the failure point are depicted (means \pm SEM, $n=3,{ }^{*} p<0.05$ vs. control, values illustrate numbers of $r E C T$ measured). 


\subsubsection{Modelling tissue fibrosis using TGF $\beta 1$ as a stimulus}

Enhanced TGF $\beta 1$ signalling is known to increase the production of ECM and to induce fibrosis in various tissues. We therefore wanted to investigate whether inhibition of ROCK activity can have beneficial, "fibrosis-reducing" effects on viscoelastic properties of tissues that are treated with TGF $\beta 1$. To test this, rECTs were treated with $\mathrm{H} 1152 \mathrm{P}(3 \mu \mathrm{M}), \operatorname{TGF} \beta 1(5 \mathrm{ng} / \mathrm{mL})$, or $\mathrm{H} 1152 \mathrm{P}$ and TGF $\beta 1$ together. Additionally, for some rECT, TGF $\beta 1$ treatment was stopped after three days and $\mathrm{rECT}$ treated with $\mathrm{H} 1152 \mathrm{P}$ until rheological measurement was performed. As can be seen in Figure 34A, the treatment with TGF $\beta 1$ did not have a significant influence on the CSA of rECT compared to control. Treatment with H1152P increased the CSA of $r E C T$, as described before.

A

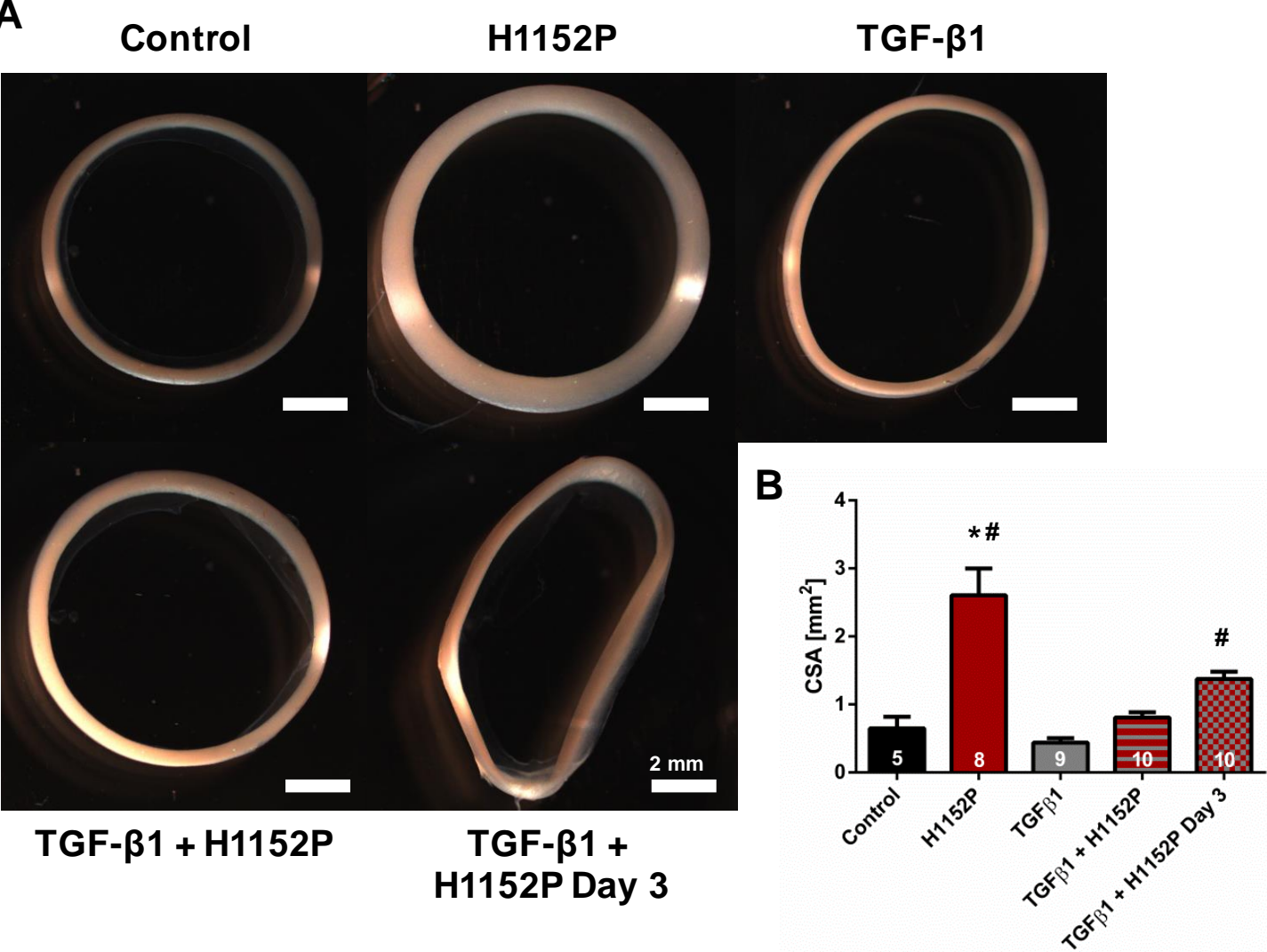

Figure 34: Morphometric changes of rECT after ROCK inhibition and TGF $\beta 1$ treatment. rECT were treated with H1152P $(3 \mu \mathrm{M})$, TGF $\beta 1$ ( $5 \mathrm{ng} / \mathrm{mL})$, or $\mathrm{H} 1152 \mathrm{P}$ and TGF $\beta 1$. Additionally, for half of the TGF $\beta 1$-treated rECTs the treatment was stopped on day 3 and instead H1152P was added to the medium. (A) Shown are representative images of the rECT. (B) Differences in calculated CSA of the rECT are shown (means $\pm S E M, n=3,{ }^{*} p<0.05$ vs. control, \# $p<0.05$ vs. TGF $\beta 1$, values illustrate numbers of rECT measured). 
Interestingly, rECT treated with both TGF $\beta 1$ and H1152P slightly increased in size. This was even more striking in rECT for which TGF $\beta 1$-treatment was stopped after two days and continued with $\mathrm{H} 1152 \mathrm{P}$, as the CSA was significantly increased about 3-fold compared to TGF $\beta 1$-treated rECT (Figure 34B).

Next, viscoelastic properties of the rECT were assessed using rheological destructive tensile strength measurement. Representative stress-strain curves of control, H1152P, TGF $\beta 1$-, TGF $\beta 1$ and H1152P-treated, and rECT treated with TGF $\beta 1$ for two days and subsequently with $\mathrm{H} 1152 \mathrm{P}$ for additional three days are depicted in Figure 35. rECT treated with $\mathrm{H} 1152 \mathrm{P}$ and both $\mathrm{H} 1152 \mathrm{P}$ and $\mathrm{TGF} \beta 1$ showed a flatter curve than control or TGF $\beta 1$-treated $\mathrm{rECT}$, independent of when $\mathrm{H} 1152 \mathrm{P}$ treatment was started.

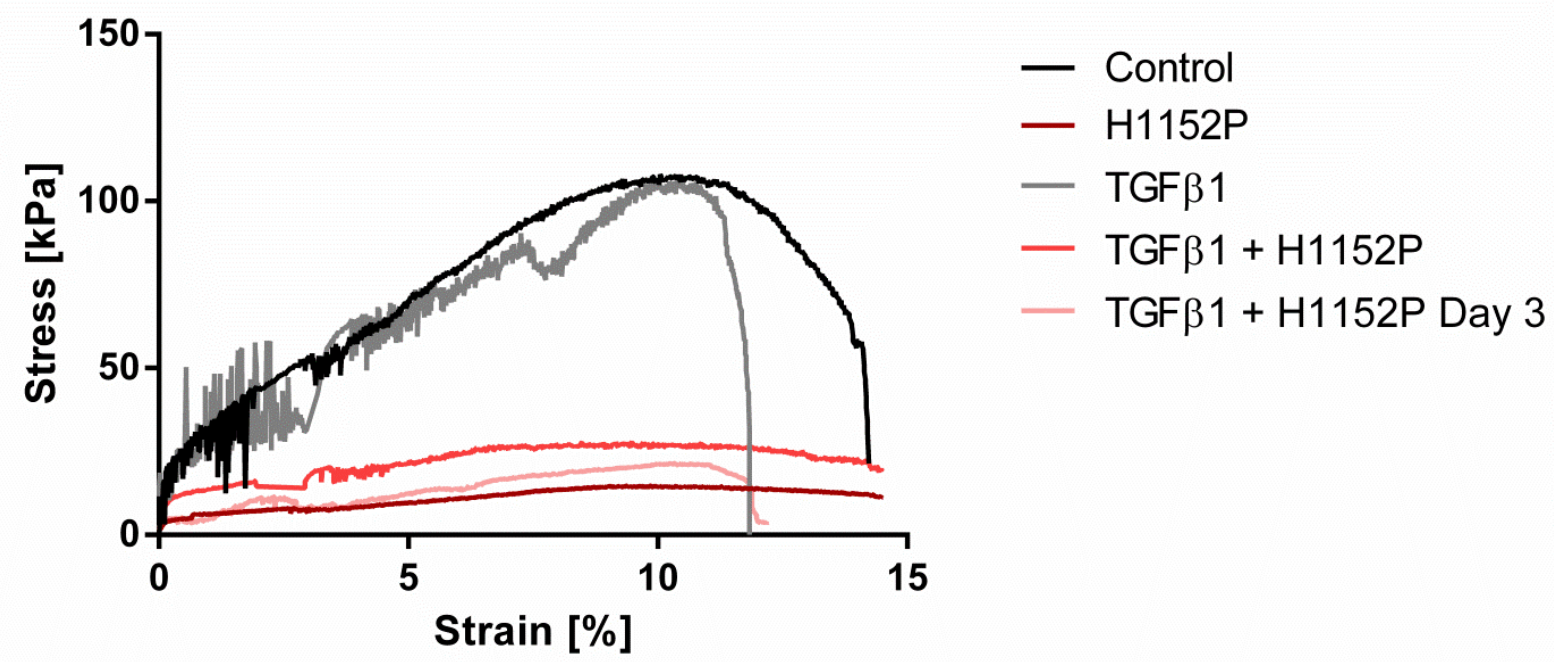

Figure 35: Representative stress-strain curves of control, H1152P- and TGF $\beta 1$-treated rECT during a rheological destructive tensile strength measurement.

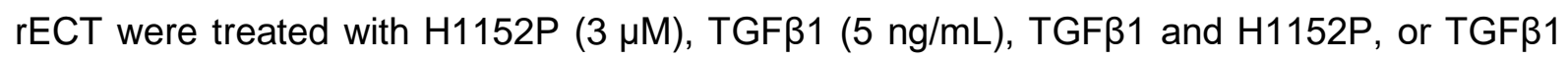
until day 3 , continued with $\mathrm{H} 1152 \mathrm{P}$ until day 5 . Shown are representative stress-strain curves for each condition.

Analysis of the measurements showed that stiffness of TGF $\beta 1$-treated rECT did not change compared to control. However, additional treatment with $\mathrm{H} 1152 \mathrm{P}$ significantly decreased the Young's modulus by $60 \%$. The effect of $\mathrm{H} 1152 \mathrm{P}$ was even more striking when TGF $\beta 1$ treatment was stopped after two days (79\% decrease; Figure $36 \mathrm{~A})$. Maximum stress was decreased following treatment with $\mathrm{H} 1152 \mathrm{P}$ alone (86\%), 
$\mathrm{H} 1152 \mathrm{P}$ in combination with TGF $\beta 1$ (73\%), and in TGF $\beta 1$-rECT in which H1152P treatment was started on day three (79\%; Figure $36 \mathrm{~B})$. Stress at the yield and failure point was significantly decreased in rECT treated with H1152P (both 85\%), TGF $\beta 1$ and $\mathrm{H} 1152 \mathrm{P}$ (both $75 \%$ ), and in TGF $\beta 1$-rECT with $\mathrm{H} 1152 \mathrm{P}$ added on day three (both $79 \%$; Figure 36C, D left). However, no difference was found regarding strain values at the yield and failure point (Figure $36 \mathrm{C}$, D right).

In summary, treatment with TGF $\beta 1$ was shown to have an effect on consolidation of rECT, rather than viscoelastic properties. TGF $\beta 1$ did not significantly change the stiffness of rECT compared to control and also did not have an effect when the rECT were additionally treated with H1152P. However, the increase in CSA observed in H1152P-treated tissues could be significantly decreased by TGF $\beta 1$. 
A

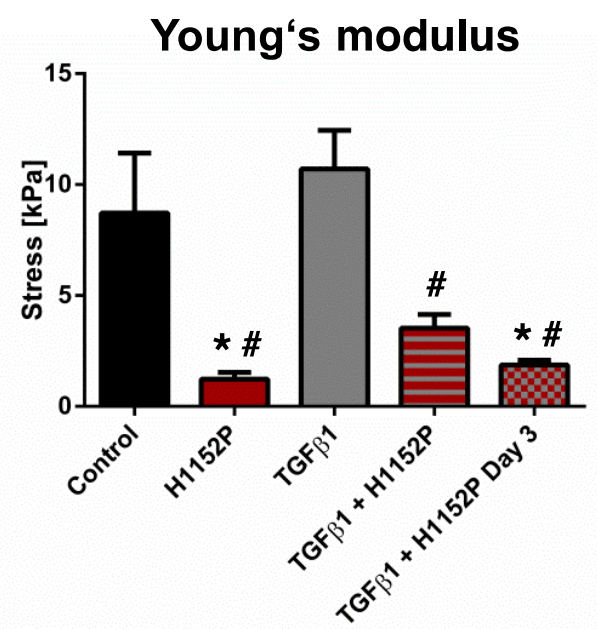

B

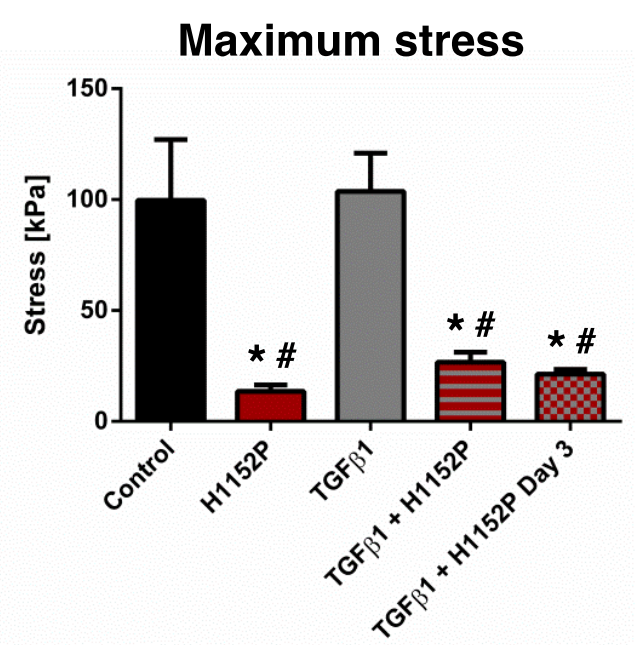

C

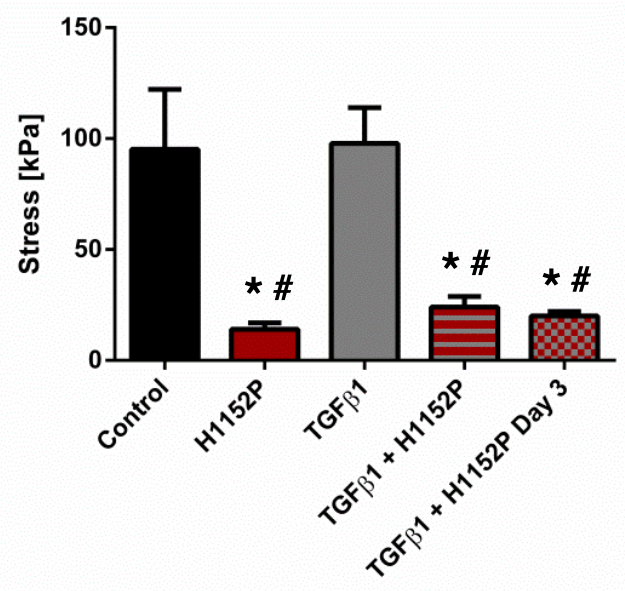

Yield point

D

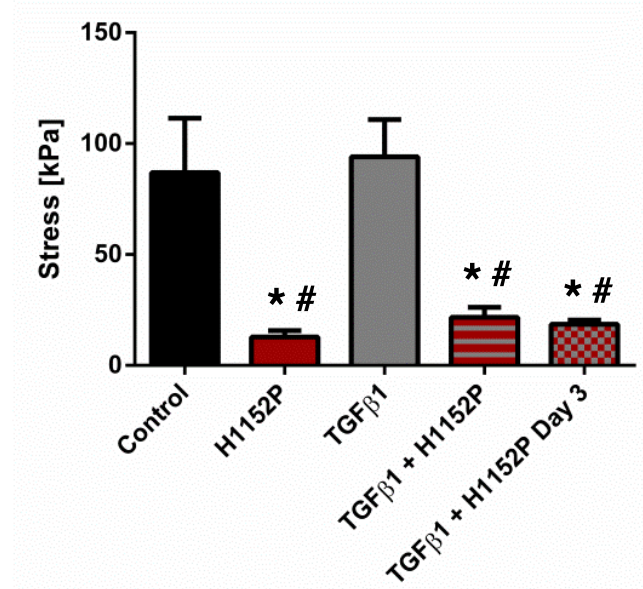

Failure point

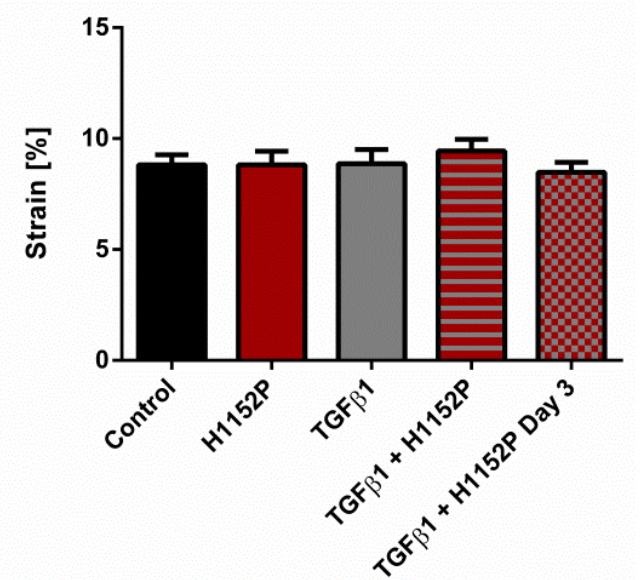

Figure 36: Analysis of the viscoelastic properties of control, H1152P- and TGF $\beta 1$ treated rECT.

Changes in (A) the Young's modulus, (B) maximum stress value, (C) stress (left) and strain value (right) at the yield point, and (D) stress (left) and strain value (right) at the failure point are depicted (means $\pm S E M, n=3,{ }^{*} p<0.05$ vs. control, $\# p<0.05$ vs. TGF $\beta 1$, values illustrate numbers of rECT measured). 
4.5 ROCK1 and ROCK2 influence the contractility of engineered tissues and this is dependent on the maturation status of cardiomyocytes

\subsubsection{Inhibition of ROCK1 and ROCK2 has no influence on contractile parameters of rEHM}

In the next step, we wanted to investigate the effect of ROCK1 and ROCK2 on contractile and functional properties of engineered heart muscle (EHM). To do so, we constructed EHMs from primary neonatal rat cardiac cells (rEHM), collagen I and Matrigel. The rEHM were allowed to consolidate for seven days and then transferred onto phasic stretchers for mechanical load, which is essential for formation of a functional syncytium. During this phase, rEHM were treated with Fasudil $(10 \mu \mathrm{M})$ and $\mathrm{H} 1152 \mathrm{P}(3 \mu \mathrm{M})$. Previous results showed that treatment with $\mathrm{H} 1152 \mathrm{P}$ resulted in an increase in force of contraction (FoC, Figure 7). However, FoC was not based on the CSA of the tissues, which was different between ROCK inhibitor-treated and control rEHM. Thus, experiments were repeated to evaluate the effect of ROCK inhibition on contractility of $\mathrm{rEHM}$. Figure 37 shows, that $\mathrm{rEHM}$ treated with Fasudil and H1152P showed a $50 \%$ increase in CSA. 


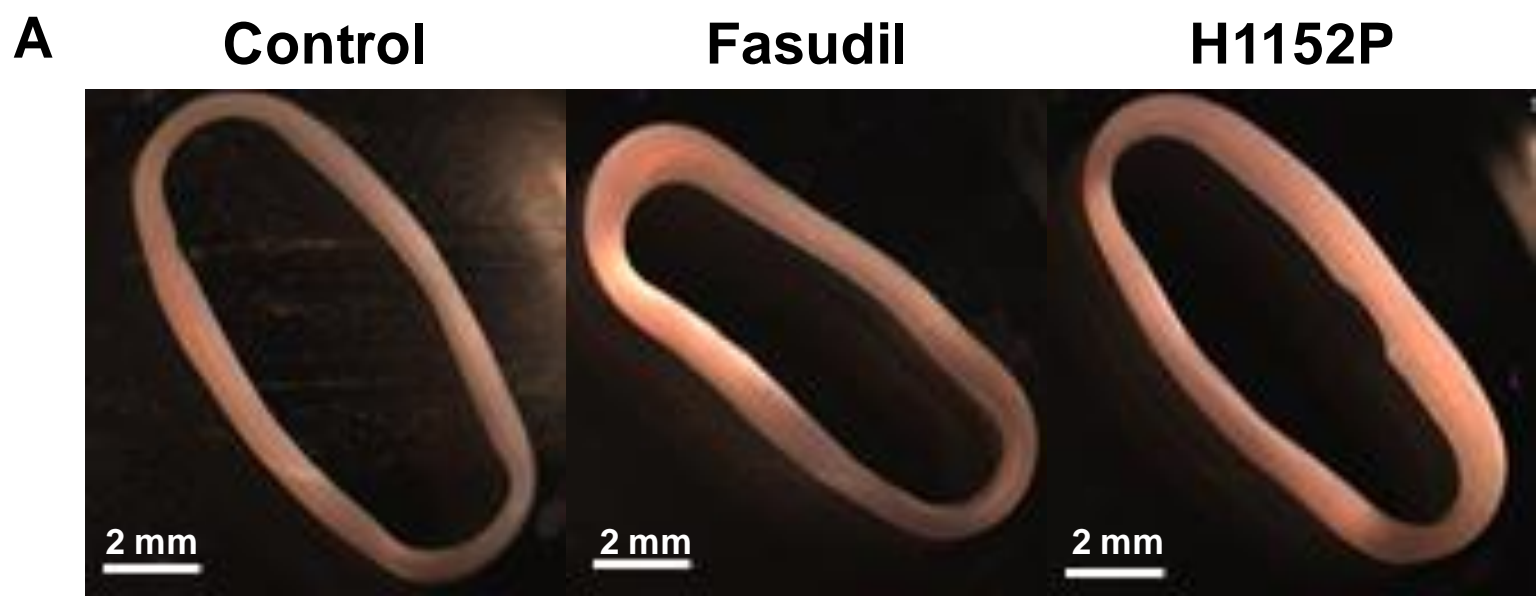

B

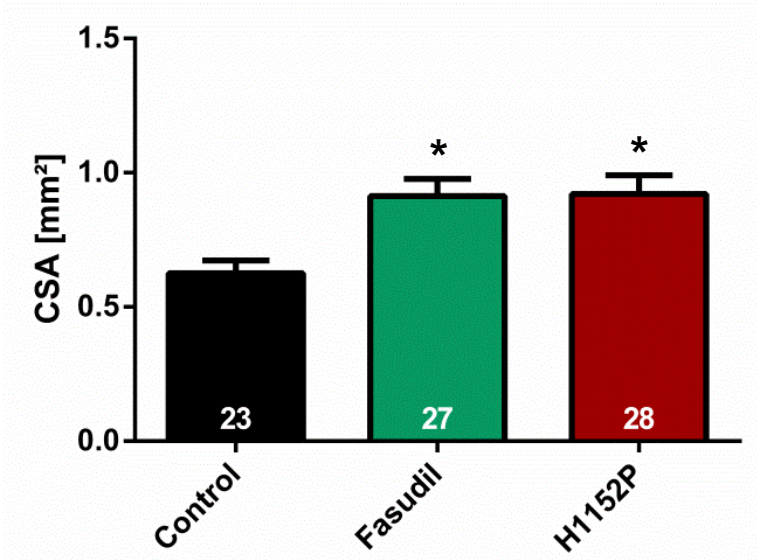

Figure 37: Morphometric changes of engineered heart muscle from neonatal cardiac cells of the rat (rEHM) after ROCK inhibition.

rEHM were cultured for 7 days until they were fully consolidated and then transferred onto phasic stretchers for mechanical load for another 7 days. During this phase, rEHM were treated with Fasudil $(10 \mu \mathrm{M})$ and $\mathrm{H} 1152 \mathrm{P}(3 \mu \mathrm{M})$. (A) Shown are representative images of control-, Fasudil-, and H1152P-treated hEHM. (B) Differences in calculated CSA of the rEHM are shown (means $\pm S E M, n=5,{ }^{*} p<0.05$ vs. control, values illustrate numbers of $r E H M$ measured).

On culture day 14, rEHM were subjected to isometric force measurement under increasing extracellular calcium. Fasudil and H1152P-treated rEHM showed a reduced resting force per CSA compared to control, which was independent of the calcium concentration (Figure 38A). In contrast to previous results, FoC per CSA in ROCK inhibitor-treated $\mathrm{rEHM}$ was not different to control rEHM, although a slight trend towards an increased contractility could be detected (Figure 38B). Similarly, no 
change in half maximal effective concentration of $\mathrm{Ca}^{2+}\left(\mathrm{EC}_{50} \mathrm{Ca}^{2+}\right)$ was found (Figure $38 \mathrm{C})$.

A

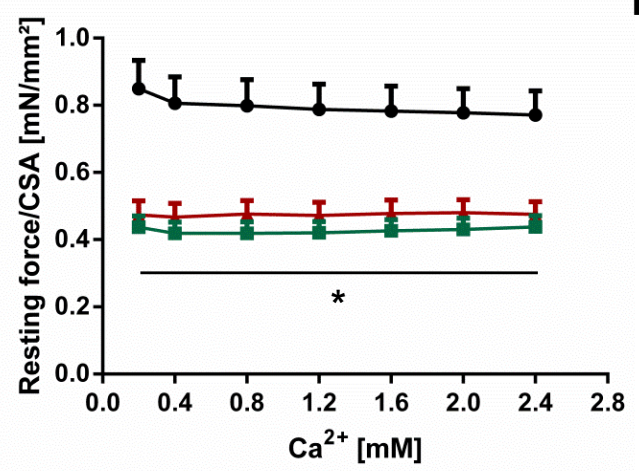

C

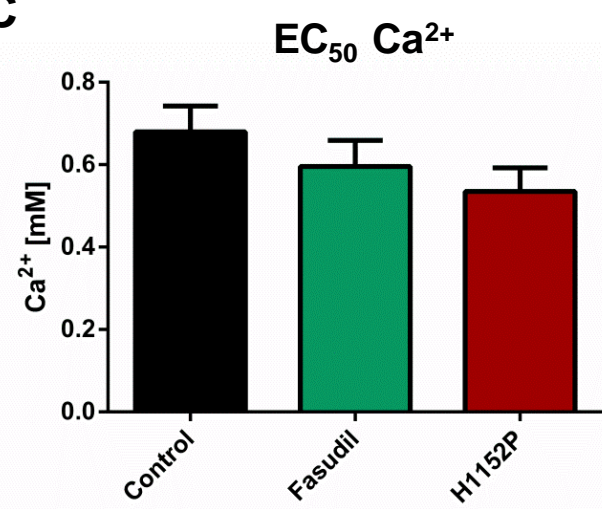

B

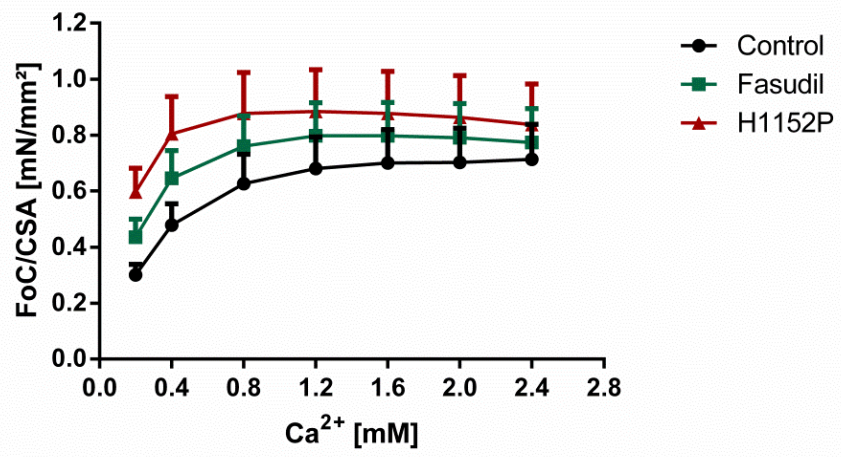

Figure 38: Isometric force measurement of control-, Fasudil-, and H1152P-treated rEHM.

(A) Analysis of resting force normalized to the CSA at different calcium concentrations, (B) Analysis of the force of contraction (FoC) normalized to the CSA at different calcium concentrations, (C) Bar graph summary of the calculated EC50 for $\mathrm{Ca}^{2+}$ (means $\pm S E M, n=8$, 29-31 rEHM measured in total, * $p<0.05$ vs. control).

\subsubsection{Inhibition of ROCK1 and ROCK2 activity influences viscoelastic properties of rEHM}

After performing isometric force measurements, $\mathrm{rEHM}$ were subjected to rheological destructive tensile strength measurement to evaluate viscoelastic properties of the tissues. Representative stress-strain curves can be seen in Figure 39. 


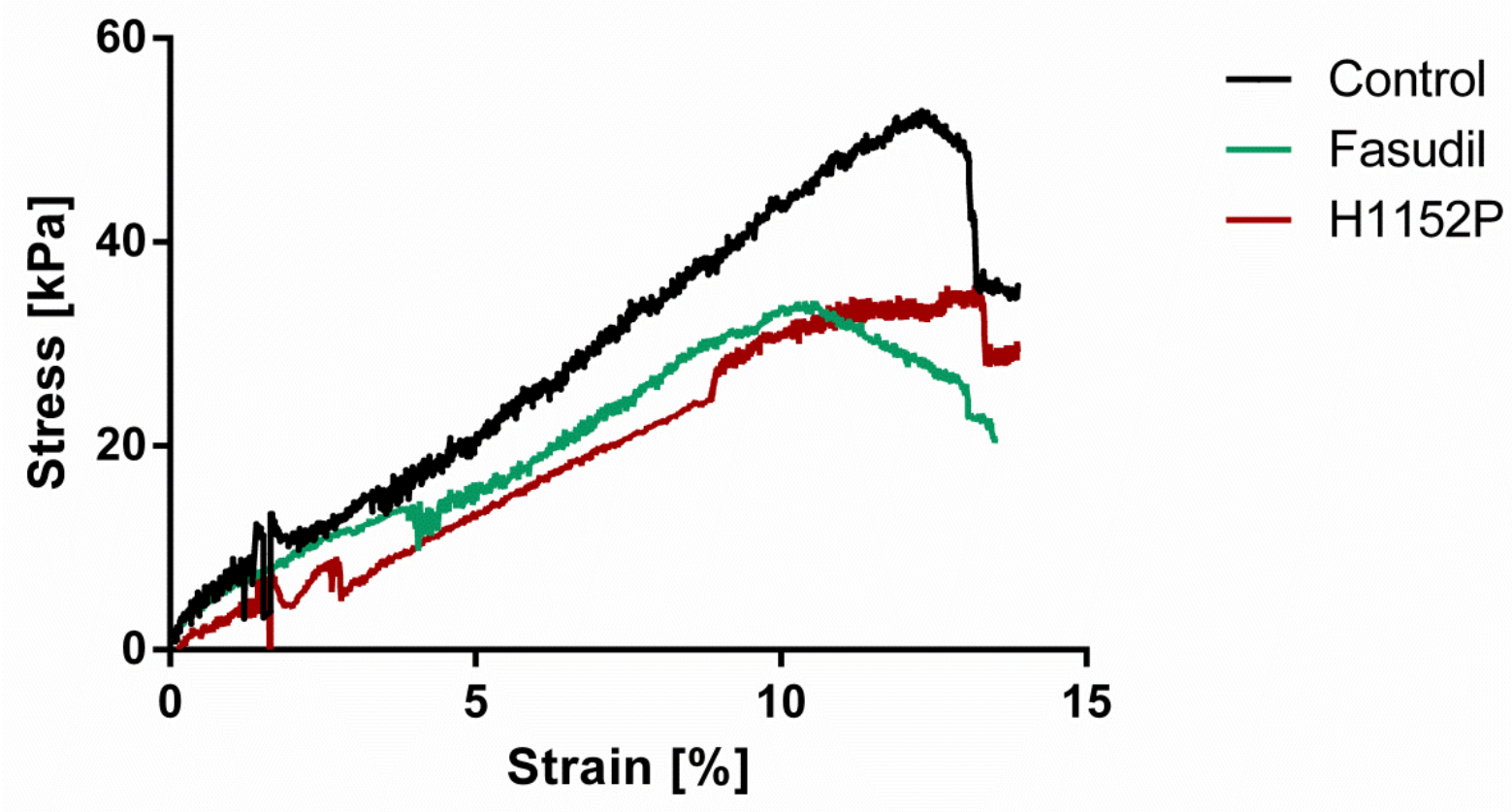

Figure 39: Representative stress-strain curves of control, Fasudil-, and H1152P-treated rEHM during a rheological destructive tensile strength measurement.

rEHM were treated with Fasudil $(10 \mu \mathrm{M})$ or H1152P $(3 \mu \mathrm{M})$. Shown are representative stressstrain curves for each condition.

Similar to rECT, the Young's modulus of Fasudil- and H1152P-treated rEHM was reduced $31 \%$ and $45 \%$, respectively (Figure $40 \mathrm{~A}$ ). In addition, maximum stress was decreased by about $45 \%$ in both conditions compared to control (Figure 40B). Less ultimate stress was needed until the yield point and failure point were reached, as stress was decreased by $44 \%$ in Fasudil- and by $48 \%$ in H1152P-treated rEHM for both yield and failure point (Figure $40 \mathrm{C}$, D left). ROCK inhibitor treatment did not change strain values at the yield and failure point (Figure 40C, D right). 
A

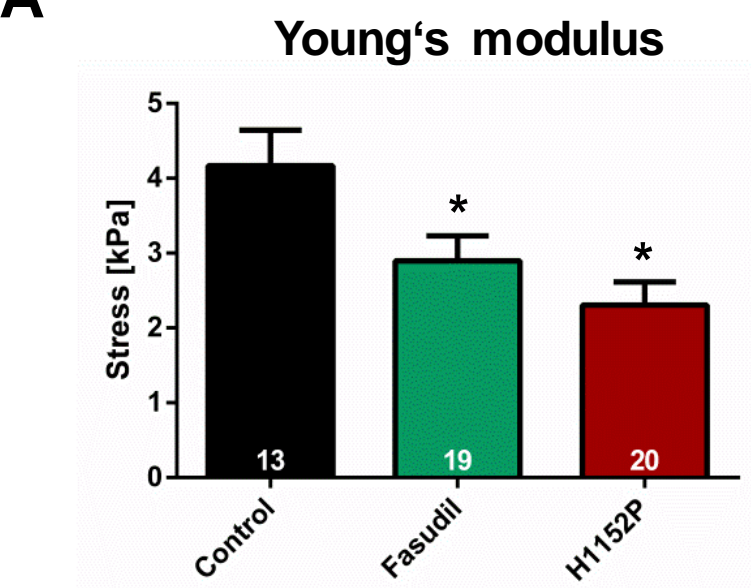

B

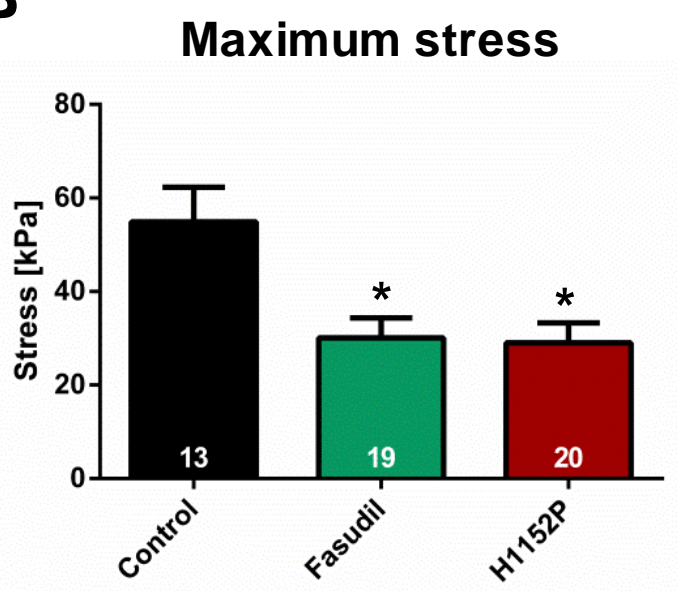

C

Yield point
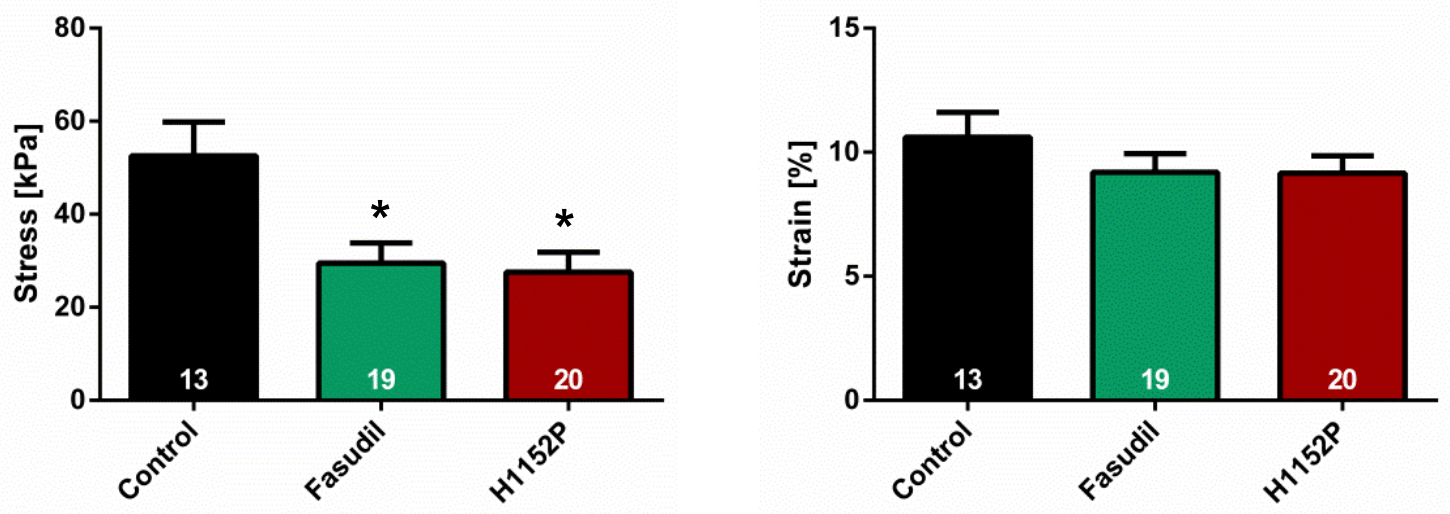

D

Failure point
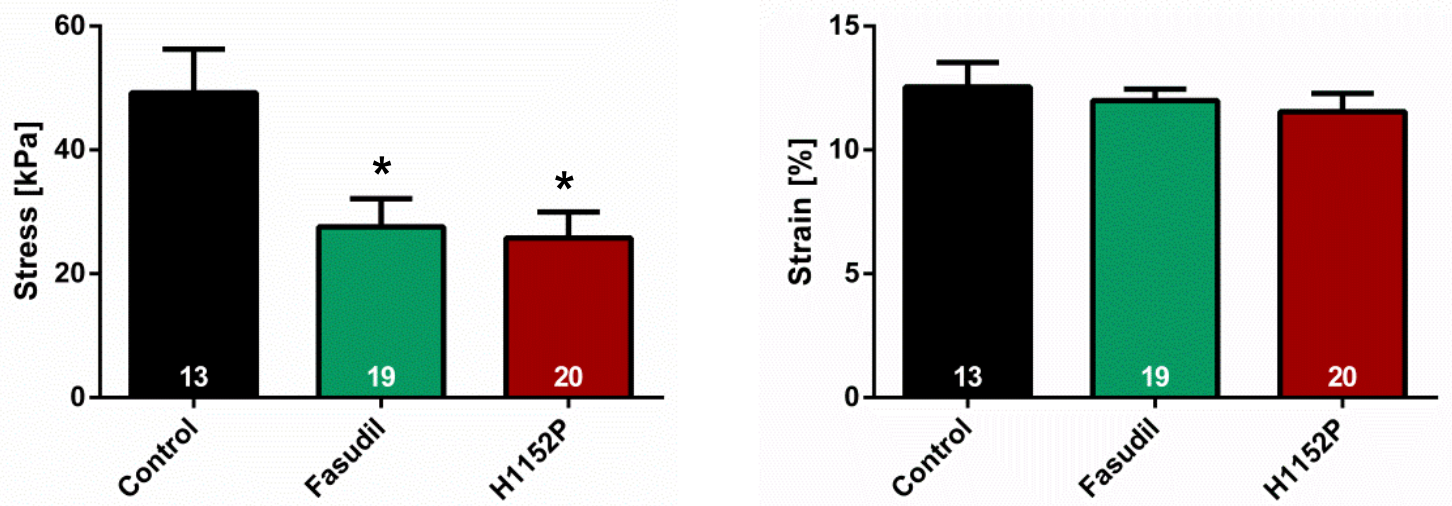

Figure 40: Analysis of the viscoelastic properties of control, Fasudil-, and H1152Ptreated rEHM.

Changes in (A) the Young's modulus, (B) maximum stress value, (C) stress (left) and strain value (right) at the yield point, and (D) stress (left) and strain value (right) at the failure point are depicted (means $\pm S E M, n=3$, ${ }^{*} p<0.05$ vs. control, values illustrate numbers of $r E H M$ measured). 


\subsubsection{Inhibition of ROCK activity decreases contractile force of hEHM}

To evaluate the influence of ROCK signalling on contractility of EHM in the human model, hEHMs were constructed from a mixture of hES2 wt CM, NHCF-V and collagen I. As only two cell types were added, namely cardiomyocytes and cardiac fibroblasts, this model is considered more defined than the rEHM model. The hEHM were allowed to consolidate for three days and then transferred to dynamic stretchers. hEHM were treated either from day zero or day three with H1152P $(3 \mu \mathrm{M})$. No change in CSA was detected after H1152P-treatment (Figure 41).

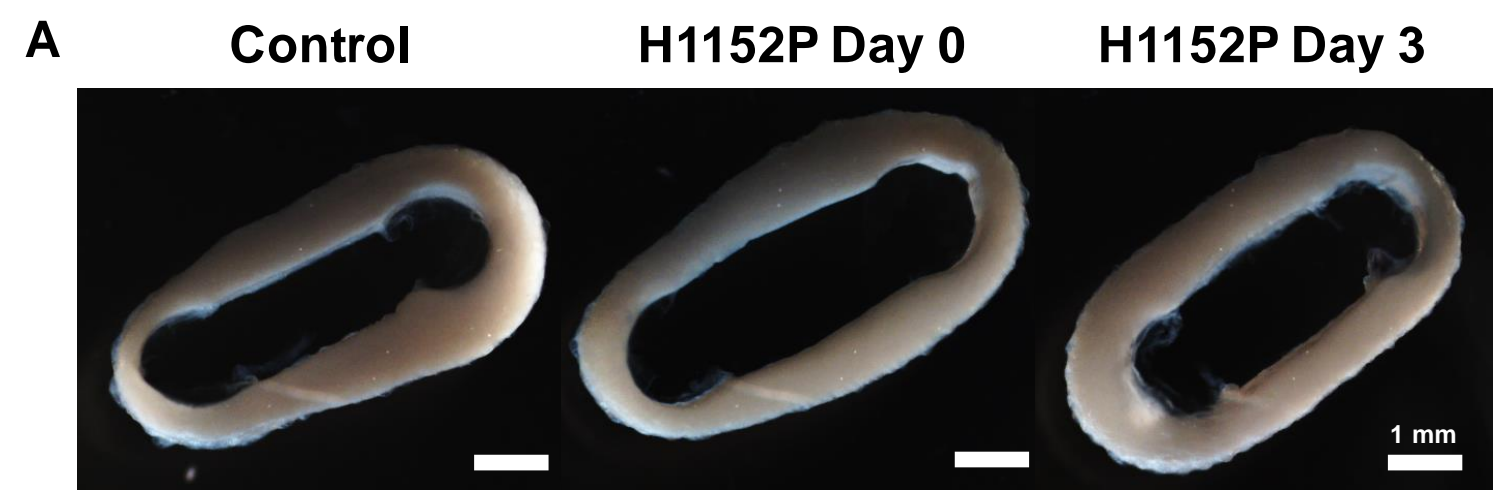

B

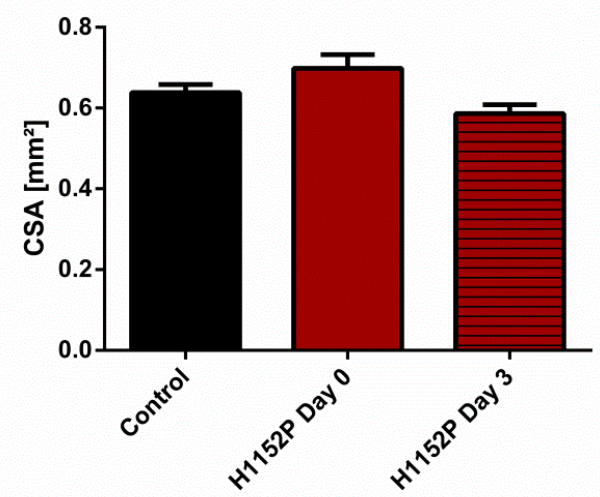

Figure 41: Morphometric changes of engineered heart muscle from hES2 wt CM and NHCF-V (hEHM).

hEHM were cultured for 3 days until they were fully consolidated and then transferred onto dynamic mechanical stretchers for mechanical loading for another 25 days. hEHM were treated with $\mathrm{H} 1152 \mathrm{P}(3 \mu \mathrm{M})$ from day 0 or day 3 on. (A) Shown are representative images of control hEHM and those treated with H1152P day 0 and day 3. (B) Bar graph summary of the calculated CSA of the hEHM are shown (means \pm SEM, $n=4-7,>25 \mathrm{hEHMs}$ measured per condition). 
On culture day 28 , hEHM were subjected to isometric force measurement under increasing extracellular calcium. The relative resting force per CSA of day 0 and day $3 \mathrm{H} 1152 \mathrm{P}$-treated $\mathrm{hEHM}$ showed no difference compared to control (Figure 42A). However, FoC per CSA of hEHM that were treated with H1152P on day 0 and day 3 was significantly reduced compared to control. The effect of H1152P was most striking in hEHM that were treated from day 0 (Figure 42B). Interestingly, no change in $\mathrm{EC}_{50} \mathrm{Ca}^{2+}$ was found (Figure $42 \mathrm{C}$ ).

A
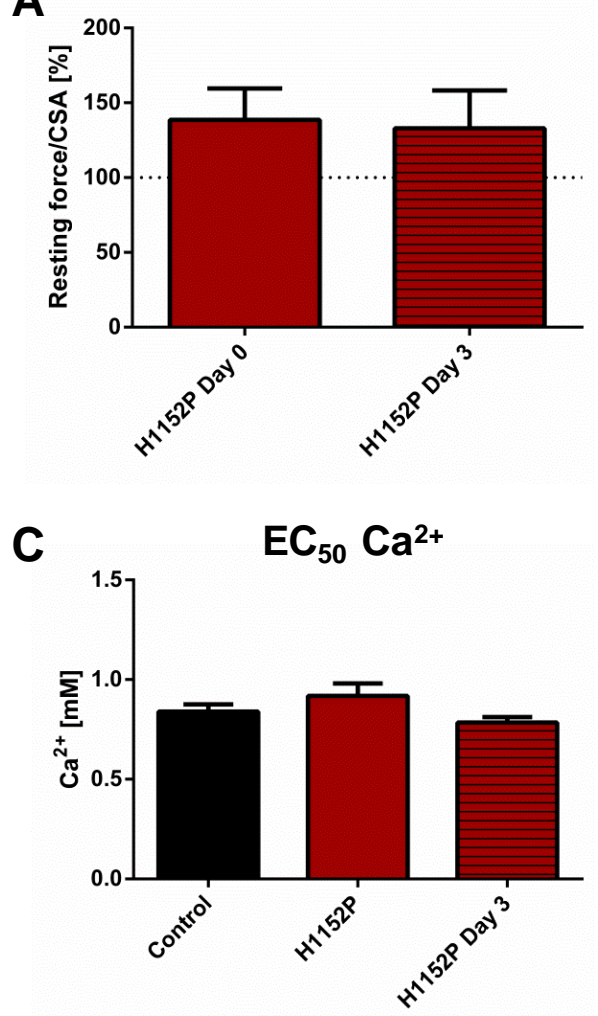

B

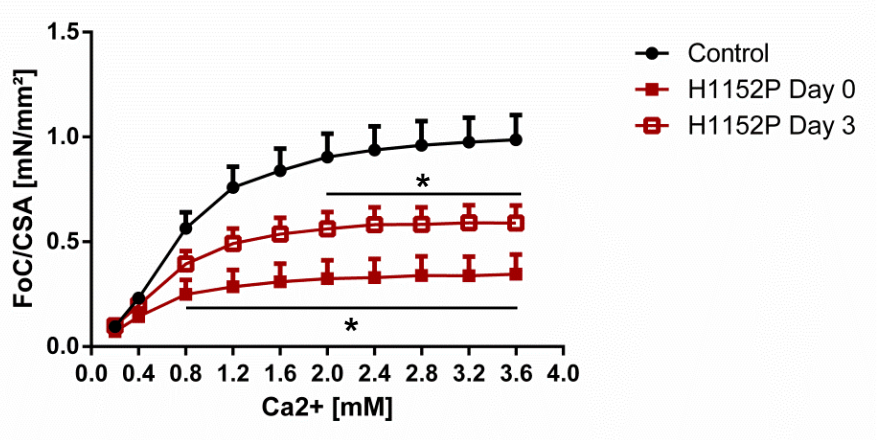

Figure 42: Isometric force measurement of control- and H1152P-treated hEHM.

(A) Analysis of the relative resting force normalized to the CSA at $2 \mathrm{mM}$ extracellular $\mathrm{Ca2+}$ with resting force/CSA of control set to $100 \%$, and (B) Analysis of FoC normalized to the CSA at different calcium concentrations (means \pm SEM, $n=8,29-31$ rEHM measured in total, * $\mathrm{p}<0.05$ vs. control). (C) Bar graph summary of the calculated EC50 for $\mathrm{Ca} 2+$ (means $\pm \mathrm{SEM}$, $\mathrm{n}=4-7,>18 \mathrm{hEHMs}$ measured per condition).

In Figure 43A and B, representative force traces and curves of a single contraction of the different groups are depicted. Analysis of single contractions revealed that treatment of hEHM with $\mathrm{H} 1152 \mathrm{P}$ significantly decreased the amplitude of contraction by about 70\% in H1152P Day 0 and 45\% in H1152P Day 3 hEHM (Figure 43C). In 
addition, contraction time was slowed in hEHM that were treated with $\mathrm{H} 1152 \mathrm{P}$ from day 0 , as $90 \%$ time-to-peak was decreased by $9 \%$ and $50 \%$ time-to-baseline by $11 \%$. Contraction time in H1152P Day 3 hEHM was similar to control.

A

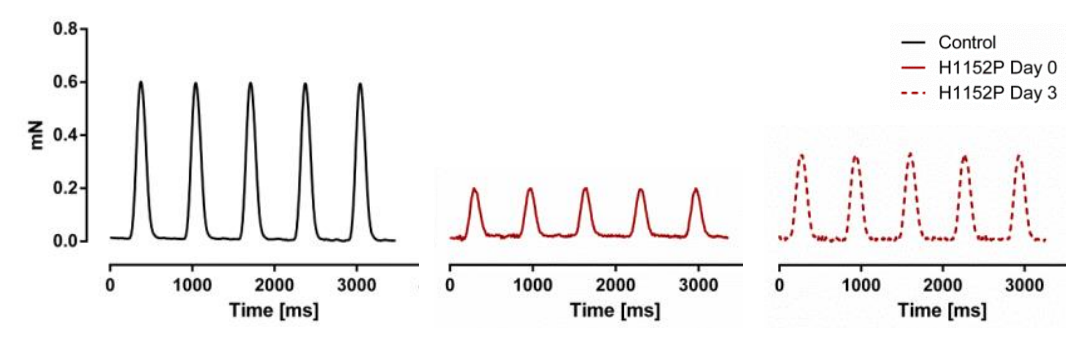

C

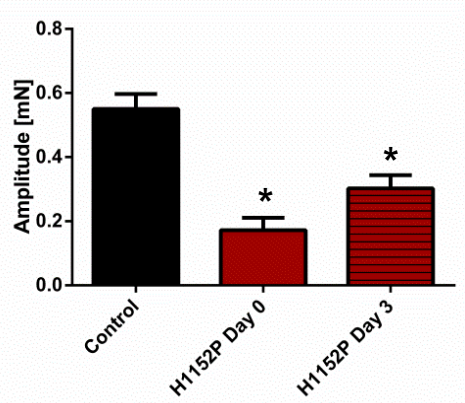

D

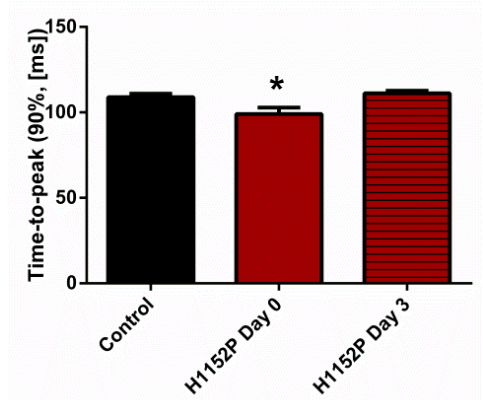

B

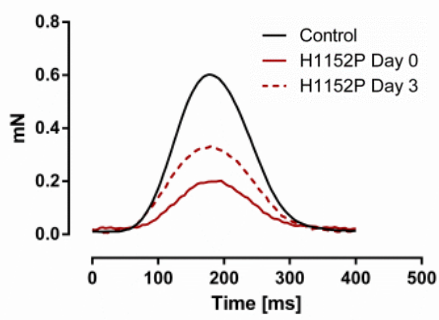

$\mathbf{E}$

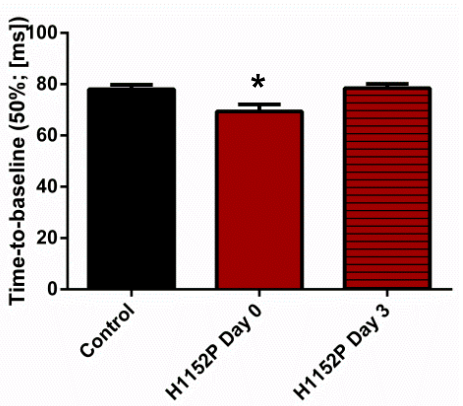

Figure 43: Analysis of force traces of control- and H1152P-treated hEHM.

(A) Representative force traces recorded by isometric force measurements in day 28 controland H1152P-treated hEHMs. (B) Representative curves of a single contraction of controland H1152P-treated hEHMs. Bar graph summary of (C) amplitude, (D) 90\% time-to-peak, and (E) 50\% time-to-baseline (means \pm SEM, $n=4-7$, >18 hEHMs measured per condition, ${ }^{*} p<0.05$ vs. control).

\subsubsection{Inhibition of ROCK1 and ROCK2 activity does not change viscoelastic properties of hEHM}

Next, hEHM were subjected to rheological destructive tensile strength measurement to evaluate viscoelastic properties of the tissues. Representative stress-strain curves of the different groups were all similar and can be seen in Figure 44 . 


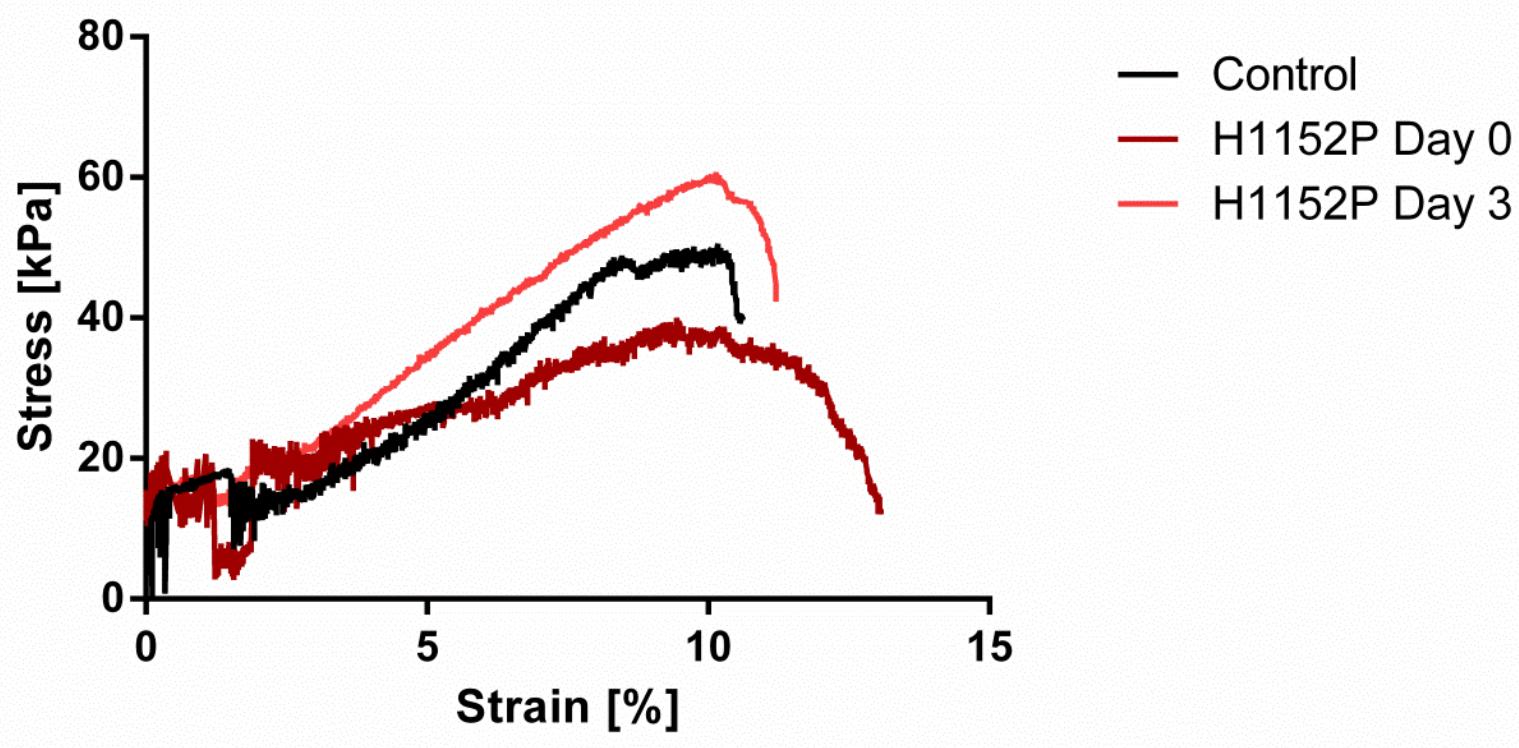

Figure 44: Representative stress-strain curves of control and H1152P-treated hEHM during a rheological destructive tensile strength measurement.

hEHM were treated with $\mathrm{H} 1152 \mathrm{P}(3 \mu \mathrm{M})$ from day 0 or day 3 on. Shown are representative stress-strain curves for each condition.

In accordance with the results of the resting force, analysis of the Young's modulus, maximum stress, yield, and failure point showed no differences between H1152P. treated and control hEHM (Figure 45). 
A

Young's modulus

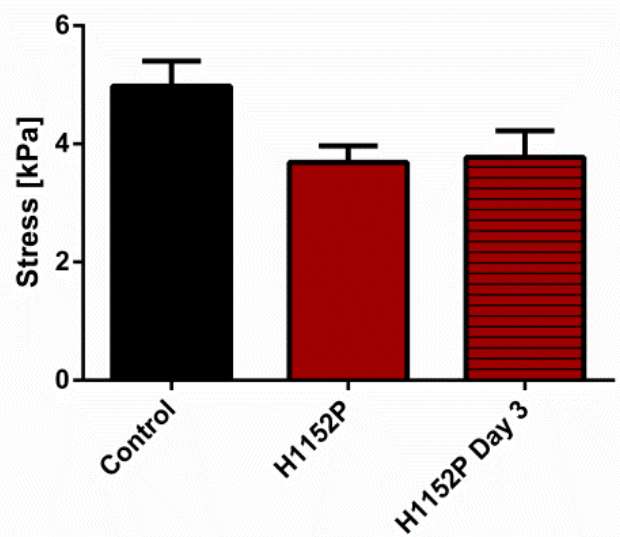

B

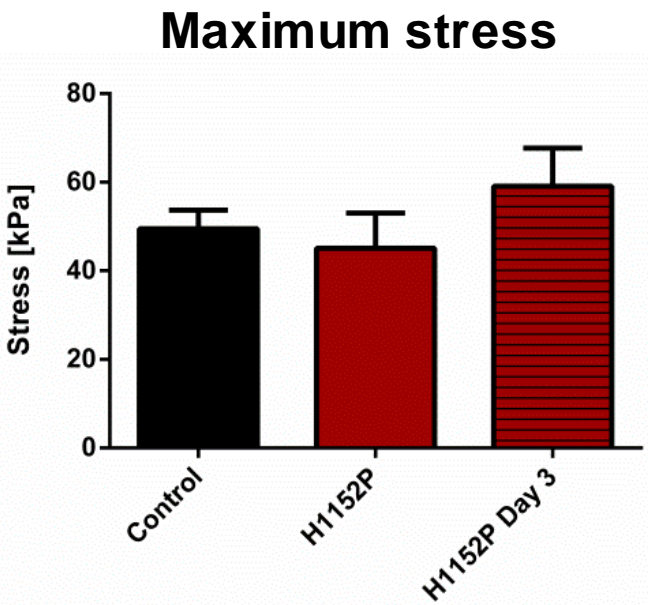

C

Yield point
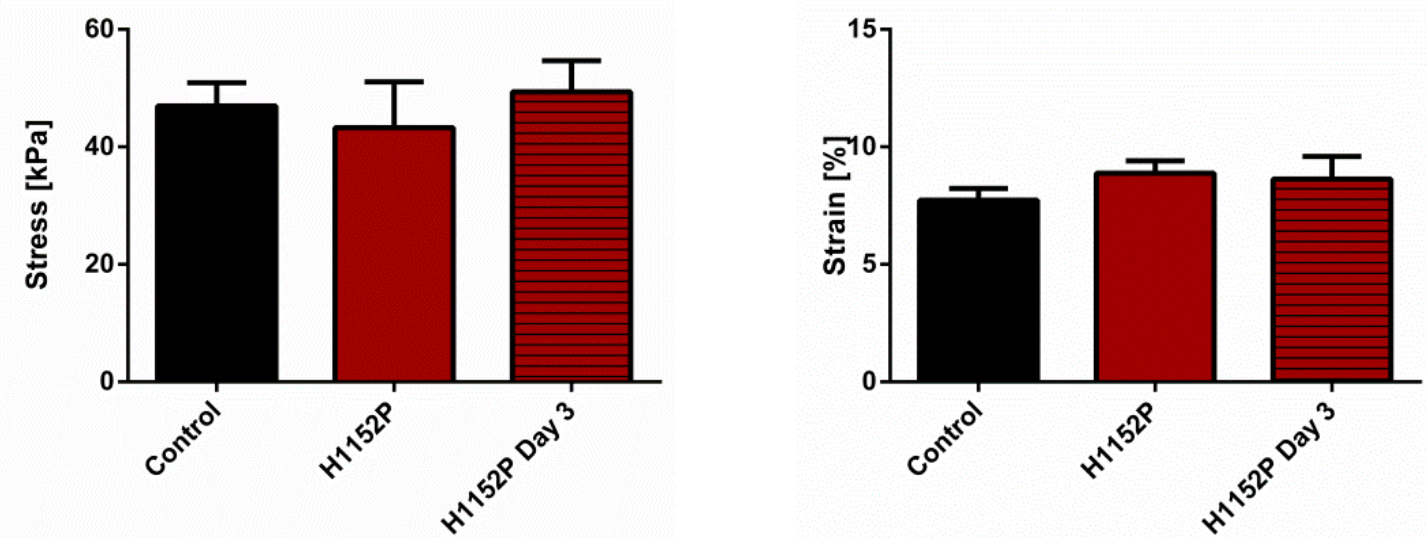

D
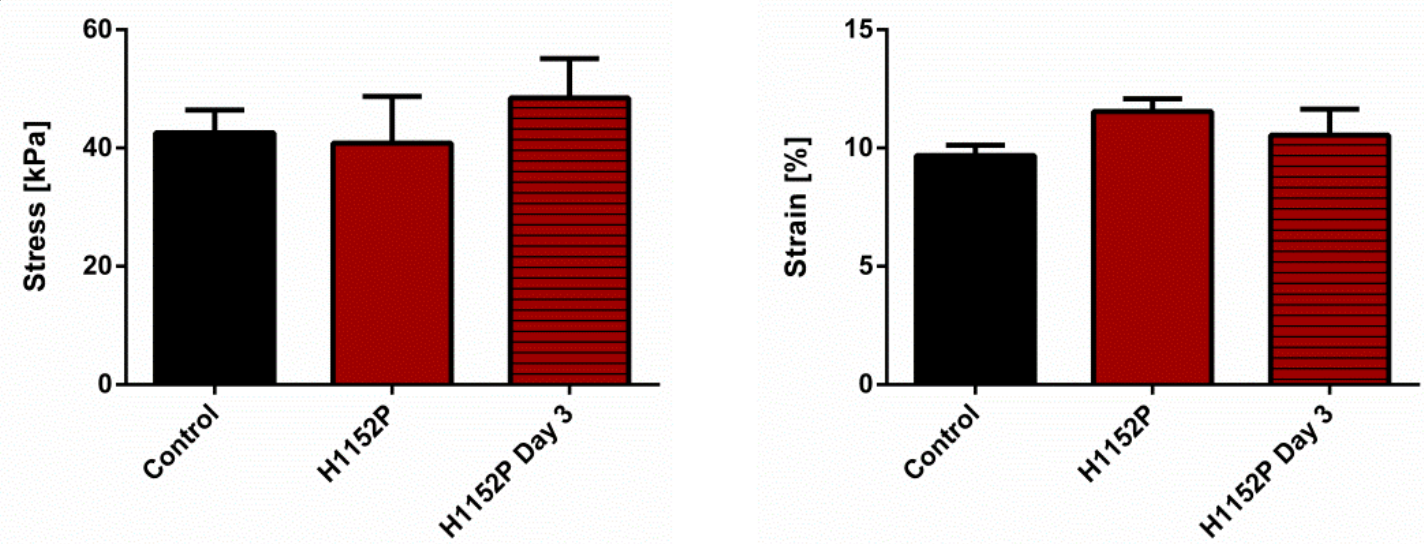

Figure 45: Analysis of the viscoelastic properties of control and H1152P-treated hEHM. Changes in (A) the Young's modulus, (B) maximum stress value, (C) stress (left) and strain value (right) at the yield point, and (D) stress (left) and strain value (right) at the failure point are depicted (means $\pm S E M, n=4-7$, values illustrate numbers of $r E H M$ measured). 


\subsection{Outlook: Finding new selective targets for ROCK1 and ROCK2}

\subsubsection{Identification of new potential ROCK targets}

The role of ROCK1 and ROCK2 has long been considered to be similar, especially because they mostly share common targets and functions. The only wellcharacterized specific substrate is Rnd3 (also known as RhoE), which was shown to be phosphorylated by ROCK1 but not ROCK2 [77]. Thus, the aim was to find new potential selective targets for ROCK1 and ROCK2 using PamGene's kinase activity profiling technology. The system is based on detecting peptide phosphorylation by kinases on a microarray using a mixture of primary and fluorescently labelled secondary antibodies.

A representative image of a microarray after a successful experiment can be seen in Figure 46A. First, different protein amounts of ROCK1 and ROCK2 were applied to the microarray. Of all peptides that were phosphorylated by ROCK1 and ROCK1, the peptides corresponding to a sequence in the human p21 protein (Figure 46B) and the human cyclin-dependent kinase 7 (CDK7) protein (Figure 46C) were chosen for further analysis. p21, also known as cyclin-dependent kinase inhibitor 1 or CDKinteracting protein 1 , is a potent inhibitor of cyclin-CDK1, -CDK2, and -CDK4/6 complexes and proliferating cell nuclear antigen (PCNA). It has been shown that p21 regulates cell cycle progression at $G_{1}$ and $S$ phase, thus mediating growth arrest, differentiation or senescence [186]. CDK7 acts as a CDK activating kinases and can additionally be part of the transcription factor $\mathrm{TFIIH}$, which is involved in transcription initiation by phosphorylating the C-terminal domain of RNA polymerase II. Both p21 and CDK7 were chosen, as knockdown and inhibition of ROCKs had an impact on the cell cycle and proliferation of cardiac fibroblasts.

In Figure $46 \mathrm{~B}$ and $\mathrm{C}$, quantification of the fluorescence intensity for the phosphorylation of the peptides corresponding to human p21 and CDK7 protein dependent on the protein amount of ROCK1 and ROCK2 is shown. As expected, fluorescence intensity was increased the more amount of kinase protein was used, proving the quantitative nature of the assay. Interestingly, p21 seemed to be a much better target for ROCK1 and ROCK2, than CDK7. In a different approach, ROCK1 and ROCK2 were treated with $\mathrm{H} 1152 \mathrm{P}(3 \mu \mathrm{M})$ or the putative ROCK2-selective 
inhibitor SLx-2119 (3 $\mu \mathrm{M})$ prior to performing the assay (Figure 46D, E). As can be seen in Figure 46D and E, pre-treatment with $\mathrm{H} 1152 \mathrm{P}$ mostly resulted in a slight decrease of phosphorylation activity. Only phosphorylation of CDK7 by ROCK2 was diminished by H1152P treatment. Interestingly, pre-treatment with SLX-2119 did not lead to changes in p21 phosphorylation, but slightly decreased CDK7 phosphorylation by ROCK2.
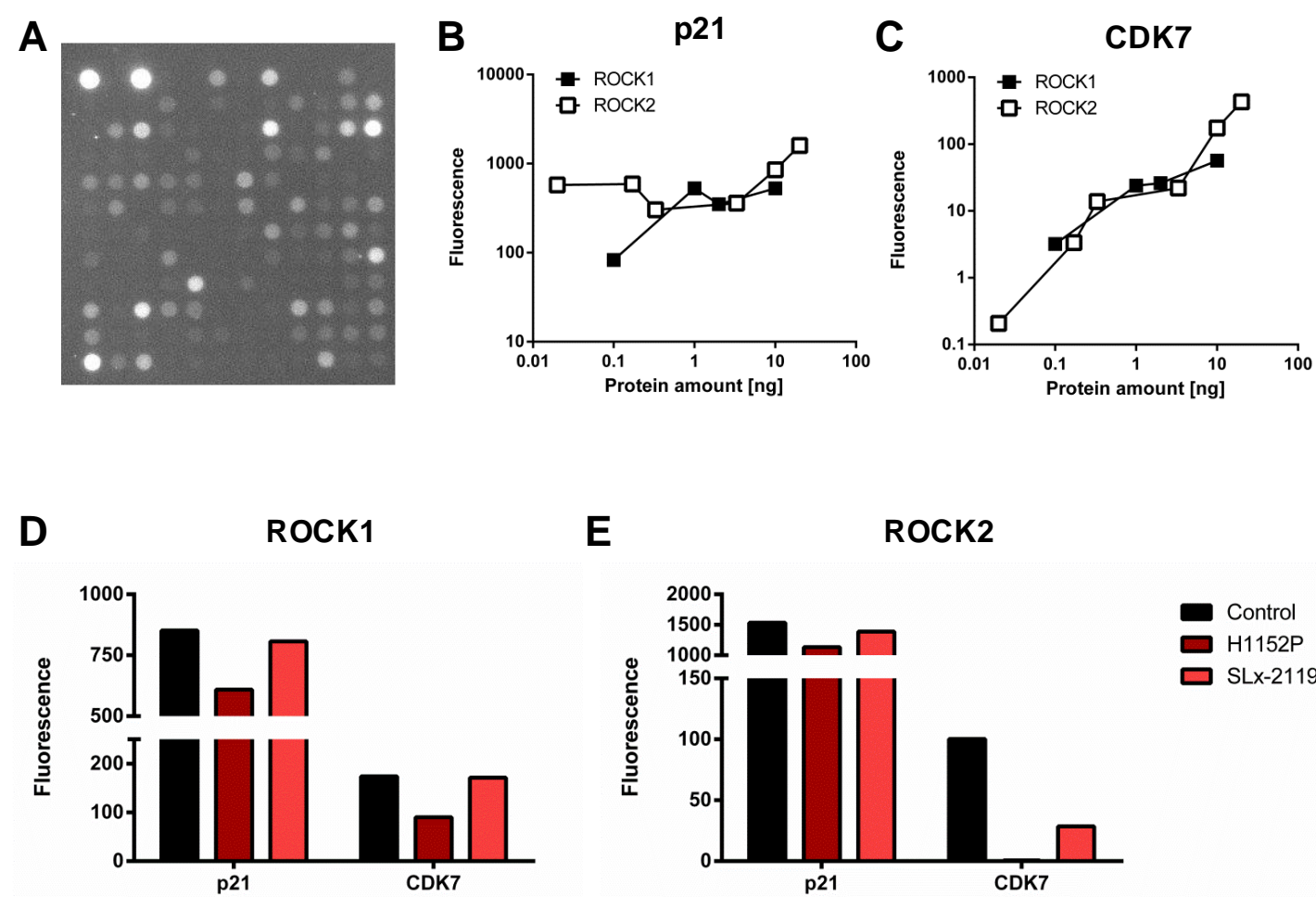

E

ROCK2

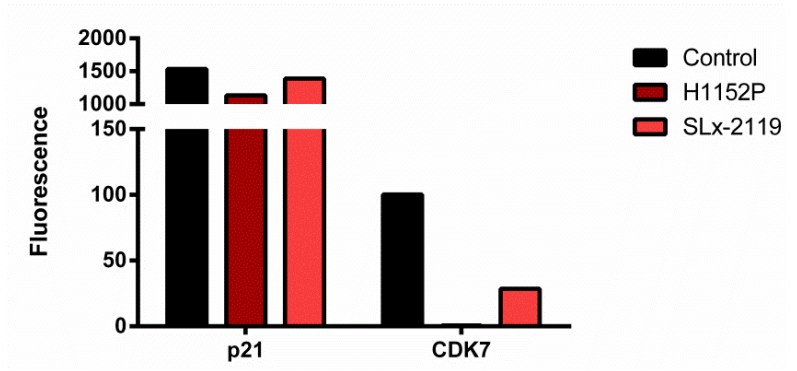

Figure 46: Identification of new ROCK targets using PamGene's kinase activity profiling technology.

(A) Representative fluorescent image showing one PamChip ${ }^{\circledR}$ microarray after termination of the assay. The microarray consists of $140 \mathrm{Ser} / \mathrm{Thr}$ containing peptides and 4 positive control phosphorylated peptides. (B, C) Quantification of the fluorescence intensity for the phosphorylation of the peptide corresponding to a sequence in (B) the human p21 protein and (C) the human CDK7 protein. Different amounts of purified kinase were used (ROCK1: 0.1-20 ng; ROCK2: 0.02-20 ng; $n=1$ ). (D, E) The purified kinases were treated with ROCK inhibitor H1152P $(3 \mu \mathrm{M})$ or ROCK2-specific SLx-2119 (3 $\mu \mathrm{M})$ prior to performing the assay. Bar graph summary of the fluorescence intensity for phosphorylation of peptides corresponding to specific sequences in human p21 und CDK7 proteins by (D) ROCK1 and (E) ROCK2. $10 \mathrm{ng}$ purified kinase were used. 


\subsection{2 p21 and CDK7 are phosphorylated by ROCK1 and ROCK2 in vitro}

In 4.6.1 it was shown that ROCK1 and ROCK2 can phosphorylate peptides of 13 amino acids corresponding to a sequence in the human p21 and CDK7 proteins. In order to investigate if p21 is phosphorylated by ROCK1 and ROCK2, purified recombinant p21 protein was incubated with purified ROCK1 and ROCK2 in an in vitro kinase assay. Additionally, ROCK1 and ROCK2 were incubated with Histone $\mathrm{H} 1$ protein as a positive control and GST protein to rule out that ROCK1 and ROCK2 phosphorylate the GST-tag of the recombinant p21. Using [Y-32P]ATP, p21 was shown to be phosphorylated by both ROCK1 and ROCK2 (Figure 47A). In the next step, purified ROCK1 and ROCK2 were incubated with H1152P (3 $\mu \mathrm{M})$ or SLx-2119 $(3 \mu \mathrm{M})$ prior to performing the in vitro kinase assay. As can be seen in Figure 47B, treatment with ROCK inhibitors did not decrease phosphorylation of $\mathrm{p} 21$, but autophosphorylation of ROCK1 and ROCK2 itself. 


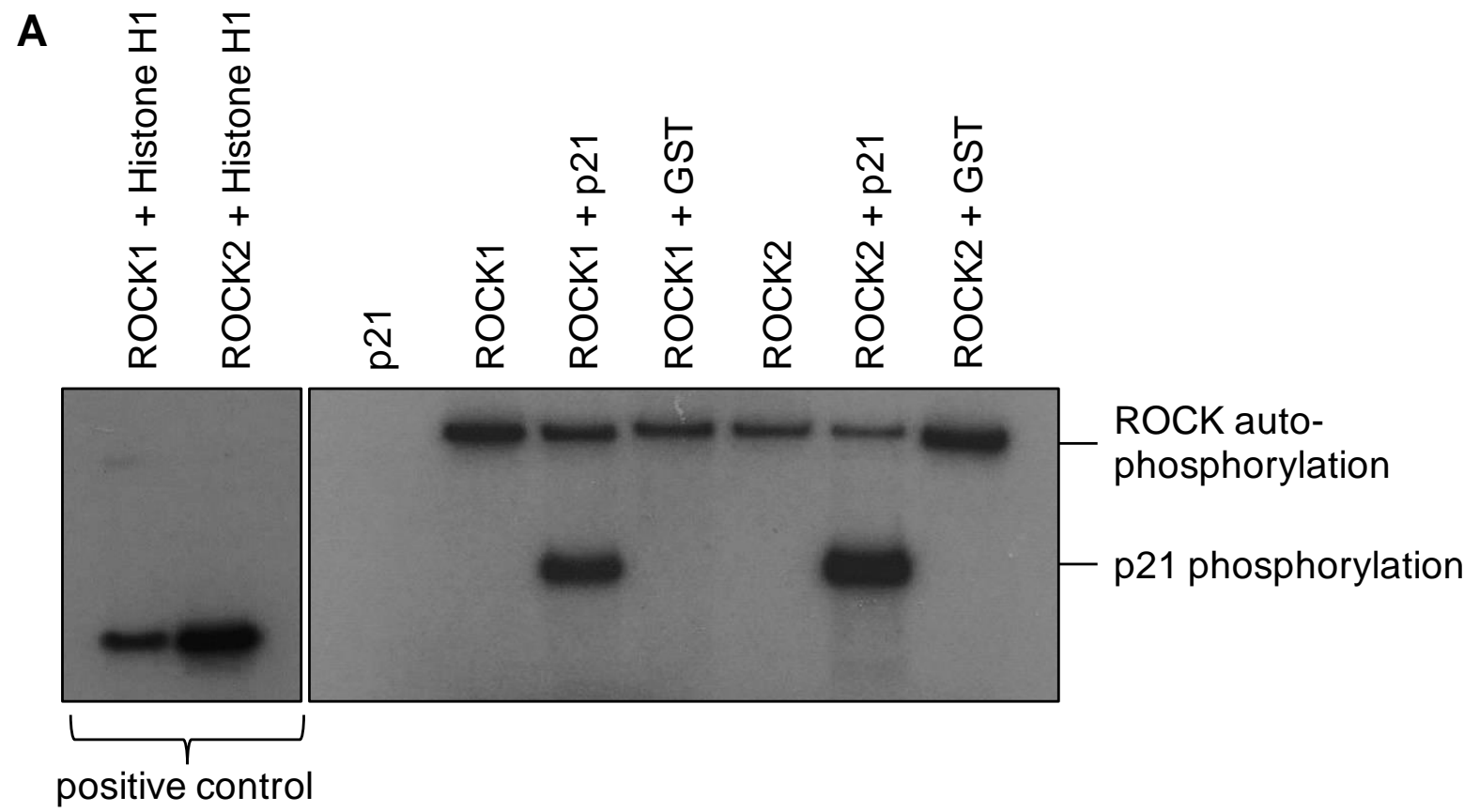

B

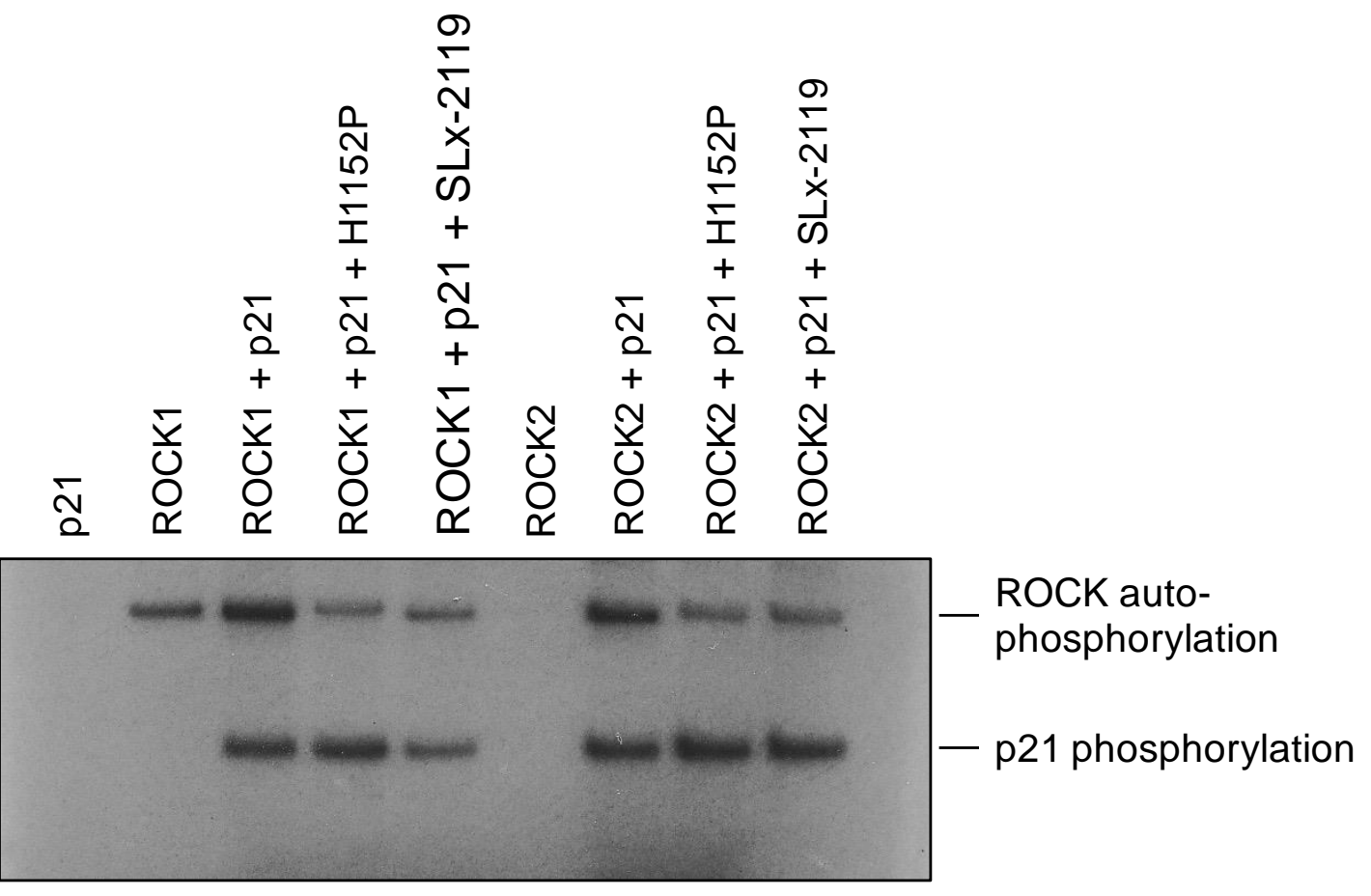

Figure 47: p21 is phosphorylated by ROCK2 and ROCK2 in an in vitro kinase assay.

(A) Purified recombinant p21 protein, histone H1, or GST (2 $\mu$ g each) were incubated with purified ROCK1 or ROCK2 in an in vitro kinase assay in the presence of [ $\left.\mathrm{Y}^{-32} \mathrm{P}\right] \mathrm{ATP}$. Proteins were resolved by SDS-PAGE and protein phosphorylation was detected by autoradiography. (A) Representative autoradiography of in vitro kinase assay showing the phosphorylation of p21 by ROCK1 and ROCK2 ( $n=3)$. (B) Purified ROCK1 and ROCK2 were incubated with $\mathrm{H} 1152 \mathrm{P}(3 \mu \mathrm{M})$ or SLx-2119 $(3 \mu \mathrm{M})$ prior to performing the in vitro kinase assay. Shown is a representative autoradiography $(n=3)$. 
To prove that also CDK7 is phosphorylated by ROCK1 and ROCK2, purified inactive CDK7 protein was incubated with purified ROCK1 and ROCK2 in the presence of [Y${ }^{32} \mathrm{PJATP}$. Also in this experiment, ROCK1 and ROCK2 were pre-treated with $\mathrm{H} 1152 \mathrm{P}$ $(3 \mu \mathrm{M})$ or SLx-2119 $(3 \mu \mathrm{M})$ prior to performing the in vitro kinase assay. Interestingly, a weak phosphorylation of CDK7 could already be detected without the addition of ROCK1 or ROCK2, arguing for an autophosphorylation of CDK7, although the purified protein ought to be inactive. However, phosphorylation of CDK7 by ROCK1 and ROCK2 was much stronger (Figure 48).

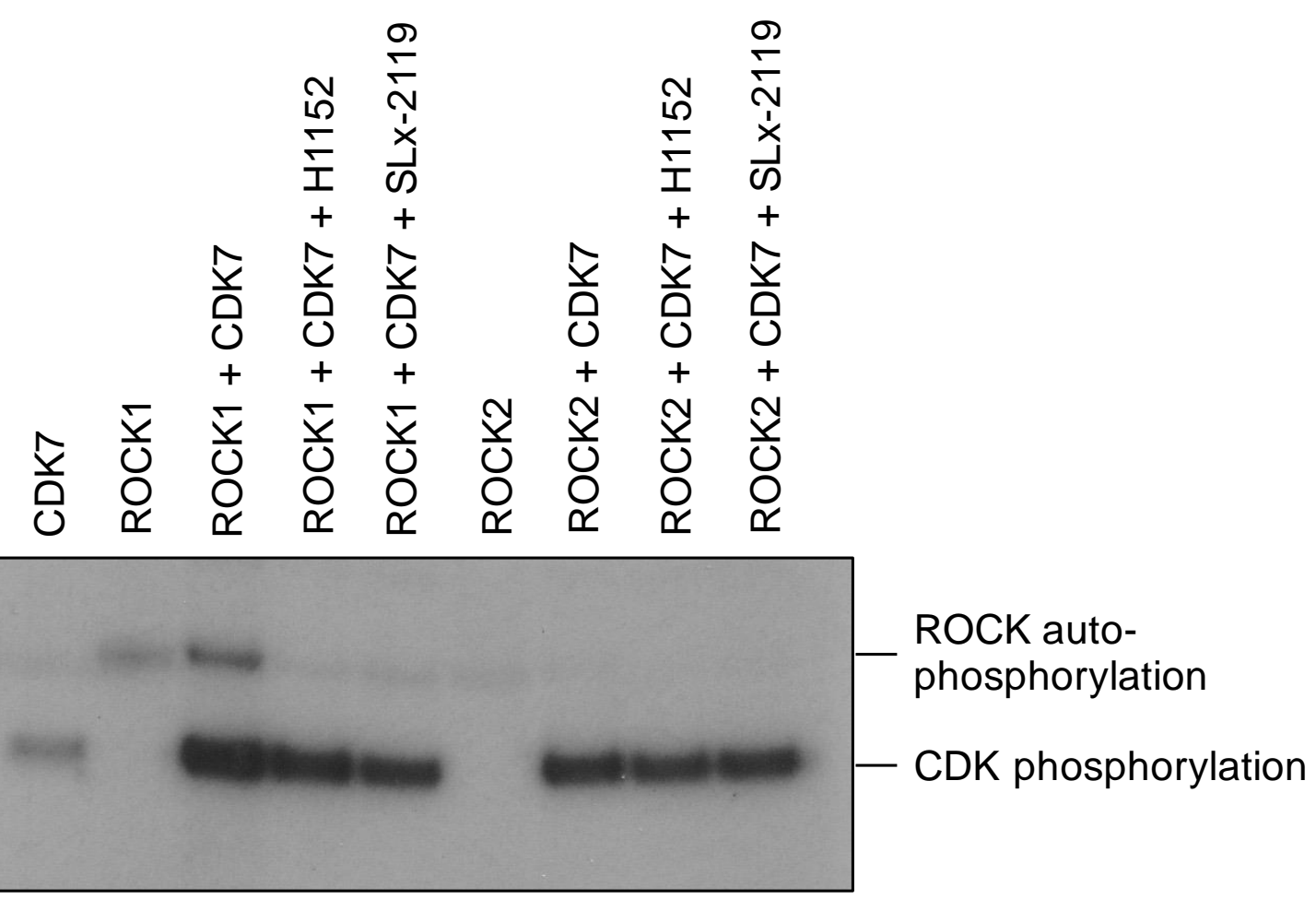

Figure 48: CDK7 is phosphorylated by ROCK2 and ROCK2 in an in vitro kinase assay. Purified recombinant CDK7 protein $(2 \mu \mathrm{g})$ were incubated with purified ROCK1 or ROCK2 in an in vitro kinase assay in the presence of [Y-32P]ATP. Additionally, ROCK1 and ROCK2 were incubated with H1152P $(3 \mu \mathrm{M})$ or SLx-2119 $(3 \mu \mathrm{M})$ prior to performing the in vitro kinase assay. Proteins were resolved by SDS-PAGE and protein phosphorylation was detected by autoradiography. Shown is a representative autoradiography of in vitro kinase assay showing the phosphorylation of CDK7 by ROCK1 and ROCK2 ( $n=3)$. 


\subsection{3 p21 and ROCK1 interact in cells}

To investigate whether p21 and ROCK1 can associate with each other in cells, HEK293A cells were co-transfected with plasmids encoding FLAG-p21 together with myc-ROCK1 wt or myc-ROCK1 $1 \Delta 1$, a constitutively active C-terminally truncated ROCK 1 (Figure 49A). As can be seen in Figure 49B, p21 co-immunoprecipitated with myc-ROCK1 11 and, although weakly, with myc-ROCK1 wt from transfected cell lysates.

A

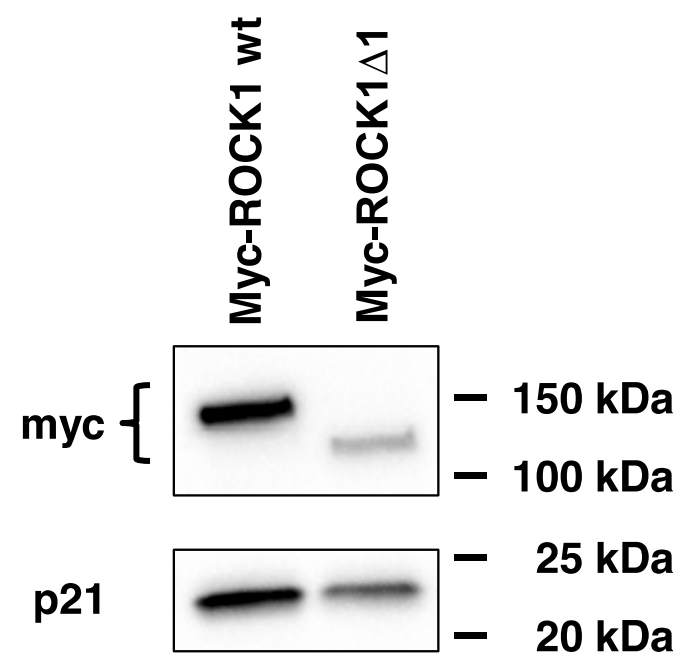

B

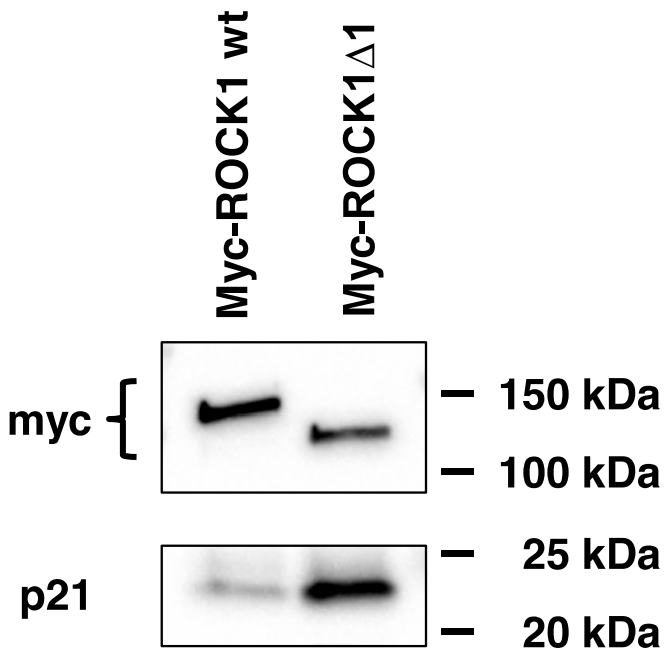

Figure 49: p21 co-immunoprecipitates with ROCK1.

(A) Lysates of HEK293A cells expressing FLAG-p21 and myc-ROCK1 wt or myc-ROCK1 1 were separated by SDS-PAGE followed by immunoblotting. Overexpression of myc-ROCK1 wt, myc-ROCK1 $\Delta 1$, and FLAG-p21 was confirmed using anti-myc and anti-p21 antibodies, respectively. (B) Lysates were subjected to immunoprecipitation with anti-myc beads. The precipitates were separated by SDS-PAGE followed by immunoblotting. 


\section{Discussion}

During the progression of disease, the heart undergoes structural, as well as functional changes. Most work so far focused on the behaviour of cardiomyocytes in pathological conditions. However, it is becoming appreciated that cardiac fibroblasts represent not only the predominant non-myocyte cell population in the heart and are essential for maintaining homeostasis and functionality of the myocardium, but after transdifferentiation into myofibroblasts also play a critical role in the pathogenesis of cardiac hypertrophy, remodelling and heart failure [187]. It is known so far that cFBs communicate with CMs by secretion of paracrine acting factors via direct cell-cell contacts and through secretion and remodelling of the ECM. However, the mechanisms behind what drives the activation and transdifferentiation of cFBs into myofibroblasts remain largely unknown [188]. In this regard, Rho-associated kinases ROCK1 and ROCK2 are known to play a critical role in the pathogenesis of myocardial fibrosis; however, their specific function in cFBs remains unclear [3]. In previous experiments, a knockdown of ROCK1 and of both kinases was established in NRCF using lentiviral delivery of shRNAs. Here it was shown that ROCK signalling has an influence on cFB morphology and that knockdown of ROCK1 and ROCK2 together stops proliferation of cFBs. Moreover, in engineered connective tissue (ECT) and engineered heart muscle (EHM) an effect of ROCK inhibition on viscoelastic and contractile properties, respectively, could be observed. Thus, the hypothesis was that ROCK1 and ROCK2 have an impact on cFB characteristics and are important mediators of myofibroblast differentiation. In this study, it was demonstrated that:

I. ROCK1 and ROCK2 control myofibroblast characteristics like remodelling of the actin cytoskeleton, adhesion, migration, and proliferation in cardiac fibroblasts.

II. ROCK signalling affects ECM protein expression and ECM remodelling.

III. ROCKs are important mediators of viscoelastic and contractile properties of homogeneous and heterogeneous engineered tissues. 


\subsection{ROCK1 and ROCK2 influence morphology and the actin cytoskeleton of cardiac fibroblasts}

To investigate the influence of ROCK1 and ROCK2 signalling further, first an isoform selective knockdown of ROCK1 and ROCK2 was established in NRCF via transfection of siRNAs (Figure 14). Moreover, NRCF were treated with the nonselective ROCK inhibitors Fasudil and H1152P to investigate the effect of an inhibition of ROCK activity.

As ROCK1 and ROCK2 are known to be major regulators of the cytoskeleton in various cell types, the effect of ROCKs on NRCF morphology was evaluated. Upon knockdown of ROCK1 or ROCK2, as well as after treatment with ROCK inhibitors, an increase in NRCF area was observed (Figure 15). Moreover, the actin cytoskeleton was found to be disturbed, as the formation of geodesic actin domes was reduced. Interestingly, geodesic domes were most abundant in lentiviral transduced NRCF compared to those transfected with siRNAs or treated with inhibitors, suggesting that their formation might also be a reaction to the increased stress provided by the lentivirus (Figure 16). Geodesic domes are very rare and highly organised actin structures consisting of specifically ordered polygonal elements. The function of these structures is not clear so far, however, geodesic domes are postulated to be highly stable structures which can provide resistance against tension or compression [189]. Moreover, it has been shown that geodesic domes and stress fibres can transform into each other in neonatal rat cardiac fibroblasts [190]. In line with the findings of this study, Malek et al. showed that using the Rho inhibitor C3 transferase and the ROCK inhibitor Y-27632 the formation of these actin structures was suppressed in hypertonic endothelial cells and is thus dependent on RhoA/Rock signalling [191]. Loss of stress fibres and geodesic domes leading to reduced intracellular tension could also partly explain the increase in cell area observed following ROCK knockdown and inhibition of ROCK activity [189]. Furthermore, ROCK inhibition by H1152P has already been shown to lead to an increase in cell area accompanied by a reduction in stress fibre formation in lung fibroblasts [192]. Also, one of the major effects of ROCK signalling is an increased actomyosin contractility by phosphorylation of MYPT1 and MLC $[45,104]$. Decreased actomyosin contractility due to a knockdown or inhibition of ROCK1 and ROCK2 could increase 
the main area per cell. Additionally, knockdown of RhoA, one of the major activators of ROCKs, also led to an increase in cell size in NRCF [126].

Although a strong effect on NRCF morphology after downregulation of ROCKs could be seen, no change in the expression of the focal adhesion protein vinculin or cytoskeletal proteins, as for example $\beta$-actin, $\alpha$-tubulin or the myofibroblast marker aSMA could be detected by immunoblot analyses (Figure 17). The expression of aSMA and the activity of its regulator serum response factor (SRF) were previously shown to be decreased in NRCF with a downregulation of RhoA [126]. Moreover, inhibition of RhoA with $\mathrm{C} 3$ transferase inhibited the angiotensin II-induced activation of SRF in NRCF. In contrast, treatment with H1152P to inhibit ROCKs was not sufficient to inhibit the angiotensin II-induced activation of SRF in NRCF, which might in part explain why no change in $\alpha$-sm-actin expression could be found [193]. Although the RhoA/ROCK pathway was previously shown to activate SRF, the activation itself is Rho dependent and ROCK activity does not always appear necessary for this process. Thus, other RhoA effectors like $\mathrm{mDia}$, citron kinase, or PLC might be of greater importance in this process than ROCKs [194].

\subsection{ROCK1 and ROCK2 are essential players in cardiac fibroblast adhesion and migration}

Although vinculin protein expression was found unchanged, ROCK1 and ROCK2 knockdown NRCF adhered faster than their respective control cells. No difference between adhesion velocity of the ROCK1 or ROCK2 knockdown was observed (Figure 18). An explanation for the changed adhesion behaviour might be that ROCK1 and ROCK2 knockdown NRCF had more focal adhesions (FAs) than control NRCF. The size of single FAs and the overall area of all FAs per cell were increased in ROCK1 knockdown NRCF. In contrast, ROCK2 knockdown NRCF had smaller FAs and the overall area per cell was unchanged (Figure 19). Focal adhesions are complexes that link actin stress fibres to the ECM. The important role of ROCKs in adhesion processes has mostly been investigated in cancer research together with migration [195]. For example, three activating genetic ROCK1 mutations have been shown to decrease adhesion in lung carcinoma cells [196]. It has been postulated that Rho/ROCK signalling regulates cell adhesion by enhancing actomyosin 
contractility, however the exact mechanism is not clear so far. One possible mechanism involves $\mathrm{Na}^{+} / \mathrm{H}^{+}$exchanger 1 (NHE1), which can be phosphorylated by ROCKs and is known to mediate the turnover and assembly of FAs, thereby possibly contributing to cell migration [197, 198]. Moreover, recent data from our group showed that also after RhoA knockdown in NRCF, adhesion velocity was increased. Interestingly, RhoA knockdown NRCF had smaller FAs, similar to the ROCK2 knockdown [126].

The changes in cFB morphology and adhesion also had an impact on migratory behaviour of the ROCK1 and ROCK2 knockdown NRCF. In this study, the knockdown of ROCK1 and ROCK2 decreased migration velocity and absolute migrated distance on a focal plane (Figure 20). The involvement of ROCK1 and ROCK2 in cardiac fibroblast migration has not been investigated in great detail so far. However, several studies are available focussing on ROCKs and migration in cancer cells, which confirmed our findings for the planar migration [195, 199, 200]. In general, it is known that for all migratory processes, a dynamic remodelling of the actin cytoskeleton is essential. This is usually regulated by the RhoGTP family: Cdc42 has been shown to be important for cell polarity and together with Rac controls the formation and turnover of lamellipodia and focal complexes, whereas Rho/ROCK signalling is important for actomyosin contraction at the rear of the cell to facilitate tail retraction. However, as Rho activity also plays a role in the formation of focal adhesions, a strong activity rather inhibits migration [201, 202]. There are different types of fibroblast migration: the lamellipodia-dependent, mesenchymal migration which requires cell polarity, the blebbing-dependent amoeboid migration, and an intermixed way, termed lobopodia-dependent migration. Fibroblasts have been shown to mostly migrate lamellipodia-dependent in culture, and lamellipodia- or lobopodia-dependent in a 3D environment, depending on the matrix and also on the activity of RhoA [203, 204]. In this study, not only the migration on a focal plane, but also the invasive migration of NRCF with a knockdown of both kinases in a transwell migration assay was found to be reduced (Figure 23). This is especially interesting as the invasive migration of myofibroblasts in remodelling processes is essential for the development of fibrosis and scar formation [38]. 
In contrast, knockdown of both kinases, as well as inhibition of ROCK activity using $\mathrm{H} 1152 \mathrm{P}$, had an opposing effect on the migratory behaviour of NRCF, as velocity and absolute migrated distance of NRCF were both significantly increased (Figure 21). These findings were quite unexpected. However, it has already been shown in cancer cells that inhibition of ROCK sometimes leads to contradicting effects on cell migration. For example, ROCK inhibition by Y-27632 in MCF-7 breast cancer cells led to enhanced migration and invasion of these cells, partly due to a loss of $\mathrm{E}$ cadherin and $\beta$-catenin from the cell membrane and activation of Rac1 signalling [205]. The contradicting effects of ROCK inhibition on cancer cells is usually attributed to the high plasticity of these cells, as well as an upregulation of other pathways like Rac signalling [195]. Due to the fact that both ROCKs are affected in the double knockdown or after inhibition with H1152P, an upregulation of other GTPase pathways involved in migration like Rac1 or Cdc42 is likely. For example, activation of Cdc42 and subsequent activation of the kinase Pak2 can also promote actomyosin contractility similar to RhoA/ROCK signalling by phosphorylation of MLC at Ser19, thereby activating myosin-II [206].

\subsection{ROCK1 and ROCK2 control proliferation of cardiac fibroblasts}

Myofibroblasts are also characterised by an increased proliferative capacity when compared to quiescent cardiac fibroblasts. Analysis of proliferation in response to a serum stimulus showed that only if both ROCK1 and ROCK2 were affected, i.e. after inhibition of ROCK activity by H1152P, proliferation of NRCF was diminished (Figure 24). This has already been shown for the double knockdown in NRCF (Figure 6) and it is in line with findings from other groups. For example, simvastatin, a HMG-CoA reductase inhibitor that inhibits RhoA geranylgeranylation thereby preventing its association to the plasma membrane, inhibited the FCS-driven proliferation of human atrial myofibroblasts. This effect could be mimicked by treatment of the cells with the ROCK inhibitor Y-27632, proving an involvement of ROCK signalling [128]. Similarly, the ROCK inhibitor GSK-576371 was shown to reduce angiotensin II and TGF $\beta 1$ induced proliferation of NRCF [207]. In contrast to these findings, downregulation of either ROCK1 or ROCK2 did not have an effect on CFB proliferation, suggesting that at least in CFB, this process is dependent on both ROCK1 and ROCK2, or that they can compensate for each other (Figure 24). 
The reason for the effect on cFB proliferation was further investigated and it was found that H1152P treatment might lead to a cytokinesis defect in NRCF. H1152Ptreated NRCF failed to divide, which resulted in a higher percentage of doublenucleated cells. Another finding that supports the hypothesis of a cytokinesis defect is that H1152P-treated NRCF within engineered tissues were found to be increasingly present in $\mathrm{G}_{2} \mathrm{M}$ phase when compared to control tissues (Figure 25). Cytokinesis is a complex process that occurs in four stages: (I) Specification of the cleavage plane and recruitment of RhoA, a central regulator of cytokinesis, to the cleavage site; (II) Furrow ingression by formation of an actomyosin ring; (III) Midbody formation and stabilisation of the cytokinetic furrow by compacting the central spindle microtubules; (IV) Abscission of the furrow by separation of the cytoplasm of the daughter cells [208]. ROCKs play a vital role during the second phase, the ingression of the cleavage furrow. They have been shown to localise at the cleavage furrow and contribute together with citron kinase to myosin activation by phosphorylating MLC at Thr18 and Ser19, which is important for proper localization of myosin to the furrow [209-213]. However, it can be assumed that ROCKs and citron kinase have partially overlapping functions, as treatment with Y-27632 and Fasudil significantly slowed the cleavage, but did not stop it [212].

Using kinase activity profiling, in vitro kinase assays and immunoprecipitation, p21 and CDK7 were identified as potential new ROCK substrates (Figure 46-Figure 49). p21 is a multifunctional protein that is usually upregulated in response to cellular stresses as for example DNA damage or oxidative stress, to arrest the cell cycle. It primarily does so by acting as a CDK inhibitor by binding to CDK2 and CDK1 and inhibiting their activity. Depending on the binding partner, this leads to growth arrest at specific stages of the cell cycle. Moreover, p21 also binds proliferating cell nuclear antigen (PCNA), thereby interfering with its DNA-polymerase activity and inhibiting DNA replication, as well as modulating PCNA-dependent DNA repair processes [186]. Each peptide on the PamGene chip represents a 15 amino acid sequence, of which 13 residues were derived from the phosphorylation site in the respecting human protein, in this case amino acids 139-151 of p21. Phosphorylation of p21 at the potential ROCK phosphorylation site Thr145 by Akt1/PKB and PKA was shown to inhibit binding to PCNA $[214,215]$. Phosphorylation of Ser146 by Akt1/PKB 
increased p21 stability and promoted cell survival, whereas PKC inhibited PCNA binding $[215,216]$. The putative phosphorylation of p21 by ROCK1 or ROCK2 could have a negative regulatory effect on p21 function, as knockdown or inhibition of ROCKs stops proliferation of cFBs.

CDK7 on the other hand has a dual function in cell cycle control and transcription. It can act as a CDK-activating kinase by phosphorylating cell cycle CDKs within their activating T-loop, which together with binding to the respective cyclin is required for full activity of the kinases. Moreover, CDK7 is part of the transcription factor TFIIH, which is known to phosphorylate the C-terminal domain of DNA polymerase II [217]. In the case of CDK7, the 13 residues on the PamGene chip were derived from the phosphorylation site involving amino acids 163-175 of CDK7. Both potential ROCK phosphorylation sites, Ser164 and Thr170 have been linked to the regulation of transcriptional activity by CDK7 [218-220]. By this, also ROCK could interfere with transcription and cell cycle progression.

\subsection{ROCK signalling influences the regulation and turnover of the ECM and thus viscoelastic properties of engineered tissues}

In order to study the functional role of cardiac fibroblasts regarding regulation of the ECM in a more physiological model, ECT consisting of cardiac fibroblasts and collagen I as a hydrogel were utilised. ROCK inhibitor-treated tissues were less consolidated than control tissues with an increase in CSA (Figure 26). Using destructive tensile strength measurement, it was demonstrated in this study that not only in the rat, but also in the human model, treatment of ECT with ROCK inhibitors altered their viscoelastic properties. Stiffness as defined by the Young's modulus was decreased in ROCK inhibitor-treated tissues. Also, these tissues tolerated less maximal stress and more ultimate stress was needed until the yield and failure point were reached (Figure 33).

After it was excluded that the observed changes were due to a different amount of cells in the tissues, i.e. due to an altered proliferation, gene expression analysis of ECM genes was performed. Inhibition of ROCK activity in ECT increased elastin gene expression and decreased the expression of its respective degrading enzyme MMP12 (Figure 30). Elastin is a major component of the extracellular matrix and its 
major biological function is to give elasticity to organs and tissues, thereby allowing them to resume their shape after stretching or contracting [221]. Genomic mutations in the elastin gene have been shown to play a role in supravalvular aortic stenosis, which causes narrowing of the large arteries [222]. Translocations or point mutations in the gene lead to a truncated form of elastin which lacks important crosslinking domains, resulting in the deposition of abnormal elastin fibres [222, 223]. With the help of the ECT model, it was tested whether an increase in the amount of elastin fibres by inhibiting its degrading enzyme MMP12 using a small molecule inhibitor, MMP408, had a similar effect on the viscoelastic properties of the ECT as ROCK inhibition. However, treatment with MMP408 alone did not alter cross-sectional area or viscoelastic properties of the ECT when compared to control tissues, and simultaneous treatment with H1152P did not lead to a cumulative effect (Figure 31, Figure 32). These results suggest that increased expression of elastin and decreased expression of MMP12 is not the only mechanism underlying the observed effects in ROCK inhibitor-treated tissues.

Also, the expression of the collagen and elastin crosslinking enzyme lysyl oxidase was found to be decreased upon ROCK inhibition (Figure 30). Lysyl oxidase is of considerable importance in heart disease, as the degree of collagen crosslinking determines its thickness, stiffness, and resistance to degradation and thus affects myocardial dysfunction [184]. In heart failure patients, lysyl oxidase expression was found to be increased, and the resulting enhanced collagen crosslinking had an impact on increased LV stiffness and filling pressures [224, 225]. Thus, reduced expression of lysyl oxidase in ROCK inhibitor-treated ECT might lead to less crosslinking of collagens and elastin, resulting in the observed decrease in tissue stiffness.

Interestingly, expression of typical collagens and MMPs, as for example collagens 1a1 and 3a1, and MMP2 and 9, as well as of the collagen organisers biglycan and decorin, and the pro-fibrotic factors CTGF and TGF $\beta$ was not affected (Figure 30). These results are in contrast to findings from other groups in cultured cells. For example, Akhmetshina et al. demonstrated in scleroderma fibroblasts that expression and synthesis of the ECM proteins fibronectin, collagen 1a1, and collagen 1a2 was decreased upon ROCK inhibition. However, in accordance to this study, no change in 
expression of MMPs was detected [226]. In contrast, several independent groups have shown that ROCK inhibitor treatment can lead to diminished expression of MMP2 and MMP9 in various cell types [227-229]. Until now, these discrepancies cannot be explained satisfactorily.

Due to its 3D properties, the ECT model provides a more physiological environment for the cardiac fibroblasts than a 2D culture and might thus prevent their immediate transition into myofibroblasts, which usually happens during culturing. Effects of ROCK inhibition on ECM protein expression and secretion might therefore not be as obvious. For this reason, a different approach was to push the transdifferentiation of cFBs to myofibroblasts by treatment of ECT with TGF $\beta 1$. It was found that treatment with TGF $\beta 1$ together with $\mathrm{H} 1152 \mathrm{P}$ had an effect on consolidation of ECT, but not on their viscoelastic properties (Figure 34, Figure 36). It is known that canonical (SMAD) and non-canonical (MAPK-p38) TGF $\beta$ signalling is sufficient to initiate cardiac fibroblast to myofibroblast transdifferentiation by inducing the transcription of ECM and smooth muscle contractile genes. In contrast, the Rho/ROCK-MRTF-SRF pathway gets activated later in the process and then helps cement the phenotype [230]. Thus, simultaneous treatment of ECT with TGF $\beta$ and H1152P might be sufficient to alter consolidation properties, i.e. decrease the CSA of rECT as there is already a change in ECM composition. However, this is insufficient to alter viscoelastic characteristics as the Rho/ROCK-MRTF-SRF pathway is blocked. This might in part explain why rECT that were treated with TGF $\beta 1$ and H1152P showed a decreased CSA compared to H1152P treatment alone, whereas stiffness was similar to H1152P-treated rECT. In addition, as treatment with TGF $\beta 1$ alone did not increase tissue stiffness compared to control, a higher concentration of TGF $\beta 1$ might be needed to adequately push cFB to myofibroblast transition in the ECT model.

\subsection{ROCK1 and ROCK2 have an influence on the contractility of EHM}

As ROCK inhibition led to a reduced stiffness in ECT, it was investigated whether this applies also for heterogeneous tissues consisting of cFBs and CMs and if so, whether a decreased stiffness influences contractile properties of EHM. 
First, engineered tissues consisting of cFBs and $\mathrm{CMs}$ to model heart muscle were subjected to rheological destructive tensile strength measurement to evaluate viscoelastic properties of these tissues. Similar to rECT, the Young's modulus and maximum stress of Fasudil- and H1152P-treated rEHM was reduced and less ultimate stress was needed until the yield point and failure point were reached (Figure 40). This suggests that the influence of cFBs on the regulation and turnover of the ECM applies also for the heterogeneous heart muscle model. However, analysis of hEHM consisting of NHCF-V and hES2 wt CM treated with H1152P did not show any differences in viscoelastic properties, although a trend towards a reduced stiffness could be detected (Figure 45). When comparing the stress-strain curves of EHM versus ECT in destructive tensile strength measurements it became apparent that there are certain differences. For example, EHM usually had a clear defined failure point as these tissues ruptured instantaneously when reaching the point. In contrast, ECT ruptured much slower, usually starting at one point and then slowly continuing over several seconds. In addition, ECT were stiffer, as the Young's modulus was significantly higher. This showed that due to the distinct cell composition of the tissues, EHM rather behave as an elastic material, whereas ECT behave as a viscous material in destructive tensile strength measurements.

To analyse functional parameters of the EHM, the tissues were subjected to isometric force measurement under increasing extracellular calcium. In the rat model, Fasudil- and H1152P-treated rEHM showed a decreased resting force (Figure 38). This is in accordance to the findings from the rheological measurements, as the resting force is also a measure for stiffness of the EHM. In the human model, no change in resting force could be detected, which supports the rheological data (Figure 42).

Interestingly, in the rat model, no effect of ROCK inhibition on force of contraction was found. In addition, there was no effect on $\mathrm{EC}_{50} \mathrm{Ca}^{2+}$ (Figure 38). In the human model, force of contraction was significantly reduced after H1152P treatment from day three of culturing, and even further if ROCKs were inhibited directly from the beginning. Also in $\mathrm{hEHM}$ there was no change in $\mathrm{EC}_{50} \mathrm{Ca}^{2+}$ (Figure 42). So far, these findings cannot be explained to full extent. For the human EHM model, CMs derived from human embryonic stem cells ( $\mathrm{hES} 2$ wt $\mathrm{CM}$ ) were utilised, which resemble the 
maturation status of embryonic CMs, and for $\mathrm{rEHM}$ neonatal $\mathrm{CMs}$ were used. It was already demonstrated in the rat that the EHM model induces further maturation of initially immature CMs towards a ventricle-like phenotype [231]. Therefore, it can be assumed that this is also the case in the human EHM model. hEHM that were treated with $\mathrm{H} 1152 \mathrm{P}$ from the beginning developed a lower force of contraction than those in which treatment was started after three days of consolidation, and in both force of contraction was decreased compared to control tissues. Consistent with these findings, force of contraction of ROCK inhibitor-treated rEHM consisting of neonatal CMs was unchanged compared to control, but higher than force of contraction of both H1152P-treated hEHM, although the rat and human model cannot be compared that easily. Therefore, it was hypothesized that inhibition of ROCK signalling influences not only ECM synthesis and turnover in engineered tissues, but also impacts the maturation of CMs in EHM.

\subsection{Conclusion and perspectives}

In conclusion, this study showed that ROCK1 and ROCK2 are indeed important players in the transdifferentiation from cardiac fibroblasts to myofibroblasts. Utilizing a neonatal rat cardiac fibroblast culture, it was demonstrated that downregulation or inhibition of ROCK1 and ROCK2 resulted in (I) a disturbed actin cytoskeleton and reduced formation of higher order actin structures; (II) enhanced adhesion; (III) an ambivalent influence on migration; (IV) reduced proliferation. Moreover, the important cell cycle regulatory proteins p21 and CDK7 were identified as potential new targets for ROCK1 and ROCK2. However, further critical experiments need to be performed for verification and identification of the exact phosphorylation site. Furthermore, it was shown that inhibition of ROCK activity affects viscoelastic and contractile properties of ECT and EHM, which could possibly be due to a change in ECM composition, as well as an impairment of $\mathrm{CM}$ maturation. Additional experiments utilising ROCK1 and ROCK2 knockdown cFBs or CMs would provide evidence whether the effect of ROCK inhibition on contractility of EHM is mainly due to an effect on cFBs, CMs, or both. It is also of great importance to further determine selective function of ROCK1 and ROCK2, i.e. using conditional ROCK1 and ROCK2 depletion in CFBs or CMs in mice. There is growing evidence that ROCK1 and ROCK2 play an important role in the development of cardiovascular diseases. The 
findings of this study show that this is especially true for the transdifferentiation of cFBs to myofibroblasts and hence, the development of cardiac fibrosis. Thus, ROCK1 and ROCK2 represent an attractive therapeutic target regarding treatment and prevention of cardiovascular diseases. 


\section{Bibliography}

1. WHO. 2016 [cited 2016 08/23]; Available from: http://www.who.int/mediacentre/factsheets/fs317/en/.

2. Hill, J.A. and E.N. Olson, Cardiac plasticity. N Engl J Med, 2008. 358(13): p. 1370-80.

3. Hartmann, S., A.J. Ridley, and S. Lutz, The Function of Rho-Associated Kinases ROCK1 and ROCK2 in the Pathogenesis of Cardiovascular Disease. Front Pharmacol, 2015. 6: p. 276.

4. Janicki, J.S. and G.L. Brower, The role of myocardial fibrillar collagen in ventricular remodeling and function. J Card Fail, 2002. 8(6 Suppl): p. S319-25.

5. Abraham, W.T., B.H. Greenberg, and C.W. Yancy, Pharmacologic therapies across the continuum of left ventricular dysfunction. Am J Cardiol, 2008. 102(5A): p. 21G-28G.

6. Bristow, M.R., beta-adrenergic receptor blockade in chronic heart failure. Circulation, 2000. 101(5): p. 558-69.

7. Souders, C.A., S.L. Bowers, and T.A. Baudino, Cardiac fibroblast: the renaissance cell. Circ Res, 2009. 105(12): p. 1164-76.

8. Naito, H., et al., Optimizing engineered heart tissue for therapeutic applications as surrogate heart muscle. Circulation, 2006. 114(1 Suppl): p. 172-8.

9. Krenning, G., E.M. Zeisberg, and R. Kalluri, The origin of fibroblasts and mechanism of cardiac fibrosis. J Cell Physiol, 2010. 225(3): p. 631-7.

10. Zeisberg, E.M. and R. Kalluri, Origins of cardiac fibroblasts. Circ Res, 2010. 107(11): p. 1304-12.

11. Fan, D., et al., Cardiac fibroblasts, fibrosis and extracellular matrix remodeling in heart disease. Fibrogenesis Tissue Repair, 2012. 5(1): p. 15.

12. Kong, P., et al., Lack of specificity of fibroblast-specific protein 1 in cardiac remodeling and fibrosis. Am J Physiol Heart Circ Physiol, 2013. 305(9): p. H1363-72.

13. Lie-Venema, H., et al., Origin, fate, and function of epicardium-derived cells (EPDCs) in normal and abnormal cardiac development. ScientificWorldJournal, 2007. 7: p. 1777-98.

14. Olivey, H.E., et al., Transforming growth factor-beta stimulates epithelialmesenchymal transformation in the proepicardium. Dev Dyn, 2006. 235(1): $p$. 50-9. 
15. Norris, R.A., et al., Periostin regulates collagen fibrillogenesis and the biomechanical properties of connective tissues. J Cell Biochem, 2007. 101(3): p. 695-711.

16. de Lange, F.J., et al., Lineage and morphogenetic analysis of the cardiac valves. Circ Res, 2004. 95(6): p. 645-54.

17. Kanekar, S., et al., Cardiac fibroblasts form and function. Cardiovasc Pathol, 1998. 7(3): p. 127-33.

18. Lindner, D., et al., Differential expression of matrix metalloproteases in human fibroblasts with different origins. Biochem Res Int, 2012. 2012: p. 875742.

19. Camelliti, P., et al., Spatially and temporally distinct expression of fibroblast connexins after sheep ventricular infarction. Cardiovasc Res, 2004. 62(2): p. 415-25.

20. Gaudesius, G., et al., Coupling of cardiac electrical activity over extended distances by fibroblasts of cardiac origin. Circ Res, 2003. 93(5): p. 421-8.

21. Kohl, P., Heterogeneous cell coupling in the heart: an electrophysiological role for fibroblasts. Circ Res, 2003. 93(5): p. 381-3.

22. Kapoun, A.M., et al., B-type natriuretic peptide exerts broad functional opposition to transforming growth factor-beta in primary human cardiac fibroblasts: fibrosis, myofibroblast conversion, proliferation, and inflammation. Circ Res, 2004. 94(4): p. 453-61.

23. Ikeuchi, M., et al., Inhibition of TGF-beta signaling exacerbates early cardiac dysfunction but prevents late remodeling after infarction. Cardiovasc Res, 2004. 64(3): p. 526-35.

24. Segura, A.M., O.H. Frazier, and L.M. Buja, Fibrosis and heart failure. Heart Fail Rev, 2014. 19(2): p. 173-85.

25. Leask, A., TGFbeta, cardiac fibroblasts, and the fibrotic response. Cardiovasc Res, 2007. 74(2): p. 207-12.

26. Hinz, B., et al., The myofibroblast: one function, multiple origins. Am J Pathol, 2007. 170(6): p. 1807-16.

27. Haudek, S.B., et al., Monocytic fibroblast precursors mediate fibrosis in angiotensin-II-induced cardiac hypertrophy. J Mol Cell Cardiol, 2010. 49(3): p. 499-507.

28. Mack, C.P., Signaling mechanisms that regulate smooth muscle cell differentiation. Arterioscler Thromb Vasc Biol, 2011. 31(7): p. 1495-505.

29. Miralles, F., et al., Actin dynamics control SRF activity by regulation of its coactivator MAL. Cell, 2003. 113(3): p. 329-42. 
30. Posern, G. and R. Treisman, Actin' together: serum response factor, its cofactors and the link to signal transduction. Trends Cell Biol, 2006. 16(11): p. 588-96.

31. Miano, J.M., Serum response factor: toggling between disparate programs of gene expression. J Mol Cell Cardiol, 2003. 35(6): p. 577-93.

32. Davis, J. and J.D. Molkentin, Myofibroblasts: trust your heart and let fate decide. J Mol Cell Cardiol, 2014. 70: p. 9-18.

33. Tomasek, J.J., et al., Myofibroblasts and mechano-regulation of connective tissue remodelling. Nat Rev Mol Cell Biol, 2002. 3(5): p. 349-63.

34. Hinz, B., Formation and function of the myofibroblast during tissue repair. J Invest Dermatol, 2007. 127(3): p. 526-37.

35. Serini, G., et al., The fibronectin domain ED-A is crucial for myofibroblastic phenotype induction by transforming growth factor-beta1. J Cell Biol, 1998. 142(3): p. 873-81.

36. Sun, Y., et al., Infarct scar as living tissue. Basic Res Cardiol, 2002. 97(5): p. 343-7.

37. Willems, I.E., et al., The alpha-smooth muscle actin-positive cells in healing human myocardial scars. Am J Pathol, 1994. 145(4): p. 868-75.

38. Weber, K.T., et al., Myofibroblast-mediated mechanisms of pathological remodelling of the heart. Nat Rev Cardiol, 2013. 10(1): p. 15-26.

39. Christia, P., et al., Systematic characterization of myocardial inflammation, repair, and remodeling in a mouse model of reperfused myocardial infarction. J Histochem Cytochem, 2013. 61(8): p. 555-70.

40. Porter, K.E., et al., Tumor necrosis factor alpha induces human atrial myofibroblast proliferation, invasion and MMP-9 secretion: inhibition by simvastatin. Cardiovasc Res, 2004. 64(3): p. 507-15.

41. Fredj, S., et al., Role of interleukin-6 in cardiomyocyte/cardiac fibroblast interactions during myocyte hypertrophy and fibroblast proliferation. J Cell Physiol, 2005. 204(2): p. 428-36.

42. Krizhanovsky, V., et al., Senescence of activated stellate cells limits liver fibrosis. Cell, 2008. 134(4): p. 657-67.

43. Desmouliere, A., et al., Apoptosis mediates the decrease in cellularity during the transition between granulation tissue and scar. Am J Pathol, 1995. 146(1): p. 56-66.

44. Takemura, G., et al., Role of apoptosis in the disappearance of infiltrated and proliferated interstitial cells after myocardial infarction. Circ Res, 1998. 82(11): p. $1130-8$. 
45. Amano, M., et al., Phosphorylation and activation of myosin by Rhoassociated kinase (Rho-kinase). J Biol Chem, 1996. 271(34): p. 20246-9.

46. Kimura, K., et al., Regulation of myosin phosphatase by Rho and Rhoassociated kinase (Rho-kinase). Science, 1996. 273(5272): p. 245-8.

47. Ishizaki, T., et al., The small GTP-binding protein Rho binds to and activates a $160 \mathrm{kDa}$ Ser/Thr protein kinase homologous to myotonic dystrophy kinase. EMBO J, 1996. 15(8): p. 1885-93.

48. Nakagawa, O., et al., ROCK-I and ROCK-II, two isoforms of Rho-associated coiled-coil forming protein serine/threonine kinase in mice. FEBS Lett, 1996. 392(2): p. 189-93.

49. Doran, J.D., et al., New insights into the structure-function relationships of Rho-associated kinase: a thermodynamic and hydrodynamic study of the dimer-to-monomer transition and its kinetic implications. Biochem J, 2004. 384(Pt 2): p. 255-62.

50. Shimizu, T., et al., Parallel coiled-coil association of the RhoA-binding domain in Rho-kinase. J Biol Chem, 2003. 278(46): p. 46046-51.

51. Dvorsky, R., et al., Structural insights into the interaction of ROCKI with the switch regions of RhoA. J Biol Chem, 2004. 279(8): p. 7098-104.

52. Cherfils, J. and M. Zeghouf, Regulation of small GTPases by GEFs, GAPs, and GDls. Physiol Rev, 2013. 93(1): p. 269-309.

53. Wen, W., et al., Structure basis and unconventional lipid membrane binding properties of the $\mathrm{PH}-\mathrm{C} 1$ tandem of rho kinases. J Biol Chem, 2008. 283(38): p. 26263-73.

54. Yoneda, A., H.A. Multhaupt, and J.R. Couchman, The Rho kinases I and II regulate different aspects of myosin II activity. J Cell Biol, 2005. 170(3): p. 443-53.

55. Julian, L. and M.F. Olson, Rho-associated coiled-coil containing kinases (ROCK): structure, regulation, and functions. Small GTPases, 2014. 5: p. e29846.

56. Pelosi, M., et al., ROCK2 and its alternatively spliced isoform ROCK2m positively control the maturation of the myogenic program. Mol Cell Biol, 2007. 27(17): p. 6163-76.

57. Leung, T., et al., A novel serine/threonine kinase binding the Ras-related RhoA GTPase which translocates the kinase to peripheral membranes. J Biol Chem, 1995. 270(49): p. 29051-4.

58. Matsui, T., et al., Rho-associated kinase, a novel serine/threonine kinase, as a putative target for small GTP binding protein Rho. EMBO J, 1996. 15(9): p. 2208-16. 
59. Sin, W.C., et al., RhoA-binding kinase alpha translocation is facilitated by the collapse of the vimentin intermediate filament network. Mol Cell Biol, 1998. 18(11): p. 6325-39.

60. Katoh, K., et al., Rho-kinase--mediated contraction of isolated stress fibers. J Cell Biol, 2001. 153(3): p. 569-84.

61. Kawabata, S., et al., Interaction of Rho-kinase with myosin II at stress fibres. Genes Cells, 2004. 9(7): p. 653-60.

62. Ma, Z., et al., Interaction between ROCK II and nucleophosmin/B23 in the regulation of centrosome duplication. Mol Cell Biol, 2006. 26(23): p. 9016-34.

63. Tanaka, T., et al., Nuclear Rho kinase, ROCK2, targets p300 acetyltransferase. J Biol Chem, 2006. 281(22): p. 15320-9.

64. lizuka, M., et al., Distinct distribution and localization of Rho-kinase in mouse epithelial, muscle and neural tissues. Cell Struct Funct, 2012. 37(2): p. 155-75.

65. Kosako, H., et al., Specific accumulation of Rho-associated kinase at the cleavage furrow during cytokinesis: cleavage furrow-specific phosphorylation of intermediate filaments. Oncogene, 1999. 18(17): p. 2783-8.

66. Chevrier, V., et al., The Rho-associated protein kinase p160ROCK is required for centrosome positioning. J Cell Biol, 2002. 157(5): p. 807-17.

67. Glyn, M.C., J.G. Lawrenson, and B.J. Ward, A Rho-associated kinase mitigates reperfusion-induced change in the shape of cardiac capillary endothelial cells in situ. Cardiovasc Res, 2003. 57(1): p. 195-206.

68. Stroeken, P.J., et al., Integrin cytoplasmic domain-associated protein-1 (ICAP1) interacts with the ROCK-I kinase at the plasma membrane. J Cell Physiol, 2006. 208(3): p. 620-8.

69. Leung, T., et al., The $p 160$ RhoA-binding kinase ROK alpha is a member of a kinase family and is involved in the reorganization of the cytoskeleton. Mol Cell Biol, 1996. 16(10): p. 5313-27.

70. Amano, M., et al., The $\mathrm{COOH}$ terminus of Rho-kinase negatively regulates rho-kinase activity. J Biol Chem, 1999. 274(45): p. 32418-24.

71. Jacobs, M., et al., The structure of dimeric ROCK I reveals the mechanism for ligand selectivity. J Biol Chem, 2006. 281(1): p. 260-8.

72. Yamaguchi, H., et al., Molecular mechanism for the regulation of rho-kinase by dimerization and its inhibition by fasudil. Structure, 2006. 14(3): p. 589-600.

73. Chuang, H.H., et al., Ser1333 phosphorylation indicates ROCKI activation. J Biomed Sci, 2013. 20: p. 83.

74. Chuang, H.H., et al., ROCKII Ser1366 phosphorylation reflects the activation status. Biochem J, 2012. 443(1): p. 145-51. 
75. Sebbagh, M., et al., Caspase-3-mediated cleavage of ROCK I induces MLC phosphorylation and apoptotic membrane blebbing. Nat Cell Biol, 2001. 3(4): p. 346-52.

76. Riou, P., P. Villalonga, and A.J. Ridley, Rnd proteins: multifunctional regulators of the cytoskeleton and cell cycle progression. Bioessays, 2010. 32(11): p. 986-92.

77. Riento, K., et al., RhoE binds to ROCK I and inhibits downstream signaling. Mol Cell Biol, 2003. 23(12): p. 4219-29.

78. Riento, K., et al., RhoE function is regulated by ROCK I-mediated phosphorylation. EMBO J, 2005. 24(6): p. 1170-80.

79. Riou, P., et al., 14-3-3 proteins interact with a hybrid prenyl-phosphorylation motif to inhibit G proteins. Cell, 2013. 153(3): p. 640-53.

80. Pinner, S. and E. Sahai, PDK1 regulates cancer cell motility by antagonising inhibition of ROCK1 by RhoE. Nat Cell Biol, 2008. 10(2): p. 127-37.

81. Barry, M. and R.C. Bleackley, Cytotoxic T lymphocytes: all roads lead to death. Nat Rev Immunol, 2002. 2(6): p. 401-9.

82. Sebbagh, M., et al., Direct cleavage of ROCK II by granzyme $B$ induces target cell membrane blebbing in a caspase-independent manner. J Exp Med, 2005. 201(3): p. 465-71.

83. Sapet, C., et al., Thrombin-induced endothelial microparticle generation: identification of a novel pathway involving ROCK-II activation by caspase-2. Blood, 2006. 108(6): p. 1868-76.

84. Xie, Z., et al., Smooth-muscle BMAL1 participates in blood pressure circadian rhythm regulation. J Clin Invest, 2015. 125(1): p. 324-36.

85. Davies, S.P., et al., Specificity and mechanism of action of some commonly used protein kinase inhibitors. Biochem J, 2000. 351(Pt 1): p. 95-105.

86. Narumiya, S., T. Ishizaki, and M. Uehata, Use and properties of ROCKspecific inhibitor Y-27632. Methods Enzymol, 2000. 325: p. 273-84.

87. Asano, T., et al., Mechanism of action of a novel antivasospasm drug, HA1077. J Pharmacol Exp Ther, 1987. 241(3): p. 1033-40.

88. Ishizaki, T., et al., Pharmacological properties of Y-27632, a specific inhibitor of rho-associated kinases. Mol Pharmacol, 2000. 57(5): p. 976-83.

89. Ikenoya, M., et al., Inhibition of rho-kinase-induced myristoylated alanine-rich $C$ kinase substrate (MARCKS) phosphorylation in human neuronal cells by $\mathrm{H}$ 1152, a novel and specific Rho-kinase inhibitor. J Neurochem, 2002. 81(1): p. $9-16$.

90. Rikitake, Y., et al., Inhibition of Rho kinase (ROCK) leads to increased cerebral blood flow and stroke protection. Stroke, 2005. 36(10): p. 2251-7. 
91. Masumoto, A., et al., Possible involvement of Rho-kinase in the pathogenesis of hypertension in humans. Hypertension, 2001. 38(6): p. 1307-10.

92. Masumoto, A., et al., Suppression of coronary artery spasm by the Rho-kinase inhibitor fasudil in patients with vasospastic angina. Circulation, 2002. 105(13): p. 1545-7.

93. Fukumoto, Y., et al., Acute vasodilator effects of a Rho-kinase inhibitor, fasudil, in patients with severe pulmonary hypertension. Heart, 2005. 91(3): $\mathrm{p}$. 391-2.

94. Kishi, T., et al., Rho-kinase inhibitor improves increased vascular resistance and impaired vasodilation of the forearm in patients with heart failure. Circulation, 2005. 111(21): p. 2741-7.

95. Shibuya, M., et al., Effects of fasudil in acute ischemic stroke: results of a prospective placebo-controlled double-blind trial. J Neurol Sci, 2005. 238(1-2): p. 31-9.

96. Sasaki, Y., M. Suzuki, and H. Hidaka, The novel and specific Rho-kinase inhibitor (S)-(+)-2-methyl-1-[(4-methyl-5-isoquinoline)sulfonyl]-homopiperazine as a probing molecule for Rho-kinase-involved pathway. Pharmacol Ther, 2002. 93(2-3): p. 225-32.

97. Boerma, M., et al., Comparative gene expression profiling in three primary human cell lines after treatment with a novel inhibitor of Rho kinase or atorvastatin. Blood Coagul Fibrinolysis, 2008. 19(7): p. 709-18.

98. Lee, J.H., et al., Selective ROCK2 Inhibition In Focal Cerebral Ischemia. Ann Clin Transl Neurol, 2014. 1(1): p. 2-14.

99. Zanin-Zhorov, A., et al., Selective oral ROCK2 inhibitor down-regulates IL-21 and IL-17 secretion in human T cells via STAT3-dependent mechanism. Proc Natl Acad Sci U S A, 2014. 111(47): p. 16814-9.

100. Kang, J.H., et al., Phosphorylation of Rho-associated kinase (Rhokinase/ROCK/ROK) substrates by protein kinases $A$ and $C$. Biochimie, 2007. 89(1): p. 39-47.

101. Feng, J., et al., Inhibitory phosphorylation site for Rho-associated kinase on smooth muscle myosin phosphatase. J Biol Chem, 1999. 274(52): p. 3738590.

102. Kawano, Y., et al., Phosphorylation of myosin-binding subunit (MBS) of myosin phosphatase by Rho-kinase in vivo. J Cell Biol, 1999. 147(5): p. 102338.

103. Velasco, G., et al., Phosphorylation of the regulatory subunit of smooth muscle protein phosphatase $1 \mathrm{M}$ at Thr850 induces its dissociation from myosin. FEBS Lett, 2002. 527(1-3): p. 101-4. 
104. Kureishi, Y., et al., Rho-associated kinase directly induces smooth muscle contraction through myosin light chain phosphorylation. J Biol Chem, 1997. 272(19): p. 12257-60.

105. Rajashree, R., B.C. Blunt, and P.A. Hofmann, Modulation of myosin phosphatase targeting subunit and protein phosphatase 1 in the heart. Am J Physiol Heart Circ Physiol, 2005. 289(4): p. H1736-43.

106. Koyama, M., et al., Phosphorylation of CPI-17, an inhibitory phosphoprotein of smooth muscle myosin phosphatase, by Rho-kinase. FEBS Lett, 2000. 475(3): p. 197-200.

107. Eto, M., Regulation of cellular protein phosphatase-1 (PP1) by phosphorylation of the CPI-17 family, C-kinase-activated PP1 inhibitors. J Biol Chem, 2009. 284(51): p. 35273-7.

108. Foletta, V.C., et al., LIM kinase 1, a key regulator of actin dynamics, is widely expressed in embryonic and adult tissues. Exp Cell Res, 2004. 294(2): p. 392405.

109. Maekawa, M., et al., Signaling from Rho to the actin cytoskeleton through protein kinases ROCK and LIM-kinase. Science, 1999. 285(5429): p. 895-8.

110. Bravo-Cordero, J.J., et al., Functions of cofilin in cell locomotion and invasion. Nat Rev Mol Cell Biol, 2013. 14(7): p. 405-15.

111. Subramanian, K., et al., Cofilin-2 phosphorylation and sequestration in myocardial aggregates: novel pathogenetic mechanisms for idiopathic dilated cardiomyopathy. J Am Coll Cardiol, 2015. 65(12): p. 1199-214.

112. Ganguly, R., et al., Adiponectin increases LPL activity via RhoA/ROCKmediated actin remodelling in adult rat cardiomyocytes. Endocrinology, 2011. 152(1): p. 247-54.

113. Iskratsch, T., et al., Two distinct phosphorylation events govern the function of muscle FHOD3. Cell Mol Life Sci, 2013. 70(5): p. 893-908.

114. Pestonjamasp, K., et al., Moesin, ezrin, and p205 are actin-binding proteins associated with neutrophil plasma membranes. Mol Biol Cell, 1995. 6(3): p. 247-59.

115. Matsui, T., et al., Rho-kinase phosphorylates COOH-terminal threonines of ezrin/radixin/moesin (ERM) proteins and regulates their head-to-tail association. J Cell Biol, 1998. 140(3): p. 647-57.

116. Adyshev, D.M., et al., Differential involvement of ezrin/radixin/moesin proteins in sphingosine 1-phosphate-induced human pulmonary endothelial cell barrier enhancement. Cell Signal, 2011. 23(12): p. 2086-96.

117. Adyshev, D.M., et al., Ezrin/radixin/moesin proteins differentially regulate endothelial hyperpermeability after thrombin. Am J Physiol Lung Cell Mol Physiol, 2013. 305(3): p. L240-55. 
118. Barreiro, O., et al., Dynamic interaction of VCAM-1 and ICAM-1 with moesin and ezrin in a novel endothelial docking structure for adherent leukocytes. J Cell Biol, 2002. 157(7): p. 1233-45.

119. Guo, X., et al., ERM protein moesin is phosphorylated by advanced glycation end products and modulates endothelial permeability. Am J Physiol Heart Circ Physiol, 2009. 297(1): p. H238-46.

120. Zhang, C., et al., p38MAPK, Rho/ROCK and PKC pathways are involved in influenza-induced cytoskeletal rearrangement and hyperpermeability in PMVEC via phosphorylating ERM. Virus Res, 2014. 192: p. 6-15.

121. Boratko, A. and C. Csortos, NHERF2 is crucial in ERM phosphorylation in pulmonary endothelial cells. Cell Commun Signal, 2013. 11: p. 99.

122. Baeyens, N., et al., Identification and functional implication of a Rho kinasedependent moesin-EBP50 interaction in noradrenaline-stimulated artery. Am J Physiol Cell Physiol, 2010. 299(6): p. C1530-40.

123. Ye, Y., et al., Alendronate prevents angiotensin II-induced collagen I production through geranylgeranylation-dependent RhoA/Rho kinase activation in cardiac fibroblasts. J Pharmacol Sci, 2015. 129(4): p. 205-9.

124. Ding, W.Y., et al., Prostaglandin F2alpha facilitates collagen synthesis in cardiac fibroblasts via an F-prostanoid receptor/protein kinase C/Rho kinase pathway independent of transforming growth factor beta1. Int J Biochem Cell Biol, 2012. 44(6): p. 1031-9.

125. Zhou, H., et al., Fasudil hydrochloride hydrate, a Rho-kinase inhibitor, suppresses high glucose-induced proliferation and collagen synthesis in rat cardiac fibroblasts. Clin Exp Pharmacol Physiol, 2011. 38(6): p. 387-94.

126. Jatho, A., et al., RhoA Ambivalently Controls Prominent Myofibroblast Characteritics by Involving Distinct Signaling Routes. PLoS One, 2015. 10(10): p. e0137519.

127. Turner, N.A., et al., Simvastatin inhibits TNFalpha-induced invasion of human cardiac myofibroblasts via both MMP-9-dependent and -independent mechanisms. J Mol Cell Cardiol, 2007. 43(2): p. 168-76.

128. Porter, K.E., et al., Simvastatin reduces human atrial myofibroblast proliferation independently of cholesterol lowering via inhibition of RhoA. Cardiovasc Res, 2004. 61(4): p. 745-55.

129. Shimokawa, H., et al., Anti-anginal effect of fasudil, a Rho-kinase inhibitor, in patients with stable effort angina: a multicenter study. J Cardiovasc Pharmacol, 2002. 40(5): p. 751-61.

130. Vicari, R.M., et al., Efficacy and safety of fasudil in patients with stable angina: a double-blind, placebo-controlled, phase 2 trial. J Am Coll Cardiol, 2005. 46(10): p. 1803-11. 
131. Ishikura, K., et al., Beneficial acute effects of rho-kinase inhibitor in patients with pulmonary arterial hypertension. Circ J, 2006. 70(2): p. 174-8.

132. Soga, J., et al., Rho-associated kinase activity, endothelial function, and cardiovascular risk factors. Arterioscler Thromb Vasc Biol, 2011. 31(10): p. 2353-9.

133. Smith, C.J., L. Santhanam, and L.M. Alexander, Rho-Kinase activity and cutaneous vasoconstriction is upregulated in essential hypertensive humans. Microvasc Res, 2013. 87: p. 58-64.

134. Seko, T., et al., Activation of RhoA and inhibition of myosin phosphatase as important components in hypertension in vascular smooth muscle. Circ Res, 2003. 92(4): p. 411-8.

135. Moriki, N., et al., RhoA activation in vascular smooth muscle cells from strokeprone spontaneously hypertensive rats. Hypertens Res, 2004. 27(4): p. 26370.

136. Wirth, A., et al., G12-G13-LARG-mediated signaling in vascular smooth muscle is required for salt-induced hypertension. Nat Med, 2008. 14(1): p. 648.

137. Guilluy, C., et al., The Rho exchange factor Arhgef1 mediates the effects of angiotensin II on vascular tone and blood pressure. Nat Med, 2010. 16(2): p. 183-90.

138. Sun, Q., et al., Air pollution exposure potentiates hypertension through reactive oxygen species-mediated activation of Rho/ROCK. Arterioscler Thromb Vasc Biol, 2008. 28(10): p. 1760-6.

139. Tsounapi, P., et al., Fasudil improves the endothelial dysfunction in the aorta of spontaneously hypertensive rats. Eur J Pharmacol, 2012. 691(1-3): p. 1829.

140. Mukai, Y., et al., Involvement of Rho-kinase in hypertensive vascular disease: a novel therapeutic target in hypertension. FASEB J, 2001. 15(6): p. 1062-4.

141. Rankinen, T., et al., A major haplotype block at the rho-associated kinase 2 locus is associated with a lower risk of hypertension in a recessive manner: the HYPGENE study. Hypertens Res, 2008. 31(8): p. 1651-7.

142. Shimizu, T., et al., Crucial role of ROCK2 in vascular smooth muscle cells for hypoxia-induced pulmonary hypertension in mice. Arterioscler Thromb Vasc Biol, 2013. 33(12): p. 2780-91.

143. Abe, K., et al., Long-term treatment with a Rho-kinase inhibitor improves monocrotaline-induced fatal pulmonary hypertension in rats. Circ Res, 2004. 94(3): p. 385-93.

144. Katsumata, N., et al., Enhanced myosin light chain phosphorylations as a central mechanism for coronary artery spasm in a swine model with interleukin-1beta. Circulation, 1997. 96(12): p. 4357-63. 
145. Shimokawa, H., et al., Rho-kinase-mediated pathway induces enhanced myosin light chain phosphorylations in a swine model of coronary artery spasm. Cardiovasc Res, 1999. 43(4): p. 1029-39.

146. Kandabashi, T., et al., Inhibition of myosin phosphatase by upregulated rhokinase plays a key role for coronary artery spasm in a porcine model with interleukin-1beta. Circulation, 2000. 101(11): p. 1319-23.

147. Abrams, J., Clinical practice. Chronic stable angina. N Engl J Med, 2005. 352(24): p. 2524-33.

148. Maruhashi, T., et al., Exogenous nitric oxide inhibits Rho-associated kinase activity in patients with angina pectoris: a randomized controlled trial. Hypertens Res, 2015. 38(7): p. 485-90.

149. Liu, P.Y. and J.K. Liao, $A$ method for measuring Rho kinase activity in tissues and cells. Methods Enzymol, 2008. 439: p. 181-9.

150. Do e, Z., et al., Rho-kinase activation in patients with heart failure. Circ J, 2013. $77(10)$ : p. $2542-50$.

151. Ocaranza, M.P., et al., Markedly increased Rho-kinase activity in circulating leukocytes in patients with chronic heart failure. Am Heart J, 2011. 161(5): p. 931-7.

152. Dong, M., et al., Increased Rho kinase activity in congestive heart failure. Eur J Heart Fail, 2012. 14(9): p. 965-73.

153. Dong, M., et al., A combination of increased Rho kinase activity and $\mathrm{N}$ terminal pro-B-type natriuretic peptide predicts worse cardiovascular outcome in patients with acute coronary syndrome. Int J Cardiol, 2013. 167(6): p. 28139.

154. Kobayashi, N., et al., Critical role of Rho-kinase pathway for cardiac performance and remodeling in failing rat hearts. Cardiovasc Res, 2002. 55(4): p. 757-67.

155. Hattori, T., et al., Long-term inhibition of Rho-kinase suppresses left ventricular remodeling after myocardial infarction in mice. Circulation, 2004. 109(18): p. 2234-9.

156. Vlasblom, R., et al., RhoA-ROCK signaling is involved in contraction-mediated inhibition of SERCA2a expression in cardiomyocytes. Pflugers Arch, 2009. 458(4): p. 785-93.

157. Kuwahara, K., et al., The effects of the selective ROCK inhibitor, Y27632, on ET-1-induced hypertrophic response in neonatal rat cardiac myocytes-possible involvement of Rho/ROCK pathway in cardiac muscle cell hypertrophy. FEBS Lett, 1999. 452(3): p. 314-8.

158. Yanazume, T., et al., Rho/ROCK pathway contributes to the activation of extracellular signal-regulated kinase/GATA-4 during myocardial cell hypertrophy. J Biol Chem, 2002. 277(10): p. 8618-25. 
159. Hunter, J.C., et al., Nitric oxide inhibits endothelin-1-induced neonatal cardiomyocyte hypertrophy via a RhoA-ROCK-dependent pathway. J Mol Cell Cardiol, 2009. 47(6): p. 810-8.

160. Ye, Y., S.J. Hu, and L. Li, Inhibition of farnesylpyrophosphate synthase prevents angiotensin II-induced hypertrophic responses in rat neonatal cardiomyocytes: involvement of the RhoA/Rho kinase pathway. FEBS Lett, 2009. 583(18): p. 2997-3003.

161. Chang, J., et al., Activation of Rho-associated coiled-coil protein kinase 1 (ROCK-1) by caspase-3 cleavage plays an essential role in cardiac myocyte apoptosis. Proc Natl Acad Sci U S A, 2006. 103(39): p. 14495-500.

162. Shi, J., et al., ROCK1 plays an essential role in the transition from cardiac hypertrophy to failure in mice. J Mol Cell Cardiol, 2010. 49(5): p. 819-28.

163. Zhang, Y.M., et al., Targeted deletion of ROCK1 protects the heart against pressure overload by inhibiting reactive fibrosis. Faseb j, 2006. 20(7): p. 91625.

164. Shimizu, Y., et al., ROCK-I regulates closure of the eyelids and ventral body wall by inducing assembly of actomyosin bundles. J Cell Biol, 2005. 168(6): p. 941-53.

165. Thumkeo, D., et al., Targeted disruption of the mouse rho-associated kinase 2 gene results in intrauterine growth retardation and fetal death. Mol Cell Biol, 2003. 23(14): p. 5043-55.

166. Duffy, P., et al., Rho-associated kinase II (ROCKII) limits axonal growth after trauma within the adult mouse spinal cord. J Neurosci, 2009. 29(48): p. 1526676.

167. Thumkeo, D., et al., ROCK-I and ROCK-II cooperatively regulate closure of eyelid and ventral body wall in mouse embryo. Genes Cells, 2005. 10(8): p. 825-34.

168. Rockman, H.A., et al., Segregation of atrial-specific and inducible expression of an atrial natriuretic factor transgene in an in vivo murine model of cardiac hypertrophy. Proc Natl Acad Sci U S A, 1991. 88(18): p. 8277-81.

169. Heineke, J. and J.D. Molkentin, Regulation of cardiac hypertrophy by intracellular signalling pathways. Nat Rev Mol Cell Biol, 2006. 7(8): p. 589600 .

170. Shi, J., et al., Disruption of ROCK1 gene attenuates cardiac dilation and improves contractile function in pathological cardiac hypertrophy. J Mol Cell Cardiol, 2008. 44(3): p. 551-60.

171. Rikitake, Y., et al., Decreased perivascular fibrosis but not cardiac hypertrophy in ROCK1+/- haploinsufficient mice. Circulation, 2005. 112(19): p. 2959-65. 
172. Yang, X., et al., Mechanism of fibrotic cardiomyopathy in mice expressing truncated Rho-associated coiled-coil protein kinase 1. FASEB J, 2012. 26(5): p. 2105-16.

173. Yue, X., et al., Rnd3 haploinsufficient mice are predisposed to hemodynamic stress and develop apoptotic cardiomyopathy with heart failure. Cell Death Dis, 2014. 5: p. e1284.

174. Haudek, S.B., et al., Bone marrow-derived fibroblast precursors mediate ischemic cardiomyopathy in mice. Proc Natl Acad Sci U S A, 2006. 103(48): p. 18284-9.

175. Haudek, S.B., et al., Rho kinase-1 mediates cardiac fibrosis by regulating fibroblast precursor cell differentiation. Cardiovasc Res, 2009. 83(3): p. 511-8.

176. Okamoto, R., et al., FHL2 prevents cardiac hypertrophy in mice with cardiacspecific deletion of ROCK2. Faseb j, 2013. 27(4): p. 1439-49.

177. Ikeda, S., et al., Crucial role of rho-kinase in pressure overload-induced right ventricular hypertrophy and dysfunction in mice. Arterioscler Thromb Vasc Biol, 2014. 34(6): p. 1260-71.

178. Tiburcy, M., et al., Collagen-based engineered heart muscle. Methods Mol Biol, 2014. 1181: p. 167-76.

179. Zimmermann, W.H., et al., Three-dimensional engineered heart tissue from neonatal rat cardiac myocytes. Biotechnol Bioeng, 2000. 68(1): p. 106-14.

180. Horzum, U., B. Ozdil, and D. Pesen-Okvur, Step-by-step quantitative analysis of focal adhesions. MethodsX, 2014. 1: p. 56-9.

181. Saalfeld, S. CLAHE (Contrast Limited Adaptive Histogram Equalization). 2009 [cited 2016 08/15]; Available from: http://rsbweb.nih.gov/ij/plugins/clahe/index.html.

182. Bradford, M.M., A rapid and sensitive method for the quantitation of microgram quantities of protein utilizing the principle of protein-dye binding. Anal Biochem, 1976. 72: p. 248-54.

183. PamGene. Kinase activity profiling providing vibrant applications. 2015 2016/08/15; Available from: https://www.pamgene.com/upload/image/brochures/Kinasebrochure 20150523.pdf

184. Heymans, S., et al., Searching for new mechanisms of myocardial fibrosis with diagnostic and/or therapeutic potential. Eur J Heart Fail, 2015. 17(8): p. 76471.

185. Lala, R.I., et al., Galectin-3 in heart failure pathology--"another brick in the wall"? Acta Cardiol, 2015. 70(3): p. 323-31.

186. Kreis, N.N., F. Louwen, and J. Yuan, Less understood issues: p21(Cip1) in mitosis and its therapeutic potential. Oncogene, 2015. 34(14): p. 1758-67. 
187. Takeda, N. and I. Manabe, Cellular Interplay between Cardiomyocytes and Nonmyocytes in Cardiac Remodeling. Int J Inflam, 2011. 2011: p. 535241.

188. Kakkar, R. and R.T. Lee, Intramyocardial fibroblast myocyte communication. Circ Res, 2010. 106(1): p. 47-57.

189. Simmel, S.S., P.C. Nickels, and T. Liedl, Wireframe and tensegrity DNA nanostructures. Acc Chem Res, 2014. 47(6): p. 1691-9.

190. Entcheva, E. and H. Bien, Mechanical and spatial determinants of cytoskeletal geodesic dome formation in cardiac fibroblasts. Integr Biol (Camb), 2009. 1(2): p. 212-9.

191. Malek, A.M., et al., Hypertonicity triggers RhoA-dependent assembly of myosin-containing striated polygonal actin networks in endothelial cells. Am J Physiol Cell Physiol, 2007. 292(5): p. C1645-59.

192. Harvey, K.A., et al., Diverse signaling pathways regulate fibroblast differentiation and transformation through Rho kinase activation. J Cell Physiol, 2007. 211(2): p. 353-63.

193. Ongherth, A., et al., p63RhoGEF regulates auto- and paracrine signaling in cardiac fibroblasts. J Mol Cell Cardiol, 2015. 88: p. 39-54.

194. Sahai, E., A.S. Alberts, and R. Treisman, RhoA effector mutants reveal distinct effector pathways for cytoskeletal reorganization, SRF activation and transformation. EMBO J, 1998. 17(5): p. 1350-61.

195. Wei, L., et al., Novel Insights into the Roles of Rho Kinase in Cancer. Arch Immunol Ther Exp (Warsz), 2016. 64(4): p. 259-78.

196. Lochhead, P.A., et al., Activating ROCK1 somatic mutations in human cancer. Oncogene, 2010. 29(17): p. 2591-8.

197. Tominaga, T. and D.L. Barber, Na-H exchange acts downstream of RhoA to regulate integrin-induced cell adhesion and spreading. Mol Biol Cell, 1998. 9(8): p. 2287-303.

198. Denker, S.P., et al., Direct binding of the Na--H exchanger NHE1 to ERM proteins regulates the cortical cytoskeleton and cell shape independently of $H(+)$ translocation. Mol Cell, 2000. 6(6): p. 1425-36.

199. de Toledo, M., et al., Cooperative anti-invasive effect of Cdc42/Rac1 activation and ROCK inhibition in SW620 colorectal cancer cells with elevated blebbing activity. PLoS One, 2012. 7(11): p. e48344.

200. Zhu, F., et al., Rho kinase inhibitor fasudil suppresses migration and invasion though down-regulating the expression of VEGF in lung cancer cell line A549. Med Oncol, 2011. 28(2): p. 565-71.

201. Ridley, A.J., Rho GTPases and cell migration. J Cell Sci, 2001. 114(Pt 15): p. 2713-22. 
202. Worthylake, R.A., et al., RhoA is required for monocyte tail retraction during transendothelial migration. J Cell Biol, 2001. 154(1): p. 147-60.

203. Sixt, M., Cell migration: fibroblasts find a new way to get ahead. J Cell Biol, 2012. 197(3): p. 347-9.

204. Petrie, R.J., et al., Nonpolarized signaling reveals two distinct modes of $3 D$ cell migration. J Cell Biol, 2012. 197(3): p. 439-55.

205. Yang, S. and H.M. Kim, ROCK inhibition activates MCF-7 cells. PLoS One, 2014. 9(2): p. e88489.

206. Gadea, G., et al., DOCK10-mediated Cdc42 activation is necessary for amoeboid invasion of melanoma cells. Curr Biol, 2008. 18(19): p. 1456-65.

207. Phrommintikul, A., et al., Effects of a Rho kinase inhibitor on pressure overload induced cardiac hypertrophy and associated diastolic dysfunction. Am J Physiol Heart Circ Physiol, 2008. 294(4): p. H1804-14.

208. Normand, G. and R.W. King, Understanding cytokinesis failure. Adv Exp Med Biol, 2010. 676: p. 27-55.

209. Jordan, P. and R. Karess, Myosin light chain-activating phosphorylation sites are required for oogenesis in Drosophila. J Cell Biol, 1997. 139(7): p. 1805-19.

210. Matsumura, F., et al., Specific localization of serine 19 phosphorylated myosin II during cell locomotion and mitosis of cultured cells. J Cell Biol, 1998. 140(1): p. 119-29.

211. Yamakita, Y., S. Yamashiro, and F. Matsumura, In vivo phosphorylation of regulatory light chain of myosin II during mitosis of cultured cells. J Cell Biol, 1994. 124(1-2): p. 129-37.

212. Kosako, H., et al., Rho-kinase/ROCK is involved in cytokinesis through the phosphorylation of myosin light chain and not ezrin/radixin/moesin proteins at the cleavage furrow. Oncogene, 2000. 19(52): p. 6059-64.

213. Ueda, K., et al., Rho-kinase contributes to diphosphorylation of myosin II regulatory light chain in nonmuscle cells. Oncogene, 2002. 21(38): p. 5852-60.

214. Rossig, L., et al., Akt-dependent phosphorylation of p21(Cip1) regulates PCNA binding and proliferation of endothelial cells. Mol Cell Biol, 2001. 21(16): p. 5644-57.

215. Scott, M.T., N. Morrice, and K.L. Ball, Reversible phosphorylation at the Cterminal regulatory domain of p21(Waf1/Cip1) modulates proliferating cell nuclear antigen binding. J Biol Chem, 2000. 275(15): p. 11529-37.

216. Li, Y., D. Dowbenko, and L.A. Lasky, $A K T / P K B$ phosphorylation of p21Cip/WAF1 enhances protein stability of p21Cip/WAF1 and promotes cell survival. J Biol Chem, 2002. 277(13): p. 11352-61. 
217. Fisher, R.P., Secrets of a double agent: CDK7 in cell-cycle control and transcription. J Cell Sci, 2005. 118(Pt 22): p. 5171-80.

218. Larochelle, S., et al., T-loop phosphorylation stabilizes the CDK7-cyclin $\mathrm{H}$ MAT1 complex in vivo and regulates its CTD kinase activity. EMBO J, 2001. 20(14): p. 3749-59.

219. Leclerc, V., S. Raisin, and P. Leopold, Dominant-negative mutants reveal a role for the Cdk7 kinase at the mid-blastula transition in Drosophila embryos. EMBO J, 2000. 19(7): p. 1567-75.

220. Akoulitchev, S. and D. Reinberg, The molecular mechanism of mitotic inhibition of TFIIH is mediated by phosphorylation of CDK7. Genes Dev, 1998. 12(22): p. 3541-50.

221. Debelle, L. and A.M. Tamburro, Elastin: molecular description and function. Int J Biochem Cell Biol, 1999. 31(2): p. 261-72.

222. Curran, M.E., et al., The elastin gene is disrupted by a translocation associated with supravalvular aortic stenosis. Cell, 1993. 73(1): p. 159-68.

223. Tassabehji, M., et al., Elastin: genomic structure and point mutations in patients with supravalvular aortic stenosis. Hum Mol Genet, 1997. 6(7): p. 1029-36.

224. Lopez, B., et al., Impact of treatment on myocardial lysyl oxidase expression and collagen cross-linking in patients with heart failure. Hypertension, 2009. 53(2): p. 236-42.

225. Lopez, B., et al., Collagen cross-linking but not collagen amount associates with elevated filling pressures in hypertensive patients with stage $C$ heart failure: potential role of lysyl oxidase. Hypertension, 2012. 60(3): p. 677-83.

226. Akhmetshina, A., et al., Rho-associated kinases are crucial for myofibroblast differentiation and production of extracellular matrix in scleroderma fibroblasts. Arthritis Rheum, 2008. 58(8): p. 2553-64.

227. Deng, L., et al., Rho-kinase inhibitor, fasudil, suppresses glioblastoma cell line progression in vitro and in vivo. Cancer Biol Ther, 2010. 9(11): p. 875-84.

228. Schram, K., et al., Regulation of MT1-MMP and MMP-2 by leptin in cardiac fibroblasts involves Rho/ROCK-dependent actin cytoskeletal reorganization and leads to enhanced cell migration. Endocrinology, 2011. 152(5): p. 203747.

229. Ishiguro, M., et al., A Rho kinase (ROCK) inhibitor, fasudil, prevents matrix metalloproteinase-9-related hemorrhagic transformation in mice treated with tissue plasminogen activator. Neuroscience, 2012. 220: p. 302-12.

230. Sandbo, N., et al., Delayed stress fiber formation mediates pulmonary myofibroblast differentiation in response to TGF-beta. Am J Physiol Lung Cell Mol Physiol, 2011. 301(5): p. L656-66. 
231. Tiburcy, M., et al., Terminal differentiation, advanced organotypic maturation, and modeling of hypertrophic growth in engineered heart tissue. Circ Res, 2011. 109(10): p. 1105-14. 
